\title{
Investigating neurobiological mechanisms underlying comorbid cognitive symptoms in psychosis and substance use
}

Citation for published version (APA):

Vingerhoets, W. A. M. (2017). Investigating neurobiological mechanisms underlying comorbid cognitive symptoms in psychosis and substance use. [Doctoral Thesis, Maastricht University]. Maastricht University. https://doi.org/10.26481/dis.20170323wv

Document status and date:

Published: 01/01/2017

DOI:

10.26481/dis.20170323wv

Document Version:

Publisher's PDF, also known as Version of record

Please check the document version of this publication:

- A submitted manuscript is the version of the article upon submission and before peer-review. There can be important differences between the submitted version and the official published version of record.

People interested in the research are advised to contact the author for the final version of the publication, or visit the DOI to the publisher's website.

- The final author version and the galley proof are versions of the publication after peer review.

- The final published version features the final layout of the paper including the volume, issue and page numbers.

Link to publication

\footnotetext{
General rights rights.

- You may freely distribute the URL identifying the publication in the public portal. please follow below link for the End User Agreement:

www.umlib.nl/taverne-license

Take down policy

If you believe that this document breaches copyright please contact us at:

repository@maastrichtuniversity.nl

providing details and we will investigate your claim.
}

Copyright and moral rights for the publications made accessible in the public portal are retained by the authors and/or other copyright owners and it is a condition of accessing publications that users recognise and abide by the legal requirements associated with these

- Users may download and print one copy of any publication from the public portal for the purpose of private study or research.

- You may not further distribute the material or use it for any profit-making activity or commercial gain

If the publication is distributed under the terms of Article $25 \mathrm{fa}$ of the Dutch Copyright Act, indicated by the "Taverne" license above, 


\section{Investigating neurobiological mechanisms underlying comorbid cognitive symptoms in psychosis and substance use}

Wilhelmina Antonia Maria Vingerhoets 
Copyright (C) W.A.M. Vingerhoets, Maastricht 2017

All rights reserved. No part of this publication may be reproduced or transmitted in any form or by any means without prior permission in writing of the author.

ISBN:

978-94-6299-552-9

Cover Design: $\quad$ Geoffrey Cramm

Printed by: $\quad$ Ridderprint B.V. 


\title{
Investigating neurobiological mechanisms underlying comorbid cognitive symptoms in psychosis and substance use
}

\author{
Proefschrift \\ Ter verkrijging van de graad van doctor \\ aan de Universiteit Maastricht \\ Op gezag van de Rector Magnificus \\ Prof. dr. Rianne M. Letschert \\ Volgens het besluit van het College van Decanen, \\ In het openbaar te verdedigen \\ op 23 maart 2017 om 14:00 uur
}

Door Wilhelmina Antonia Maria Vingerhoets

Geboren op 06-05-1988 te Oirschot 


\author{
Promotores: $\quad$ Prof. dr. T.A.M.J. van Amelsvoort \\ Prof. dr. J. Booij, Universiteit van Amsterdam \\ Copromotor: Dr. O.J.N. Bloemen
}

Beoordelingscommissie: Prof. Dr. J. Ramaekers (voorzitter)

Dr. R. Bruggeman, Rijksuniversiteit Groningen

Prof. Dr. M. Meeter, Vrije Universiteit Amsterdam

Prof. Dr. W. Riedel

Prof. Dr. K. Schruers

The research presented in this dissertation was performed at the School for Mental Health \& Neuroscience (MH\&NS)

Department of Psychiatry \& Psychology of Maastricht University, And The department of Nuclear Medicine of the Academic Medical Center.

The research described in the first part of the dissertaton was funded by the Dutch Organization for Health Research and Development (ZonMw; middelgroot investeringen; VIDI: 91712394, awarded to T. van Amelsvoort). The research in the second part of the dissertation was funded by the Netherlands Organization for Scientific research - Health Research and Development, (ZonMW grant 31180002 awarded to A.E. Goudriaan and W. van den Brink and grant 31160007 awarded to L. de Haan). Additional funding was obtained from Vici grant 453.008.001 awarded to R.W. Wiers by the Dutch Organization for Scientific Research (NWO). Funding sources were not involved in the content of this dissertation. 
Table of contents

Chapter 1 General introduction and outline of the dissertation

Part I Neurobiological mechanisms underlying cognitive symptoms in psychosis

Chapter 2 Pharmacological interventions for the MATRICS cognitive domains in schizophrenia: what's the evidence?

Chapter 3 The effect of the muscarinic $\mathrm{M}_{1}$ receptor antagonist biperiden on cognition in medication free subjects with psychosis

Chapter 4 Cholinergic neurotransmission and cognition in psychosis: a placebo-controlled, cross-over MRS study

Part II Neurobiological mechanisms underlying substance use

Chapter 5 Relationship between working-memory network function and substance use: a 3-year longitudinal fMRI study in heavy cannabis users and controls

Chapter 6 Cue-induced striatal activity in frequent cannabis users independently predicts cannabis problem severity three years later

Chapter 7 Low prevalence of substance use in people with 22q11.2 deletion syndrome

Chapter 8 Summary and general discussion

Chapter 9

Dutch summary | Nederlandse samenvatting

\section{Appendices}

Valorisation

List if of publications

Acknowledgements | Dankwoord

Curriculum Vitae 



\section{Chapter | 1}

General introduction and outline of the dissertation

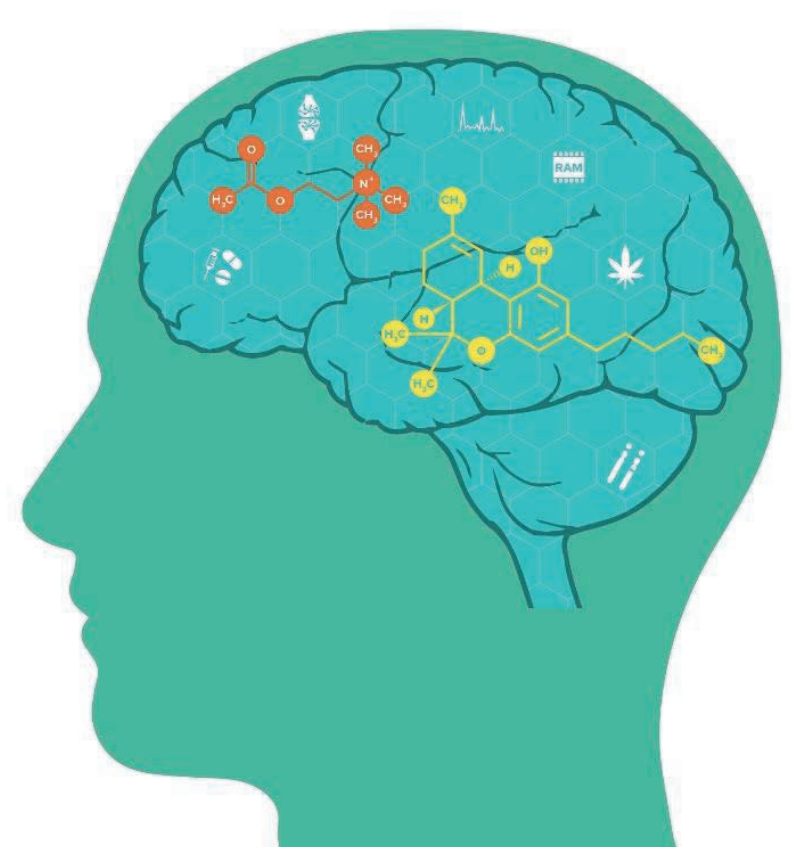




\section{Schizophrenia and related psychotic disorders}

Psychotic disorders, schizophrenia being the best known and most severe form, refer to mental conditions characterized by severe impairments in reality testing and are relatively common, with a prevalence of approximately $3 \%$ in the general population (1). The onset of psychotic disorders, and particularly schizophrenia, usually occurs during adolescence or early adulthood and is among the most disabling diseases worldwide with devastating consequences, not only for patients but also for their families (2). The most characteristic symptoms of psychotic disorders are the so-called positive symptoms including hallucinations (perceptions in absence of a stimulus such as hearing voices) and delusions (false or erroneous beliefs). Other symptoms of psychotic disorders include negative symptoms such as social withdrawal and flattening of affect and disorganized behavior. The etiology of psychotic disorders is highly complex and it is generally believed that both genetic and environmental factors such as childhood trauma, urbanicity and substance use are involved (3). Also, several genetic variations including copy number variants at chromosome 1q21.1, 2p16.3, 15q11.2, 15q13.3, 16p11.2, and 22q11.2 have been implicated in the risk for psychotic disorders (4), and multiple susceptibility genes have been identified such as catechol-O-methyltransferase (COMT) and Disrupted In Schizophrenia C1 (DISC1) (5).

\section{Cognitive impairments}

Approximately $75-85 \%$ of the patients with a psychotic disorder report cognitive impairments such as memory and attention problems in addition to the positive and negative symptoms (6). These neurocognitive impairments are widely recognized as a primary factor in causing and maintaining disability in schizophrenia and other psychotic disorders (2). Cognitive impairments often precede onset of other psychotic symptoms and continue when other symptoms have been treated and have been found to predict treatment adherence (7), medication compliance (8) and tendency for relapse in first-episode patients (9). Cognitive deficits are increasingly considered a core feature of schizophrenia symptomatology and over the recent years, a large number of studies have been conducted in an attempt to unravel the complex neurobiological mechanisms underlying these symptoms. Nevertheless, these mechanisms are still largely unknown and currently no effective treatment options are available as cognitive symptoms are almost untouched by existing antipsychotics. To develop new and effective (pharmacological) treatment strategies, more insight needs to be gained in underlying neurobiological mechanisms of cognitive impairments in psychosis. To improve cognition research in psychosis the Measurement and Treatment to 
Improve Cognition in Schizophrenia (MATRICS) was established. Seven domains of cognitive function were identified by the MATRICS as fundamentally impaired in schizophrenia; visual learning and memory, verbal learning and memory, working memory, attention and vigilance, processing speed, reasoning and problem solving and social cognition (10). To facilitate future research on cognition in psychosis, it was proposed that studies should mainly focus on these domains to enable development of new (pharmacological) treatment strategies. In this dissertation, we aimed to provide more insight in the underlying neurobiological mechanisms of cognitive function in psychotic disorders by reviewing previous research that attempted to provide potential new targets for the treatment of cognitive symptoms in psychosis, as well as examining the role of the cholinergic system in these symptoms.

\section{The cholinergic system}

\section{Acetylcholine}

The lack of effective treatments options has led to an increase in studies attempting to identify new molecular targets to enhance cognition in patients with psychotic disorders. These studies mainly focused on the several different neurotransmitter systems such as the dopaminergic, serotonergic, $y$-aminobutyric acid (GABA)ergic, glutamatergic and cholinergic system as potential new targets for cognitive enhancement in psychosis. Neurotransmitters are endogenous messenger chemicals that enable communication between neurons (cells). These neurotransmitters transmit a signal by binding to specific receptors (protein molecules). Each class of receptors responds to a specific neurotransmitter. Over the past years, there has been increasing interest in the cholinergic system as potential target of cognitive enhancement in psychosis since this system has been linked to both cognitive function and psychosis. Acetylcholine is a neurotransmitter synthesized from a reaction between acetyl-co-enzyme $A$ and choline and is catalyzed by choline acetyltransferase and stored in synaptic vesicles (11). In turn, free acetylcholine is converted into the inactive metabolites choline and acetate by the enzyme acetylcholinesterase (12). Acetylcholine plays an important role in motor function but also in several domains of cognition, particularly attention, learning, and memory $(13,14)$ and has been implicated in psychotic disorders (15).

\section{Muscarinic receptors}

Acetylcholine binds primarily to the muscarinic (mAChR) and nicotinic receptors ( $\mathrm{nAChR}$ ) in the brain. mAChRs are metabotropic G-protein coupled receptors (acts through a second messenger). Acetylcholine binds to the mAChRs located on the 
cell membrane and the intracellular receptors which in turn activate a particular Gprotein. Five $m A C h R$ subtypes can be distinguished, $M_{1}-M_{5}$ of which the $M_{1}$ receptor is the most abundantly expressed in the central nervous system (16). The $M_{1}$ receptor has been most directly implicated in psychotic disorders and cognitive functioning. Indeed, brain regions with the highest density of $M_{1}$ receptors include the cerebral cortex, hippocampus and striatum (17), all regions crucial for cognition. Both animal and human studies have demonstrated that mAChR antagonists such as scopolamine and biperiden induce cognitive impairments, in particular in the domains of attention, learning and memory (18-27). mAChRs have been implicated in schizophrenia as well; several post-mortem studies demonstrated decreased $M_{1}$ and $M_{4}$ expression in patients with schizophrenia (28$32,15)$. Furthermore, in a landmark post-mortem study, a subgroup, comprising approximately $25 \%$ of schizophrenia patients, was identified with up to $75 \%$ reduction in $\mathrm{M}_{1}$ receptor expression in the dorsolateral prefrontal cortex (DLPFC) (33). This subgroup of patients, so called 'muscarinic receptor deficit schizophrenia' (MRDS), may represent a distinct phenotype with more pronounced cognitive deficits (33). However, because of the design of these post-mortem studies, it is unknown whether decreased $M_{1}$ expression is indeed directly related to cognition in these patients. Nonetheless, the cholinergic system, the $M_{1}$ receptor in particular, may be an interesting target for cognitive enhancement in psychotic disorders. Indeed, a trial investigating the effects of 4 weeks of monotherapy with xanomeline, a $\mathrm{M}_{1 / 4}$ receptor agonist, found improvement in (verbal) memory in patients with schizophrenia (34). Overall, these results indicate that the $M_{1}$ receptor may be a promising target for enhancement of cognition in psychosis.

\section{Nicotinic receptors}

The other family of receptors to which acetylcholine binds are the nicotinic receptors (nAChRs). The $\mathrm{nAChRs}$ are ionotropic receptors (transmembrane ion channel receptors) facilitating fast neurotransmission and are highly abundant in the central nervous system (35). So far, $9 \alpha\left(\alpha_{2}-\alpha_{10}\right)$ and three $b\left(b_{2}-b_{4}\right)$ subunits have been identified. These subunits can be either homomeric (composed of only one type of subunit) or heteromeric (combinations of $\alpha$ - and $\beta$ subtypes). Of all nAChR subtypes, the $\alpha_{7}$ and $\alpha_{4} \beta_{2}$ receptors have received the most attention in relation to psychotic disorders (35). Studies in psychotic disorders have found decreased expression of nicotinic $\alpha_{7}$ receptor subtype in the hippocampus (36), thalamus (37) and cingulate cortex (38) of patients with schizophrenia (36). Moreover, reduced $\alpha_{7}$ receptors have been found in the frontal lobe (39) and DLPFC (40) in schizophrenia. The nAChRs has been linked to cognitive function, particular 
attention, in both healthy smoking and non-smoking individuals and schizophrenia (41). A meta-analysis comprising 41 studies in healthy non-smokers or nondeprived smokers found enhancement of several cognitive domains including attention, response time and working memory after nicotine administration (42). In addition, abnormal desensitization or turnover of $\alpha_{4} b_{2}$ nicotinic receptors has been related to excessive smoking by patients with schizophrenia (43). Excessive nicotine use in schizophrenia is estimated at $80-90 \%$ of the patients versus $20-30 \%$ in the general population (43).

\section{Substance use in psychotic and healthy populations}

With a lifetime prevalence of approximately 95\% (44), substance use in patients with schizophrenia is higher than lifetime substance use in the general population which is estimated at approximately $70 \%$ (45). In addition, patients with schizophrenia are 4.6 times more likely to develop substance related disorders such as substance dependence (46). Besides nicotine, cannabis is a substance frequently used among patients with a psychotic disorder (47). Approximately $42 \%$ of the patients with a psychotic disorder report lifetime cannabis use and $23 \%$ report a comorbid cannabis related disorder (abuse or dependence) (48). At present, it is unknown what causes this excessive substance use in psychosis patients, but is has been suggested that genetic factors and gene/environment interaction are likely to be involved since both schizophrenia and addiction are highly heritable (49). More insight in the genetic and neurobiological mechanisms underlying (excessive) substance use in healthy populations could contribute to better treatment and possibly prevention of substance use disorders in the healthy population but also in psychotic patients. Therefore, the second aim of the studies described in this dissertation was to provide more insight in neurobiological mechanisms underlying substance use, particularly frequent cannabis use.

\section{Theoretical framework of continued substance use and transition to addiction}

At present, it is unknown why some frequent substance users develop a substance related disorder whereas others do not. Individuals with a substance use disorder continue to use despite knowledge of potential harmful effects. Over the years, extensive research has been conducted and different models have been developed in an attempt to explain this detrimental behavior. These models suggest that substance use disorders arise from an imbalance between motivational processes and regulatory executive functions (50-52). Nowadays it is generally believed that 
in patients who transition to substance dependence a shift occurs from recreational, pleasure drug use because of its rewarding effects, to compulsive drug intake due to loss of control (53). This transition to compulsive drug intake is associated with neuroadaptations (50). Gaining more insight in this transition and the associated neurobiological mechanisms involved is important for the development of treatment strategies and prevention.

\section{Cannabis}

With a prevalence of lifetime use of $2.8-4.5 \%$ in the general population, cannabis is the most frequent recreational drug used (54). It is estimated that approximately one out of 10 weekly cannabis users transition to a cannabis addict (55). The rates of use peak in early adulthood and tend to decrease when people start working, engage in higher education or marry and have children (54). At present, the underlying mechanisms of continued, frequent cannabis use and progression to related disorders are largely unknown. Gaining more insight in the underlying neurobiological mechanism of continued, frequent cannabis use, could provide better treatment or even preventions options, not only for the general population but may contribute to the development of better treatment strategies for comorbid cannabis use disorders in psychosis. Therefore, in this dissertation neurobiological mechanisms underlying two core aspects of substance use disorders, cue-reactivity (motivational aspect) and working memory (regulatory executive function aspect) were examined.

\section{Cue-reactivity}

Cue-reactivity is a multi-faceted process which refers to the physiological, psychological, neural and behavioral response triggered by substance related cues (56). Existing literature on cue-reactivity indicates that substance related cues increase craving, capture attention and activate an approach tendency and thus bias motivational processes (57). Repetitive association between certain cues such as emotional states and paraphernalia, extremely sensitizes the brain towards this cues (57). Consequently, an encounter with a drug related cue may trigger a conditioned response. Indeed, cue-reactivity has been found to predict treatment outcome and relapse in several substances of abuse, including alcohol and nicotine (58-60). Moreover, both behavioral and neural responses to cannabis cues were found to predict cannabis use and related problems over a course of 6 months (61), suggesting that cue-reactivity might be an underlying factor in continued cannabis 
use. Several studies have found increased activation in brain regions involved in reward processing, motivation and cognitive control in response to drug related cues in subjects with a substance use disorder (59,61-64). These core regions include the ventral tegmental area (VTA), orbitofrontal cortex (OFC), anterior cingulate cortex (ACC), striatum and amygdala (53). The VTA projects dopaminergic neurons into the ventral striatum (nucleus accumbens) and prefrontal regions including the ACC and this process comprises parts of the reward circuit (61). The amygdala attributes emotional salience to cues and initiates approach or avoid behaviors (61). Finally, the dorsal striatum has been associated with later stages of addiction as it is involved in habit formation (53). Cross-sectional research demonstrated significant activation in the VTA in response to cannabis cues in heavy cannabis users compared to healthy controls (61). Moreover, higher activation in the ACC, OFC and striatum was only found in those cannabis users reporting more cannabis related problems (61). However, given the cross-sectional design, this study does not provide insight in the causality of these altered brain patterns in heavy cannabis users. In this dissertation, we were interested in the role of cue-reactivity in continued, frequent cannabis use.

\section{Working memory}

Working memory refers to the capacity to maintain and manipulate information for a limited amount of time (65) and integrity of this system is required for a variety of cognitive functions (66). Working memory plays an important role in attention control; higher memory load leads to increased interference (67) thereby constraining attentional control (68), which is particularly important when interfering signals trigger behavioral tendencies which are in conflict with chased goals (68). Translated to substance use disorders, this would suggest that individuals with a better working memory are more capable to resist the urge to use drugs compared to individuals with poorer working memory (51). The core brain regions that comprise the working memory network are the DLPFC, ventrolateral prefrontal cortex (VLPFC), premotor cortex, lateral/medial parietal cortex, paracingulate gyrus and the frontal pole $(69,70)$. Hyperactivity of this network during a working memory task has been associated with cannabis use despite normal performance (71-73) which suggest that cannabis users need to make more effort, reflected in higher memory load (51). Although a role of working memory network dysfunction in the development of substance use disorders, including cannabis has been implied (51), less is known about whether working memory function can predict future cannabis use and problem related severity. One functional magnetic resonance imaging (fMRI) study has found that, despite 
comparable performance between heavy cannabis users and healthy controls, a stronger response during a working memory task was related to an increase weekly cannabis use at 6-months follow-up. However, given the effects of cannabis on working memory, it would be interesting to investigate how working memory functioning develops in heavy cannabis users develops over time.

\section{2q11.2 deletion syndrome}

Both psychotic and substance use disorders are highly heritable and both disorders seem to have a strong genetic component $(74,75)$. Genetic studies in schizophrenia and substance use disorders identified some genes that seem to overlap between both disorders (49) including genes that encode for the $\alpha_{7}$ nAChR subtype and genes that modulate the activity of dopamine, a neurotransmitter implicated in both schizophrenia and substance use disorders, such as COMT (49).

The COMT gene has also been associated with $22 q 11.2$ deletion syndrome (22q11DS). 22q11DS (also known as velo-cardio-facial syndrome, diGeorge or Sphrintzen syndrome) is one of the most prevalent copy number variant disorders and is caused by a microdeletion on the long arm of chromosome 22 (76). The typically deleted region is usually 1.5-3 megabases ( $\mathrm{Mb}$ ) in size including 30-60 known genes, most of which are expressed in the brain (77). One of the genes within this deleted region in 22q11DS is the COMT gene. The prevalence of 22q11DS is estimated at 2,000-4,000 live births (76). Phenotypic characteristics include heart malformations, palatal abnormalities and are highly variable between patients. In addition, intellectual disability and high rates of psychiatric illness are highly common in these patients (76). Since approximately $30 \%$ of the patients with 22q11DS develop a psychotic disorder (76), the 22q11.2 deletion is amongst the strongest genetic risk factors for the development of psychosis currently identified. Therefore, studying patterns of substance use in these patients can provide valuable insight in the role of certain genes and associated neurobiological mechanisms in substance related disorders in patients with a psychotic disorder as well as in the general population.

Methods for investigating neurobiological mechanisms in cognitive symptoms of psychosis and frequent cannabis use

\section{Magnetic resonance imaging}

The development of MRI has provided a method to in-vivo measure neurobiological mechanisms in a non-invasive manner, and without introducing a radiation burden to the subject. It can compute detailed images of the brain by means of powerful magnetic field and radio frequencies. Manipulating the static and dynamic 
magnetic fields and radiofrequency pulses, produces signals which are reconstructed in digital images and enables localization of protons in the brain (78). Several modalities are available to measure for example brain structure and function including proton magnetic resonance spectroscopy $\left({ }^{1} \mathrm{H}-\mathrm{MRS}\right)$ and functional MRI (fMR).

\section{${ }^{1} \mathrm{H}-\mathrm{MRS}$}

The principle of ${ }^{1} \mathrm{H}-\mathrm{MRS}$ is based on the principle of what is called the 'chemical shift' which refers to the resonant frequency of a nucleus within a magnetic field (79). The nuclei in a certain molecule are surrounded by clouds of electrons shielding the molecule by producing their own magnetic field. The different shielding of each molecule causes differences in the resonant frequency of molecules, thereby enabling detection of different metabolites (79). ${ }^{1} \mathrm{H}$-MRS is relatively new technique and is commonly applied in psychosis research since it allows in-vivo and non-invasive measurement of several metabolites / neurotransmitters implicated in psychotic disorders, including glutamate, GABA and choline (80) .

\section{fMRI}

Another commonly applied MRI technique is functional MRI (fMRI). This technique measures changes in oxygenation of blood induces by neural activity (81). Active brain areas consumes more oxygen and increases blood flow which is referred to as the blood oxygen level dependent (BOLD) response (82). $\mathrm{fMRI}$ is commonly applied in combination with a task. By measuring the BOLD response when performing specific tasks, brain regions involved in task performance can be identified.

\section{Pharmacological studies}

In addition to MRI, the use of a pharmacological challenge is a valid method for investigating neurobiological mechanisms. In this type of studies, a pharmacological agent with a specific mechanism of action is administered to investigate the effect on a chosen outcome measure. This method is easy applicable for behavioural outcome measures but can also be used in combination with MRI (pharmacological $\mathrm{MRI}$ ) to study the effect of a pharmaceutical on brain function or metabolites. This method is especially suitable for in in-vivo examination of different neurotransmitter systems in a non-invasive manner, and without introducing a radiation burden. 


\section{Outline of this dissertation}

The overall aim of this dissertation is to further examine neurobiological mechanisms underlying cognitive functioning in patients with a psychotic disorder and substance use, in particular heavy cannabis use. For this we used different techniques including behavioral assessment of cognition as well as brain metabolite concentrations and functional brain activity. This dissertation is divided into 2 parts. In the first part, neurobiological mechanisms of cognitive functioning in psychosis were examined (chapters 2, 3 and 4).

First, chapter 2 provides an overview of evidence of the effectiveness of currently available pharmacological interventions for cognitive impairment in patients with schizophrenia.

In chapter 3, the role of the muscarinic system in cognitive function in psychotic patients was examined using a muscarinic $M_{1}$ antagonist (biperiden) as an acute pharmacological challenge and it was examined whether this effect was more pronounced in subjects with a psychotic disorder than in healthy control subjects.

In chapter 4, using MRS, differences in brain choline concentrations between subjects with a psychotic disorder and healthy control subjects were examined and whether choline concentrations were related to separate domains of cognition. In addition, it was examined whether choline levels increased after blocking of the $M_{1}$ receptor with biperiden.

The second part of this dissertation focused on neurobiological mechanisms underlying substance use, cannabis in particular. Hereby, we focused on behavioral and brain activation patterns in cannabis and substance use in general were examined (chapters 5, 6 and 7).

Elucidating on previous finding by our research group, chapter $\mathbf{5}$ describes the result of a 3-year follow-up study investigating the relationship between working memory network function and cannabis use.

In chapter 6, it was investigated whether neural cue-reactivity plays a causal role in continued, heavy cannabis use and the development of cannabis related problems and dependence using a 3-year follow-up design.

Chapter 7 describes the results of a study examining the prevalence of substance use in patients with 22q11DS, a patient population with a genetic high risk of developing a psychotic disorder. In addition, the relation with psychotic disorders is described.

Finally, in chapter 8 the studies described in chapters 2-7 are summarized and discussed.

In chapter 9 the studies are summarized in Dutch. 


\section{References}

1. Perälä J, Suvisaari J, Saarni SI, Kuoppasalmi K, Isometsä E, Pirkola S, et al. Lifetime prevalence of psychotic and bipolar I disorders in a general population. Arch Gen Psychiatry. 2007;64(1):19-28.

2. Bowie CR, Depp C, McGrath JA, Wolyniec P, Mausbach BT, Thornquist MH, et al. Prediction of RealWorld Functional Disability in Chronic Mental Disorders: A Comparison of Schizophrenia and Bipolar Disorder. Am J Psychiatry. 2010;167(9):1116-24.

3. van Os J, Kapur S. Schizophrenia. Lancet. 2009;374(9690):635-45.

4. Van Winkel R, Esquivel G, Kenis G, Wichers M, Collip D, Peerbooms O, et al. REVIEW: GenomeWide Findings in Schizophrenia and the Role of Gene-Environment Interplay. CNS Neurosci Ther. 2010;16(5):e185-92.

5. Farrell MS, Werge T, Sklar P, Owen MJ, Ophoff RA, O'Donovan MC, et al. Evaluating historical candidate genes for schizophrenia. Mol Psychiatry. 2015;20(5):555-62.

6. Reichenberg A, Weiser M, Caspi A, Knobler HY, Lubin G, Harvey PD, et al. Premorbid intellectual functioning and risk of schizophrenia and spectrum disorders. J Clin Exp Neuropsychol. 2006;28(2):193-207.

7. Stip E, Chouinard S, Boulay L. On the trail of a cognitive enhancer for the treatment of schizophrenia. Prog Neuropsychopharmacol Biol Psychiatry. 2005;29(2):219-32.

8. Chen EY-H, Hui CL-M, Dunn EL-W, Miao MY-K, Yeung W-S, Wong C-K, et al. A prospective 3-year longitudinal study of cognitive predictors of relapse in first-episode schizophrenic patients. Schizophr Res. 2005;77(1):99-104.

9. Green MF. What are the functional consequences of neurocognitive deficits in schizophrenia? Am J Psychiatry. 1996;153:321-30.

10. Nuechterlein KH, Barch DM, Gold JM, Goldberg TE, Green MF, Heaton RK. Identification of separable cognitive factors in schizophrenia. Schizophr Res. 2004;72(1):29-39.

11. Sarter M, Parikh V. Choline transporters, cholinergic transmission and cognition. Nat Rev Neurosci. 2005;6(1):48-56.

12. Artenie VG, Artenie GR, Ciobîcă A-S, Hriţcu L. Current Aspects Regarding The Acetylcholine Metabolism. Analele Ştiinţifice ale Univ „Alexandru Ioan CuzaAlexandru Ioan Cuza. 2010;11:1-10.

13. Friedman J. Cholinergic targets for cognitive enhancement in schizophrenia: focus on cholinesterase inhibitors and muscarinic agonists. Psychopharmacology. 2004;174(1):45-53.

14. Klinkenberg I, Sambeth A, Blokland A. Acetylcholine and attention. Behav Brain Res. 2011;221(2):430-42.

15. Carruthers SP, Gurvich CT, Rossell SL. The muscarinic system, cognition and schizophrenia. Neurosci Biobehav Rev. 2015;55:393-402

16. Bymaster FP, McKinzie DL, Felder CC, Wess J. Use of M1-M5 Muscarinic Receptor Knockout Mice as Novel Tools to Delineate the Physiological Roles of the Muscarinic Cholinergic System. Neurochem Res. 2003;28(3/4):437-42.

17. Levey Al. Immunological localization of $\mathrm{m} 1-\mathrm{m} 5$ muscarinic acetylcholine receptors in peripheral tissues and brain. Life Sci. 1993;52(5-6):441-8.

18. Broks P, Preston GC, Traub M, Poppleton P, Ward C, Stahl SM. Modelling dementia: Effects of scopolamine on memory and attention. Neuropsychologia. 1988;26(5):685-700.

19. Fadda P, Robinson L, Fratta W, Pertwee RG, Riedel G. Scopolamine and MK801-induced working memory deficits in rats are not reversed by CBD-rich cannabis extracts. Behav Brain Res. 2006;168(2):307-11.

20. Klinkenberg I, Blokland A. The validity of scopolamine as a pharmacological model for cognitive impairment: a review of animal behavioral studies. Neurosci Biobehav Rev. 2010;34(8):1307-50. 
21. Hodges DB, Lindner MD, Hogan JB, Jones KM, Markus EJ. Scopolamine induced deficits in a battery of rat cognitive tests: comparisons of sensitivity and specificity. Behav Pharmacol. 2009;20(3):23751.

22. Ebert, Kirch. Scopolamine model of dementia: electroencephalogram findings and cognitive performance. Eur J Clin Invest. 1998;28(11):944-9.

23. Wesnes $K$, Simpson $P$, Kidd A. An investigation of the range of cognitive impairments induced by scopolamine 0.6 mg s.c. Hum Psychopharmacol Clin Exp. 1988;3(1):27-41.

24. Klinkenberg I, Blokland A, Riedel W, Sambeth A. Human electrophysiological correlates of learned irrelevance: effects of the muscarinic M1 antagonist biperiden. Int J Neuropsychopharmacol. 2012;15(10):1375-85.

25. Wezenberg E, Verkes RJ, Sabbe BGC, Ruigt GSF, Hulstijn W. Modulation of memory and visuospatial processes by biperiden and rivastigmine in elderly healthy subjects. Psychopharmacology. 2005;181(3):582-94.

26. Klinkenberg I, Blokland A. A comparison of scopolamine and biperiden as a rodent model for cholinergic cognitive impairment. Psychopharmacology. 2011;215(3):549-66.

27. Veselinović $T$, Vernaleken I, Janouschek H, Kellermann T, Paulzen M, Cumming P, et al. Effects of anticholinergic challenge on psychopathology and cognition in drug-free patients with schizophrenia and healthy volunteers. Psychopharmacology. 2015;232(9):1607-17.

28. Crook JM, Ph D, Tomaskovic-crook E, Hons BS, Dean B. Low Muscarinic Receptor Binding in Prefrontal Cortex From Subjects With Schizophrenia : and the Effects of Neuroleptic Drug Treatment. 2001;158:918-25.

29. Dean B, Crook J, Opeskin K, Hill C, Keks N, Copolov D. The density of muscarinic M1 receptors is decreased in the caudate-putamen of subjects with schizophrenia. Mol Psychiatry. 1996;1:54-8.

30. Crook JM, Tomaskovic-Crook E, Copolov DL, Dean B. Decreased muscarinic receptor binding in subjects with schizophrenia: a study of the human hippocampal formation. Biol Psychiatry. 2000;48(5):381-8.

31. Gibbons AS, Scarr E, Boer S, Money T, Jeon W-J, Felder C, et al. Widespread decreases in cortical muscarinic receptors in a subset of people with schizophrenia. Int J Neuropsychopharmacol. 2013;16(1):37-46.

32. Dean B, Mcleod M, Keriakous D, Mckenzie J, Scarr E. Decreased muscarinic 1 receptors in the dorsolateral prefrontal cortex of subjects with schizophrenia. Mol Psychiatry. 2002;7(10):1083-91.

33. Scarr E, Cowie TF, Kanellakis S, Sundram S, Pantelis C, Dean B. Decreased cortical muscarinic receptors define a subgroup of subjects with schizophrenia. Mol Psychiatry. 2009 ;14(11):1017-23.

34. Shekhar A, Potter WZ, Lightfoot J, Lienemann J, Dubé S, Mallinckrodt C, et al. Selective muscarinic receptor agonist xanomeline as a novel treatment approach for schizophrenia. Am J Psychiatry. 2008;165(8):1033-9.

35. Adams CE, Stevens KE. Evidence for a role of nicotinic acetylcholine receptors in schizophrenia. Front Biosci. 2007;12:4755-72.

36. Freedman R, Hall M, Adler LE, Leonard S. Evidence in postmortem brain tissue for decreased numbers of hippocampal nicotinic receptors in schizophrenia. Biol Psychiatry. 1995;38(1):22-33.

37. Court J, Spurden D, Lloyd S, McKeith I, Ballard C, Cairns N, et al. Neuronal nicotinic receptors in dementia with lewy bodies and schizophrenia: $\alpha$-bungarotoxin and nicotine binding in the thalamus. 1999;73(4):1590-7.

38. Marutle A, Zhang X, Court J, Piggott M, Johnson M, Perry R, et al. Laminar distribution of nicotinic receptor subtypes in cortical regions in schizophrenia. J Chem Neuroanat. 2001;22(1):115-26. 
39. Guan ZZ, Zhang X, Blennow K, Nordberg A. Decreased protein level of nicotinic receptor $\alpha 7$ subunit in the frontal cortex from schizophrenic brain. 1999;10(8):1779-82.

40. Martin-Ruiz CM, Haroutunian VH, Long P, Young AH, Davis KL, Perry EK, et al. Dementia rating and nicotinic receptor expression in the prefrontal cortex in schizophrenia. 2003;54(11):1222-33.

41. Ripoll N, Bronnec M, Bourin M. Nicotinic receptors and schizophrenia. Curr Med Res Opin. 2004;20:1057-74.

42. Heishman SJ, Kleykamp BA, Singleton EG. Meta-analysis of the acute effects of nicotine and smoking on human performance. Psychopharmacology. 2010;210(4):453-69.

43. Parikh V, Kutlu MG, Gould TJ. nAChR dysfunction as a common substrate for schizophrenia and comorbid nicotine addiction: Current trends and perspectives. Schizophr Res. 2016;171(1-3):1-15.

44. Barnes TRE, Mutsatsa SH, Hutton SB, Watt HC, Joyce EM. Comorbid substance use and age at onset of schizophrenia. Br J Psychiatry. 2006;188(3):237-42.

45. Young S., Corley R., Stallings M., Rhee S., Crowley T., Hewitt J. Substance use, abuse and dependence in adolescence: prevalence, symptom profiles and correlates. Drug Alcohol Depend. 2002;68(3):309-22.

46. Chambers RA, Krystal JH, Self DW. A neurobiological basis for substance abuse comorbidity in schizophrenia. Biol Psychiatry. 2001;50(2):71-83.

47. Yücel M, Bora E, Lubman DI, Solowij N, Brewer WJ, Cotton SM, et al. The impact of cannabis use on cognitive functioning in patients with schizophrenia: a meta-analysis of existing findings and new data in a first-episode sample. Schizophr Bull. 2012;38(2):316-30.

48. Green B, Young R, Kavanagh D. Cannabis use and misuse prevalence among people with psychosis. Br J Psychiatry. 2005;187(4):306-13.

49. Volkow ND. Substance Use Disorders in Schizophrenia--Clinical Implications of Comorbidity. Schizophr Bull. 2009;35(3):469-72.

50. Koob GF, Volkow ND. Neurocircuitry of addiction. Neuropsychopharmacology. 2010;35(1):217-38.

51. Cousijn J, Wiers RW, Ridderinkhof KR, van den Brink W, Veltman DJ, Goudriaan AE. Effect of baseline cannabis use and working-memory network function on changes in cannabis use in heavy cannabis users: A prospective fMRI study. Hum Brain Mapp. 2014;35(5):2470-82.

52. Wiers R, Bartholow B, van den Wildenberg E, Thush C, Engels R, Sher K, et al. Automatic and controlled processes and the development of addictive behaviors in adolescents: A review and a model. Pharmacol Biochem Behav. 2007;86:263-83.

53. Everitt BJ, Robbins TW. Neural systems of reinforcement for drug addiction: from actions to habits to compulsion. Nat Neurosci. 2005;8(11):1481-9.

54. Degenhardt L, Hall W. Extent of illicit drug use and dependence, and their contribution to the global burden of disease. Lancet. 2012;379(9810):55-70.

55. Degenhardt L, Chiu W-T, Sampson N, Kessler RC, Anthony JC, Angermeyer M, et al. Toward a Global View of Alcohol, Tobacco, Cannabis, and Cocaine Use: Findings from the WHO World Mental Health Surveys. Hay P, editor. PLoS Med. 2008;5(7):e141.

56. Chiamulera C. Cue reactivity in nicotine and tobacco dependence: a "multiple-action" model of nicotine as a primary reinforcement and as an enhancer of the effects of smoking-associated stimuli. Brain Res Brain Res Rev. 2005;48(1):74-97.

57. Carter BL, Tiffany ST. Meta-analysis of cue-reactivity in addiction research. Addiction. 1999;94(3):327-40.

58. Grüsser SM, Wrase J, Klein S, Hermann D, Smolka MN, Ruf M, et al. Cue-induced activation of the striatum and medial prefrontal cortex is associated with subsequent relapse in abstinent alcoholics. Psychopharmacology. 2004;175(3):296-302. 
59. Janes AC, Pizzagalli D a, Richardt S, deB Frederick B, Chuzi S, Pachas G, et al. Brain reactivity to smoking cues prior to smoking cessation predicts ability to maintain tobacco abstinence. Biol Psychiatry. 2010;67(8):722-9.

60. Payne TJ, Smith PO, Adams SG, Diefenbach L. Pretreatment cue reactivity predicts end-oftreatment smoking. Addict Behav. 2006;31(4):702-10.

61. Cousijn J, Goudriaan AE, Ridderinkhof KR, van den Brink W, Veltman DJ, Wiers RW. Neural responses associated with cue-reactivity in frequent cannabis users. Addict Biol. 2013;18(3):57080.

62. Goldstein RZ, Alia-Klein N, Tomasi D, Carrillo JH, Maloney T, Woicik PA, et al. Anterior cingulate cortex hypoactivations to an emotionally salient task in cocaine addiction. Proc Natl Acad Sci U S A. 2009;106(23):9453-8.

63. Garavan H, Pankiewicz J, Bloom A, Cho J-K, Sperry L, Ross TJ, et al. Cue-Induced Cocaine Craving: Neuroanatomical Specificity for Drug Users and Drug Stimuli. Am J Psychiatry. 2000;157(11):178998.

64. Zijlstra F, Veltman DJ, Booij J, van den Brink W, Franken IHA. Neurobiological substrates of cueelicited craving and anhedonia in recently abstinent opioid-dependent males. Drug Alcohol Depend. 2009;99(1-3):183-92.

65. Hasselmo ME, Stern CE. Mechanisms underlying working memory for novel information. Trends Cogn Sci. 2006;10(11):487-93.

66. Baddeley A. Working memory. Curr Biol. 2010;20(4):R136-40.

67. de Fockert JW, Rees G, Frith CD, Lavie N. The Role of Working Memory in Visual Selective Attention. Science (80- ). 2001;291(5509).

68. Kane MJ, Engle RW. The role of prefrontal cortex in working-memory capacity, executive attention, and general fluid intelligence: An individual-differences perspective. Psychon Bull Rev. 2002;9(4):637-71.

69. Wager TD, Smith EE. Neuroimaging studies of working memory: Cogn Affect Behav Neurosci. 2003;3(4):255-74.

70. Owen AM, McMillan KM, Laird AR, Bullmore E. N-back working memory paradigm: A meta-analysis of normative functional neuroimaging studies. Hum Brain Mapp. 2005;25(1):46-59.

71. Padula $C B$, Schweinsburg AD, Tapert SF. Spatial working memory performance and $f M R I$ activation interaction in abstinent adolescent marijuana users. Psychol Addict Behav. 2007;21(4):478-87.

72. Schweinsburg AD, Schweinsburg BC, Medina KL, McQueeny T, Brown SA, Tapert SF. The Influence of Recency of Use on fMRI Response During Spatial Working Memory in Adolescent Marijuana Users. J Psychoactive Drugs. 2010;42(3):401-12.

73. Jager G, Van Hell HH, De Win MML, Kahn RS, Van Den Brink W, Van Ree JM, et al. Effects of frequent cannabis use on hippocampal activity during an associative memory task. Eur Neuropsychopharmacol. 2007;17(4):289-97.

74. Yu C, McClellan J. Genetics of Substance Use Disorders. Child Adolesc Psychiatr Clin N Am. 2016;25(3):377-85.

75. Escudero I, Johnstone M. Genetics of Schizophrenia. Curr Psychiatry Rep. 2014 Nov 9;16(11):502.

76. Schneider M, Debbané $M$, Bassett AS, Chow EWC, Fung WLA, van den Bree M, et al. Psychiatric disorders from childhood to adulthood in 22q11.2 deletion syndrome: results from the International Consortium on Brain and Behavior in 22q11.2 Deletion Syndrome. Am J Psychiatry. 2014;171(6):627-39.

77. Murphy KC, Jones LA, Owen MJ. High rates of schizophrenia in adults with velo-cardio-facial syndrome. Arch Gen Psychiatry. 1999 Oct;56(10):940-5. 
78. Kennedy DN, Makris N, Herbert MR, Takahashi T, Caviness VS. Basic principles of MRI and morphometry studies of human brain development. Dev Sci. 2002;5(3):268-78.

79. Bertolino A, Weinberger DR. Proton magnetic resonance spectroscopy in schizophrenia. Eur J Radiol. 1999;30(2):132-41.

80. Schwerk A, Alves FDS, Pouwels PJW, van Amelsvoort T. Metabolic alterations associated with schizophrenia: a critical evaluation of proton magnetic resonance spectroscopy studies. J Neurochem. 2014;128(1):1-87.

81. Amaro E, Barker GJ. Study design in fMRI: Basic principles. Brain Cogn. 2006;60(3):220-32.

82. Logothetis NK, Pauls J, Augath M, Trinath T, Oeltermann A. Neurophysiological investigation of the basis of the fMRI signal. Nature. 2001;412(6843):150-7. 


\section{Part I}

Neurobiological mechanisms underlying cognitive symptoms in psychosis 


\section{Chapter | 2}

Pharmacological interventions for the MATRICS cognitive domains in schizophrenia: what's the evidence?

Wilhelmina A. M. Vingerhoets, Oswald J.N. Bloemen, Geor Bakker, Therese A.M.J. van Amelsvoort

Frontiers in Psychiatry, 2013, 4: 1-22 


\begin{abstract}
Schizophrenia is a disabling, chronic psychiatric disorder with a prevalence rate of $0.5-1 \%$ in the general population. Symptoms include positive (e.g. delusions, hallucinations), negative (e.g. blunted affect, social withdrawal), as well as cognitive symptoms (e.g. memory and attention problems). Although $75-85 \%$ of patients with schizophrenia report cognitive impairments, the underlying neuropharmacological mechanisms are not well understood and currently no effective treatment is available for these impairments. This has led to the MATRICS initiative (Measurement and Treatment Research to Improve Cognition in Schizophrenia), which established seven cognitive domains that are fundamentally impaired in schizophrenia. These domains include verbal learning and memory, visual learning and memory, working memory, attention and vigilance, processing speed, reasoning and problem solving, and social cognition. Recently, a growing number of studies have been conducted trying to identify the underlying neuropharmacological mechanisms of cognitive impairments in schizophrenia patients. Specific cognitive impairments seem to arise from different underlying neuropharmacological mechanisms. However, most review articles describe cognition in general and an overview of the mechanisms involved in these seven separate cognitive domains is currently lacking. Therefore, we reviewed the underlying neuropharmacological mechanisms focussing on the domains as established by the MATRICS initiative which are considered most crucial in schizophrenia.
\end{abstract}




\section{Introduction}

Schizophrenia is a disabling, chronic psychiatric disorder with a prevalence rate of $0.5-1 \%$ in the general population. Symptoms include positive and negative symptoms and disorganisation. Approximately $75-85 \%$ of the schizophrenia patients report cognitive impairments as well (1). Although this aspect of schizophrenia was already described by Kraepelin nearly a century ago, cognitive impairments have long been under-identified as a symptom of schizophrenia and relatively little research has been conducted on this topic. Previous research showed that cognitive functioning is strongly associated with functional outcome in schizophrenia (e.g. skill acquisition in psychosocial rehabilitation treatment, demonstration of ability to solve simulated interpersonal problems, and community functioning $(2,3))$. Cognitive impairments often precede the onset of other symptoms and persist after other psychotic symptoms have been effectively treated (4). Furthermore, severity of cognitive impairments is predictive of poorer medication compliance (5), treatment adherence (6) and increased tendency for relapse in first-episode patients (7). At present, no effective treatment is available as existing (antipsychotic) medication mainly targets positive symptoms and does not improve cognition. Although it is sometimes assumed by clinicians (possibly due to marketing) that atypical antipsychotics are superior to typical antipsychotics, results from recent studies contradict this theory. Presently available guidelines for treatment of schizophrenia, such as the NICE (8), PORT (9) and WFSBP (10) guidelines, indicate that there is no superiority of atypical antipsychotics on positive symptoms with the exception of clozapine, and instead state that use of antipsychotics should be evaluated based on their side effects. Since cognitive dysfunction is associated with functional outcome, development of an effective intervention strategy for these symptoms and corresponding guidelines is essential, as such guidelines are currently still lacking.

Lack of effective treatment strategies has over recent years led to an increase in studies investigating underlying neurobiological mechanisms of cognitive impairments and potential new pharmacological targets to enhance cognition in schizophrenia. Research has mainly focussed on the role of neurotransmitters such as dopamine, serotonin, $\boldsymbol{v}$-aminobutyric acid (GABA), glutamate and acetylcholine. Previous research indicated that specific cognitive impairments seem to arise from different underlying neurobiological mechanisms (8). For example, the prefrontal cortex (PFC) has been implicated in the executive functioning aspect of cognition (9) whereas the hippocampus has been linked to e.g. episodic memory (10). This suggests that specific pharmacological agents could enhance domains of cognition differentially. Nonetheless, still little is known about the underlying neurobiology of 
cognition. Knowledge about these neurobiological mechanisms is highly necessary for development of new pharmacological intervention strategies.

To improve cognition research in schizophrenia the Measurement and Treatment to Improve Cognition in Schizophrenia (MATRICS) was developed. The MATRICS identified seven cognitive domains that are fundamentally impaired in schizophrenia: verbal learning and memory, visual learning and memory, working memory, attention and vigilance, processing speed, reasoning and problem solving and social cognition (11). It was decided that cognition research in schizophrenia should mainly focus on these domains in order to identify the neurobiological mechanisms, ultimately to facilitate development of new pharmacological treatment strategies.

Although specific domains of cognition have been identified, most studies tend to describe cognition in general terms using a composite score. Currently, a review differentiating between separate MATRICS domains is lacking. Therefore, the aim of this review is to provide an outline of the underlying neuropharmacological mechanisms of each individual cognitive domain. We will focus on pharmacological intervention studies which used validated instruments to measure the effect on the MATRICS cognitive domains.

\section{Methods}

\section{Search strategy}

A literature search was conducted in medical database PubMed. The following keywords were used: "Pharmacology", "schizophrenia", "Cognition". Subsequently, a separate search was conducted for each individual domain combining the key words "Pharmacology" and "schizophrenia" with the following key words: "verbal learning", "verbal memory", "visual learning", "visual memory", "working memory", "attention", "vigilance", "processing speed", "reasoning", "problem solving", "social cognition".

\section{Inclusion and exclusion criteria}

Papers that met the following inclusion criteria were included: (1) original research papers, both single challenge and clinical trials (full text available); (2) published in English; (3) use of a pharmacological intervention; (4) use of validated cognitive tests to measure one or more of the MATRICS domains; (5) subjects were patients with schizophrenia (6) were published between January 2000 and May 2013. Papers were excluded if: (1) only healthy subjects were included; (2) also schizoaffective disorders and other psychotic disorders were included; (3) cognitive 
domains were measured with non-validated tests; (4) cognitive domains other than the MATRICS domains were measured; (5) only a composite score of cognition was reported.

\section{Results}

In total, the search strategy yielded 938 articles of which 293 articles were found using the keywords "pharmacology", "cognition" and "schizophrenia". The separate searches yielded 158 articles for verbal learning and memory, 85 for visual learning and memory, 100 for working memory, 234 for attention and vigilance, 22 for processing speed, 17 for reasoning and problem solving and 29 for social cognition. After final screening 44 articles were included for verbal learning and memory, 26 for visual learning and memory, 43 for working memory, 22 for attention and vigilance, 31 for processing speed, 30 for reasoning and problem solving and 7 for social cognition. Study characteristics and specifics are shown in table 2 (studies investigating antipsychotics) and table 3 (studies investigating non-antipsychotic intervention strategies).

\section{Verbal learning and memory}

It has been proposed that impairments in verbal learning and memory are one of the most consistent cognitive deficits seen in schizophrenia (12) and is one of the most examined cognitive domains in these patients. A majority of the 44 included studies investigated the effects of typical and atypical antipsychotic medication on verbal learning and memory.

In the past, it was assumed that atypical antipsychotics are superior to typical antipsychotics in enhancing cognition in schizophrenia due to their affinity for both dopamine $D_{2}$ receptors and serotonin $5-\mathrm{HT}_{2 A}$ receptors $(13,14)$. However large studies such as the Clinical Antipsychotic Trials of Intervention Effectiveness (CATIE) (15) and the European First Episode Schizophrenia Trial (EUFEST) (16) did not find differences between typical and atypical antipsychotics in cognitive enhancing effects. This theory was tested by Wagner et al., (16) who compared olanzapine, a dopamine $\mathrm{D}_{2}$ and serotonin $5-\mathrm{HT}_{2 \mathrm{~A}}$ antagonist, to amisulpride, a dopamine $\mathrm{D}_{2} / \mathrm{D}_{3}$ antagonist in 52 patients. No significant differences were found after eight weeks between the two groups in terms verbal memory; both groups improved on verbal learning and memory tasks. Olanzapine was compared to risperidone and haloperidol by Purdon et al. (20). Although not significant after corrections for multiple comparisons, olanzapine was found to be superior to risperidone and haloperidol in enhancing verbal learning and memory. 
The atypical antipsychotic ziprasidone was found to improve verbal learning and memory after 12 weeks of monotherapy (18). However, the study did not include a control group and practice effects were not adequately controlled for. Therefore, the results have to be interpreted with caution. A study comparing the effects of risperidone and haloperidol on verbal memory found that performance on a verbal memory task remained essentially unchanged in both groups (19). Since the authors did not include a non-medicated schizophrenia group but included a healthy group as control this mainly provides evidence that there is no difference between risperidone and haloperidol. Nevertheless, it suggests that both medications did not cause a clinically relevant enhancement of verbal memory. However, Harvey et al. (23) compared the effects of risperidone and quetiapine and found improvement in verbal memory in both treatment groups. The dropout rate of $57 \%$ in this trial was high which may have caused a selection bias. These results are not consistent with other findings. A small study with substantial methodological shortcomings by Purdon et al. (21) found no effect of haloperidol and quetiapine. Velligan et al. (25) also compared quetiapine to haloperidol and found that patients in the quetiapine group improved to a greater extent than the patients in the haloperidol group. However, these findings were not significant after correction for multiple comparisons. Moreover, Kivircik Akdede et al. (26) did not find improvement on a verbal learning and memory task after eight weeks of quetiapine treatment.

Kim et al. (27) found that switching from oral atypical antipsychotics to depot risperidone led to significant improvement in verbal learning and memory. However, they also did not include a control group and did not correct for possible practice effects. Furthermore a high percentage of the patients dropped out in an early stage of the study which could have caused a bias in the sample. Despite these limitations, their results are supported by Suzuki and Gen (28) who also found an improvement in verbal learning and memory in patients treated with depot risperidone compared to patients who received haloperidol treatment (depot). However, the differences between these two treatments might be caused by the high rate of anticholinergic co-medication in the haloperidol group which is well known for its adverse effects on cognition (26). Additionally, improvement in verbal learning and memory was found by Surguladze et al. (30) with both depot risperidone and typical antipsychotics (depot). Performance did not significantly differ between the groups. However, they did not control for practice effects. Therefore, improvement cannot reliably be attributed to medication effects. In addition, Kim et al. (31) found that compared to patients using risperidone, verbal memory improved more in patients using paliperidone extend release (ER), an 
active metabolite of risperidone with an extended delivery system that decreases fluctuations in serum drug concentrations.

Hence, the theory that atypical antipsychotic medications are superior to typical antipsychotics in enhancing verbal learning and memory is not supported by these findings. Nonetheless, some of the atypical antipsychotics, especially risperidone depot, have shown beneficial effects on this aspect of cognition.

Results regarding the effects of clozapine on verbal learning and memory are inconclusive. Three studies which investigated the effects of clozapine on verbal learning and memory were found. Purdon et al. (32) reported significant improvement in verbal learning and memory after treatment with clozapine. Their results were not replicated by Ertugrul et al. (33) and Sumiyoshi et al. (34) as both of these studies did not find improvement in verbal memory in clozapine-treated patients. This discrepancy in findings could be due to methodological differences such as different test batteries and trial duration. Moreover, the study by Purdon et al. (32) did not correct for possible practice effects and since they did not include a control group, improvement in verbal memory cannot be reliably attributed to the effects of clozapine. Thus, although results are inconclusive, at present no convincing evidence is available for the effectiveness of clozapine in enhancing verbal learning and memory in schizophrenia.

Geffen et al. (35) compared the effects of $10 \mathrm{mg}$. and 20-30 mg. of BL-1020, a new antipsychotic drug, to risperidone and placebo. BL-1020 is an antagonist for $D_{2}$ and $5-\mathrm{HT}_{2 a}$ receptors and agonist for $\mathrm{GABA}_{\mathrm{A}}$ receptors (32). Post-mortem studies have found altered GABAergic transmission in schizophrenia, predominantly in the PFC $(33,34)$. Treatment with $20-30 \mathrm{mg}$. BL-1020 was found to improve performance on a verbal learning memory task compared to placebo, whereas $10 \mathrm{mg}$. of BL-1020 and risperidone did not have enhancing effects compared to placebo. A substantial number of patients, especially in the risperidone group, received anticholinergics as well, which could have influenced the results.

Although the findings described above do not support the theory that blocking the $5-\mathrm{HT}_{2 \mathrm{~A}}$ receptors improves verbal learning and memory, a role for serotonin in this domain of cognition cannot be ruled out. Sumiyoshi et al. (38) found a significant improvement on verbal memory after adjunctive tandospirone (a $5-\mathrm{HT}_{1 \mathrm{a}}$ agonist) treatment compared to patients who did not receive adjunctive tandospirone. Riedel et al. (39) and Bervoets et al. (40) both found a significant improvement in verbal memory in patients treated with aripiprazole, an atypical antipsychotic drug with partial $\mathrm{D}_{2}$ agonistic and antagonistic and $5-\mathrm{HT}_{2 \mathrm{a}}$ antagonistic properties in addition to partial agonistic activity at the $5-\mathrm{HT}_{1 \mathrm{a}}$ receptors. However, this is contradicted by Suzuki et al. (41) who compared the effects of aripiprazole, 
olanzapine and perospirone on verbal memory. None of the three conditions showed significant changes in verbal memory scores and no differences were found between the three treatment conditions. Moreover, aripiprazole added to atypical antipsychotics did not improve verbal learning and memory in a trial by YasuiFurukori et al. (39). This discrepancy in findings could be due to practice effects in the studies of Riedel et al. (39) and Bervoets et al. (40), since both studies did not include a control group and did not correct for possible practice effects. Furthermore, different tasks were used which makes it difficult to directly compare the results.

The role of the serotonin $5-\mathrm{HT}_{3 a}$ receptor in verbal learning and memory has been examined as well. Akhondzadeh et al. (43) and Levkovitz et al. (44) investigated the effects of ondansetron, a serotonin $5-\mathrm{HT}_{3 a}$ receptor antagonist, added to respectively risperidone and clozapine treatment and found no enhancing effects on verbal learning and memory. However, the sample size of both studies was small. In contrast to these results, Zhang et al. (45) did find improvement in verbal memory after add-on tropisetron (a $5-\mathrm{HT}_{3}$ receptor antagonist and nicotinic $\alpha_{7}$ agonist) to risperidone treatment compared to placebo. This discrepancy in findings could be explained by the fact that the two studies used different pharmacological interventions. Both Akhondzadeh et al. (43) and Levkovitz et al. (44) administered ondansetron whereas Zhang et al. (45) used tropisetron. Since ondansetron has been found to have low affinity for the nicotinic $\alpha_{7}$ receptors (43), the positive effects of tropisetron on verbal learning and memory could be due to its nicotinic $\alpha_{7}$ agonistic properties rather than its antagonistic effects on the $5-\mathrm{HT}_{3 \mathrm{a}}$ receptors. Effects of a selective serotonin reuptake inhibitor (SSRI) were examined by Friedman et al. (47) who added citalopram to treatment with atypical antipsychotics but found no improvement in verbal learning and memory.

Thus, although results are inconclusive there is preliminary evidence of positive effects of $5-\mathrm{HT}_{1}$ agonists, but not $5-\mathrm{HT}_{3 \mathrm{a}}$ antagonists on verbal learning and memory in schizophrenia.

One study examined the effects of a dopamine $D_{1}$ agonist on verbal learning and memory in schizophrenia. George et al. (48) administered dihydrexidine as a pharmacological challenge and found no effects of dihydrexidine on verbal learning and memory.

The role of the neurotransmitter acetylcholine in cognition has been widely investigated and established (33). Post-mortem, a correlation was found between cognitive impairment and decreased levels of brain choline acetyltransferase in schizophrenia (46). Post-mortem studies have shown changes in both muscarinic and nicotinic acetylcholine receptors in patients with schizophrenia (47). Velligan et 
al. (51) conducted a trial to assess the effects adjunctive therapy with the selective nicotinic $\alpha_{4} \beta_{2}$ receptor agonist AZD3480 on verbal learning and memory in patients but found no improvement. An important limitation of this study is that only patients who smoked were included. Therefore, the lack of effect could be due to desensitization of the nicotinic receptors caused by chronic tobacco use. However, Freedman et al. (52) also did not find an improvement in verbal learning and memory after administration of the partial nicotinic $\alpha_{7}$ agonist DMXB-A, added to antipsychotic treatment in patients, who abstained from nicotine at least one month prior to participation. Studies using acetylcholinesterase (enzyme that breaks down acetylcholine, thereby increasing acetylcholine levels) inhibitors (AChE-Is) as adjunctive therapy to antipsychotic medication also found no improvement on verbal learning and memory (50-55). These results suggest that acetylcholinesterase inhibitors do not effectively enhance verbal memory in patients with schizophrenia. However, all studies used a small sample size and one study included patients who were taking anticholinergic medication as well. This could have influenced the outcome of the study. Another important limitation is that none of these studies controlled for the effects of smoking. Hence, although there is theoretical evidence for a role of acetylcholine in cognition, various (possibly underpowered) intervention studies have not yielded positive results. Since Zhang et al. (45) found improvement in verbal learning and memory after adjunctive tropisetron treatment, it remains possible that enhancement of verbal learning and memory can be achieved with nicotinic $\alpha_{7}$ agonists while simultaneously blocking the $5-\mathrm{HT}_{3 a}$ receptors.

The role of the neurotransmitters GABA and norepinephrine in verbal learning in memory has also been investigated. Buchanan et al. (59) found no improvement in verbal learning and memory with adjunctive MK-0777, a partial GABA $\alpha_{2} / \alpha_{3}$ agonist, therapy to antipsychotics. However, the authors argue that a lack of effect may be due to the fact that MK-0777 is a weak GABA $\alpha_{2} / \alpha_{3}$ agonist. A pilot study by Friedman et al. (60) found no effects of the norepinephrine reuptake inhibitor atomoxetine, on verbal memory when added to treatment with atypical antipsychotics.

Hence, although positive effects were found with the antipsychotic BL-1020 with $\mathrm{GABA}_{\mathrm{A}}$ agonistic properties, the available studies were not able to detect positive effects of both a partial GABA $\alpha_{2} / \alpha_{3}$ agonist and a norepinephrine reuptake inhibitor on verbal learning and memory. Nonetheless, these results suggest that $\mathrm{GABA}_{\mathrm{A}}$ receptors may be a potential target for future studies in verbal learning and memory. 
Effects of the psychostimulant armodafinil were investigated by Kane et al. (61). Armodafinil is a longer-lasting isomer of modafinil, which is an alertness-promoting medication with mechanisms of action different from those of amphetamine (59) and has been found to improve cognition in healthy subjects and adults with ADHD (60). However, the exact mechanisms of action are complex and not entirely understood (61). Armodifinil, added to atypical antipsychotics, did not enhance verbal learning and memory.

The effects of several other pharmacological interventions on verbal learning and memory in schizophrenia have been investigated. Six months of daily creatine administration added to antipsychotic treatment did not have beneficial effects on verbal learning and memory (62). Effects of adjunctive mifepristone, a glucocorticoid receptor (GR) antagonist, on verbal learning and memory was examined by Gallagher et al. (66). They found no improvement in this domain of cognition. Goff et al. (67) examined the effects of sildenafil, a phosphodiesterase 5 (PDE 5) inhibitor used to treat erectile dysfunction, on verbal learning and memory. PDE 5 inhibitors increase cyclic guanine monophosphate (cGMP) which is thought to modulate long term potentiation. They found single dose of $50 \mathrm{mg}$ and $100 \mathrm{mg}$. not to improve verbal learning and memory. On the other hand, Feifel et al. (15) found that patients who received intranasal oxytocin for three weeks performed better on a verbal learning and memory task. Additionally, Stone et al. (68) found that additional glucose administration in patients who were stable on clozapine, enhanced verbal learning and memory. All studies used a small sample and the dropout rate in the study by Feifel et al. (15) was $25 \%$. Moreover, the majority of the patients in the study of Stone et al. (68) received additional medication besides clozapine. Therefore, the effect cannot be attributed to a unique interaction of clozapine and glucose.

To summarize, the proposed superior effect on verbal learning and memory of atypical to typical antipsychotics, is not supported by the available data and any effect does not result from blocking the $5-\mathrm{HT}_{2 \mathrm{a}}$ receptors. Despite the fact that multiple studies describe a role of acetylcholine in cognition, nicotinic receptor agonist and acetylcholinesterase inhibitors do not seem to effectively improve verbal learning and memory in schizophrenia. However, some positive results have been found with risperidone depot, possibly because of medication compliance. In addition, serotonin $5-\mathrm{HT}_{1}$ a receptors and $\mathrm{GABA}_{\mathrm{A}}$ receptors may be molecular targets for enhancing this aspect of cognition. Additionally, there is preliminary evidence that adjunctive oxytocin and glucose treatment may be beneficial in enhancing verbal learning and memory. However, results have to be interpreted with care as 
the available studies are mostly pilot studies which, although important in early stages of research, inherently suffer from methodological shortcomings.

\section{Visual learning and memory}

Compared to verbal learning and memory, considerably less research has been conducted regarding visual learning and memory in schizophrenia. Results of studies that examined the effects of antipsychotic medication on visual learning and memory are, similar to verbal learning and memory, indecisive. Tyson et al. (17) compared the effects of atypical antipsychotic medication with high and low affinity for the $5-\mathrm{HT}_{2 \mathrm{a}}$ receptors on visual learning and memory. Patients treated with risperidone, olanzapine and clozapine were assigned to the high affinity group and patients using quetiapine and amisulpride were assigned to the low affinity group. Performance on visual memory tasks improved in patients in the low affinity group whereas performance in the high affinity group declined. A limitation is that the authors did not correct for multiple testing. However, the effects were already present after nine months of treatment and show a consistent pattern. Since performance declined in the high affinity group, it is not likely that the improvement in the low affinity group is driven by practice effects. However, Rollnik et al. (69) found atypical antipsychotics (olanzapine, risperidone or clozapine) to be superior to typical antipsychotics (haloperidol, chlorprothixene, perazine or flupenthixole) in improving visual learning and after three weeks of treatment, although at the final assessment, this difference was no longer significant. Purdon et al. (20) compared the effects of olanzapine, risperidone and haloperidol. After correction for multiple comparisons, no significant differences were found between the three treatment conditions; visual learning and memory did not improve in all three groups. As mentioned earlier, lack of effect could be caused by concomitant anticholinergic treatment and the small sample size.

Two studies compared the effects of haloperidol to respectively quetiapine (21) and risperidone (67). In both studies haloperidol and both quetiapine and risperidone were found not to enhance visual learning and memory. However, a substantial number of patients in both studies were treated with anticholinergics in addition to antipsychotics, which could have influenced the results. Surguladze et al. (30) found no differences in visual learning and memory between depot risperidone and a typical antipsychotic depot treatment, although performance in both groups improved. As discussed earlier, it cannot be ruled that this improvement is caused by practice effects rather than the effects of medication. 
Although results are inconclusive, clozapine does not seem to effectively enhance visual learning and memory. A study by Ertugrul et al. (33) did not find improvement with clozapine whereas Purdon et al. (32) found significant improvement on performance on one of three assessed visual memory subtests. However, this study has important limitations, which were described earlier.

Treatment with aripiprazole did not significantly improve visual learning and memory in the study by Riedel et al. (39). Tandospirone, which like aripiprazole has serotonin $5-\mathrm{HT}_{1 \mathrm{a}}$ agonistic properties, also did not significantly enhance visual learning and memory in the study of Sumiyoshi et al. (38). These findings suggest that stimulating the serotonin $5-\mathrm{HT}_{1 a}$ receptors does not enhance visual learning and memory in schizophrenia. However, the serotonin $5-\mathrm{HT}_{3 a}$ receptors may play a role in visual memory in schizophrenia. Both Akhondzadeh et al. (43) and Levkovitz et al. (44) found visual learning and memory to improve with adjunctive ondansetron treatment. Although both studies did not correct for multiple testing and possible practice effects, visual memory was the only aspect of the cognitive domains measured that improved in both studies. Adjunctive tropisetron treatment on the other hand did not enhance visual memory (42). As mentioned earlier, tropisetron is both a $5-\mathrm{HT}_{3 a}$ antagonist and partial nicotinic $\alpha_{7}$ agonist whereas ondansetron has low affinity for the nicotinic $\alpha_{7}$ receptors (43). Hence, the $5-\mathrm{HT}_{3 \mathrm{a}}$ receptors may play a role in visual learning and memory. However, enhancement of this aspect of cognition may depend on blockade of nicotinic $\alpha_{7}$ receptors. The 5 $\mathrm{HT}_{1 \mathrm{a}}$ receptor does not seem to be a promising target for enhancing visual learning and memory.

A preliminary study by Niitsu et al. (71) investigated the effect of the SSRI fluvoxamine, a sigma-1 receptor agonist, on cognition and found it not to enhance visual learning and memory. These preliminary results indicate sigma-1 receptor agonism does not enhance visual learning and memory in schizophrenia patients.

Studies investigating the role acetylcholine in visual learning and memory in schizophrenia have not yielded positive results. Selective nicotinic $\alpha_{4} \beta_{2}$ receptor agonist AZD3480 and partial nicotinic $\alpha_{7}$ agonist DMXB-A both did not enhance visual learning and memory when added to antipsychotic treatment $(48,49)$. As mentioned earlier, the lack of effect in the study of Velligan et al. (51) could be due to desensitization of the nicotinic receptors caused by chronic tobacco use since only smokers were included. Studies conducted with acetylcholinesterase inhibitors do not report positive results either. Although Lee et al. (54) found improvement on the recognition subtest of Rey Complex Figure Test (RCTF) with galantamine, the other aspects of the task did not improve. Studies using donepezil also did not find improvement in visual learning and memory $(47,50,52)$. Hence, both nicotinic 
receptor agonists and acetylcholinesterase inhibitors do not seem to effectively enhance visual learning and memory in schizophrenia.

Based on preliminary results of Buchanan et al. (59), GABA does not seem to enhance visual learning and memory in schizophrenia as they found no improvement with partial GABA $\alpha_{2} / \alpha_{3}$ agonist MK-0777. However, this is the only study investigating the role of GABA in visual learning and memory and MK-0777 is a weak GABA $\alpha_{2} / \alpha_{3}$ agonist.

The possible enhancing effect of psychostimulant drugs on visual learning and memory has been investigated in schizophrenia as well. A single dose of $d$ amphetamine, an indirect dopamine $D_{1}$ agonist, did not improve visual learning and memory (69). A single administration of modafinil did not significantly enhance visual memory either (63). In addition, adjunctive armodafinil treatment did not improve visual learning and memory (58). Hence, based on these findings $d$ amphetamine and modafinil do not seem to be promising intervention strategies for enhancing visual learning and memory.

Results of other pharmacological interventions on visual learning and memory are mixed. Gallagher et al. (66) found no improvement after adjunctive mifepristone (a glucocorticoid receptor antagonist) treatment. The effect of adjunctive creatine treatment was investigated by Kaptsan et al. (65) but they found it not to enhance visual learning and memory. Levkovitz et al. (73) investigated the effects of minocycline, a second generation tetracycline with anti-inflammatory and antimicrobial effects. Minocycline modulates the glutamate pathway by blocking nitric oxide induced neurotoxicity. Hyperactivity of glutamatergic neurotransmission (possibly caused by hypofunction of $\mathrm{N}$-methyl-D-asparate (NMDA) receptors) has been found in schizophrenia (33). Stimulated by glutamate, the NMDA receptors activate production of nitric oxide. The authors found improvement on a spatial recognition memory task after minocycline administration, added to antipsychotic treatment. Task performance showed a decrease after 10 weeks, but compared to baseline, performance improved at the final assessment. The drop-out rate in this study was high (due to adverse events and nonadherence) and although it did not differ between the two treatment groups, this could have biased the results.

To summarize, results regarding visual learning and memory are inconclusive. At present, there is some evidence for a role of the serotonin $5-\mathrm{HT}_{3 \mathrm{a}}$ receptors in this cognitive domain. 5- $\mathrm{HT}_{1 \mathrm{a}}$ and sigma-1 receptor agonist on the other hand, did not yield promising results. Additionally, minocycline was found to have positive effects on visual learning memory when added to antipsychotic treatment. Both typical and atypical antipsychotics do not seem to enhance visual learning and memory. 
Studies investigating nicotinic receptor agonist, acetylcholinesterase inhibitors, GABA $\alpha_{2} / \alpha_{3}$ agonist, psychostimulants and GR antagonist did not yield positive results but are in need of replication as they were possibly underpowered. Overall, results need be interpreted with care as the described studies are often small pilot studies with inherent limitations.

\section{Working memory}

Working memory refers to a system with limited capacity for temporary storage and manipulation of information, necessary for cognitive tasks (71), and has been the subject of many studies investigating cognition in schizophrenia. Most of these studies focused on the effects of antipsychotic medication on working memory.

Although results are inconclusive at present, both typical and atypical antipsychotics show little beneficial effects on working memory. Rollnik et al. (69) compared the effectiveness of typical and atypical antipsychotics and found no differences between the two groups. Quetiapine and amisulpride, which both have low affinity for the $5-\mathrm{HT}_{2 \mathrm{a}}$ receptors, improved performance on a verbal working memory task compared to risperidone, olanzapine and clozapine (high affinity for 5- $\mathrm{HT}_{2 \mathrm{a}}$ ) treatment (14). However, performance on visual working memory tasks did not significantly improve in both groups. No differences were found in working memory performance between amisulpride and olanzapine by Wagner et al. (16). However, working memory performance did improve in both groups. Effects of olanzapine, risperidone and haloperidol were compared by Purdon et al. (20). After correction for multiple comparisons, no significant differences were found between the three treatment conditions and working memory did not improve in any group. Mori et al. (75) examined the effects of switching from typical antipsychotics to olanzapine, quetiapine, risperidone or perospirone on working memory and found improvement in working memory with risperidone, while working memory performance of the patients treated with quetiapine decreased. Working memory performance did not change in the olanzapine and perospirone group. It must be noted that the mean age in the sample was high (59.9 years) and correlated negatively with working memory scores. Therefore age related cognitive decline may have confounded these results. On the contrary, Kivircik Akdede et al. (26) found improvement on working memory with quetiapine. However, this study did not include a control group and did not correct for possible practice effects. Risperidone treatment was found to be superior to haloperidol in the study by McGurk et al. (70), but after correcting for anticholinergic co-medication, this effect was no longer significant. Working memory performance did not improve in both 
groups. Paliperidone treatment was not superior to risperidone treatment in enhancing working memory in the study by Kim et al. (31) and working memory did not improve in both groups.

Results regarding clozapine are inconclusive. Papageorgiou et al. (76) compared the effects of clozapine and olanzapine on working memory and found that working memory improved in both groups. No differences were found between the two treatment conditions. Ertugrul et al. (33) conducted two working memory tasks (Digit Span Test and the Auditory Consonant Trigram Test) and found that performance on the Digit Span test improved with clozapine treatment, whereas performance on the Auditory Consonant Trigram Test did not. Both studies did not correct for possible practice effects or multiple testing. These results are contradicted by Purdon et al. (32) who did not find improvement in working memory with clozapine treatment. This discrepancy in findings could be due to methodological shortcomings and differences such as different test batteries and trial duration.

Riedel et al. found that aripiprazole did not significantly enhance working memory (36). Aripiprazole also did not improve working memory when added to atypical antipsychotics (39). Adjunctive sertindole, an atypical antipsychotic with high affinity for the $\mathrm{D}_{2}$ and $5-\mathrm{HT}_{2 \mathrm{a}}$ receptors, did not improve working memory in patients treated with clozapine (77). Finally, working memory did improve after 20 $30 \mathrm{mg}$. of the novel antipsychotic BL-1020 (a dopamine antagonist with GABA agonistic properties) compared to placebo whereas $10 \mathrm{mg}$. BL-1020 and risperidone did not (32).

Hence, although results are preliminary and inconclusive, at present no convincing evidence is available for the effectiveness of both typical and atypical antipsychotics on working memory in schizophrenia. However, the antipsychotic BL-1020 was found to improve working memory, possibly through its $G_{A B A}$ agonistic properties.

Single administration of the dopamine $D_{1}$ agonist dihydrexidine did not enhance working memory in a trial by George et al. (48). Given the small sample size and the fact that dihydrexidine was only administered a single time, beneficial effects of long term dihydrexidine administration on working memory cannot be ruled out.

Serotonin $5-\mathrm{HT}_{3}$ a receptors seem to be less important for working memory functioning. Both Akhondzadeh et al. (43) and Levkovitz et al. (44) found no improvement in working memory with adjunctive ondansetron (5- $\mathrm{HT}_{3 \mathrm{a}}$ antagonist) treatment. Moreover, adjunctive tropisetron treatment also did not enhance working memory (42). 
In addition, Niitsu et al. (69) found no improvement in working memory after adjunctive fluvoxamine treatment. Moreover, 12 weeks of adjunctive citalopram treatment did not enhance working memory (44). Hence, these results suggest that serotonin modulation pharmacological agents do not significantly enhance working memory in schizophrenia.

Both the selective nicotinic $\alpha_{4} \beta_{2}$ receptor agonist AZD3480 and the partial nicotinic $\alpha_{7}$ agonist DMXB-A did not enhance working memory performance $(48,49)$. Acetylcholinesterase inhibitors donepezil and rivastigmine did not enhance working memory either $(47,50-52,54,55,74)$. Jacobsen et al. (78) examined the effects of a single administration of nicotine (nicotinic acetylcholine receptor agonist (79)) on working memory in tobacco using patients and tobacco using healthy subjects. Although patients performed significantly worse on the N-back task compared to healthy controls, nicotine administration did improve performance on the 2-back in patients while performance of the healthy controls declined. Thus, although the acetylcholinesterase inhibitors donepezil and rivastigimine and nicotinic receptor agonists do not show positive effects on working memory in schizophrenia, positive results were found with a single dose of nicotine administration. Therefore, a role of acetylcholine and nicotinic receptors in enhancing working memory cannot be ruled out.

Working memory did not improve in a study by Buchanan et al. (59) after four weeks of treatment with partial GABA $\alpha_{2} / \alpha_{3}$ agonist MK-0777. Menzies et al. (81) studied the effects of lorazepam, a $\mathrm{GABA}_{A}$ receptor agonist, and flumazinil, a $\mathrm{GABA}_{A}$ receptor antagonist, on working memory in patients and healthy subjects. Working memory performance declined after a single dose of lorazepam whereas performance did not change significantly after flumazinil. Thus, although results are inconclusive, there is some evidence that in $\mathrm{GABA}_{A}$ agonists may lower working memory. However positive effects on working memory were found with an antipsychotic with additional $\mathrm{GABA}_{\mathrm{A}}$ agonistic properties.

Friedman et al. (60) found no effects of atomoxetine (norepinephrine reuptake inhibitor) on working memory in patients. A lack of effect could be due to insufficient power.

Glutamatergic pathways have been examined by Duncan et al. (82). They added 50 $\mathrm{mg}$. of d-cycloserine, an antituberculous drug which, at low doses has agonistic properties at the NDMA receptors, to typical antipsychotics. After four weeks of treatment, working memory did not improve. However, these results need to be replicated before the role of NMDA receptors in working memory can be established. 
Armodafinil, a longer-lasting isomer of modafinil, did not enhance performance on working memory task when added to atypical antipsychotics for four weeks (58). However, Turner et al. (63) found that a single dose of modafinil improved performance on a verbal working memory task compared to placebo. Performance on a spatial working memory task did not differ between modafinil condition and placebo condition. These results were not replicated by Spence et al. (83) who did not find differences in performance on a (verbal) working memory task after a single administration of modafinil compared to placebo. This discrepancy in findings could be due to differences in modafinil dose $(200 \mathrm{mg}$. and $100 \mathrm{mg}$. respectively). Moreover, both studies used different tasks which make direct comparison of results difficult. Nonetheless, a single dose of modafinil might enhance working memory in schizophrenia patients, although recurrent treatment with a longer-lasting variant showed no effect.

Add-on intranasal oxytocin treatment did not improve working memory (12). Furthermore, adjunctive mifepristone (glucocorticoid receptor antagonist) treatment did not enhance working memory (63). Goff et al. (67) did not find improvement in working memory after both $50 \mathrm{mg}$. and $100 \mathrm{mg}$. sildenafil administration. Furthermore, daily creatine administration added to antipsychotic treatment did not have beneficial effects on working memory either (62). Add-on minocycline treatment on the other hand, improved working memory in a study by Levkovitz et al. (73); the number of errors on a working memory task decreased significantly in the minocycline group whereas the number of errors in the placebo group increased. However, this study has some limitations which are described earlier. Thus, apart from minocycline, other lines of research did not identify possible new intervention strategies for working memory enhancement in schizophrenia.

To summarize, even though some positive results were found with minocycline, nicotine and modafinil, the presently available studies did not identify promising molecular targets for enhancement of working memory in schizophrenia. GABA agonists have shown mixed results. Most of the studies examined the effects of antipsychotic treatment on working memory and only a limited number of studies used other pharmacological interventions, which makes it difficult to draw definite conclusions. More research needs to be conducted, especially on the potential role of GABA, norepinephrine, acetylcholine, glutamate and psychostimulants. 


\section{Attention and vigilance}

The construct of attention refers to a core cognitive function that relates to the ability to select, filter, focus and process different stimuli in the environment. Attention is closely related to working memory and executive functioning (80) and therefore, it is difficult to distinguish between these constructs. Because of the broad definition, impairment in virtually any task can be considered as impairment in attention (80). Therefore, in this review, we only included articles which used the Continuous Performance Test (CPT) to specifically measure attention as this test is recommend by the MATRICS (81).

Studies using antipsychotics to enhance attention report little beneficial effects. The theory that atypical antipsychotics are superior to typical antipsychotics in enhancing cognition was tested for attention as well. A trial comparing olanzapine to amisulpride did not find differences in effects on attention; attention did not significantly improve in both groups (13). Olanzapine did not enhance attention in a study by Molina et al. (86), who examined the effects of switching from typical antipsychotics or risperidone to olanzapine. Attention did not improve with olanzapine treatment.

The effects of risperidone on attention were compared to the effects of respectively haloperidol (83) and quetiapine (20). In the study of Liu et al. (87) no improvement was found in both the haloperidol and the risperidone group. Additionally, although no differences were found between the risperidone and quetiapine in the study by Harvey et al. (23), within group analyses showed significant improvement in attention in the risperidone group, whereas the quetiapine group did not improve. Kim et al. (27) reported improvement with depot risperidone. However, paliperidone did not improve attention (28). To summarize, both typical and atypical antipsychotics have shown little beneficial effects on attention in schizophrenia patients.

The possible role of dopamine and serotonin in attention has also been examined with intervention strategies other than antipsychotic treatment. George et al. (48) examined the effects of a full dopamine $\mathrm{D}_{1}$ agonist, dihydrexidine but found it not to enhance attention.

Studies using serotonin intervention strategies have not yielded positive results either. Golightly et al. (88) examined the role of serotonin in attention by using acute tryptophan, a precursor for serotonin, depletion. Depletion had no effect on performance on the CPT. Niitsu et al. (71) investigated the effect of adjunctive fluvoxamine treatment on attention and found no improvement in attention either. The effects of citalopram, added to treatment with atypical antipsychotics was 
examined by Friedman et al. (47). They found that adjunctive citalopram treatment did not enhance attention. Thus, although serotonin has been implicated in both verbal and visual memory, it does not seem to play a prominent role in attention. Based on results of mostly preliminary studies, acetylcholine does not seem to play an important role in attention. Selective nicotinic $\alpha_{4} \beta_{2}$ receptor agonist AZD3480, did not enhance attention in a study by Velligan et al. (51). Nonetheless, Freedman et al. (52) found some beneficial effects of partial nicotinic $\alpha_{7}$ agonist DMXB-A on attention. In their cross-over study, patients were treated with 75 mg., 150 mg., and placebo. All treatment arms lasted four weeks, followed- by a one-week washout period. Over the course of the trial, attention improved in all treatment groups. The authors suggested that possible practice effects had obscured the potential effect of treatment, and therefore also examined the scores after the first four weeks of treatment. They found that attention improved with both doses of DMXB-A compared to the placebo. Two types of acetylcholinesterase inhibitors, rivastigmine and donepezil, did not enhance attention in schizophrenia $(55,74,85)$. On the other hand, a single nicotine administration improved attention in schizophrenia patients but not in healthy controls (86). Thus, despite negative results with acetylcholinesterase inhibitors, some promising results have been obtained with nicotine and a partial nicotinic $\alpha_{7}$ agonist. These preliminary results suggest that the nicotinic receptors are a potential target for enhancement of attention in schizophrenia.

Partial GABA $\alpha_{2} / \alpha_{3}$ agonist MK-0777 did not enhance attention when added to antipsychotic treatment (56). However, as mentioned earlier, MK-0777 is a weak GABA $\alpha_{2} / \alpha_{3}$ agonist and this is the only study investigating the potential role of GABA in attention in schizophrenia. Therefore, these results need to be replicated using specific and more potent GABA modulatory agents.

Other lines of research have not yielded positive results. The psychostimulant drug armodafinil did not enhance attention (58). Furthermore, adjunctive mifepristone (glucocorticoid receptor antagonist) therapy did not improve attention (63). Duncan et al. (82) found no improvement in attention with adjunctive D-cycloserine treatment. Also, sildenafil (PDE 5 inhibitor) did not enhance attention in schizophrenia in a trial by Goff et al. (67). Stone et al. (68) compared the effects of single administration of glucose to placebo in clozapine treated patients and found attention to be significantly worse in the glucose condition. Thus, several other lines of research did not identify potential new intervention strategies enhancement of attention in schizophrenia.

To summarize, at present only a few pharmacological intervention strategies have been effective in enhancing attention in schizophrenia. Although results are not 
consistent, positive results have been found with both oral and depot risperidone treatment. Furthermore, a partial nicotinic $\alpha_{7}$ agonist, and a single administration of nicotine did improve attention in schizophrenia, suggesting a role for acetylcholine and nicotinic receptors in attention. Overall, results need to be considered preliminary and more research needs to be conducted to replicate these findings as these studies have some important limitations.

\section{Processing speed}

Processing speed is considered a core cognitive function and refers to the speed at which the brain processes information. It can be measured as the number of correct responses during a task within a given amount of time (87).

As for other domains of cognition, a majority of the studies examined the effects of antipsychotic medication on processing speed. The theory that atypical antipsychotics are superior to typical antipsychotics in improving cognition in patients was tested for processing speed as well. A study comparing amisulpride with olanzapine found that processing speed did not improve in both groups (13). Moreover, performance on a processing speed task did not differ between patients treated with different typical antipsychotics and atypical antipsychotics and performance did not improve in both groups (66). Purdon et al. (20) compared the effects of olanzapine, risperidone and haloperidol on processing speed. After correction for multiple comparisons, no significant differences were found between the three treatment conditions and processing speed did not improve in any of the groups. Thus, atypical antipsychotics do not appear to be superior to typical antipsychotics. Furthermore, no beneficial effects of the atypical antipsychotic ziprasidone were found on processing speed (18). Anticholinergics were allowed during the trial which might have influenced the results. Risperidone depot treatment did not enhance processing speed in the study by Kim et al. (27). Moreover, paliperidone ER was not found to be superior to risperidone (28). Unfortunately, within group comparisons were not reported. However, although no significant differences were found between two treatment groups, risperidone was found to improve processing speed (measured by the Trail Making Test, part A) whereas quetiapine did not in a study comparing these two antipsychotics (20). Contrary to those results, quetiapine was found to enhance processing speed in a trial by Kivircik Akdede et al. (26). As described earlier, this study did not include a control group and did not correct for possible practice effects. These results were not replicated by Purdon et al. (24). Although processing speed improved in both the quetiapine and haloperidol group, these results were not significant after correcting for multiple comparisons. Velligan et al. (25) compared the effectiveness 
on processing speed between quetiapine and haloperidol treatment. They found no differences between the two treatment groups. Purdon et al. (32) found that processing speed improved with clozapine treatment. However, this improvement cannot reliably be attributed to the effects of clozapine as the study did not include a control group and they did not correct for possible practice effects. Beneficial effects of aripiprazole on processing speed were found by Riedel et al. (39). YasuiFurukori et al. (42) found no improvement in processing speed with adjunctive aripiprazole treatment to olanzapine or risperidone. Furthermore, a new antipsychotic with $G_{A B A}$ receptor agonistic properties in addition to dopamine $D_{2}$ and serotonin $5-\mathrm{HT}_{2 a}$ receptor blockade (BL-1020) did not improve processing speed (32).

To summarize, both typical and atypical antipsychotics do not seem to effectively enhance processing speed in schizophrenia patients. Although some studies reported positive effects of clozapine, quetiapine and risperidone, these results should be interpreted with care as these studies have important limitations.

Studies examining the role of serotonin in processing speed did not yield positive results. Adjunctive ondansetron (5- $\mathrm{HT}_{3 \mathrm{a}}$ receptor antagonist) therapy to antipsychotic medication did not enhance processing speed in a study by Levkovitz et al. (44). Adding citalopram to atypical antipsychotic treatment also did not enhance processing speed in the study by Friedman et al. (47). In addition, tryptophan depletion did not affect processing speed in the study by Golightly et al. (88). Thus, the available studies do not provide evidence for a prominent role of serotonin in processing speed in schizophrenia. However, all studies used small samples and the study of Golightly et al. (88) allowed concomitant anticholinergics which could have influenced the results.

Studies using acetylcholine related intervention strategies did not yield positive results either. Both the selective nicotinic $\alpha_{4} \beta_{2}$ receptor agonist AZD3480 and the partial nicotinic $\alpha_{7}$ agonist DMXB-A did not enhance processing speed $(48,49)$. Moreover, three types of acetylcholinesterase inhibitors, donepezil, galantamine and rivastigmine, did not improve processing speed (47,51-55). Thus, although the role of acetylcholine in memory and attention has been well established, it does not seem to be a potential target in enhancing processing speed in schizophrenia. However, these studies have limitations such as small sample sizes.

Effects of GABA and norepinephrine on processing speed were also examined. Processing speed did not improve after adjunctive treatment with partial $\alpha_{2} / \alpha_{3}$ agonist MK-0777 (56). As mentioned earlier, BL-1020 (antipsychotic with GABA agonistic properties) enhanced antipsychotic also did not enhance processing speed (32). In the pilot study of Friedman et al. (60), processing speed did not 
improve after adjunctive treatment with the norepinephrine reuptake inhibitor atomoxetine. Thus, norepinephrine and GABA $\alpha_{2} / \alpha_{3}$ receptors do not seem to play an important role in processing speed in schizophrenia as the available studies were not able to detect positive effects. However, lack of effect could be due to the small sample size of both studies.

Processing speed did increase after a single dose of d-amphetamine in the study of Pietrzak et al. (72). Adjunctive armodafinil treatment had no beneficial effects on processing speed in the study by Kane et al. (61). Hence, since d-amphetamine is an indirect dopamine $D_{1}$ agonist, dopamine $D_{1}$ receptors could be a possible target for enhancing processing speed in schizophrenia although the study by Pietrzak et al. (72) needs replication.

Lastly, there are some studies of agents that have no direct (known) effect on neurotransmission. Processing speed did not improve after single dose of $50 \mathrm{mg}$ and $100 \mathrm{mg}$ sildenafil (a PDE 5 inhibitor commonly used for erectile dysfunction) in the cross-over trial by Goff et al. (67). Furthermore, adjunctive dehydroepiandrosterone (DHEA) therapy, a corticosteroid that serves as a precursor for both androgenic and estrogenic steroids, did not enhance processing speed (88). Thus, other lines of research did not identify promising intervention strategies for enhancement of processing speed in schizophrenia.

To summarize, at present no convincing evidence exist for the effectiveness of both typical and atypical antipsychotics on processing speed in schizophrenia. Although, positive results were found with quetiapine, risperidone, clozapine and aripiprazole, these studies have important limitations and therefore the effects cannot be reliably attributed to the effects of the medication. One positive result was found with single dose d-amphetamine, suggesting a potential role of dopamine $D_{1}$ receptors in processing speed. Studies investigating $5-\mathrm{HT}_{3 a}$ receptor antagonist, SSRI, nicotinic receptor agonist, acetylcholinesterase inhibitors, a GABA $\alpha_{2} / \alpha_{3}$ agonist, and a norepinephrine reuptake inhibitor did not find clinically relevant improvement in processing speed but are in need for replication as the described studies used small samples and were possibly underpowered.

\section{Reasoning and problem solving}

We found 30 studies that measured reasoning and problem solving after a pharmacological intervention. Reasoning and problem solving is considered an aspect of cognitive functioning. As for the other cognitive domains, a relatively large number of studies investigated the effects of antipsychotics on reasoning and problem solving. 
Tyson et al. (17) compared antipsychotics with low-affinity for 5- $\mathrm{HT}_{2 \mathrm{a}}$ receptors to antipsychotics with high affinity for these receptors. Response latency on a reasoning and problem solving task decreased in the low-affinity group, whereas latency increased in the high-affinity group. The authors did not correct for multiple comparisons. Since response latency increased in the high-affinity group, it is not likely that the improvement in the low-affinity group is (only) driven by practice effects. Purdon et al. (20) compared the effects of olanzapine, risperidone and haloperidol and found that olanzapine was superior in enhancing reasoning and problem solving. However, after correcting for multiple comparisons, none of the medications improved reasoning and problem solving. On the contrary, Kim et al. (27) both and Suzuki and Gen (28) found improvement in performance on a reasoning and problem solving task However, Kim et al. (27) did not include a control group and did not correct for possible practice effects. Therefore, improvement cannot be reliably attributed to the effects of medication. Moreover, in the study of Suzuki and Gen (28) a high percentage of the patients in the haloperidol group was using concomitant anticholinergics whereas in the risperidone group anticholinergics were tapered during the first weeks of the trial. Therefore, improvement in this group could be due to effects of diminishing anticholinergics.

Purdon et al. (24) investigated the effects of haloperidol and quetiapine and found that reasoning and problem solving did not improve in both groups. Olanzapine, perospirone and aripiprazole did not improve reasoning and problem solving either (38). Moreover, adding aripiprazole to atypical antipsychotics also did not yield positive results (39). Furthermore, no improvement was found with clozapine by Ertugrul et al. (30) and Purdon et al (29). Nielsen et al. (77) added sertindole to clozapine but found no improvement in reasoning and problem solving either. Finally, the new antipsychotic with GABA agonistic properties BL-1020 also did not improve reasoning and problem solving (32). Hence, although positive results were found with risperidone depot, both typical and atypical antipsychotics have shown little clinically relevant effects on reasoning and problem solving.

Serotonergic intervention strategies have not yielded positive results. Adjunctive ondansetron (5- $\mathrm{HT}_{3}$ antagonist) treatment had no beneficial effects on reasoning and problem solving (40). Fluvoxamine and citalopram both did not enhance reasoning and problem solving either $(44,68)$. On the contrary, Golightly et al. (88) found that patients who underwent tryptophan depletion during the first session performed significantly worse on the Wisconsin Card Sorting Test (WCST) compared to placebo. However, this effect was not present during the second session. The WCST requires subjects to sort cards by a certain parameter. The 
subject is not told which parameter. The sorting principle changes after 10 correct responses in a row. Thus subjects have to acquire a certain strategy to sort the cards. The authors concluded that tryptophan depletion only affected strategy acquisition and that once this is learned; tryptophan depletion did not interfere with application of this strategy. Thus, based on the results described above, $5-\mathrm{HT}_{3 \mathrm{a}}$ antagonist and SSRI's did not effectively enhance reasoning and problem solving. However, a role for serotonin in this aspect of cognition cannot be ruled out since tryptophan depletion did interfere with strategy acquisition.

Partial nicotinic $\alpha_{7}$ agonist DMXB-A had no enhancing effects on reasoning and problem solving in the study by Freedman et al. (52). In addition, studies investigating the effects of the acetylcholinesterase inhibitors donepezil and rivastigmine did not find improvement in performance on a reasoning and problem solving task either $(47,50,53,55)$. Hence, based on these results, nicotinic $\alpha_{7}$ agonists and acetylcholinesterase inhibitors do not appear to significantly enhance reasoning and problem solving in schizophrenia.

In line with the results of Geffen et al. (35) described earlier, no positive results were obtained with other GABAergic interventions strategies. Adjunctive therapy with partial GABA $\alpha_{2} / \alpha_{3}$ agonist MK-0777 did not enhance reasoning and problem solving abilities in the study by Buchanan et al. (59). In addition, adjunctive topiramate (an antiepileptic drug which potentiates GABAergic transmission probably through its AMPA / kainite receptor antagonistic properties) treatment did not enhance reasoning and problem solving either (90). Zoccali et al. (91) examined the effects of adjunctive lamotrigine, an anticonvulsant drug which reduces excessive glutamate release in the brain via inhibition of voltage-gated sodium and calcium channels (92). Reasoning and problem solving did not improve. The potential role of norepinephrine in reasoning and problem solving in schizophrenia was examined in a pilot study by Friedman et al. (60) by adding atomoxetine to antipsychotic treatment. They found no in this aspect of cognition. In conclusion, the available evidence suggests that modulation of GABA and glutamate transmission and norepinephrine reuptake inhibition does not have enhancing effects on reasoning and problem solving abilities in schizophrenia.

Some positive results have been found with psychostimulating drugs. Compared to placebo, performance on a reasoning and problem solving task improved after a single dose of $d$-amphetamine (indirect dopamine $D_{1}$ agonist, (69)). Contrary to these results, Turner et al. (63) found that, compared to placebo, latency on the 
Tower of London task was significantly lower after modafinil administration. The number of attempts to obtain the correct solution did not differ between the two groups. Armodafinil, the longer-lasting isomer of modafinil, did not affect reasoning and problem solving abilities (58). Thus, although armodafinil and modafinil did not enhance reasoning and problem solving, $d$-amphetamine did improve this aspect of cognition. This suggests that dopamine $D_{1}$ agonists are a potential area for further study in reasoning and problem solving in schizophrenia.

Pharmacological intervention strategies that do not directly influence neurotransmission were also investigated. Levkovitz et al. (73) found that reasoning and problem solving abilities improved after add-on minocycline treatment whereas performance in the placebo group did not change. Both creatine and glucose had no enhancing effects on reasoning and problem solving; daily creatine administration in addition to antipsychotic treatment did not have beneficial effects on working memory in the study by Kaptsan et al. (65). Stone et al. (68) found no improvement in reasoning and problem solving after a single dose of glucose. Hence, despite of the study's limitations, minocycline's putative ability to improve reasoning and problem solving abilities should be studied further.

In conclusion, although positive results were found with depot risperidone treatment in studies with important limitations, antipsychotics do not seem to effectively improve reasoning and problem solving in schizophrenia. The available studies did not show enhancing effects of the neurotransmitters serotonin, acetylcholine, GABA or norepinephrine on reasoning and problem solving. However, dopamine $D_{1}$ agonists may have potential in this cognitive domain since one positive result was found with a single dose d-amphetamine. Finally, minocycline had enhancing effects on reasoning and problem solving abilities. However, this study has important limitations. Therefore, these results are in need for replication.

\section{Social cognition}

In general terms, social cognition refers to the cognitive processes used to decode and encode the social world (93). Of all the MATRICS cognitive domains, social cognition has received the least attention in research. This is probably due to the fact that it is a relatively new area in schizophrenia research (81) and that the boundaries of this domain are not entirely clear (94). Final screening yielded no 
more than seven articles on social cognition and pharmacology using validated outcome measures.

A study by Mizrahi et al. (98) examined the effects of antipsychotic treatment on social cognition in schizophrenia. They investigated the effects of clozapine, risperidone, olanzapine and loxapine on Theory of Mind (TOM). TOM is an aspect of social cognition which refers to the ability to understand intentions of others and to recognize that their actions are guided by beliefs about the world (95). They found that TOM improved after two weeks of medication use and continued to improve during the rest of the trial. Unfortunately, the authors did not differentiate between the four different antipsychotics. However, all four types of medication have high affinity for dopamine $\mathrm{D}_{2}$ receptors as well as the $5-\mathrm{HT}_{2 a}$ receptors $(96,97)$. These results are in line with the results of Sumiyoshi et al. (101) who found that perospirone treatment improved performance on a social cognition task. Nonetheless, both studies did not include a control group and used small samples. Hence, given the longitudinal design of this study, natural progression and practice effects cannot be excluded. Additionally, the high drop-out rate in the study of Sumiyoshi et al. (101) could have led to a bias in the sample. Behere et al. (102) found that performance on an emotion recognition task improved after risperidone treatment. However, it must be noted that they did not include a control group and that time of follow-up assessment was not equal for all patients. Opposed to these results, the study by Harvey et al. (23) discussed earlier did not find improvement in performance on an emotional recognition task in patients treated with either quetiapine or risperidone.

Hence, these results imply preliminary evidence that dopamine and serotonin are important for Theory of Mind related aspects of social cognition but not for emotion recognition.

The possible role of GABA in social cognition was investigated by Buchanan et al. (59). They found no improvement with the partial GABA $\alpha_{2} / \alpha_{3}$ agonist MK-0777 when added to antipsychotic treatment. The psychostimulant armodafinil also did not improve social cognition (58). Hence, GABA $\alpha_{2} / \alpha_{3}$ receptors are not prime candidates for enhancing social cognition in schizophrenia.

Another line of research focussed on the role of oxytocin in social cognition. This neuropeptide is known for its role in positive social behaviour (100). Pedersen et al. (104) found that intranasal oxytocin administration improved social cognition. This implicates a role for oxytocin in social cognition. Since previous research showed that plasma oxytocin levels are lower in schizophrenia compared to controls (102), it could be hypothesized that increasing oxytocin levels improves social cognition in schizophrenia. However, the study of Pedersen et al. (104) has some important 
limitations. First, the sample size was small. Moreover, they carried out multiple tests in this small sample; therefore the results have to be interpreted with caution. Studies investigating the role of oxytocin in social cognition are sparse. Therefore, to determine the exact role of oxytocin in social cognition more research needs to be conducted on this topic.

In conclusion, the available seven studies suggest preliminary evidence for a role of dopamine, serotonin and oxytocin in social cognition in schizophrenia patients. GABA does not seem to be a promising target for enhancement of social cognition. However, these studies have important limitations. Therefore, future research needs to confirm the role of these transmitters in social cognition.

\section{Discussion}

With this review we aimed to provide an outline of the underlying neuropharmacological mechanisms of the separate MATRICS domains. Although some potential targets were identified, overall, results of previous studies attempting to identify potential pharmacological targets for cognitive enhancement have been unsatisfactory. This review has shown that dysfunction in separate cognitive domains seems to arise from different underlying neuropharmacological mechanisms. This suggests that schizophrenia patients with different cognitive impairments could benefit from different (adjunctive) pharmacological agents. The identified potential molecular targets, which include dopamine $D_{1}$ receptors, serotonin $5-\mathrm{HT}_{1 \mathrm{a}}$ and $5-\mathrm{HT}_{3 \mathrm{a}}$ receptors, nicotinic $\alpha_{7}$ receptors, $\mathrm{GABA}_{\mathrm{A}}$ receptors and NMDA receptors, are described more extensively below.

\section{Dopamine $D_{1}$}

Although George et al. (48) were not able to detect positive results with a single dose of $D_{1}$ agonist dihydrexidine, Pietrzak et al. (72) found improvement in both processing speed and reasoning and problems solving abilities (both aspects of executive functioning) after a single dose of $d$-amphetamine, an indirect $D_{1}$ agonist. Decreased dopaminergic neurotransmission in the PFC has been hypothesized to be associated with cognitive dysfunction in schizophrenia (33). Since $D_{1}$ receptors are highly abundant in the PFC (103), this receptor subtype has been particularly associated with executive function and working memory. A PET study by Okubo et al. (107) found decreased $D_{1}$ receptors in the PFC in schizophrenia which was indeed associated with poorer executive functioning. Animal studies provide additional evidence for cognitive enhancing effects of $D_{1}$ receptor agonists as low 
doses of several $D_{1}$ agonists were found to enhance cognition in non-human primates $(105,106)$. Because a majority of dopamine receptors in the PFC belong to the $D_{1}$ subtype, and not to the $D_{2}$ subtype $(107)$, which is related to psychotic symptom severity, $D_{1}$ receptors may be a feasible molecular target for enhancement of executive function related aspects of cognition without exacerbation of psychotic symptoms.

Serotonin $5-H T_{1 a}$ and $5-H T_{3 a}$ receptors

(Partial) 5- $\mathrm{HT}_{1 \mathrm{a}}$ receptor agonism was found to improve verbal learning and memory (35-37). These enhancing effects may be due to the high density of $5-\mathrm{HT}_{1}$ a receptors in the hippocampus (33), which is an area in the brain well known for its role in memory. In addition, preclinical studies showed that both $5-\mathrm{HT}_{1 \mathrm{a}}$ agonists and antagonist enhanced cognition in rats $(108,109)$. 5- $\mathrm{HT}_{3 a}$ receptor antagonism was associated with improvement in visual learning and memory $(40,41)$. Contrary to other subtypes of serotonin receptors, the $5-\mathrm{HT}_{3 a}$ receptor is the only ligandgated ion channel subtype (40). To date, not many studies investigated the potential role of $5-\mathrm{HT}_{3}$ receptors in cognition. However, since both Akhondzadeh et al. (43) and Levkovitz et al. (44) found improvement in visual learning and memory with the $5-\mathrm{HT}_{3 a}$ receptor antagonist ondansetron, these receptors might be a promising molecular target for enhancement of visual learning and memory in schizophrenia.

\section{Acetylcholine nicotinic $\alpha 7$ receptors}

The role of acetylcholine in cognition, (particularly in learning, memory and attention) has been widely established and central dysfunction of the cholinergic system has been found to be associated with cognitive symptoms in neurological diseases as Alzheimer and Parkinson's disease (110-112). However, with the exception of positive results found with nicotine and a partial nicotinic $\alpha_{7}$ agonist on attention $(49,86)$, cholinergic interventions strategies did not affect any of the cognitive domains in the available studies. However, all the available studies that met the inclusion criteria used acetylcholinesterase inhibitors or nicotinic agonists. Although (mostly post-mortem) both nicotinic and muscarinic receptor abnormalities have been repeatedly found in schizophrenia (113-118), nicotinic receptor antagonists do not appear to impair cognition in the same manner as antimuscarinic drugs (119). This might explain the lack of improvement in the described studies. Indeed, a small pilot study by Shekar et al. (120) found that the muscarinic receptor agonist xanomeline improves verbal, visual and working memory in patients with schizophrenia or schizoaffective disorder. Moreover, 
xanomeline improved cognition in Alzheimer disease (121). Thus, although positive effects on attention were found with nicotine and a partial nicotinic $\alpha_{7}$ agonist, future studies should focus on muscarinic agents.

\section{$G A B A_{A}$ receptors}

Both $G_{A B A}$ receptor antagonists and agonists were found to affect working memory and verbal learning and memory $(35,81)$. Multiple studies have shown reduced GABAergic transmission, especially in the PFC, in schizophrenia (122). The PFC is strongly involved in working memory functioning (123) and animal studies have shown that appropriate GABA transmission in the dorsolateral prefrontal cortex (DPFC) is essential to adequate working memory functioning $(33,124)$. Lewis et al. (37) showed that altered GABA transmission in the DPFC is possibly limited to certain cell classes, such as the chandelier cells, which synchronize the activation of the pyramidal neurons via the $G_{A B A}$ receptor subtypes. Therefore, $G_{A B A}$ receptors may be a promising molecular target for enhancement of working memory.

\section{Glutamate NMDA receptors}

Glutamate, the primary excitatory neurotransmitter in the mammalian brain , has been linked to learning and memory because of its principal role in modulating long-term potentiation (125), and hyperactivity of glutamatergic neurotransmission has been implicated in schizophrenia (33). It has been hypothesized that cognitive dysfunction in schizophrenia is due to hypofunction of the NMDA receptor (82). Small increases in NMDA-dependent glutamate transmission might enhance cognition, whereas excessive stimulation might have neurodegenerative consequences (33). Activation of the NMDA receptors leads to synthesis of nitric oxide, which is able to further increase the excitotoxicity by increasing glutamate release from presynaptic neurons and inhibition of glial glutamate transporters (70). Indeed, minocylcline (which blocks nitric oxide induced neurotoxicity) was found to improve visual learning and memory, working memory and reasoning and problem solving abilities (70). Although d-cycloserine (which noncompetitively enhances NMDA neurotransmission) was not found to improve attention and working memory (82), pharmacological agents reducing the neurotoxic effects of extensive glutamate might still be a promising intervention strategy for cognitive enhancement. 
Can the negative results be explained by studies limitations?

A substantial number of the studies evaluated in this review addressing pharmacological cognitive enhancement in schizophrenia report negative results. It is debatable whether this is due to ineffectiveness of the agents used, or that potential results were obscured by methodological shortcomings as cognition research in schizophrenia deals with pertinent limitations. First, in many of the studies included in this review, cognition was not the primary outcome parameter. As a result, the design of these studies was not always optimal to measure cognitive enhancement. Second, the sample sizes are often too small to detect clinically relevant effects. Third, concurrent medications may interfere with the investigated pharmacological agents. Patients with schizophrenia are generally treated with antipsychotics. Because the entire mechanism of action of these medications is not completely understood, it cannot be ruled out that antipsychotics alter the effects of the added agents (59). Moreover, patients often use concomitant medications such as benzodiazepines, antidepressants and anticholinergics, which could influence the effects of the adjunctive pharmacological agents' as well. Especially anticholinergic medication is well known for its adverse effects on cognition (26). Therefore, studies including only medication naive patients at early stages of the disease are necessary. Fourth, studies often do not use fixed doses. It is possible that certain agents are only effective in a certain dose. If studies do use a fixed dose, this dose is often established for treating the illness or symptoms it was originally used for. However, it is not necessarily so that the same dose is required for cognitive enhancement in schizophrenia. Fifth, research seems to focus on the direct or semi-direct enhancing effect of modulating certain receptors while cognitive decline has most often been a process of a longer period of time possibly implying that enhancement studies should equally allow for more time to yield effects. Also, different paradigms could focus on neuroprotective targets and preventing cognitive decline early in the disorder in contrast to enhancing cognition after impairment. Sixth, not all studies report information about substance use of the participants. Patients with schizophrenia often abuse substances as tobacco, alcohol and cannabis, and epidemiological studies found high co-morbidity rates of substance abuse (40-60\%) $(126,127)$. Particularly tobacco use can interfere with nicotinic receptor agents as it causes desensitization of this receptor subtype. Although most of the studies excluded patients with a (recent) co-morbid diagnosis of alcohol or drug abuse / dependence, tobacco using patients are almost never excluded. Seventh, studies often use different neuropsychological tasks to measure the same aspects of cognition which makes it difficult to compare the results. Therefore, studies should 
use a standardized cognitive battery, such as the MATRICS Consensus Cognitive Battery (MCCB (81)) or the CANTAB cognitive battery (128). The MCCB in particular, has been composed to reliably assess cognition in schizophrenia patients. At present, only three of the reported studies used this battery to measure cognition $(47,49,51)$. Finally, not all studies used a control group and repeatedly conducted the same test battery without adequately correcting for potential practice effects. Therefore, improvement often cannot be reliably attributed to the effect of the pharmacological agent. Future research should take these limitations in to account in experimental setup and optimize their design for cognition measurement. Ideally, future studies should include a placebo or other control group and should ensure sufficient power by including enough participants. Furthermore, medication-naïve patients should be recruited, preferably non-smokers who do not use other substances as cannabis and alcohol. Regarding the design, future studies should choose cognition as a primary outcome measure and optimize the design by using a fixed dose and make sure to choose a dose suitable for schizophrenia patients. Finally, future studies should make sure to choose sufficient trial duration and to use a standardized cognitive test battery which covers all MATRICS domains. In this manner, studies will be better comparable and the effects of possible confounding variables will be limited. To summarize, the negative results of 'pharmacological cognitive enhancement studies' could partially be explained by studies' limitations.

\section{Conclusion}

Although some potential targets were identified, overall, results of previous studies attempting to identify potential pharmacological targets for cognitive enhancement have been disappointing. This review has shown that dysfunction in separate cognitive domains may arise from different underlying neuropharmacological mechanisms which suggests that schizophrenia patients with different cognitive impairments could benefit from different intervention strategies. Although development of effective cognitive enhancers is a complex process, it is an exciting challenge for this area of research as improvement of cognition contributes significantly to the quality of life of these patients. 
Table 1. Pharmacological agents used and their main mechanism of action.

\begin{tabular}{|c|c|c|}
\hline $\begin{array}{l}\text { General pharmacological } \\
\text { domain }\end{array}$ & Pharmacological agent & Agents main mechanism of action \\
\hline \multirow[t]{16}{*}{ Antipsychotics } & Haloperidol & $\mathrm{D}_{2}$ antagonist \\
\hline & Chlorprothixene & $\mathrm{D}_{2}$ antagonist \\
\hline & Perazine & $\mathrm{D}_{2}$ antagonist \\
\hline & Flupenthixole & $\mathrm{D}_{2}$ antagonist \\
\hline & Amisulpride & $\mathrm{D}_{2} / \mathrm{D}_{3}$ antagonist \\
\hline & Risperidone & $\mathrm{D}_{2}$ and $5-\mathrm{HT}_{2 \mathrm{a}}$ antagonist \\
\hline & Paliperidone & $\begin{array}{l}\mathrm{D}_{2} \text { and } 5-\mathrm{HT}_{2 \mathrm{a}} \text { antagonist } \\
\text { (active metabolite of risperidone) }\end{array}$ \\
\hline & Olanzapine & $\mathrm{D}_{2}$ and $5-\mathrm{HT}_{2 \mathrm{a}}$ antagonist \\
\hline & Loxapine & $\mathrm{D}_{2}$ and $5-\mathrm{HT}_{2 \mathrm{a}}$ antagonist \\
\hline & Sertindole & $\mathrm{D}_{2}$ and $5-\mathrm{HT}_{2 \mathrm{a}}$ antagonist \\
\hline & Ziprasidone & $\mathrm{D}_{2}$ and $5-\mathrm{HT}_{2 \mathrm{a}}$ antagonist \\
\hline & Quetiapine & $\begin{array}{l}\mathrm{D}_{2} \text { and 5- } \mathrm{HT}_{2 \mathrm{a}} \text { antagonist partial 5- } \\
\mathrm{HT}_{1 \mathrm{a}} \text { agonist }\end{array}$ \\
\hline & Aripiprazole & $\begin{array}{l}5-\mathrm{HT}_{2 a} \text { antagonist and partial } \mathrm{D}_{2} \\
\text { agonist and antagonist and 5- } \mathrm{HT}_{1 \mathrm{a}} \\
\text { agonist }\end{array}$ \\
\hline & Perospirone & $\begin{array}{l}\mathrm{D}_{2} \text { and } 5-\mathrm{HT}_{2 \mathrm{a}} \text { antagonist and 5- } \\
\mathrm{HT}_{1 \mathrm{a}} \text { agonist }\end{array}$ \\
\hline & Clozapine & $\begin{array}{l}D_{2}, D_{4} \text { and } 5-H T_{2 a} \text { antagonist partial } \\
5-H T_{1 a} \text { agonist (metabolite shows } \\
\text { weak partial agonistic effects on } D_{2} \\
\text { and } D_{3} \text { ) }\end{array}$ \\
\hline & BL-1020 & $\begin{array}{l}\mathrm{D}_{2} \text { and } 5-\mathrm{HT}_{2 \mathrm{a}} \text { antagonist } \mathrm{GABA}_{\mathrm{A}} \\
\text { agonist }\end{array}$ \\
\hline Dopaminergic & Dihydrexidine & $\mathrm{D}_{1}$ agonist \\
\hline \multirow[t]{5}{*}{ Serotonergic } & Ondansetron & $5-\mathrm{HT}_{3 a}$ antagonist \\
\hline & Tandospirone & $5-\mathrm{HT}_{1 \mathrm{a}}$ agonist \\
\hline & Tropisetron & 5- $\mathrm{HT}_{3 \mathrm{a}}$ antagonist \\
\hline & Fluvoxamine & $\begin{array}{l}\text { Reuptake inhibition and sigma-1 } \\
\text { receptor agonist }\end{array}$ \\
\hline & Citalopram & Reuptake inhibition \\
\hline
\end{tabular}




\begin{tabular}{|c|c|c|}
\hline $\begin{array}{l}\text { General pharmacological } \\
\text { domain }\end{array}$ & Pharmacological agent & Agents main mechanism of action \\
\hline \multirow[t]{5}{*}{ Cholinergic } & AZD3480 & nicotinic $\alpha_{4} \beta_{2}$ agonist \\
\hline & DMXB-A & Partial nicotinic $\alpha_{7}$ agonist \\
\hline & Donepezil & Acetylcholinesterase inhibition \\
\hline & Galantamine & Acetylcholinesterase inhibition \\
\hline & Rivastigmine & Acetylcholinesterase inhibition \\
\hline \multirow[t]{5}{*}{ Glutamatergic } & Minocycline & (mainly used as antibiotic) Blocks \\
\hline & & nitricoxide induced neurotoxicity \\
\hline & D-cycloserine & NMDA partial agonist \\
\hline & Lamotrigine & Glutamate release regulation \\
\hline & Topiramate & AMPA/kainite antagonist \\
\hline \multirow[t]{3}{*}{ GABAergic } & MK-0777 & GABA $\alpha_{2} / \alpha_{3}$ agonist \\
\hline & Lorazepam & $\mathrm{GABA}_{\mathrm{A}}$ agonist \\
\hline & Fluzaminil & $\mathrm{GABA}_{\mathrm{A}}$ antagonist \\
\hline Noradrenergic & Atomoxetine & Reuptake inhibition \\
\hline \multirow[t]{3}{*}{ Stimulants } & d-amphetamine & $\begin{array}{l}\text { Dopamine/norepinephrine releaser } \\
\text { thus indirect dopamine agonist }\end{array}$ \\
\hline & Modafinil & Unknown \\
\hline & Armodifinil & Unknown \\
\hline \multirow[t]{2}{*}{ Other domains } & Mifepristone & $\begin{array}{l}\text { Glucocorticoid receptor } \\
\text { antagonist }\end{array}$ \\
\hline & Sildenafil & PDE 5 inhibition \\
\hline
\end{tabular}




.

은

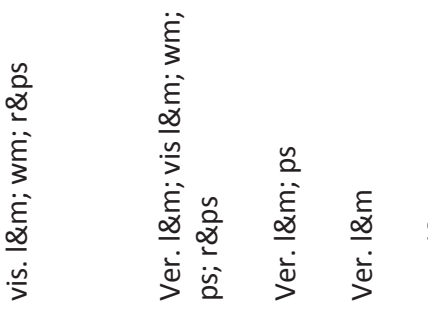

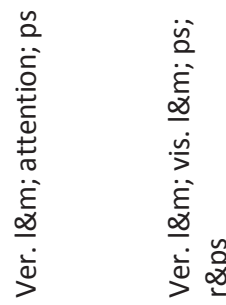

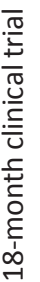

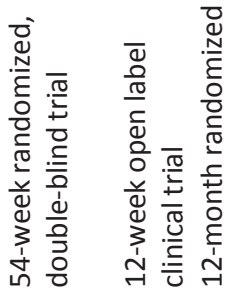

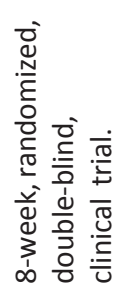

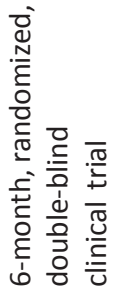

$\underset{2}{I 1}$

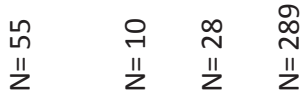

ก

II

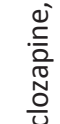

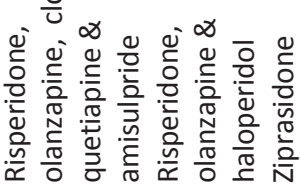

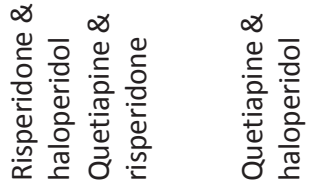

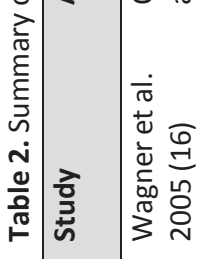

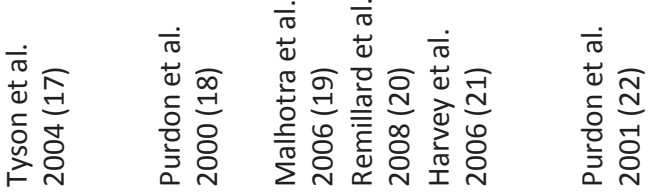




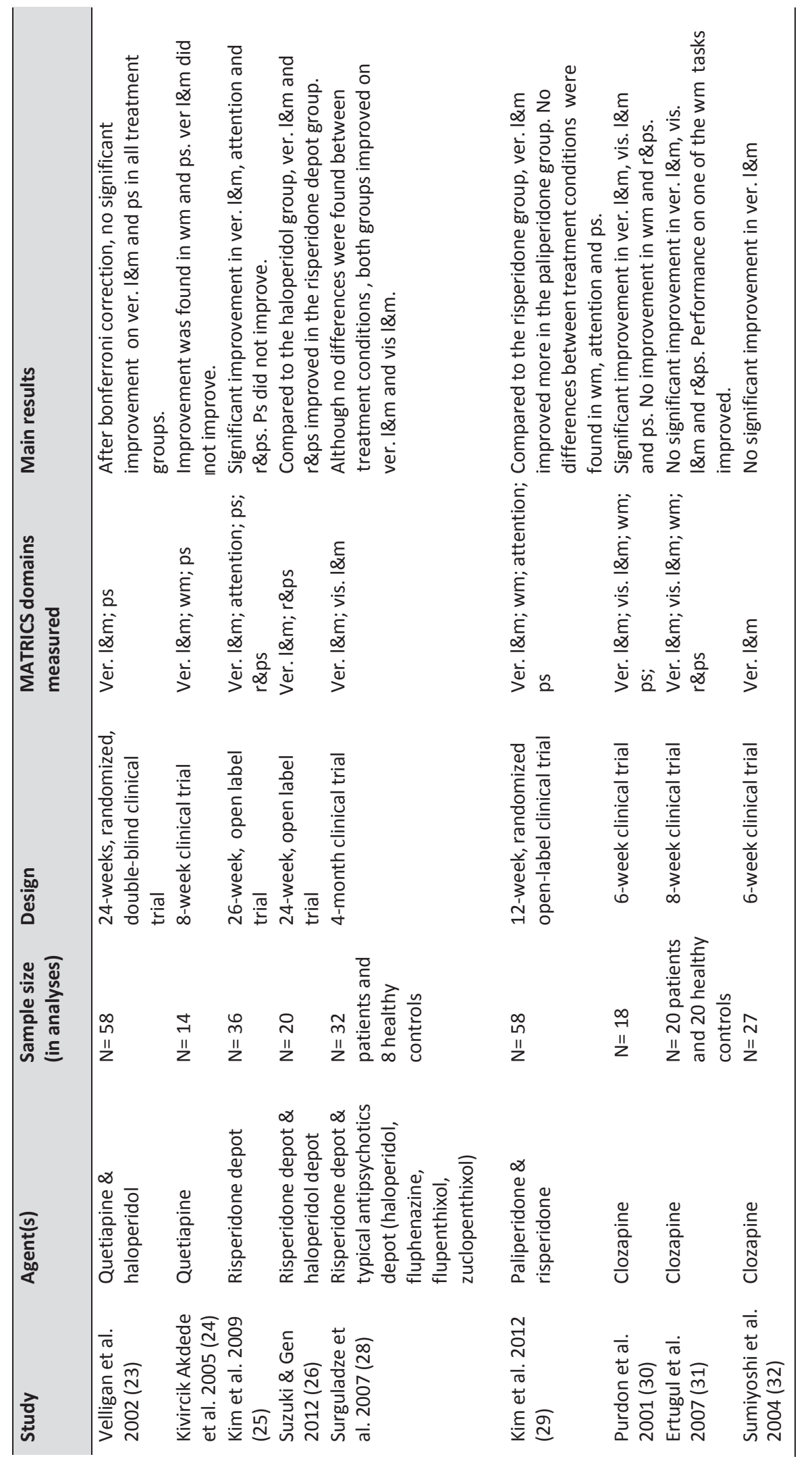




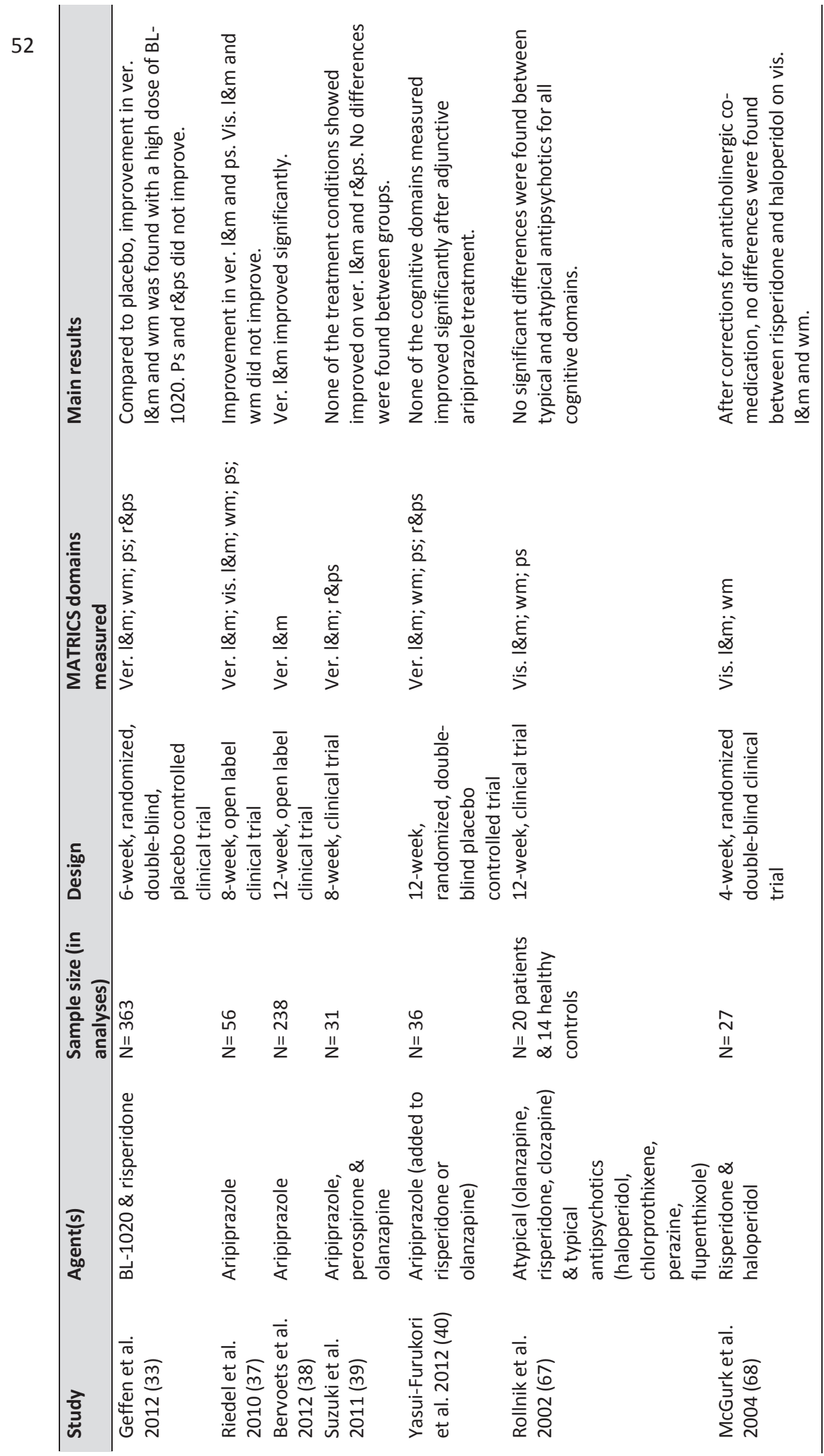




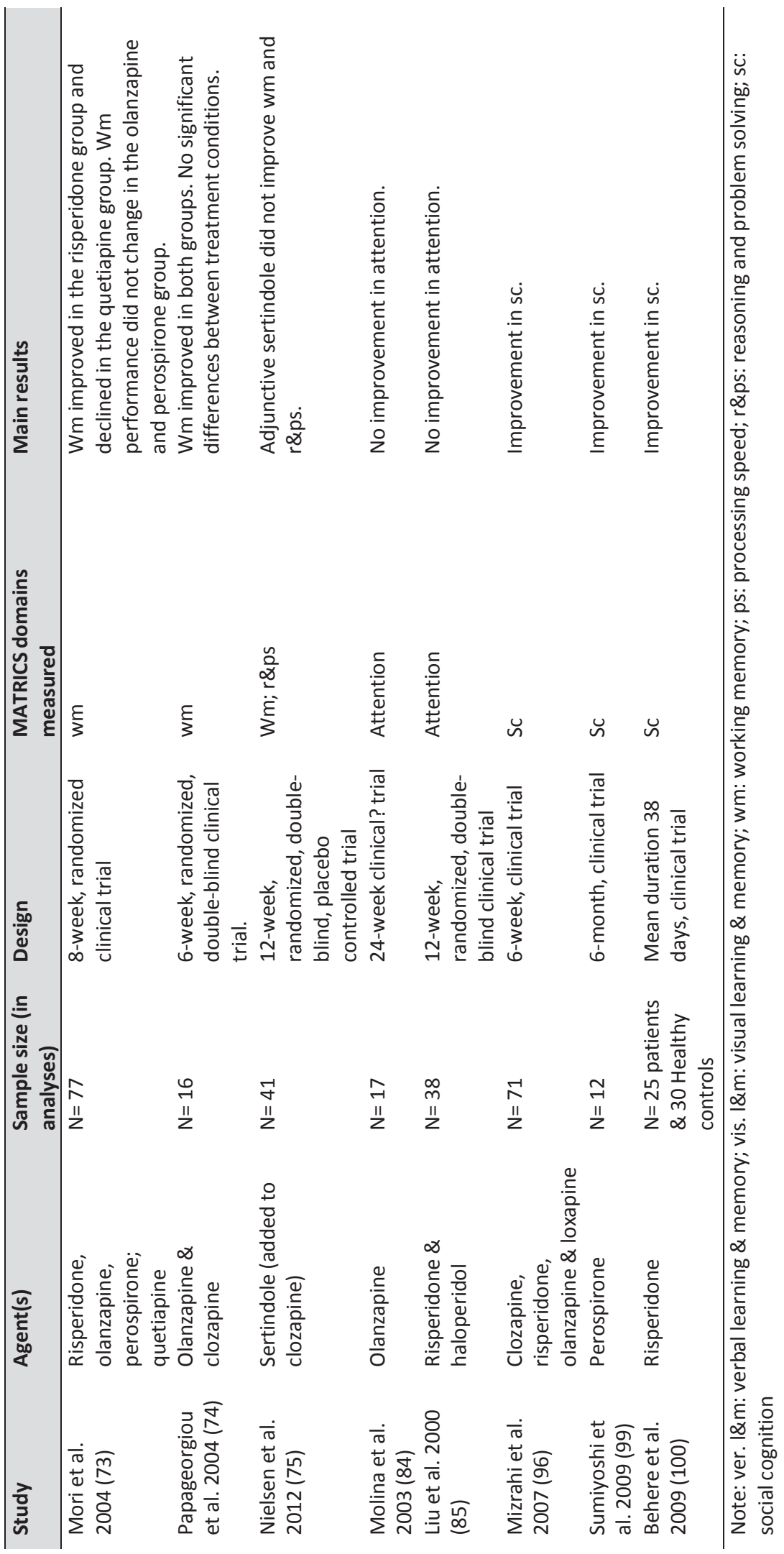




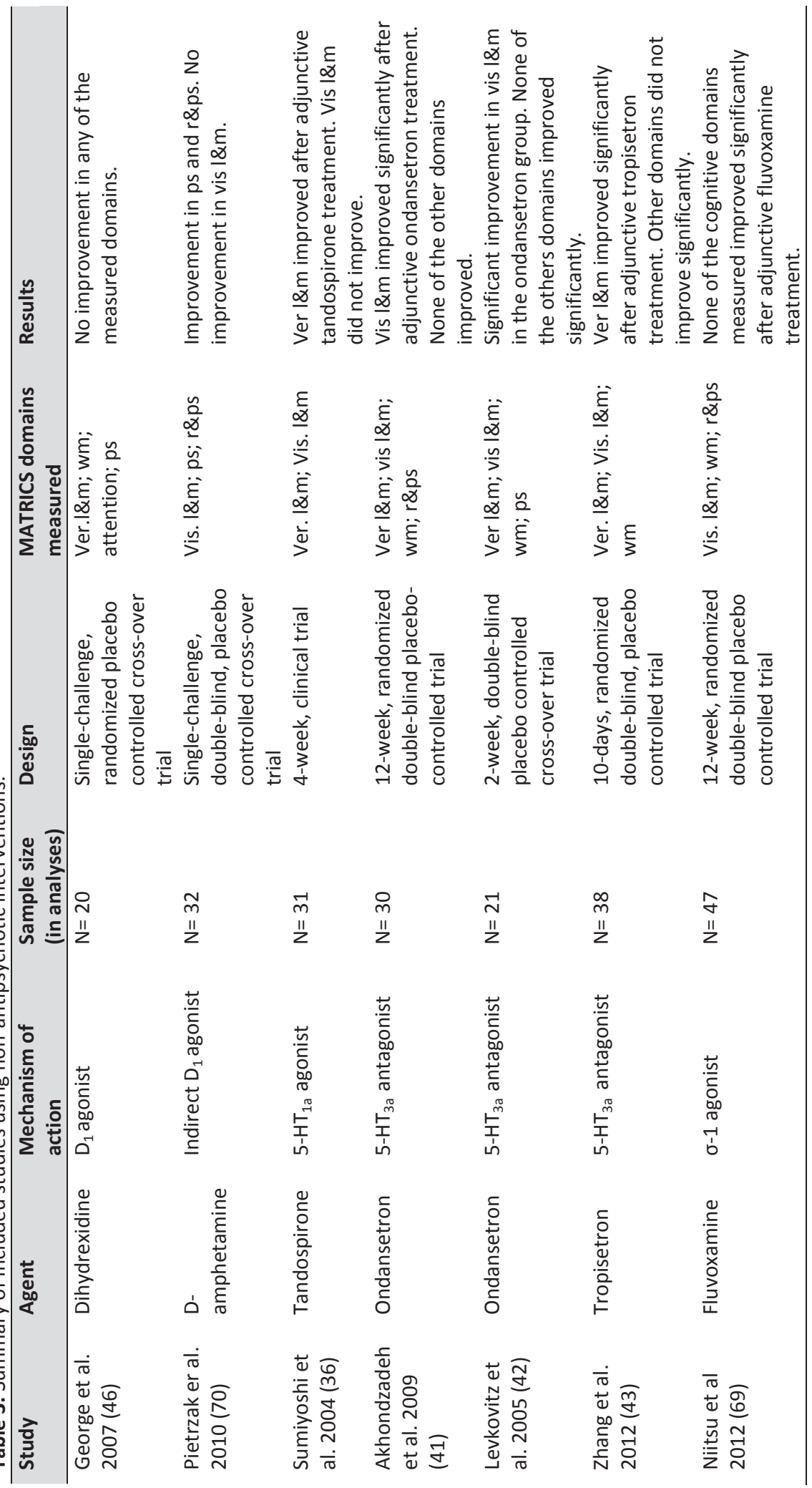




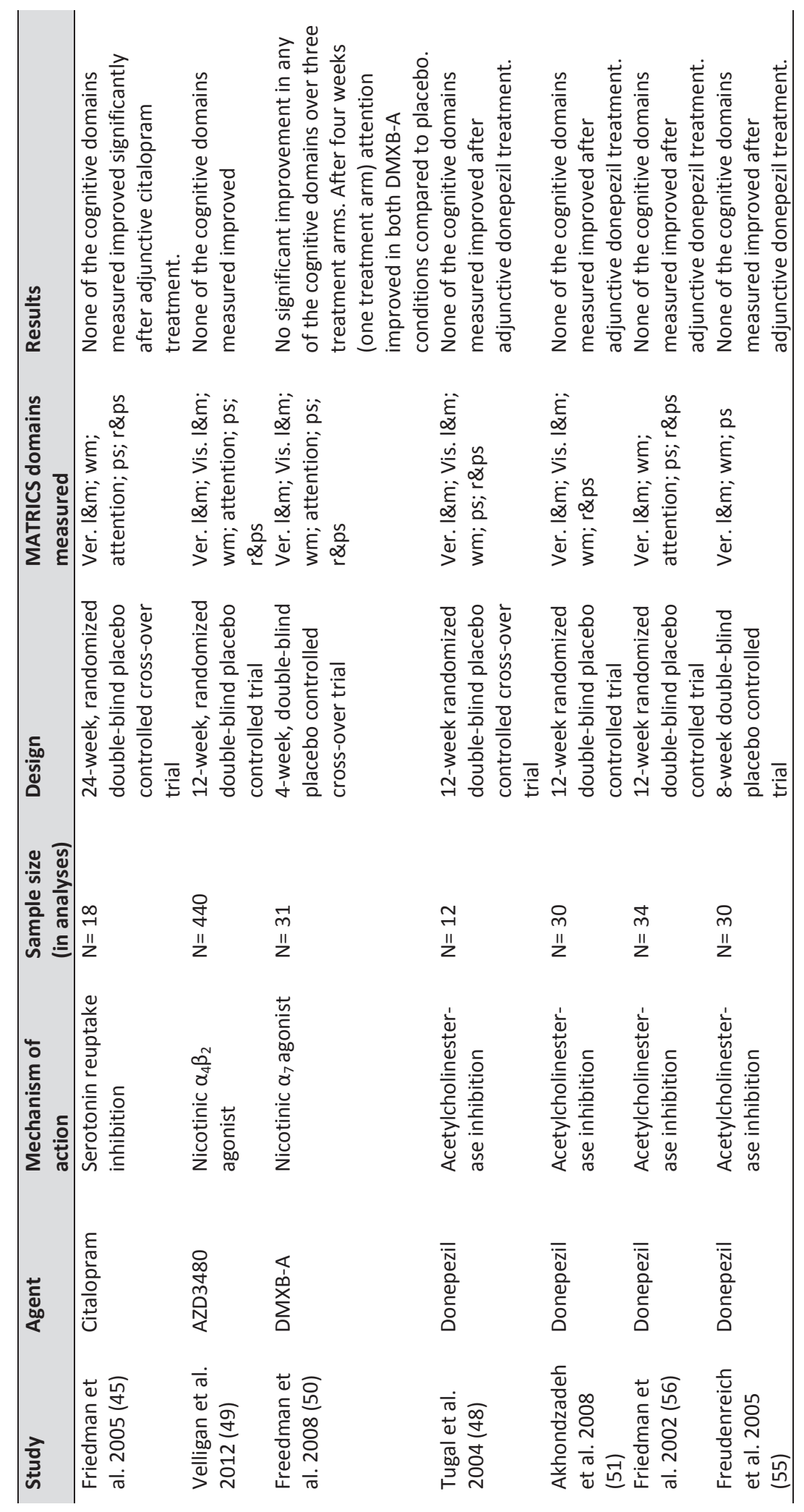




\begin{tabular}{|c|c|c|c|c|c|c|c|c|}
\hline 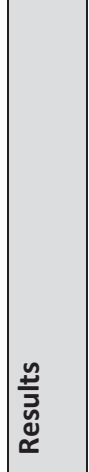 & 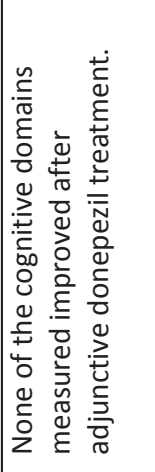 & 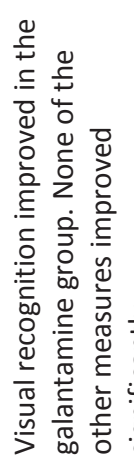 & 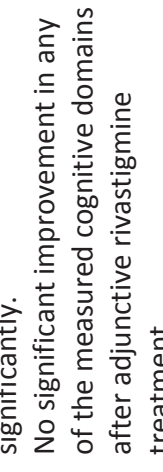 & 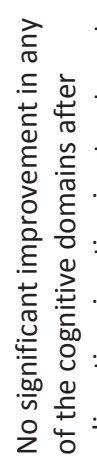 & 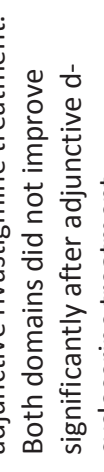 & 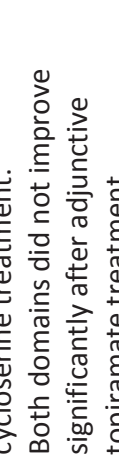 & 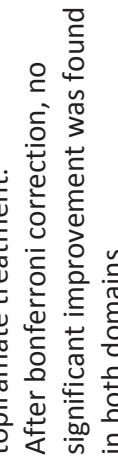 & 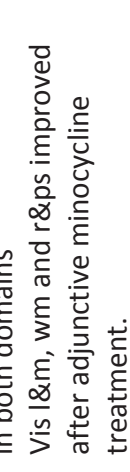 \\
\hline 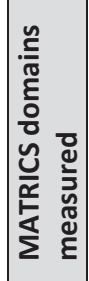 & 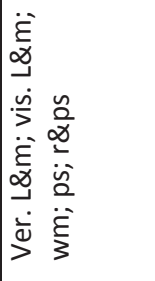 & 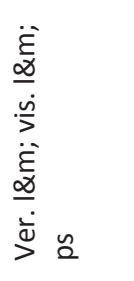 & 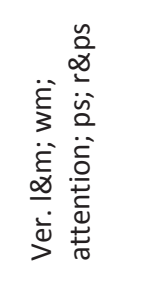 & 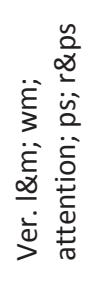 & 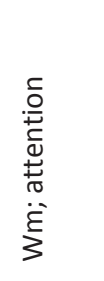 & 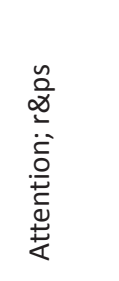 & 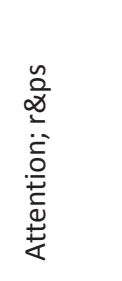 & 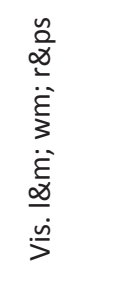 \\
\hline 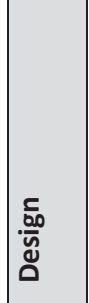 & 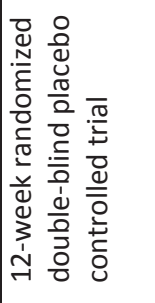 & 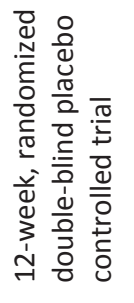 & 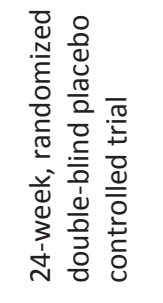 & 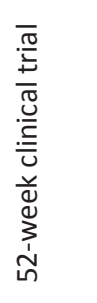 & 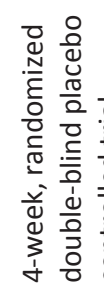 & 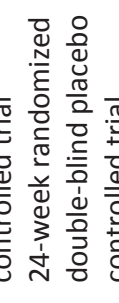 & 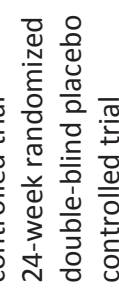 & 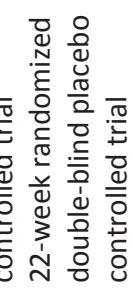 \\
\hline 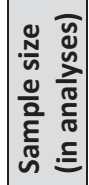 & 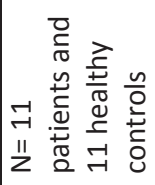 & $\begin{array}{l}\stackrel{J}{I I} \\
z\end{array}$ & $\begin{array}{l}\vec{N} \\
\ddot{z}\end{array}$ & $\begin{array}{l}\text { Oे } \\
\text { 21 }\end{array}$ & $\begin{array}{l}\underset{N}{11} \\
2\end{array}$ & $\begin{array}{l}\text { I } \\
\frac{11}{2}\end{array}$ & 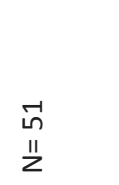 & $\begin{array}{l}\vec{N} \\
\ddot{z}\end{array}$ \\
\hline 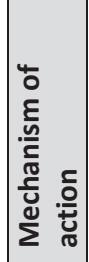 & 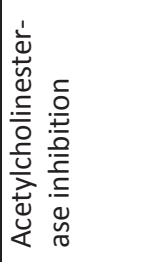 & 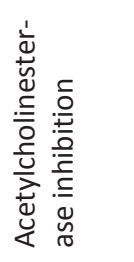 & 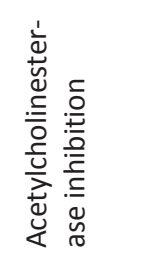 & 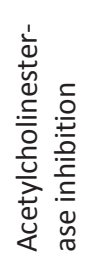 & 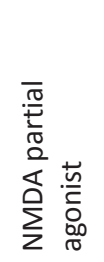 & 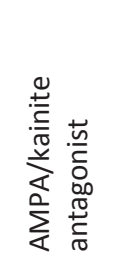 & 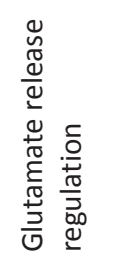 & 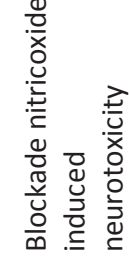 \\
\hline 离 & 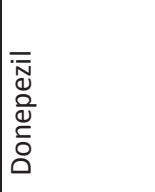 & 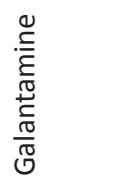 & 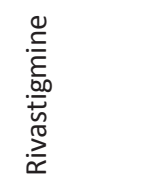 & 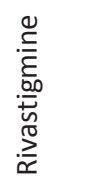 & 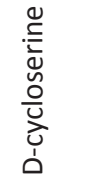 & 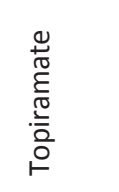 & 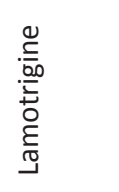 & 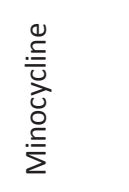 \\
\hline 离 & 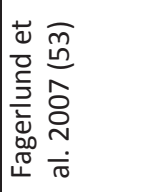 & 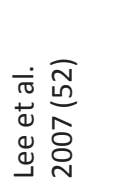 & 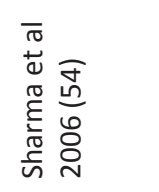 & 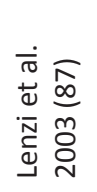 & 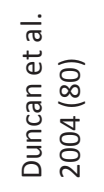 & 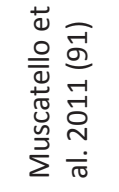 & 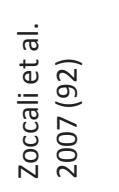 & 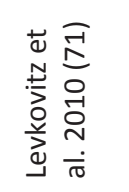 \\
\hline
\end{tabular}




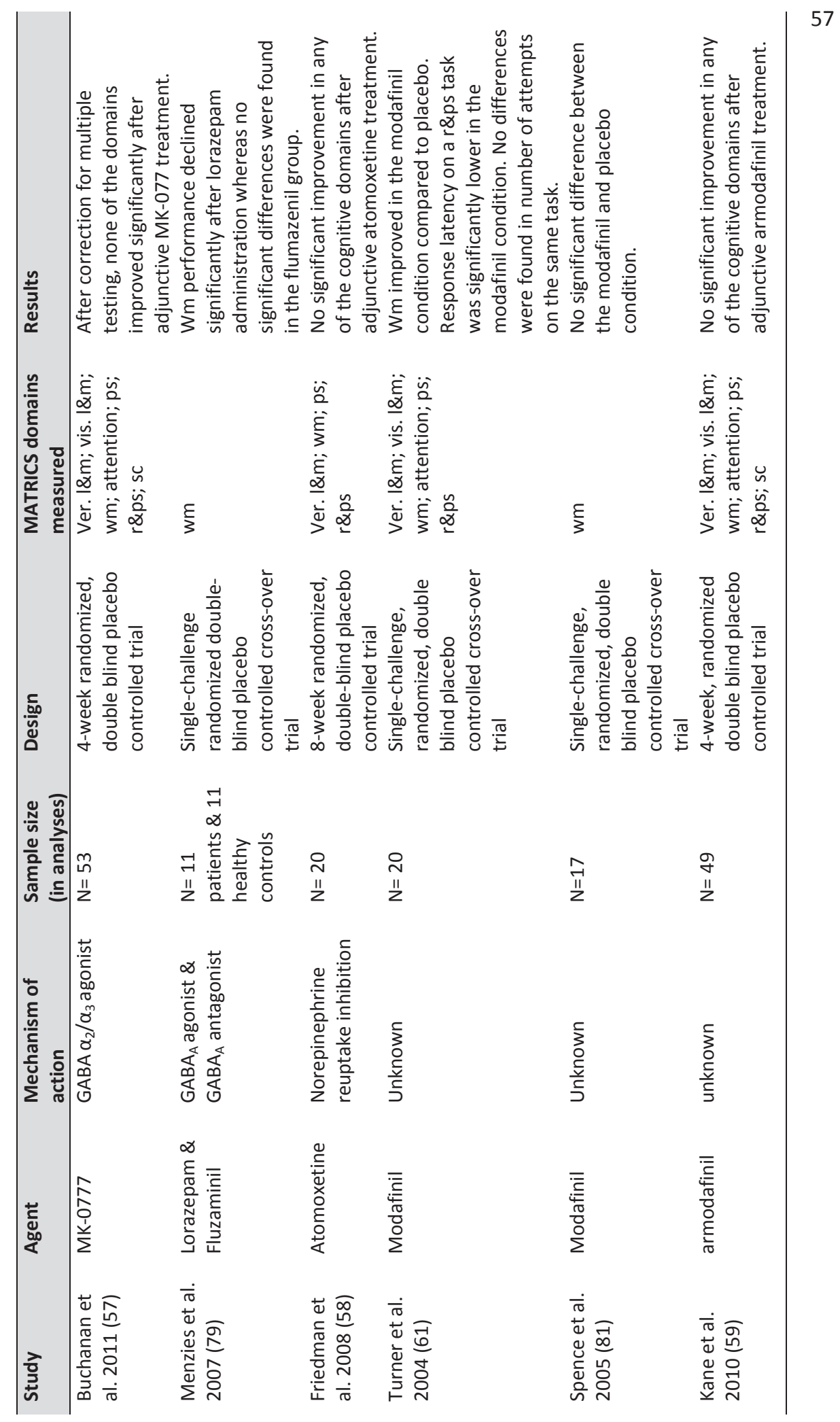




\section{References}

1. Reichenberg A, Weiser M, Caspi A, Knobler HY, Lubin G, Harvey PD, et al. Premorbid intellectual functioning and risk of schizophrenia and spectrum disorders. J Clin Exp Neuropsychol. 2006;28(2):193-207.

2. Green MF. What are the functional consequences of neurocognitive deficits in schizophrenia? Am J Psychiatry. 1996;153:321-30.

3. Green MF, Kern RS, Heaton RK. Longitudinal studies of cognition and functional outcome in schizophrenia: implications for MATRICS. Schizophr Res. 2004;72(1):41-51.

4. Heinrichs RW. The primacy of cognition in schizophrenia. Am Psychol. 2005;60(3):229-42.

5. Burton SC. Strategies for improving adherence to second-generation antipsychotics in patients with schizophrenia by increasing ease of use. J Psychiatr Pract. 2005;11(6):369-78.

6. Prouteau A, Verdoux H, Briand C, Lesage A, Lalonde P, Nicole L, et al. Cognitive predictors of psychosocial functioning outcome in schizophrenia: a follow-up study of subjects participating in a rehabilitation program. Schizophr Res. 2005;77(2-3):343-53.

7. Chen EY-H, Hui CL-M, Dunn EL-W, Miao MY-K, Yeung W-S, Wong C-K, et al. A prospective 3-year longitudinal study of cognitive predictors of relapse in first-episode schizophrenic patients. Schizophr Res. 2005;77(1):99-104.

8. Stip E, Chouinard S, Boulay $L$. On the trail of a cognitive enhancer for the treatment of schizophrenia. Prog Neuropsychopharmacol Biol Psychiatry. 2005;29(2):219-32.

9. Volk DW, Lewis D a. Impaired prefrontal inhibition in schizophrenia: relevance for cognitive dysfunction. Physiol Behav. 2002;77:501-5.

10. Cohen NJ, Ryan J, Hunt C, Romine L, Wszalek T, Nash C. Hippocampal system and declarative (relational) memory: summarizing the data from functional neuroimaging studies. Hippocampus. 1999;9(1):83-98.

11. Nuechterlein KH, Barch DM, Gold JM, Goldberg TE, Green MF, Heaton RK. Identification of separable cognitive factors in schizophrenia. Schizophr Res. 2004;72(1):29-39.

12. Feifel D, Macdonald K, Cobb P, Minassian A. Adjunctive intranasal oxytocin improves verbal memory in people with schizophrenia. Schizophr Res. 2012;139(1-3):207-10.

13. Wagner M, Quednow BB, Westheide J, Schlaepfer TE, Maier W, Kühn K-U. Cognitive improvement in schizophrenic patients does not require a serotonergic mechanism: randomized controlled trial of olanzapine vs amisulpride. Neuropsychopharmacology. 2005;30(2):381-90.

14. Tyson PJ, Roberts $\mathrm{KH}$, Mortimer AM. Are the cognitive effects of atypical antipsychotics influenced by their affinity to 5HT-2A receptors? Int J Neurosci. 2004;114(6):593-611.

15. Keefe RSE, Bilder RM, Davis SM, Harvey PD, Palmer BW, Gold JM, et al. Neurocognitive effects of antipsychotic medications in patients with chronic schizophrenia in the CATIE Trial. Arch Gen Psychiatry. 2007;64(6):633-47.

16. Davidson M, Galderisi S, Weiser M, Werbeloff N, Ph D, Fleischhacker WW, et al. Cognitive Effects of Antipsychotic Drugs in First-Episode Schizophrenia and Schizophreniform Disorder: A Randomized, Open-Label Clinical Trial (EUFEST). Am J Psychiatry. 2009;166:675-82.

17. Purdon S, Jones B, Stip E. Neuropsychological change in early phase schizophrenia during 12 months of treatment with olanzapine, risperidone, or haloperidol. Arch Gen Psychiatry. 2000;57:249-258.

18. Malhotra AK, Burdick KE, Razi K, Bates J a, Sanders M, Kane JM. Ziprasidone-induced cognitive enhancement in schizophrenia: specificity or pseudospecificity? Schizophr Res. 2006;87(1-3):1814. 
19. Rémillard S, Pourcher E, Cohen H. Long-term effects of risperidone versus haloperidol on verbal memory, attention, and symptomatology in schizophrenia. J Int Neuropsychol Soc. 2008;14(1):110-8.

20. Harvey PD, Ph D, Patterson TL, Potter LS, Zhong K, Brecher M. Improvement in Social Competence With Short-Term Atypical Antipsychotic Treatment: a Randomized Double-Blind Comparison of Quetiapine Versus Risperidone for Social Competence, Social Cognition and Neuropsychological Functioning. Am J Psychiatry 2006;163:1918-25.

21. Purdon SE, Malla a, Labelle a, Lit W. Neuropsychological change in patients with schizophrenia after treatment with quetiapine or haloperidol. J Psychiatry Neurosci. 2001;26(2):137-49.

22. Velligan DI, Newcomer J, Pultz J, Csernansky J, Hoff AL, Mahurin R, et al. Does cognitive function improve with quetiapine in comparison to haloperidol? Schizophr Res. 2002;53(3):239-48.

23. Kivircik Akdede BB, Alptekin K, Kitiş A, Arkar H, Akvardar Y. Effects of quetiapine on cognitive functions in schizophrenia. Prog Neuropsychopharmacol Biol Psychiatry. 2005;29(2):233-8.

24. Kim S, Shin I, Kim J, Lee S, Lee Y, Yang S, et al. Effects of switching to long-acting injectable risperidone from oral atypical antipsychotics on cognitive function in patients with schizophrenia.Human Psychopharmacology 2009;24:565-73.

25. Suzuki H, Gen K. The influence of switching from haloperidol decanoate depot to risperidone longacting injection on the clinical symptoms and cognitive function in schizophrenia. Human Psychopharmacology. 2012;27:470-5.

26. Campbell N, Boustani M, Limbil T, Ott C, Fox C, Maidment I, et al. The cognitive impact of anticholinergics: a clinical review. Clin Interv Aging. 2009;4:225-33.

27. Surguladze S a, Chu EM, Evans A, Anilkumar APP, Patel MX, Timehin C, et al. The effect of longacting risperidone on working memory in schizophrenia: a functional magnetic resonance imaging study. J Clin Psychopharmacol. 2007;27(6):560-70.

28. Kim S-W, Chung Y-C, Lee Y-H, Lee J-H, Kim S-Y, Bae K-Y, et al. Paliperidone ER versus risperidone for neurocognitive function in patients with schizophrenia: a randomized, open-label, controlled trial. Int Clin Psychopharmacol. 2012;27(5):267-74.

29. Purdon SE, Labelle a, Boulay L. Neuropsychological change in schizophrenia after 6 weeks of clozapine. Schizophr Res. 2001;48(1):57-67.

30. Ertugrul A, Ucar G, Basar K, Demir B, Yabanoglu S, Ulug B. Influence of clozapine on platelet serotonin, monoamine oxidase and plasma serotonin levels. Psychiatry Res. 2007;149(1-3):49-57.

31. Sumiyoshi T, Roy a, Kim C-H, Jayathilake K, Lee M a, Sumiyoshi C, et al. Prediction of changes in memory performance by plasma homovanillic acid levels in clozapine-treated patients with schizophrenia. Psychopharmacology. 2004;177(1-2):79-83.

32. Geffen Y, Keefe R, Rabinowitz J, Anand R, Davidson M. BI-1020, a new Y-aminobutyric acidenhanced antipsychotic: results of 6-week, randomized, double-blind, controlled, efficacy and safety study. J Clin Psychiatry. 2012;73(9):e1168-74.

33. Gray J a, Roth BL. Molecular targets for treating cognitive dysfunction in schizophrenia. Schizophr Bull. 2007;33(5):1100-19.

34. Lewis D a, Pierri JN, Volk DW, Melchitzky DS, Woo TU. Altered GABA neurotransmission and prefrontal cortical dysfunction in schizophrenia. Biol Psychiatry. 1999;46(5):616-26.

35. Sumiyoshi T, Matsui M, Yamashita I, Nohara S, Kurachi M, Uehara T, et al. The effect of tandospirone, a serotonin1A agonist, on memory function in schizophrenia. Biol Psychiatry. 2001;49:861-868. 
36. Riedel M, Spellmann I, Schennach-Wolff R, Musil R, Dehning S, Cerovecki a, et al. Effect of aripiprazole on cognition in the treatment of patients with schizophrenia. Pharmacopsychiatry. 2010;43(2):50-7.

37. Bervoets C, Morrens M, Vansteelandt K, Kok F, de Patoul A, Halkin V, et al. Effect of aripiprazole on verbal memory and fluency in schizophrenic patients : results from the ESCAPE study. CNS Drugs. 2012;26(11):975-82.

38. Suzuki H, Gen K, Inoue Y. An unblinded comparison of the clinical and cognitive effects of switching from first-generation antipsychotics to aripiprazole, perospirone or olanzapine in patients with chronic schizophrenia. Prog Neuropsychopharmacol Biol Psychiatry. 2011;35(1):161-8.

39. Yasui-Furukori N, Kaneda A, Sugawara N, Tomita T, Kaneko S. Effect of adjunctive treatment with aripiprazole to atypical antipsychotics on cognitive function in schizophrenia patients. J Psychopharmacol. 2012;26(6):806-12.

40. Akhondzadeh S, Mohammadi N, Noroozian M, Karamghadiri N, Ghoreishi A, Jamshidi A-H, et al. Added ondansetron for stable schizophrenia: a double blind, placebo controlled trial. Schizophr Res. Elsevier B.V.; 2009;107(2-3):206-12.

41. Levkovitz Y, Arnest G, Mendlovic S, Treves I, Fennig S. The effect of Ondansetron on memory in schizophrenic patients. Brain Res Bull. 2005;65(4):291-5.

42. Zhang $X Y$, Liu L, Liu S, Hong $X$, Chen DC, Xiu MH, et al. Short-term tropisetron treatment and cognitive and P50 auditory gating deficits in schizophrenia. Am J Psychiatry. 2012;169(9):974-81.

43. Ishikawa M, Sakata M, Toyohara J, Oda K, Ishii K, Wu J, et al. Occupancy of $\alpha 7$ Nicotinic Acetylcholine Receptors in the Brain by Tropisetron: A Positron Emission Tomography Study Using [(11)C]CHIBA-1001 in Healthy Human Subjects. Clin Psychopharmacol Neurosci. 2011;9(3):111-6.

44. Friedman JI, Ocampo R, Elbaz Z, Parrella M, White L, Bowler S, et al. The Effect of Citalopram Adjunctive Treatment Added to Atypical Antipsychotic Medications for Cognitive Performance in Patients With Schizophrenia. J Clin Psychopharmacol. 2005;25(3):237-42.

45. George MS, Molnar CE, Grenesko EL, Anderson B, Mu Q, Johnson K, et al. A single 20 mg dose of dihydrexidine (DAR-0100), a full dopamine D1 agonist, is safe and tolerated in patients with schizophrenia. Schizophr Res. 2007;93(1-3):42-50.

46. Karson CN, Mrak RE, Husain MM, Griffin WST. Decreased mesopontine choline acetyltransferase levels in schizophrenia. Mol Chem Neuropathol. 1996;29:181-91.

47. Tuğal O, Yazici KM, Anil Yağcioğlu a E, Göğüş A. A double-blind, placebo controlled, cross-over trial of adjunctive donepezil for cognitive impairment in schizophrenia. Int J Neuropsychopharmacol. 2004;7(2):117-23.

48. Velligan D, Brenner R, Sicuro F, Walling D, Riesenberg R, Sfera A, et al. Assessment of the effects of AZD3480 on cognitive function in patients with schizophrenia. Schizophr Res. 2012;134(1):59-64.

49. Freedman R, Olincy A, Buchanan RW, Harris JG, Gold JM, Johnson L, et al. Initial phase 2 trial of a nicotinic agonist in schizophrenia. Am J Psychiatry. 2008;165(8):1040-7.

50. Akhondzadeh S, Gerami M, Noroozian M, Karamghadiri N, Ghoreishi A, Abbasi S-H, et al. A 12 week, double-blind, placebo-controlled trial of donepezil adjunctive treatment to risperidone in chronic and stable schizophrenia. Prog Neuropsychopharmacol Biol Psychiatry. 2008;32(8):1810-5.

51. Lee $S$, Lee J, Lee B, Hoon Y. galantamine adjunctive treatment to conventional antipsychotics for the cognitive impairments in chronic schizophrenia. Int Clin Psychopharmacol. 2007;22:63-8.

52. Fagerlund B, Søholm B, Fink-Jensen A, Lublin H, Glenth $\varnothing j$ BY. Effects of donepezil adjunctive treatment to ziprasidone on cognitive deficits in schizophrenia: a double-blind, placebo-controlled study. Clin Neuropharmacol. 2007;30(1):3-12. 
53. Sharma T, Reed C, Aasen I, Kumari V. Cognitive effects of adjunctive 24-weeks Rivastigmine treatment to antipsychotics in schizophrenia: a randomized, placebo-controlled, double-blind investigation. Schizophr Res. 2006;85(1-3):73-83.

54. Freudenreich O, Herz L, Deckersbach T, Evins a E, Henderson DC, Cather C, et al. Added donepezil for stable schizophrenia: a double-blind, placebo-controlled trial. Psychopharmacology. 2005;181(2):358-63.

55. Friedman JI, Adler DN, Howanitz E, Harvey PD, Brenner G, Temporini H, et al. A double blind placebo controlled trial of donepezil adjunctive treatment to risperidone for the cognitive impairment of schizophrenia. Biol Psychiatry. 2002;51(5):349-57.

56. Buchanan RW, Keefe RSE, Lieberman J a, Barch DM, Csernansky JG, Goff DC, et al. A randomized clinical trial of MK-0777 for the treatment of cognitive impairments in people with schizophrenia. Biol Psychiatry. 2011;69(5):442-9.

57. Friedman JI, Carpenter D, Lu J, Fan J, Tang CY, White L, et al. A pilot study of adjunctive atomoxetine treatment to second-generation antipsychotics for cognitive impairment in schizophrenia. J Clin Psychopharmacol. 2008;28(1):59-63.

58. Kane JM, D'Souza DC, Patkar A a, Youakim JM, Tiller JM, Yang R, et al. Armodafinil as adjunctive therapy in adults with cognitive deficits associated with schizophrenia: a 4-week, double-blind, placebo-controlled study. J Clin Psychiatry. 2010;71(11):1475-81.

59. Harvey PD. Pharmacological cognitive enhancement in schizophrenia. Neuropsychol Rev. 2009;19(3):324-35.

60. Turner DC, Clark L, Pomarol-Clotet E, McKenna P, Robbins TW, Sahakian BJ. Modafinil improves cognition and attentional set shifting in patients with chronic schizophrenia. Neuropsychopharmacology. 2004;29(7):1363-73.

61. Ballon JS, Feifel D. A systematic review of Modafinil: Potential Clinical Uses and Mechanisms of Action. J Clin Psychiatry. 2006;67:554-66.

62. Kaptsan A, Odessky A, Osher Y, Levine J. Lack of efficacy of 5 grams daily of creatine in schizophrenia: a randomized, double-blind, placebo-controlled trial. J Clin Psychiatry. 2007;68(6):881-4.

63. Gallagher P, Watson S, Smith MS, Ferrier IN, Young AH. Effects of adjunctive mifepristone (RU-486) administration on neurocognitive function and symptoms in schizophrenia. Biol Psychiatry. 2005;57(2):155-61.

64. Goff DC, Cather C, Freudenreich O, Henderson DC, Evins a E, Culhane M a, et al. A placebocontrolled study of sildenafil effects on cognition in schizophrenia. Psychopharmacology. 2009;202(1-3):411-7.

65. Stone WS, Seidman L, Wojcik JD, Green Al. Glucose effects on cognition in schizophrenia. Schizophr Res. 2003;62(1-2):93-103.

66. Rollnik JD, Borsutzky M, Huber TJ, Mogk H, Seifert J, Emrich HM, et al. Short-term cognitive improvement in schizophrenics treated with typical and atypical neuroleptics. Neuropsychobiology. 2002;45(2):74-80.

67. McGurk SR, Green MF, Wirshing WC, Wirshing DA, Marder SR, Mintz J, et al. Antipsychotic and anticholinergic effects on two types of spatial memory in schizophrenia. Schizophr Res. 2004;68(23):225-33.

68. Niitsu T, Fujisaki M, Shiina A, Yoshida T, Hasegawa T, Kanahara N, et al. A randomized, doubleblind, placebo-controlled trial of fluvoxamine in patients with schizophrenia: a preliminary study. J Clin Psychopharmacol. 2012;32(5):593-601. 
69. Pietrzak RH, Snyder PJ, Maruff P. Use of an acute challenge with d-amphetamine to model cognitive improvement in chronic schizophrenia. Human Psychopharmacology. 2010;25:353-8.

70. Levkovitz Y, Mendlovich S, Riwkes S, Braw Y, Levkovitch-Verbin H, Gal G, et al. A double-blind, randomized study of minocycline for the treatment of negative and cognitive symptoms in earlyphase schizophrenia. J Clin Psychiatry. 2010;71(2):138-49.

71. Hasselmo ME, Stern CE. Mechanisms underlying working memory for novel information. Trends Cogn Sci. 2006;10(11):487-93.

72. Mori K, Nagao M, Yamashita H, Morinobu S, Yamawaki S. Effect of switching to atypical antipsychotics on memory in patients with chronic schizophrenia. Prog Neuropsychopharmacol Biol Psychiatry. 2004;28(4):659-65.

73. Papageorgiou C, Oulis P, Vasios C, Kontopantelis E, Uzunoglu N, Rabavilas A, et al. P300 alterations in schizophrenic patients experiencing auditory hallucinations. Eur Neuropsychopharmacol. 2004;14(3):227-36.

74. Sharma T, Reed C, Aasen I, Kumari V. Cognitive effects of adjunctive 24-weeks Rivastigmine treatment to antipsychotics in schizophrenia: A randomized, placebo-controlled, double-blind investigation. Schizoph Res. 2006;85:73-83.

75. Jacobsen LK, D'Souza DC, Mencl WE, Pugh KR, Skudlarski P, Krystal JH. Nicotine effects on brain function and functional connectivity in schizophrenia. Biol Psychiatry. 2004;55(8):850-8.

76. Rezvani a H, Levin ED. Cognitive effects of nicotine. Biol Psychiatry. 2001;49(3):258-67.

77. Menzies L, Ooi C, Kamath S, Suckling J, McKenna P, Fletcher P, et al. Effects of $\gamma$-Aminobutyric Acid-Modulating Drugs on Working Memory and Brain Function in Patients With Schizophrenia. Arch Gen Psychiatry. 2007;64:156-67.

78. Duncan EJ, Szilagyi S, Schwartz MP, Bugarski-Kirola D, Kunzova A, Negi S, et al. Effects of Dcycloserine on negative symptoms in schizophrenia. Schizophr Res. 2004;71(2-3):239-48.

79. Spence $S$ a, Green RD, Wilkinson ID, Hunter MD. Modafinil modulates anterior cingulate function in chronic schizophrenia. Br J Psychiatry. 2005;187:55-61.

80. Luck SJ, Gold JM. The construct of attention in schizophrenia. Biol Psychiatry. 2008;64(1):34-9.

81. Nuechterlein KH, Ph D, Green MF, Kern RS, Baade LE, Barch DM, et al. "The MATRICS Consensus Cognitive Battery, Part 1: Test Selection, Reliability, and Validity." Am J Psychiatry. 2008;165:20313.

82. Molina V, Gispert JD, Reig S, Pascau J, Martinez R, Sanz J, et al. Olanzapine-induced cerebral metabolic changes related to symptom improvement in schizophrenia. Psychopharmacology. 2003;20:13-8.

83. Liu SK, Chen WJ, Chang CJ, Lin HN. Effects of atypical neuroleptics on sustained attention deficits in schizophrenia: a trial of risperidone versus haloperidol. Neuropsychopharmacology. 2000 Mar;22(3):311-9.

84. Golightly KL, Lloyd J a, Hobson JE, Gallagher P, Mercer G, Young a H. Acute tryptophan depletion in schizophrenia. Psychol Med. 2001;31(1):75-84.

85. Lenzi A, Maltinti E, Poggi E, Fabrizio L, Coli E. Effects of rivastigmine on cognitive function and quality of life in patients with schizophrenia. Clin Neuropharmacol. 2003;26(6):317-21.

86. Dépatie L, O’Driscoll G a, Holahan A-L V, Atkinson V, Thavundayil JX, Kin NNY, et al. Nicotine and behavioral markers of risk for schizophrenia: a double-blind, placebo-controlled, cross-over study. Neuropsychopharmacology. 2002;27(6):1056-70.

87. Knowles EEM, David AS, Reichenberg A. Processing Speed Deficits in Schizophrenia: Reexamining the Evidence. Am J Psychiatry. 2010;167:828-35. 
88. Strous RD, Stryjer R, Maayan R, Gal G, Viglin D, Katz E, et al. Analysis of clinical symptomatology, extrapyramidal symptoms and neurocognitive dysfunction following dehydroepiandrosterone (DHEA) administration in olanzapine treated schizophrenia patients: a randomized, double-blind placebo controlled trial. Psychoneuroendocrinology. 2007;32(2):96-105.

89. Nielsen RE, Levander S, Thode D, Nielsen J. Effects of sertindole on cognition in clozapine-treated schizophrenia patients. Acta Psychiatr Scand. 2012;126:31-9.

90. Muscatello MR a, Bruno a, Pandolfo G, Micò U, Bellinghieri PM, Scimeca G, et al. Topiramate augmentation of clozapine in schizophrenia: a double-blind, placebo-controlled study. J Psychopharmacol. 2011;25(5):667-74.

91. Zoccali R, Muscatello M, Bruno A, Cambria R. The effect of lamotrigine augmentation of clozapine in a sample of treatment-resistant schizophrenic patients: A double-blind, placebo-controlled study. Schizophr Res. 2007;93:109-16.

92. Kalyoncu A, Mirsal H, Pektas O, Unsalan N, Tan D, Beyazyürek M. Use of lamotrigine to augment clozapine in patients with resistant schizophrenia and comorbid alcohol dependence: a potent anti-craving effect? J Psychopharmacol. 2005;19(3):301-5.

93. Beer JS, Ochsner KN. Social cognition: a multi level analysis. Brain Res. 2006;1079(1):98-105.

94. Adolphs R. The neurobiology of social cognition. Curr Opin Neurobiol. 2001;11(2):231-9.

95. Mizrahi R, Korostil M, Starkstein SE, Zipursky RB, Kapur S. The effect of antipsychotic treatment on Theory of Mind. Psychol Med. 2007;37(4):595-601.

96. Burns MJ. The pharmacology and toxicology of atypical antipsychotic agents. J Toxicol Clin Toxicol. 2001;39(1):1-14.

97. Singh AN, Barlas C, Saeedi H, Mishra RK. Effect of loxapine on peripheral dopamine-like and serotonin receptors in patients with schizophrenia. J Psychiatry Neurosci. 2003;28(1):39-47.

98. Sumiyoshi T, Higuchi $Y$, Itoh T, Matsui M, Arai H, Suzuki M. Effect of perospirone on P300 electrophysiological activity and social cognition in schizophrenia: A three-dimensional analysis with sLORETA. Psychiatry Res Neuroimaging. 2009;172(3):180-3.

99. Behere R V, Venkatasubramanian G, Arasappa R, Reddy N, Gangadhar BN. Effect of risperidone on emotion recognition deficits in antipsychotic-naïve schizophrenia: a short-term follow-up study. Schizophr Res. 2009;113(1):72-6.

100. Kosfeld M, Heinrichs M, Zak PJ, Fischbacher U, Fehr E. Oxytocin increases trust in humans. Nature. 2005;435(7042):673-6.

101. Pedersen C a, Gibson CM, Rau SW, Salimi K, Smedley KL, Casey RL, et al. Intranasal oxytocin reduces psychotic symptoms and improves Theory of Mind and social perception in schizophrenia. Schizophr Res; 2011;132(1):50-3.

102. Kéri S, Kiss I, Kelemen O. Sharing secrets: oxytocin and trust in schizophrenia. Soc Neurosci. 2009;4(4):287-93.

103. Takahashi H, Yamada M, Suhara T. Functional significance of central D1 receptors in cognition: beyond working memory. J Cereb Blood Flow Metab. Nature; 2012;32(7):1248-58.

104. Okubo Y, Suhara T, Suzuki K, Kobayashi K, Inoue O, Terasaki O, et al. Decreased prefrontal dopamine D1 receptors in schizophrenia revealed by PET. Nature. 1997;385:634-6.

105. Cai JX, Arnsten a F. Dose-dependent effects of the dopamine D1 receptor agonists A77636 or SKF81297 on spatial working memory in aged monkeys. J Pharmacol Exp Ther. 1997;283(1):183-9.

106. Arnsten AFTI, Cai JX, Murphy BL. Psychopharmacology Dopamine D1 receptor mechanisms in the cognitive performance of young adult and aged monkeys. Psychopharmacology. 1994;116:141153. 
107. Galletly C. Recent advances in treating cognitive impairment in schizophrenia. Psychopharmacology. 2009;202(1-3):259-73.

108. Winstanley C a, Chudasama Y, Dalley JW, Theobald DEH, Glennon JC, Robbins TW. Intra-prefrontal 8-OH-DPAT and M100907 improve visuospatial attention and decrease impulsivity on the fivechoice serial reaction time task in rats. Psychopharmacology (Berl). 2003;167(3):304-14.

109. Boast C, Bartolomeo a C, Morris H, Moyer J a. 5HT antagonists attenuate MK801-impaired radial arm maze performance in rats. Neurobiol Learn Mem. 1999;71(3):259-71.

110. Van der Zee E a, Platt B, Riedel G. Acetylcholine: future research and perspectives. Behav Brain Res. 2011;221(2):583-6.

111. Lieberman J a, Javitch, Jonathan A, Moore H. Cholinergic Agonists as Novel Treatments for Schizophrenia : The Promise of Rational. Am J Psychiatry. 2008;165:931-6.

112. Friedman Jl. Cholinergic targets for cognitive enhancement in schizophrenia: focus on cholinesterase inhibitors and muscarinic agonists. Psychopharmacology. 2004;174(1):45-53.

113. Raedler TJ, Knable MB, Jones DW, Urbina R a, Gorey JG, Lee KS, et al. In vivo determination of muscarinic acetylcholine receptor availability in schizophrenia. Am J Psychiatry. 2003;160(1):11827.

114. Crook JM, Ph D, Tomaskovic-crook E, Hons BS, Dean B. Low Muscarinic Receptor Binding in Prefrontal Cortex From Subjects With Schizophrenia: and the Effects of Neuroleptic Drug Treatment. 2001;158:918-25.

115. Crook JM, Tomaskovic-Crook E, Copolov DL, Dean B. Decreased muscarinic receptor binding in subjects with schizophrenia: a study of the human hippocampal formation. Biol Psychiatry. 2000;48(5):381-8.

116. Breese CR, Lee MJ, Adams CE, Sullivan B, Logel J, Gillen KM, et al. Abnormal regulation of high affinity nicotinic receptors in subjects with schizophrenia. Neuropsychopharmacology. 2000;23(4):351-64.

117. Dean B, Crook J, Opeskin K, Hill C, Keks N, Copolov D. The density of muscarinic M1 receptors is decreased in the caudate-putamen of subjects with schizophrenia. Mol Psychiatry. 1996;1:54-8.

118. Freedman R, Hall M, Adler LE, Leonard S. Evidence in postmortem brain tissue for decreased numers of hippocampal nicotinic receptors in schizophrenia. Biol Psychiatry. 1995;38(1):22-33.

119. Everitt BJ, Robbins TW. Central Cholinergic Systems. Annu Rev Psychol. 1997;48:649-684.

120. Shekhar A, Potter WZ, Lightfoot J, Lienemann J, Dubé S, Mallinckrodt C, et al. Selective muscarinic receptor agonist xanomeline as a novel treatment approach for schizophrenia. Am J Psychiatry. 2008;165(8):1033-9.

121. Bodick N, Offen W, Levey A, Cutler N, Gauthier S, Satlin A, et al. Effects of xanomeline, a selective muscarinic receptor agonist, on cognitive function and behavioral symptoms in Alzheimer disease. Arch Neurol. 1997;54(4):465-73.

122. Blum BP, Mann JJ. The GABAergic system in schizophrenia. Int J Neuropsychopharmacol. 2002 Jun;5(2):159-79.

123. Kane MJ, Engle RW. The role of prefrontal cortex in working-memory capacity, executive attention, and general fluid intelligence: an individual-differences perspective. Psychon Bull Rev. 2002;9(4):637-71.

124. Lewis D a, Volk DW, Hashimoto T. Selective alterations in prefrontal cortical GABA neurotransmission in schizophrenia: a novel target for the treatment of working memory dysfunction. Psychopharmacology. 2004;174(1):143-50.

125. Javitt DC. Glutamate as a therapeutic target in psychiatric disorders. Mol Psychiatry. 2004;9(11):984-97, 979. 
126. Malchow B, Hasan A, Fusar-Poli P, Schmitt A, Falkai P, Wobrock T. Cannabis abuse and brain morphology in schizophrenia: a review of the available evidence. Eur Arch Psychiatry Clin Neurosci. 2013;263(1):3-13.

127. Lubman DI, King J a, Castle DJ. Treating comorbid substance use disorders in schizophrenia. Int Rev Psychiatry. 2010;22(2):191-201.

128. Levaux M-N, Potvin S, Sepehry AA, Sablier J, Mendrek A, Stip E. Computerized assessment of cognition in schizophrenia: promises and pitfalls of CANTAB. Eur Psychiatry. 2007;22(2):104-15. 




\section{Chapter | 3}

The effect of the muscarinic $M_{1}$ receptor antagonist biperiden on cognition in medication-free subjects with psychosis

Claudia Vingerhoets, Geor Bakker, Jelske van Dijk, Raymond Chan, Oswald Bloemen, Ya Wang, Jan Booij,

Thérèse van Amelsvoort 


\section{Abstract}

Introduction: The acetylcholine muscarinic $\mathrm{M}_{1}$ receptor has been implicated in both psychosis and cognition. Post-mortem research has shown reduced muscarinic $M_{1}$ receptor density in $25 \%$ of chronic patients with schizophrenia. Currently it is unknown whether reduced $M_{1}$ receptor density is related to the cognitive symptoms of psychosis. With this study we investigated the role of the $M_{1}$ receptor in the separate cognitive domains in subjects with a psychotic disorder using a muscarinic $\mathrm{M}_{1}$ antagonist as an acute pharmacological challenge. It was hypothesized that administration of a muscarinic antagonist will impair cognition in both groups and that this effect will be more pronounced in subjects with a psychotic disorder.

Methods: 33 young subjects with a psychotic disorder and 30 gender, age and IQ matched healthy controls were enrolled in the study. All participants completed a comprehensive cognitive test battery twice: once after placebo and once after oral administration of $4 \mathrm{mg}$. biperiden ( $\mathrm{M}_{1}$ antagonist). The order of drug administration was counterbalanced.

Results: We found that biperiden significantly negatively influenced both verbal $(p<0.001$ and $p=0.032)$ and visual learning and memory $(p=0.028)$. A medication $\mathrm{x}$ group interaction effect was found for reasoning and problem solving ( $p=0.005)$. No main or interaction effects were found for the other cognitive domains.

Discussion: These results provide further in-vivo evidence that the $M_{1}$ receptor is involved in cognitive functioning, particularly verbal and visual memory processes. The lack of differential effects of biperiden between psychotic subjects and healthy controls may suggest that decreased $\mathrm{M}_{1}$ receptor density is only present in chronic, older schizophrenia patients. However, it remains possible that differential effects of biperiden would be present in more severe cognitive impaired subjects with psychosis after several doses of biperiden instead of a single administration. 


\section{Introduction}

Psychotic disorders, schizophrenia being the most severe form, are with a prevalence of approximately $3 \%$ relatively common (1). In addition to positive and negative symptoms, the majority of the patients have cognitive impairments as well (2). Cognitive impairment often precedes other psychotic symptoms and persist after other symptoms have been treated effectively $(3,4)$. Previous studies have shown that cognitive impairment in psychosis is associated with poorer functional outcome $(5,6)$; and severity of cognitive impairments predicts treatment non-adherence (7), poorer medication compliance (8) and tendency for relapse (9). Seven separate cognitive domains, which are fundamentally impaired in schizophrenia, have been identified by the Measurement and Treatment to Improve Cognition in Schizophrenia (MATRICS). These domains are verbal learning and memory, visual learning and memory, working memory, attention and vigilance, reasoning and problem solving, processing speed and social cognition (10). At present, standardized cognitive test batteries are available that measure these domains, such as the Cambridge Neuropsychological Automated Test Battery (CANTAB) (11). Nonetheless, to date, the underlying neurobiological mechanisms of cognitive symptoms in psychosis are not well understood and no effective treatment is yet available.

A growing number of studies have implicated the acetylcholine muscarinic system in both psychosis and cognition. Muscarinic acetylcholine receptors (mAChRs) play an important role not only in motor function but also in cognitive functioning (12). Blockade of the muscarinic system by means of mAChRs antagonists such as scopolamine has been found to impair cognitive functions in both animal and human studies, particularly attention, learning and memory (13-18). From the five subtypes of mAChRs $\left(M_{1}-M_{5}\right)$, the $M_{1}$ receptor has been most strongly associated with cognition and with psychotic disorders (19), possibly because this subtype is most abundantly expressed in the central nervous system and has lower expression rates in the peripheral nervous system (20). Indeed, brain regions with the highest density of $\mathrm{M}_{1}$ receptors include brain regions associated with cognition such as the cerebral cortex, hippocampus and striatum (21). Post-mortem studies have repeatedly described decreases in the expression of $M_{1}$ and $M_{4}$ receptors in patients with schizophrenia (22-27). Interestingly, Scarr et al. (28) found a subgroup with up to $75 \%$ reduction $\mathrm{M}_{1}$ binding in the dorsolateral prefrontal cortex (DLPFC) in post-mortem brains of schizophrenia patients. They defined this subgroup, comprising approximately $25 \%$ of the sample, as 'muscarinic receptor deficit schizophrenia' (MRDS). The authors suggested that this subgroup might represent a distinct schizophrenia phenotype with more pronounced cognitive 
impairment compared to patients with normal $M_{1}$ receptor binding. However, due to the post-mortem design, it is currently unknown whether these $M_{1}$ receptor deficits are indeed related to cognitive symptoms in psychosis. Nevertheless, previous studies did not find differences in cortical $M_{2}$ and $M_{3}$ expression in schizophrenia compared to healthy controls (29), suggesting a specific role for the $M_{1}$ receptor subtype in cognitive symptoms of psychotic disorders. Indeed, a study by Shekar et al. (30) reports improvement in verbal learning and memory after 4 weeks of monotherapy with xanomeline, a selective $M_{1 / 4}$ agonist. No improvement was found in attention and processing speed in addition to improvement in clinical symptoms. Because xanomeline has agonistic effects on both $M_{1}$ and $M_{4}$ receptors, no conclusion can be drawn regarding differential roles of $M_{1}$ and $M_{4}$ receptors in cognition. A recent study by Veselinovic et al. (31) found impaired executive functioning after an acute $M_{1}$ antagonist challenge (biperiden, $5 \mathrm{mg}$. intravenously) which was significantly more pronounced in medication-free patients with schizophrenia than in healthy controls. They did not find significant effects of biperiden on (visual) attention, verbal fluency, working memory and processing speed, although this lack of effect may be caused by the small sample size $(N=12$ per group).

To summarize, the specific role of the $M_{1}$ receptor in all separate cognitive domains impaired in psychotic disorders has not been investigated in-vivo as the study by Veselinovic et al. (31) only examined executive functioning, attention, working memory, verbal fluency and processing speed. With this study we aimed to investigate the role of the muscarinic $M_{1}$ receptor in cognitive functioning in young medication-free subjects with a psychotic disorder by means of a $M_{1}$ receptor antagonist (biperiden). We hypothesized that I) administration of a muscarinic antagonist will impair cognition in both groups, especially the domains of memory verbal and visual learning and memory and working memory based on previous observations from studies using scopolamine and xanomeline as cholinergic challenge II) since decreased levels of $M_{1}$ receptors have been reported in patients with schizophrenia, we hypothesized that the effects of biperiden on cognition will be more pronounced in the psychotic subjects than in the healthy control group.

\section{Methods}

This study was approved by the medical ethical committee of the Academic Medical Center (AMC) in Amsterdam. All participants gave written informed consent prior to participation after the study procedure had been fully explained. 


\section{Participants}

33 (22 males and 11 females) medication-free subjects with a psychotic disorder (mean age 27 years) and 30 (20 males and 10 females) healthy control subjects (mean age 25 years) were enrolled in the study. Control subjects were matched for gender, age and IQ. Subjects with a psychotic disorder were recruited through mental health care institutions and online advertisement as well as in national newspapers. Within the psychosis group, 14 subjects were diagnosed with schizophrenia, 2 were diagnosed with schizophreniform disorder, 3 were diagnosed with schizoaffective disorder and 14 subjects were diagnosed with a psychotic disorder not otherwise specified. Healthy controls were recruited trough advertisement on internet. Inclusion criteria for the psychotic subjects were: aged between 18 and 40 years, no use of antipsychotics or anticholinergics and onset of psychosis no longer than 10 years prior to participation. Subjects who were on lowdose antipsychotic medication at time of inclusion underwent a wash-out (5 times the mean terminal elimination half-life of the specific antipsychotic) procedure prior to participation ( $\mathrm{N}=3$ ). One patient was on quetiapine (200 mg.), one used haloperidol (1 mg.) and one patient used flupentixol $(0.5 \mathrm{mg})$. Patients with a bipolar disorder or psychotic depression were not included in this study. Inclusion criteria for healthy controls were aged between 18 and 40 years old, free of any medication and no history of psychiatric illness and no first-degree relatives with a history of psychotic disorders. Exclusion criteria for both groups were: contraindications for biperiden, severe neurological or comorbid psychiatric disorders and illicit drug use 4 weeks prior to participation. For female participants, pregnancy was an additional exclusion criterion. Participants were instructed to refrain from alcohol and nicotine 24 hours prior to testing. Abstinence of recreational drugs was verified with a urine drug screening prior to testing.

\section{Instruments}

Demographic information including medication history was assessed using a standardized questionnaire. IQ was determined using a shortened version of the Wechsler Adult Intelligence Scale (WAIS III, (32)). The Comprehensive Assessment of Symptoms and History (CASH, (33)) was used to verify diagnosis of a psychotic disorder. The Positive and Negative Syndrome Scale (PANSS; (34)) was used to measure psychotic symptom severity at time of assessment. Side effects of biperiden were measured on both test days using a self-report questionnaire consisting of 31-items such as nausea, headache, dry mouth etc. to be rated on a 4point scale with 0 indicating not affected and 3 very affected (35). 
The Cambridge Neuropsychological Automated Test Battery (CANTAB) schizophrenia test battery was used to measure cognition (11). This battery covers all cognitive domains that have been identified by the MATRICS (10). The CANTAB has been well validated and found to be sensitive for pharmaceutical agents (36). Because of sensitivity of the tests, the CANTAB is able to detect subtle effects. When appropriate, parallel tests were used to minimize learning effects. See table 1 for an overview of subtests and outcome measures used.

\section{Biperiden}

Biperiden (Akineton ${ }^{\odot}$, instant release, Knoll AG) is a mAChR antagonist which belongs to the class of anticholinergic medication. It is clinically used for the treatment of Parkinson's disease and extrapyramidal side effects of (typical) antipsychotics. Biperiden has approximately a 10-fold higher affinity for the $M_{1}$ receptor compared to the other muscarinic receptors and is therefore the most selective $M_{1}$ antagonist available for use in human subjects $(37,38)$. The elimination constant of a single dose is initially steep and after 6 hours there is approximately $12 \%$ biperiden plasma concentration after which the elimination constant slowly levels off. Eighteen hours after administration, plasma levels are clear of biperiden restricting duration of potential unwanted effects (39). Commonly reported side effects in case of long-term use include drowsiness, headache, dizziness, blurred vision, dry mouth and obstipation (40). The dose of $4 \mathrm{mg}$. lies within the upper range of the interval of therapeutically recommended doses (1-4 $\mathrm{mg}$ ).

\section{Procedure}

This study was a single-blind, placebo (starch tablet, placebo wit) controlled, crossover study and was part of an extensive research project investigating the role of the cholinergic muscarinic system in psychosis. Cognitive assessments were conducted twice: once after placebo and once after oral administration of $4 \mathrm{mg}$. biperiden. The order of placebo and biperiden was counterbalanced to make sure that half of the participants received placebo at the first assessment and the other half biperiden. Prior to both test days, a urine drugs screening (cannabis, cocaine, benzodiazepines, opiates, amphetamines, methamphetamines) was performed to verify abstinence of drugs. 4 subjects with a psychotic disorder tested positive prior to the placebo measurement (one for cannabis, two for cocaine and one for benzodiazepines) and one tested positive at the biperiden measurement (cannabis and cocaine) despite instructions to abstain from drugs 4 weeks prior to participation. Therefore, we repeated the analyses without these subjects to check whether this influenced the results. None of the healthy controls tested positive at 
Table 1. Overview of CANTAB tasks and outcome measures

\begin{tabular}{|c|c|c|c|c|}
\hline Domain & Task & Task description & Outcome measures & Direction \\
\hline $\begin{array}{l}\text { Visual } \\
\text { learning \& } \\
\text { memory }\end{array}$ & $\begin{array}{l}\text { Paired } \\
\text { Associate } \\
\text { Learning } \\
\text { (PAL) }\end{array}$ & $\begin{array}{l}\text { Boxes are displayed on a } \\
\text { screen which open in a } \\
\text { randomized order. One or } \\
\text { more of the boxes contain a } \\
\text { pattern. Participants must } \\
\text { remember and identify the } \\
\text { correct location of the } \\
\text { patterns. }\end{array}$ & $\begin{array}{l}\text { Total errors (adjusted } \\
\text { for stages completed) } \\
\text { First trial memory score } \\
\text { (total number of } \\
\text { patterns correctly } \\
\text { located after first trial } \\
\text { across completed } \\
\text { stages) }\end{array}$ & Lower is better \\
\hline \multirow[t]{3}{*}{$\begin{array}{l}\text { Verbal } \\
\text { learning \& } \\
\text { memory }\end{array}$} & $\begin{array}{l}\text { Verbal } \\
\text { Recog- } \\
\text { nition }\end{array}$ & $\begin{array}{l}\text { Participants are shown } 12 \\
\text { words and afterwards had } \\
\text { to reproduce as many }\end{array}$ & $\begin{array}{l}\text { Free recall total words } \\
\text { correct }\end{array}$ & Higher is better \\
\hline & $\begin{array}{l}\text { Memory } \\
\text { (VRM) }\end{array}$ & $\begin{array}{l}\text { words as possible as well as } \\
\text { to recognize the words } \\
\text { from a list of } 24 \text { words. }\end{array}$ & $\begin{array}{l}\text { Immediate recognition } \\
\text { total correct }\end{array}$ & Higher is better \\
\hline & & $\begin{array}{l}\text { Recognition phase was } \\
\text { repeated after } 20 \text { minutes. }\end{array}$ & $\begin{array}{l}\text { Delayed recognition } \\
\text { total correct }\end{array}$ & Higher is better \\
\hline \multirow[t]{2}{*}{$\begin{array}{l}\text { Working } \\
\text { memory }\end{array}$} & $\begin{array}{l}\text { Spatial } \\
\text { Working }\end{array}$ & $\begin{array}{l}\text { A self-ordered task which } \\
\text { tests a person's ability to }\end{array}$ & Total errors & Lower is better \\
\hline & $\begin{array}{l}\text { Memory } \\
\text { (SWM) }\end{array}$ & $\begin{array}{l}\text { retain spatial information } \\
\text { and to manipulate this } \\
\text { information. }\end{array}$ & Strategy & Lower is better \\
\hline $\begin{array}{l}\text { Attention } \\
\text { \& vigilance }\end{array}$ & $\begin{array}{l}\text { Rapid } \\
\text { Visual } \\
\text { Proces- } \\
\text { sing } \\
\text { (RVP) }\end{array}$ & $\begin{array}{l}\text { Participants had to detect } \\
\text { target sequences of digits. }\end{array}$ & $\begin{array}{l}\text { A'prime (measure of } \\
\text { how good a subject } \\
\text { detects a target } \\
\text { sequences using total } \\
\text { hits and total false } \\
\text { alarms) }\end{array}$ & Higher is better \\
\hline \multirow{3}{*}{$\begin{array}{l}\text { Processing } \\
\text { speed }\end{array}$} & & & Mean latency & Lower is better \\
\hline & $\begin{array}{l}\text { Reaction } \\
\text { Time } \\
\text { (RTI) }\end{array}$ & $\begin{array}{l}\text { Measures the speed of } \\
\text { response to a visual target }\end{array}$ & $\begin{array}{l}\text { Simple reaction } \\
\text { (response to stimulus in } \\
\text { a single, predictable } \\
\text { location) }\end{array}$ & Lower is better \\
\hline & & & $\begin{array}{l}\text { 5-choice reaction } \\
\text { (response to a stimulus } \\
\text { in any of } 5 \text { locations). }\end{array}$ & Lower is better \\
\hline $\begin{array}{l}\text { Reasoning } \\
\text { \& problem } \\
\text { solving }\end{array}$ & $\begin{array}{l}\text { One } \\
\text { Touch } \\
\text { Stockings } \\
\text { of Cam- } \\
\text { bridge } \\
\text { (OTS) }\end{array}$ & $\begin{array}{l}\text { Spatial planning task based } \\
\text { on the Tower of London } \\
\text { test. Participants had to } \\
\text { identify how many moves } \\
\text { are required to solve a } \\
\text { problem }\end{array}$ & $\begin{array}{l}\text { Total number of } \\
\text { problems solved on first } \\
\text { choice }\end{array}$ & Higher is better \\
\hline
\end{tabular}




\begin{tabular}{lllll}
\hline Domain & Task & Task description & Outcome measures & Direction \\
\hline $\begin{array}{l}\text { Social } \\
\text { cognition }\end{array}$ & Emotion & $\begin{array}{l}\text { Participants were shown a } \\
\text { Recognition } \\
\text { series of faces showing } \\
\text { sest (ERT) }\end{array}$ & $\begin{array}{l}\text { Total number of } \\
\text { correct identified } \\
\text { and choose the emotion that } \\
\text { most closely corresponded to } \\
\text { the emotion shown in the } \\
\text { face }\end{array}$ & Higher is better \\
& & & \\
& & & \\
\hline
\end{tabular}

both days. Both test days started with a brief explanation of the study procedure. After this explanation, the study medication was administered (placebo or biperiden). The CANTAB was conducted 2.5 hours after drug administration to maximize the chance that $T_{\max }$ was reached in all subjects. After completion of the CANTAB battery, the test day was finished. The study protocol was similar for both test days. Time interval between both test days was at least one week to minimize learning effect and to ensure complete drug wash out. The WAIS-III was always conducted during the placebo condition to prevent confounding effects of biperiden on IQ.

\section{Data-analyses}

All analyses were conducted with IBM SPSS Statistics, version 23. First, group differences in gender, age, IQ, counterbalance order, and time interval between testing, side effects after placebo, side effects after biperiden, difference in side effects ( $\Delta$ side effects: biperiden minus placebo) and PANSS scores were analyzed using an independent samples t-test for continuous variables and chi-square tests for categorical variables. Second, cognitive scores were transformed into standardized Z-scores per outcome measure to identify outliers. Z-scores smaller or larger than 3 were considered outliers and were excluded from further analyses. An analysis of covariance (ANCOVA) was conducted to examine group differences in the separate cognitive outcome measures after placebo, corrected for the counterbalance order (placebo-biperiden or biperiden-placebo). Subsequently, a repeated measures ANCOVA was performed to examine the effects of biperiden on cognition and to examine whether the effects of biperiden differed between groups (medication $\mathrm{x}$ group interaction). Bonferroni correction was applied to correct multiple comparisons. Therefore, results were considered significant if chronbach's alpha was $\leq 0.004$. 


\section{Results}

Sample demographics are displayed in table 1. Gender $\left(\chi^{2}(1)=0.00, p=1.00\right)$, age $(t(1,62)=-1.68, p=0.10)$ and IQ $(t(1,62)=-1.66 ; p=0.10)$ did not significantly differ between the two groups. As expected, subjects with a psychotic disorder had significantly higher scores on all domains of the PANSS (table 2). No significant group differences were found in terms of counterbalance order (placebo biperiden vs biperiden - placebo) and time interval between both measurements (table 2). Subjects with a psychotic disorder reported significantly more side effects in the placebo condition $(t(1,60)=-3.16 ; p=0.003)$ and trend level significant more side effects in the biperiden condition $(t(1,55)=-1.66 ; p=0.10)$ than the healthy controls. However, delta scores (total score biperiden - total score placebo) indicated that biperiden did not cause significant side effects in both groups ( $t$ $(1,55)=0.63 ; p=0.533)$.

Table 2. Sample demographics.

\begin{tabular}{lcccc}
\hline & Psychosis & Healthy controls & & \\
\hline & Mean (SD) & Mean (SD) & Statistic & $\boldsymbol{P}$ \\
\hline Gender (male/female) & $22 / 11$ & $20 / 10$ & 0.00 & 1.00 \\
Age & $27.61(5.32)$ & $25.40(5.08)$ & -1.68 & 0.10 \\
IQ & $99.70(15.10)$ & $105.93(14.76)$ & 1.66 & 0.10 \\
Counterbalance order (p-b / b-p) & $17 / 16$ & $12 / 18$ & 0.34 & 0.51 \\
Time interval between & $14.97(18.40)$ & $21.18(23.17)$ & 1.14 & 0.26 \\
assessments & & & & \\
Side effect severity placebo & $12.94(14.08)$ & $5.65(8.54)$ & -3.16 & 0.003 \\
Side effect severity biperiden & $13.43(10.76)$ & $8.04(7.27)$ & -1.97 & 0.054 \\
$\Delta$ Side effect severity (b-p) & $0.13(14.07)$ & $2.11(8.54)$ & 0.63 & 0.533 \\
PANSS & & & & \\
$\quad$ Positive symptoms & $11.97(4.72)$ & $7.10(0.31)$ & -5.91 & $<0.001$ \\
$\quad$ Negative symptoms & $11.79(5.08)$ & $7.43(1.36)$ & -4.74 & $<0.001$ \\
$\quad$ General psychiatry & $23.40(6.50)$ & $16.87(3.33)$ & -5.08 & $<0.001$ \\
$\quad$ Total score & $47.21(13.77)$ & $31.40(4.59)$ & -6.23 & $<0.001$ \\
\hline
\end{tabular}

NB: IQ: Intelligence Quotient; $\Delta$ Side effect severity $(b-p)$ : total score on the side effects scale biperiden - total score on the side effects scale placebo; PANSS: Positive and Negative Syndrom Scale. 
Table 3. Between group differences in cognitive functioning per domain after placebo corrected for counterbalance order.

\begin{tabular}{|c|c|c|c|c|c|}
\hline & Psychosis & $\begin{array}{l}\text { Healthy } \\
\text { Controls }\end{array}$ & & & \\
\hline & Mean (SD) & Mean (SD) & $F$-value & $P$ & $\eta^{2}$ \\
\hline \multicolumn{6}{|l|}{$\begin{array}{l}\text { Visual learning \& } \\
\text { memory }\end{array}$} \\
\hline PAL total errors & $19.07(20.83)$ & $10.87(15.22)$ & 2.79 & 0.101 & 0.047 \\
\hline $\begin{array}{l}\text { PAL first trial memory } \\
\text { score }\end{array}$ & $19.97(5.86)$ & $21.93(5.43)$ & 1.55 & 0.219 & 0.026 \\
\hline \multicolumn{6}{|l|}{$\begin{array}{l}\text { Verbal learning \& } \\
\text { memory }\end{array}$} \\
\hline $\begin{array}{l}\text { VRM Free recall } \\
\text { (immediate) }\end{array}$ & $7.65(1.91)$ & 8.63 (1.99) & 3.95 & 0.051 & 0.064 \\
\hline $\begin{array}{l}\text { VRM Recognition } \\
\text { (immediate) }\end{array}$ & $23.35(0.80)$ & 23.39 (0.69) & 0.06 & 0.801 & 0.001 \\
\hline $\begin{array}{l}\text { VRM Recognition } \\
\text { (delayed) }\end{array}$ & 23.03 (1.19) & $23.17(1.34)$ & 0.32 & 0.573 & 0.006 \\
\hline \multicolumn{6}{|l|}{ Working memory } \\
\hline SWM total errors & $13.42(10.60)$ & $7.17(7.03)$ & 6.74 & 0.012 & 0.104 \\
\hline SWM strategy & $16.06(3.86)$ & $14.13(3.52)$ & 3.88 & 0.054 & 0.063 \\
\hline \multicolumn{6}{|l|}{ Attention \& vigilance } \\
\hline RVP A'prime & $0.90(0.06)$ & $0.95(0.03)$ & 15.03 & $<0.001$ & 0.209 \\
\hline RVP mean latency & $517.66(122.56)$ & $441.51(74.88)$ & 7.98 & 0.007 & 0.125 \\
\hline \multicolumn{6}{|l|}{ Processing speed } \\
\hline RTI simple reaction & $297.31(36.02)$ & $276.86(32.01)$ & 5.25 & 0.026 & 0.084 \\
\hline RTI 5 choice reaction & $324.91(34.80)$ & $297.09(28.15)$ & 11.44 & $<0.001$ & 0.165 \\
\hline \multicolumn{6}{|l|}{$\begin{array}{l}\text { Reasoning \& problem } \\
\text { solving }\end{array}$} \\
\hline $\begin{array}{l}\text { OTC Problems solved } \\
\text { first choice }\end{array}$ & $10.29(2.28)$ & $11.73(2.36)$ & 5.33 & 0.025 & 0.084 \\
\hline \multicolumn{6}{|l|}{ Social cognition } \\
\hline ERT total correct & $113.00(17.67)$ & $125.53(12.41)$ & 9.41 & 0.003 & 0.142 \\
\hline
\end{tabular}

NB: PAL: Paired Associate Learning; VRM: Verbal Recognition Memory; SWM: Spatial Working Memory; RVP: Rapid Visual Processing; RTI: Reaction Time; OTC: One Touch Stockings of Cambridge; ERT: Emotion Recognition Test. 


\section{Cognition in the placebo condition}

Overall, subjects with a psychotic disorder performed worse on all cognitive domains compared to the healthy control group. Significant differences were found for working memory (SWM total errors; $(F(1,61)=6.74 ; p=0.012))$, attention (RVP A'prime $(F(1,61)=15.03 ; p<0.001)$ and RVP mean latency $(F(1,61)=7.98 ; p$ $=0.007)$ ), processing speed $(\mathrm{RTI}$ simple reaction $(F(1,61)=5.25 ; p<0.026)$ and RTI 5 choice reaction; $(F(1,61)=11.44 ; p<0.001))$, reasoning and problem solving (OTC correct on first choice; $F(1,61)=5.33 ; p=0.025)$ ) and social cognition (ERT number correct; $(F(1,61)=9.41 ; p=0.003))$. Trend level significant differences were found for verbal learning and memory (VRM free recall $(F(1,61)=; p=0.051))$ and working memory strategy (SWM strategy $(F(1,61)=3.88 ; p=0.054))$. However, after correction for multiple comparisons, only the difference in attention (RVP A'prime), processing speed and social cognition remained significant. Results are displayed in table 3.

\section{Effect of biperiden on cognition}

$A$ repeated measures ANOVA showed a significant main effect of biperiden on verbal learning and memory, free recall (VRM free recall; $(F(1,56)=23.96 ; p<$ $0.001)$ ). Both subjects with a psychotic disorder and healthy controls performed worse after biperiden compared to placebo (figure 1). No medication $\mathrm{x}$ group was found for this outcome measure $(F(1,56)=0.18 ; p=0.677)$, indicating that the effect of biperiden was comparable between the two groups. An additional significant main effect of biperiden was found on verbal learning and memory, delayed recognition $(F(1,53)=4.82 ; p=0.032)$. In both groups performance on this task was worse in the biperiden condition than in the placebo condition (figure 2). However, after correction for multiple comparisons, this result did not remain significant. No significant medication $\mathrm{x}$ group interaction effect was found $(F(1,53)$ $=0.71 ; p=0.402$ ) indicating that there was no significant difference between the two groups in effects of biperiden. Biperiden also had a significant main effect on visual learning memory (PAL first trial memory score $(F(1,55)=5.09 ; p=0.028)$ ). Biperiden negatively influenced visual memory in both the psychotic subjects and healthy controls (figure 3). However, this effect was not significant after Bonferroni correction. No significant medication $\mathrm{x}$ group interaction effect was found $(F(1,55)$ $=0.23 ; p=0.631$ ) implicating that the effect of biperiden was similar in both groups. Finally, a significant medication $x$ group interaction effect was found on reasoning and problem solving (OTC $(F(1,55)=8.68 ; p=0.005)$ in absence of a significant main effect $(F(1,55)=0.10 ; p=0.752)$. Subjects with a psychotic 
disorder performed better on the OTC task after biperiden compared to placebo whereas healthy controls performed worse after biperiden (figure 4). However, after correcting for multiple comparisons, this effect did not reach significance anymore. No significant main effects or medication $x$ group interaction effects were found for working memory, attention, processing speed and social cognition (table 4).

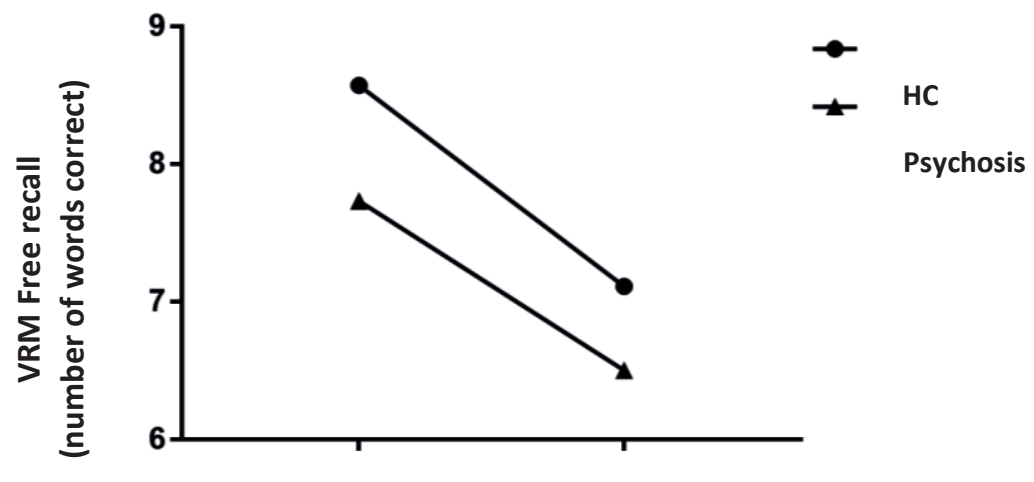

Placebo Biperiden

Figure 1. Effect of biperiden on verbal learning and memory, immediate free recall. HC: healthy controls; Psychosis: subjects with a psychotic disorder.

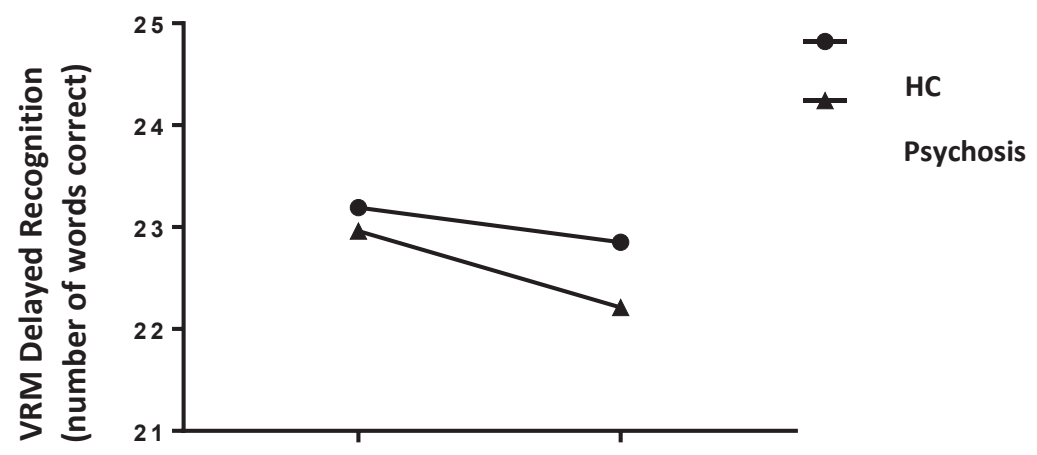

Placebo

Biperiden

Figure 2. Effect of biperiden on verbal learning and memory, delayed recognition. HC: healthy controls; Psychosis: subjects with a psychotic disorder. 


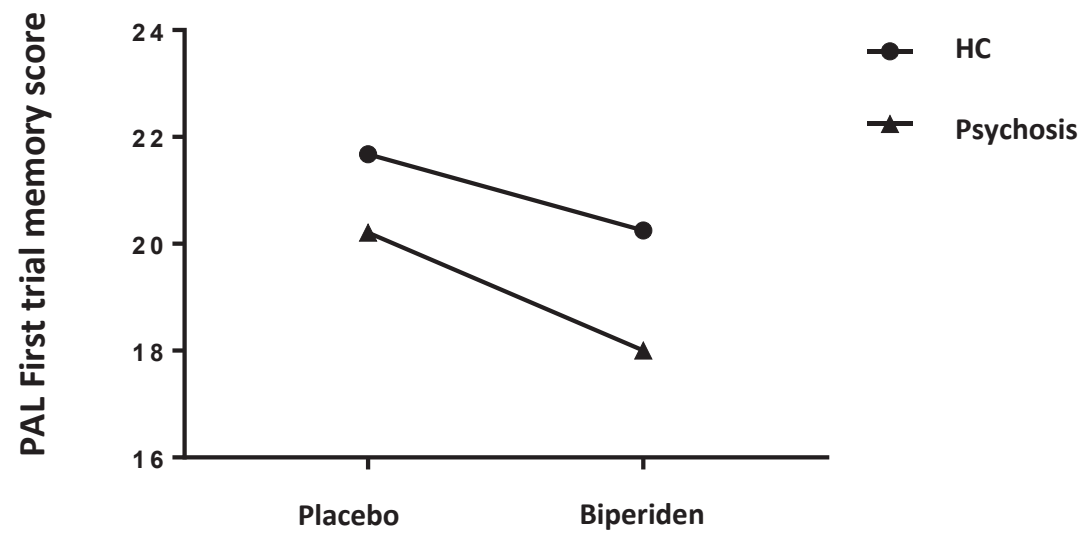

Figure 3. Effect of biperiden on visual learning and memory, PAL first trial memory score. HC: healthy controls; Psychosis: subjects with a psychotic disorder.

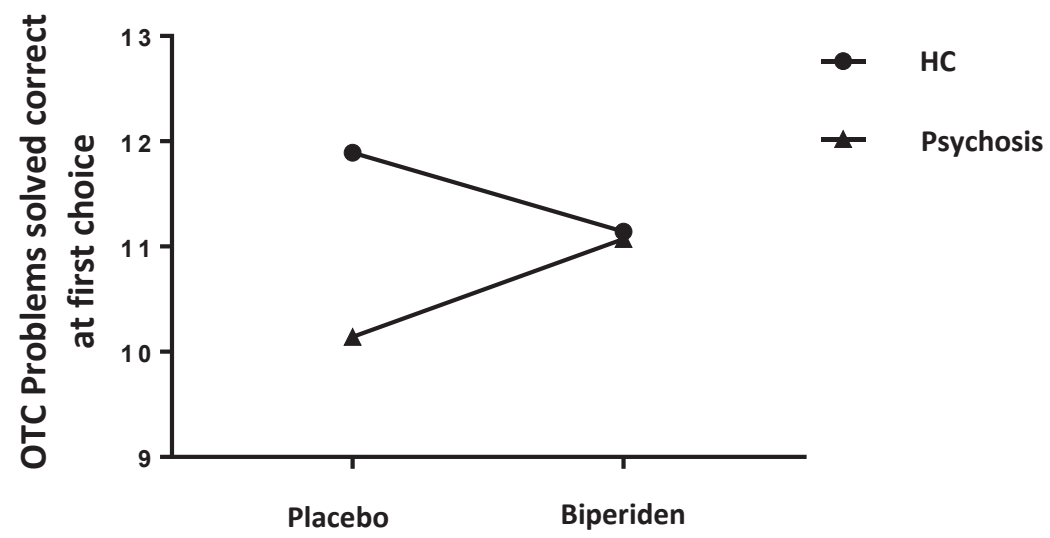

Figure 4. Effect of biperiden on reasoning and problem solving, problems solved on first choice. HC: healthy controls; Psychosis: subjects with a psychotic disorder. 


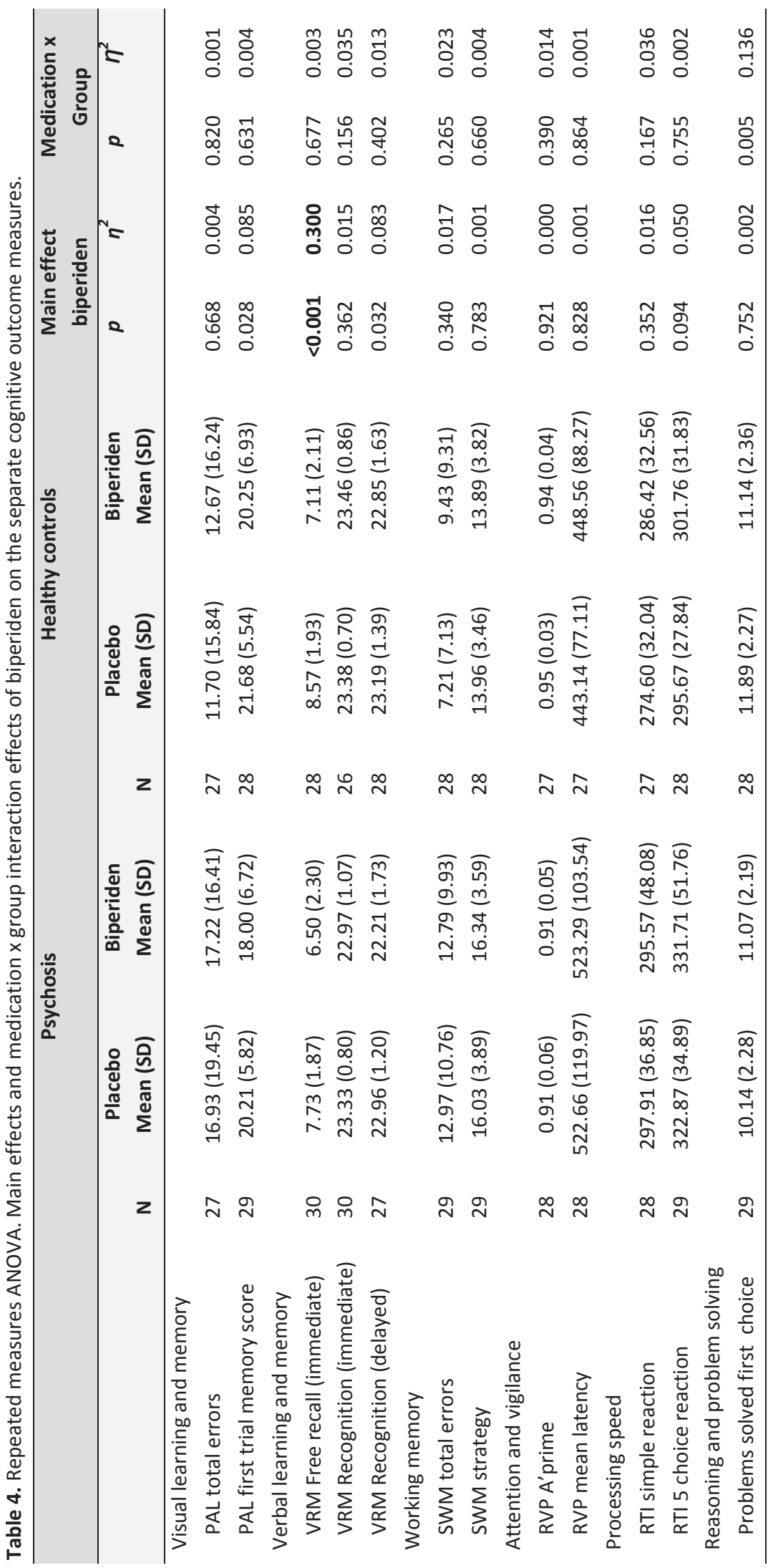




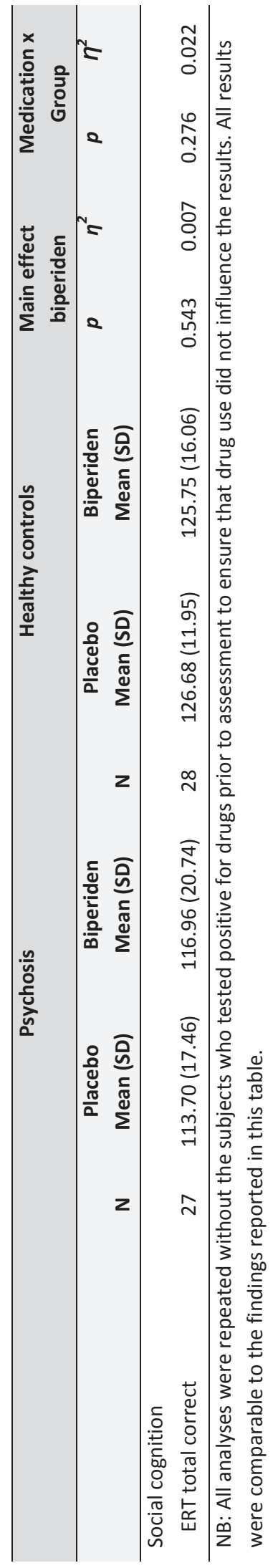




\section{Discussion}

With this study we aimed to investigate the role of the muscarinic $M_{1}$ receptor in cognitive symptoms of medication-free subjects with a recent onset psychotic disorder using a muscarinic $\mathrm{M}_{1}$ receptor antagonist as an acute pharmacological challenge. We found that blocking the $M_{1}$ receptor caused significant impairments in verbal learning memory in both subjects with a psychotic disorder and healthy control subjects. In addition, biperiden had a negative impact on delayed verbal memory and visual learning and memory, although this effect did not remain significant after correcting for multiple comparisons. The role of the $M_{1}$ receptor in memory processes has been demonstrated in both human and animals studies $(30,38,41,42)$. In line with our results, particularly memory impairments after a single administration of biperiden have been demonstrated in healthy (elderly) subjects as well as schizophrenia patients $(31,38,43)$. In addition, discontinuation of biperiden in schizophrenia patients has been found to improve verbal memory (44) as did 4 week monotherapy with $\mathrm{M}_{1}$ agonist xanomeline (30). Overall, these results suggest that the $M_{1}$ receptor is selectively involved in memory processes. Interestingly, in this study we did not find impairment of working memory after an acute challenge with one dose of biperiden. However, previous studies in both human and animals have reported impairment in working memory after biperiden and in $M_{1}$ mutant rodents $(38,41,45,46)$. This discrepancy in findings may be related to the task we used to measure working memory. Working memory refers to the ability to remember, process and manipulate information for a short period of time (47). The task we used did not require manipulation of information and is sensitive to strategy development and subsequent practice effects. Therefore, this task might have measured strategy development rather than working memory abilities. The lack of a significant difference between strategy score between the two groups after placebo indicates that psychotic subjects and controls were equally capable of developing an adequate strategy which could explain the lack of differential effects of biperiden on working memory between the groups.

Based on post-mortem findings of reduced $M_{1}$ receptors in patients with schizophrenia $(22,23,25,28)$, it has been suggested that abnormalities in the muscarinic system are related to the cognitive symptoms in schizophrenia $(27,28)$. Therefore we hypothesized that blockade of the $M_{1}$ receptor had more pronounced, and negative, effects on cognitive function in the subjects with a psychotic disorder than in healthy controls. With the exception of reasoning and problem solving, we did not find differential effects of $M_{1}$ blockade on any of the 
cognitive outcome measures. Interestingly, compared to placebo, subjects with a psychotic disorder performed better on a reasoning and problem solving task (executive functioning) after biperiden administration whereas healthy controls performed worse on this task when given biperiden. These results are not in line with previous findings of Veselinovic et al. (31) who found that executive functioning was impaired by a single-dose ( $5 \mathrm{mg}$. intravenously) of biperiden and that this impairment was more pronounced in the schizophrenia patients than in the healthy control group. Better performance on reasoning and problem solving in the psychotic subjects after biperiden may be due to more pronounced practice effects in this group. In contrast to Veselinovic et al. (31) we counterbalanced the order of placebo and biperiden assessments and although no significant group differences were found for the counterbalance order, more participants in the healthy control group received biperiden at the first assessment. Since blocking the muscarinic system is well known to impair learning $(15,18)$, it might be possible that the practice effect in the healthy group was smaller compared to the practice effect in the patient group. Furthermore, the patients in the study of Veselinovic (31), received a higher dose of biperiden which may have caused more distinct cognitive impairment. Additionally, we only used a single dose of biperiden. It could be possible that differential effects between groups are only visible after long-term use of biperiden.

The lack of significant differential effects of $M_{1}$ blockade between psychotic subjects and healthy controls could be due to the characteristics of the sample of psychotic subjects we included. Previous studies included chronic schizophrenia patients on medication. In our study a substantial part of the psychotic subjects was diagnosed with a psychotic disorder not otherwise specified or schizophreniform disorder, possibly because their psychotic episode did not last at least 6 months. Possibly, $M_{1}$ receptor density decreases are only observed in patients with severe and chronic schizophrenia which would explain the lack of differential effects of biperiden in our sample. Another explanation for the lack of significant differential effect of biperiden between the two groups may be that we selected a group of psychotic subjects that was less cognitively impaired compared to samples used in other studies. Although the psychotic subjects tended to perform worse on all cognitive outcome measures, we only found significant group differences on attention (RVP A'prime), processing speed (response to an unpredictable target) and social cognition. Patients with schizophrenia typically demonstrate cognitive impairments that range 1.5-2 standard deviations below functioning of healthy controls (48). With the exception of attention, the psychotic subjects in our sample did not deviate more than 1 standard deviation from the 
healthy controls on the separate cognitive domains suggesting that the psychotic subjects we included were less cognitive impaired compared to the samples in other studies which may be inherent to our inclusion criteria. By only including medication-free psychotic subjects we possibly selected a relatively stable sample with less severe psychotic symptoms. Indeed, the low PANSS scores in the patient group indicate that the participants were relatively stable at time of inclusion which could have beneficially affected their performance on the cognitive test batteries. However, it must be noted that the lack of significant group differences after placebo might be due to insufficient power inherent to the small sample size.

\section{Strengths and limitations}

This study has important strengths. The most important strength is that all participants in this study were free of antipsychotic medication. Therefore, the current results are not confounded by acute effects of medication, which is often the case in other studies. Furthermore, by using an extensive cognitive test battery covering all domains that are fundamentally impaired in schizophrenia (10), we were able to explore the role of the $M_{1}$ receptor in separate aspects of cognitive functioning. However, some limitations have to be taken into account as well. First, for a behavioral study, the sample size was relatively small resulting in limited power. Therefore it is possible that we were underpowered to detect smaller effects resulting in an increased chance of type II errors. Second, by counterbalancing the order of assessment some participants received biperiden at the first assessment. Since we did not conduct a baseline assessment without any intervention, we had to correct our findings for the placebo cognitive functioning for the counterbalance order thereby further reducing statistical power. Future studies should include a larger sample and a baseline assessment to reduce practice effects. Third, although drug administration was at all times supervised by the test leader to ensure actual drug intake by the participants, we were not able to verify the effects of biperiden in plasma as we did not measures biperiden plasma concentrations. The strongest effects of $M_{1}$ blockade on cognition are expected to occur at the $T_{\max }$ of biperiden. Since we did not measure biperiden plasma concentrations we tested to 2,5 hours after drug administration to ensure that $T_{\max }$ was reached. However, therefore we were not able to correlate plasma concentration to cognitive performance. Moreover, it may have been better to use a lower dose of biperiden. A dose of $4 \mathrm{mg}$. is relatively high and may have produced large effects in both groups thereby masking potential differential effects of biperiden. However, the total score on the side effects scale was in both groups not significantly higher compared to placebo. 
In conclusion, we provide further in-vivo evidence that the $M_{1}$ receptor is involved in cognitive functioning, particularly verbal and visual memory processes. The lack of differential effects of biperiden between subjects with a psychotic disorder and healthy controls may suggest that decreased $M_{1}$ receptor density is only present in chronic schizophrenia patients with more severe cognitive symptoms. However, it remains possible differential effects of biperiden would be present in more severe cognitive impaired subjects with psychosis after several doses of biperiden instead of a single administration. 


\section{References}

1. Perälä J, Suvisaari J, Saarni SI, Kuoppasalmi K, Isometsä E, Pirkola S, et al. Lifetime prevalence of psychotic and bipolar I disorders in a general population. Arch Gen Psychiatry. 2007;64(1):19-28.

2. Reichenberg A, Weiser M, Caspi A, Knobler HY, Lubin G, Harvey PD, et al. Premorbid intellectual functioning and risk of schizophrenia and spectrum disorders. J Clin Exp Neuropsychol. 2006;28(2):193-207.

3. Vingerhoets WAM, Bloemen OJN, Bakker G, van Amelsvoort TAMJ. Pharmacological Interventions for the MATRICS Cognitive Domains in Schizophrenia: What's the Evidence? Front psychiatry. 2013;4:157.

4. Heinrichs RW. The primacy of cognition in schizophrenia. Am Psychol. 2005;60(3):229-42.

5. Green MF, Kern RS, Heaton RK. Longitudinal studies of cognition and functional outcome in schizophrenia: implications for MATRICS. Schizophr Res. 2004;72(1):41-51.

6. Green MF. What are the functional consequences of neurocognitive deficits in schizophrenia? Am J Psychiatry. 1996;153:321-30.

7. Prouteau A, Verdoux H, Briand C, Lesage A, Lalonde P, Nicole L, et al. Cognitive predictors of psychosocial functioning outcome in schizophrenia: a follow-up study of subjects participating in a rehabilitation program. Schizophr Res. 2005;77(2-3):343-53.

8. Burton SC. Strategies for improving adherence to second-generation antipsychotics in patients with schizophrenia by increasing ease of use. J Psychiatr Pract. 2005;11(6):369-78.

9. Chen EY-H, Hui CL-M, Dunn EL-W, Miao MY-K, Yeung W-S, Wong C-K, et al. A prospective 3year longitudinal study of cognitive predictors of relapse in first-episode schizophrenic patients. Schizophr Res. 2005;77(1):99-104.

10. Nuechterlein KH, Barch DM, Gold JM, Goldberg TE, Green MF, Heaton RK. Identification of separable cognitive factors in schizophrenia. Schizophr Res. 2004;72(1):29-39.

11. Levaux M-N, Potvin S, Sepehry AA, Sablier J, Mendrek A, Stip E. Computerized assessment of cognition in schizophrenia: promises and pitfalls of CANTAB. Eur Psychiatry. 2007;22(2):10415.

12. Friedman JI. Cholinergic targets for cognitive enhancement in schizophrenia: focus on cholinesterase inhibitors and muscarinic agonists. Psychopharmacology. 2004;174(1):45-53.

13. Broks P, Preston GC, Traub M, Poppleton P, Ward C, Stahl SM. Modelling dementia: Effects of scopolamine on memory and attention. Neuropsychologia. 1988;26(5):685-700.

14. Fadda P, Robinson L, Fratta W, Pertwee RG, Riedel G. Scopolamine and MK801-induced working memory deficits in rats are not reversed by CBD-rich cannabis extracts. Behav Brain Res. 2006;168(2):307-11.

15. Klinkenberg I, Blokland A. The validity of scopolamine as a pharmacological model for cognitive impairment: a review of animal behavioral studies. Neurosci Biobehav Rev. 2010;34(8):1307-50.

16. Hodges DB, Lindner MD, Hogan JB, Jones KM, Markus EJ. Scopolamine induced deficits in a battery of rat cognitive tests: comparisons of sensitivity and specificity. Behav Pharmacol. 2009;20(3):237-51.

17. Ebert, Kirch. Scopolamine model of dementia: electroencephalogram findings and cognitive performance. Eur J Clin Invest. 1998;28(11):944-9.

18. Wesnes K, Simpson P, Kidd A. An investigation of the range of cognitive impairments induced by scopolamine 0.6 mg s.c. Hum Psychopharmacol Clin Exp. 1988;3(1):27-41.

19. Raedler T, Bymaster F, Tandon R, Copolov D, Dean B. Towards a muscarinic hypothesis of schizophrenia. Mol Psychiatry. 2007;12:232-46. 
20. Bymaster FP, McKinzie DL, Felder CC, Wess J. Use of M1-M5 Muscarinic Receptor Knockout Mice as Novel Tools to Delineate the Physiological Roles of the Muscarinic Cholinergic System. Neurochem Res. 2003;28(3/4):437-42.

21. Levey Al. Immunological localization of $\mathrm{m} 1-\mathrm{m} 5$ muscarinic acetylcholine receptors in peripheral tissues and brain. Life Sci. 1993;52(5-6):441-8.

22. Crook JM, Ph D, Tomaskovic-crook E, Hons BS, Dean B. Low Muscarinic Receptor Binding in Prefrontal Cortex From Subjects With Schizophrenia : and the Effects of Neuroleptic Drug Treatment. 2001;158:918-25.

23. Dean B, Crook J, Opeskin K, Hill C, Keks N, Copolov D. The density of muscarinic M1 receptors is decreased in the caudate-putamen of subjects with schizophrenia. Mol Psychiatry.

1996;1:54-8.

24. Crook JM, Tomaskovic-Crook E, Copolov DL, Dean B. Decreased muscarinic receptor binding in subjects with schizophrenia: a study of the human hippocampal formation. Biol Psychiatry. 2000;48(5):381-8.

25. Gibbons AS, Scarr E, Boer S, Money T, Jeon W-J, Felder C, et al. Widespread decreases in cortical muscarinic receptors in a subset of people with schizophrenia. Int J Neuropsychopharmacol. 2013;16(1):37-46.

26. Dean B, Mcleod M, Keriakous D, Mckenzie J, Scarr E. Decreased muscarinic 1 receptors in the dorsolateral prefrontal cortex of subjects with schizophrenia. Mol Psychiatry. 2002;7(10):1083-91.

27. Carruthers SP, Gurvich CT, Rossell SL. The muscarinic system, cognition and schizophrenia. Neurosci Biobehav Rev. 2015;55:393-402.

28. Scarr E, Cowie TF, Kanellakis S, Sundram S, Pantelis C, Dean B. Decreased cortical muscarinic receptors define a subgroup of subjects with schizophrenia. Mol Psychiatry.

2009;14(11):1017-23.

29. Scarr E, Keriakous D, Crossland N, Dean B. No change in cortical muscarinic M2, M3 receptors or [35S]GTPyS binding in schizophrenia. Life Sci. 2006;78(11):1231-7.

30. Shekhar A, Potter WZ, Lightfoot J, Lienemann J, Dubé S, Mallinckrodt C, et al. Selective muscarinic receptor agonist xanomeline as a novel treatment approach for schizophrenia. Am J Psychiatry. 2008;165(8):1033-9.

31. Veselinović T, Vernaleken I, Janouschek H, Kellermann T, Paulzen M, Cumming P, et al. Effects of anticholinergic challenge on psychopathology and cognition in drug-free patients with schizophrenia and healthy volunteers. Psychopharmacology. 2015;232(9):1607-17.

32. Velthorst E, Levine SZ, Henquet C, de Haan L, van Os J, Myin-Germeys I, et al. To cut a short test even shorter: reliability and validity of a brief assessment of intellectual ability in schizophrenia--a control-case family study. Cogn Neuropsychiatry. 2013;18(6):574-93.

33. Andreasen NC. The Comprehensive Assessment of Symptoms and History (CASH). Arch Gen Psychiatry. 1992;49(8):615.

34. Kay SR, Qpjer LA. The Positive and Negative Syndrome Scale (PANSS) for Schizophrenia. Schizophr Bull. 1987;13(2):261-76.

35. Klinkenberg I, Blokland A, Riedel W, Sambeth A. Human electrophysiological correlates of learned irrelevance: effects of the muscarinic M1 antagonist biperiden. Int J Neuropsychopharmacol. 2012;15(10):1375-85.

36. Barnett JH, Robbins TW, Leeson VC, Sahakian BJ, Joyce EM, Blackwell AD. Assessing cognitive function in clinical trials of schizophrenia. Neurosci Biobehav Rev. 2010;34(8):1161-77.

37. Bolden C, Cusack B, Richelson E. Antagonism by antimuscarinic and neuroleptic compounds at the five cloned human muscarinic cholinergic receptors expressed in Chinese hamster ovary cells. J Pharmacol Exp Ther. 1992;260(2):576-80. 
38. Sambeth A, Riedel WJ, Klinkenberg I, Kähkönen S, Blokland A. Biperiden selectively induces memory impairment in healthy volunteers: no interaction with citalopram.

Psychopharmacology. 2015;232(11):1887-97.

39. Hollmann M, Brode E, Greger G, Muller-Peltzer H, Wetzelsberger N. Biperiden effects and plasma levels in volunteers. Eur J Clin Pharmacol. 1984;27(5):619-21.

40. Mintzer J, Burns A. Anticholinergic side-effects of drugs in elderly people. J R Soc Med. 2000;93(9):457-62.

41. Klinkenberg I, Blokland A. A comparison of scopolamine and biperiden as a rodent model for cholinergic cognitive impairment. Psychopharmacology. 2011;215(3):549-66.

42. Silver $\mathrm{H}$, Geraisy N. Effects of biperiden and amantadine on memory in medicated chronic schizophrenic patients. A Double-blind cross-over study. Br J Psychiatry. 1995;166(2).

43. Wezenberg E, Verkes RJ, Sabbe BGC, Ruigt GSF, Hulstijn W. Modulation of memory and visuospatial processes by biperiden and rivastigmine in elderly healthy subjects. Psychopharmacology. 2005;181(3):582-94.

44. Desmarais JE, Beauclair L, Annable L, Bélanger M-C, Kolivakis TT, Margolese HC. Effects of discontinuing anticholinergic treatment on movement disorders, cognition and psychopathology in patients with schizophrenia. Ther Adv Psychopharmacol. 2014;4(6):25767.

45. Ogino S, Miyamoto S, Miyake N, Yamaguchi N. Benefits and limits of anticholinergic use in schizophrenia: Focusing on its effect on cognitive function. Psychiatry Clin Neurosci. 2014;68(1):37-49.

46. Anagnostaras SG, Murphy GG, Hamilton SE, Mitchell SL, Rahnama NP, Nathanson NM, et al. Selective cognitive dysfunction in acetylcholine M1 muscarinic receptor mutant mice. Nat Neurosci. 2003;6(1):51-8.

47. Hasselmo ME, Stern CE. Mechanisms underlying working memory for novel information. Trends Cogn Sci. 2006;10(11):487-93.

48. Keefe RS., Goldberg TE, Harvey PD, Gold JM, Poe MP, Coughenour L. The Brief Assessment of Cognition in Schizophrenia: reliability, sensitivity, and comparison with a standard neurocognitive battery. Schizophr Res. 2004;68(2):283-97. 




\section{Chapter | 4}

Cholinergic neurotransmission and cognition in psychosis: a placebo-controlled, cross-over MRS study

Claudia Vingerhoets, Geor Bakker, Marieke van der Pluijm, Oswald Bloemen, Matthan Caan, Jan Booij, Thérèse van Amelsvoort 


\begin{abstract}
Background: An increasing number of studies recognize a role of the muscarinic cholinergic system in psychosis and cognitive dysfunction. Increased choline concentrations and reduced muscarinic $M_{1}$ receptor expression have been reported in schizophrenia. Also, animal studies have shown an increase in brain choline concentrations after administration of a muscarinic antagonist. The present study investigated the role of brain choline levels; its responsivity to $M_{1}$ receptor blockage, and its relation to cognitive function in psychosis.
\end{abstract}

Methods: 32 medication-free subjects with a psychotic disorder and 31 gender, age and IQ-matched healthy control subjects underwent ${ }^{1} \mathrm{H}$-proton magnetic resonance spectroscopy $\left({ }^{1} \mathrm{H}-\mathrm{MRS}, \mathrm{PRESS}\right)$, twice, and choline concentrations were measured in the anterior cingulate cortex (ACC) and striatum after placebo or one single dose of $4 \mathrm{mg}$ of biperiden. In addition, the relation between choline concentrations in these regions and cognition and symptom severity was examined.

Results: No significant differences were found in both ACC and striatal choline levels between the two groups after placebo. Moreover, $M_{1}$ blockade did not significantly affect choline levels in these regions. However, in subjects with a psychotic disorder, but not in healthy controls, striatal choline levels were inversely correlated with attention $(p=0.025)$ and positively correlated at trend level with negative symptom severity $(p=0.059)$ under placebo.

Conclusion: These results suggest a role for the cholinergic system in cognition in psychosis in that striatal choline levels were inversely correlated with attention. The lack of group differences in choline concentrations, both after biperiden and placebo, could indicate that there were no severe cholinergic abnormalities present in our psychotic sample, although they might be present in chronic schizophrenia patients with more severe symptoms. 


\section{Introduction}

The majority of patients with schizophrenia or other psychotic disorders report cognitive impairments in addition to positive and negative symptoms (1). These cognitive impairments are predictive of poor functional outcome, tendency for relapse and poor medication compliance and treatment adherence (2). Because the neurobiological mechanisms underlying cognitive functioning in psychosis are mostly unknown, at present, effective treatment options are not yet available (3). More insight in the underlying mechanisms of cognitive functioning is highly necessary as this can contribute to the development of better treatment strategies or even prevention as cognitive symptoms often precede other symptoms of psychosis (4).

A growing number of studies implicated the cholinergic system in both cognitive function and psychosis $(5,6)$. The neurotransmitter acetylcholine (Ach) plays an important role in motor function but also in various domains of cognition, particularly attention, learning, and memory $(7,8)$. Ach is synthesized from a reaction between acetyl-co-enzyme $A$ and choline (cho) and is then catalyzed by cho acetyltransferase and stored in synaptic vesicles (9). Hence, the rate of Ach synthesis is most dependent on the availability of cho (9). Although Ach concentrations in the brain cannot be directly measured, proton magnetic resonance spectroscopy $\left({ }^{1} \mathrm{H}-\mathrm{MRS}\right)$ allows for the in-vivo measurement of cho in the brain in a non-invasive manner. Since free Ach is converted into the inactive metabolites cho and acetate by the enzyme acetylcholinesterase (10), cho levels may be an acceptable proxy for non-invasive measurement of cholinergic neurotransmission (11). Indeed, studies in rodents have shown that a single dose of the muscarinic antagonist scopolamine led to an marked increase in Ach concentrations in the striatum, frontal cortex and hippocampus (12-14). Moreover, striatal cho concentrations increased after scopolamine injections in rodents (14).

Previous ${ }^{1} \mathrm{H}$-MRS studies in psychosis compared to healthy controls demonstrated higher cho levels in the dorsolateral prefrontal cortex (DLPFC) of medicated firstepisode and chronic schizophrenia patients (15), the caudate nucleus of medication-free first-episode and schizophrenia patients $(16,17)$ and the dorsal anterior cingulate in medicated schizophrenia patients (18), which suggests altered cholinergic neurotransmission in psychosis. Moreover, cho concentrations in the thalamus and anterior cingulate have been found to be positively correlated to duration of untreated psychosis (19). However, not all studies reported differences in cho concentrations between patients with schizophrenia or schizoaffective disorder and healthy control subjects (20-24). These discrepancies in findings are probably related to differences in methodological approach and differences in 
sample sizes. Furthermore, it is unknown whether cho concentration is related to cognitive functioning in these patients.

Because Ach primarily binds to the muscarinic and nicotinic receptors in the brain, cognitive impairment could be related to altered production of this neurotransmitter and/or dysfunction of these receptors. Previous (post-mortem) studies have found decreased expression of both nicotinic (25-27) and muscarinic receptors in patients with schizophrenia (28-32) and both groups of receptors play an important role in cognitive functioning in general $(5,33)$. However, with the exception of encenicline, nicotinic receptor ( $\alpha_{7}$ subtype) agonists have shown limited beneficial effects for treatment of cognitive symptoms in schizophrenia and are associated with cardiotoxicity (34). On the other hand, the muscarinic receptor $\left(\mathrm{M}_{1 / 4}\right)$ agonist xanomeline improved memory and clinical symptoms in schizophrenia (35). Furthermore, a single dose of the $M_{1}$ receptor antagonist biperiden impaired executive functioning (36) and memory (37) in patients with schizophrenia. This suggests that cognition in patients with a psychotic disorder may be improved by stimulating cholinergic neurotransmission via muscarinic $M_{1 / 4}$ receptors.

With this study we aimed to compare cho (a proxy for cholinergic neurotransmission) concentrations between subjects with a psychotic disorder and healthy control subjects as well as the influence of a $M_{1}$ receptor antagonist (biperiden) on cho concentrations. The vast majority of the muscarinic receptor subtypes $\left(M_{1}-M_{5}\right)$ in the brain belong to the muscarinic receptor subtype $1\left(M_{1}\right.$ (38)) which is expressed most abundantly in the cortex, striatum and hippocampus (39), brain regions indispensable to normal cognitive functioning. Biperiden was chosen as a cholinergic challenge because it is the most selective $M_{1}$ receptor antagonist available for use in humans (40).

In addition, we examined whether cho concentrations are related to cognitive functioning and symptom severity in psychosis. Based on previous findings, it was hypothesized that compared to healthy controls, subjects with a psychotic disorder would have higher cho concentrations in the anterior cingulate cortex (ACC) and striatum. Furthermore, based on findings of increased Ach and cho after ACh receptor blockade in rodents, we hypothesized that administration of biperiden will significantly increase cho concentrations in both groups. Finally, based on previous findings of altered cholinergic neurotransmission in patients with schizophrenia and the role of Ach in cognition, we hypothesized that cho concentrations would be inversely correlated with cognitive functioning in psychosis. 


\section{Methods}

This study was approved by the Medical Ethical Committee of the Academic Medical Center (AMC) in Amsterdam. All participants gave written informed consent prior to participation after the study procedure had been explained to them.

\section{Participants}

32 (22 males and 10 females) medication-free subjects with a psychotic disorder (mean age 27.66 years) and 31 (20 males and 11 females) gender, age and IQmatched healthy control subjects (mean age 25.45 years) were included in the study. Within the psychosis group, 14 subjects were diagnosed with a psychotic disorder not otherwise specified, 13 with schizophrenia, 2 with schizophreniform disorder and 3 were diagnosed with schizoaffective disorder. Subjects with a psychotic disorder were recruited via specialized mental health care institutions and advertisement in national newspapers and on internet. Healthy controls were recruited via advertisement on internet. For the subjects with a psychotic disorder inclusion criteria were: a confirmed diagnosis of a psychotic disorder (diagnosis of bipolar disorder or psychotic depression was an exclusions criterion), aged between 18 and 40 years, no use of antipsychotics or anticholinergics and onset of psychosis no longer than 10 years prior to participation. Three patients using lowdose antipsychotic medication at time of inclusion that were willing to participate underwent a wash-out period of 5 times the mean terminal elimination half-life of the specific antipsychotic prior to participation. Patients using olanzapine or clozapine were excluded from participation because of the capacity of these drugs to occupy muscarinic receptors (41)). One participant was using quetiapine (200 $\mathrm{mg})$, one patient used flupentixol $(0.5 \mathrm{mg}$ ) and one used haloperidol (1 $\mathrm{mg})$. Exclusion criteria for both groups were: contra-indications for biperiden or MRI, severe neurological or comorbid psychiatric disorders and illicit drug use 4 weeks prior to participation. In addition, healthy controls with a first degree relative with a psychotic disorder were also excluded from participation as well as pregnant females. All participants were instructed to abstain from alcohol and nicotine at least 24 hours prior to testing. Abstinence of recreational drugs was verified with a urine drug screening prior to testing. Despite these instructions 4 subjects with a psychotic disorder tested positive prior to the placebo measurement (two for cocaine, one for cannabis, and one for benzodiazepines) and one psychotic subject tested positive for cannabis and cocaine prior to the biperiden measurement. Therefore, the analyses were repeated without these participants to test whether this influenced the results. 


\section{Instruments}

Diagnosis of a psychotic disorder was validated with The Comprehensive Assessment of Symptoms and History (CASH, (42)) in subjects with a psychotic disorder and to exclude such a diagnosis in the healthy control group. The Positive and Negative Syndrome Scale (PANSS, (43)) was conducted to measure psychotic symptoms severity at time of assessment. On both occasions, potential side effects of biperiden were measured by means of a 31-items self-report questionnaire which included items such as nausea, headache and dry mouth. Participants were asked to report to what extend they experienced these symptoms on a 4-point scale with 0 indicating not affected and 3 very affected (44). A shortened version of the Wechsler Adult Intelligence Scale (WAIS III, (45)) was used to determine the Intelligence quotient (IQ) of the participants.

Cognitive functions on separated domains were measured with the Cambridge Neuropsychological Automated Test Battery (CANTAB (46)). We used the schizophrenia test battery (extended with a social cognition task) as this battery covers all cognitive domains that have been found to be significantly impaired in schizophrenia (47). The CANTAB is a well validated, automated test battery and found to be sensitive for effects of pharmaceutical agents (48). A brief description of the different subtests and outcome measures is displayed in table 1.

\section{Procedure}

This study had a single blind, placebo-controlled, cross-over design. All participants were scanned twice on separate occasions, once after placebo and once after oral administration of biperiden. The order of drug administration was counterbalanced so that in each group half of the participant received placebo first and the other half biperiden. To ensure complete drug wash out, the time interval between both test days was at least one week. The scan protocol was similar for both test days. All participants were instructed to abstain from alcohol and nicotine 24 hours prior to testing. On both test days, prior to scanning a urine drugs screening was conducted to verify abstinence of recreational drugs (cannabis, cocaine, benzodiazepines, opiates, amphetamines, methamphetamines). After the drug screening the medication (placebo or biperiden) was administered orally. To measure cho concentrations, participants underwent two ${ }^{1} \mathrm{H}-\mathrm{MRS}$ scanning sessions on each occasion, once after administration of a cholinergic challenge (4 mg biperiden) and once after receiving a placebo (cellulose, corn starch, Placebo Wit) tablet. Drug intake was at all times supervised to make sure the participant indeed swallowed the pills. Central pharmacodynamic effects of biperiden peak 
around 90 minutes (49). Therefore, MRS scanning commenced 90 minutes after administration of placebo/biperiden. During this 90 minute waiting period, the $\mathrm{CASH}$ and the PANSS were conducted. The side effects questionnaire was always conducted at $T_{\max }$ of biperiden just prior to scanning. The CANTAB and shortened version of the WAIS-III were always conducted before administration of medication to eliminate confounding effects. Both test days lasted approximately 4 hours. Subjects were reimbursed for participation.

Table 1. Overview of CANTAB tasks and outcome measures

\begin{tabular}{|c|c|c|c|c|}
\hline Domain & Task & Task description & Outcome measures & Direction \\
\hline $\begin{array}{l}\text { Visual } \\
\text { learning \& } \\
\text { memory }\end{array}$ & $\begin{array}{l}\text { Paired } \\
\text { Associate } \\
\text { Learning } \\
\text { (PAL) }\end{array}$ & $\begin{array}{l}\text { Boxes are } \\
\text { displayed on a } \\
\text { screen which } \\
\text { open in a } \\
\text { randomized } \\
\text { order. One or } \\
\text { more of the boxes } \\
\text { contain a pattern. } \\
\text { Participants must } \\
\text { remember and } \\
\text { identify the } \\
\text { correct location of } \\
\text { the patterns. }\end{array}$ & $\begin{array}{l}\text { Total errors (adjusted } \\
\text { for stages completed) } \\
\text { First trial memory score } \\
\text { (total number of } \\
\text { patterns correctly } \\
\text { located after first trial } \\
\text { across completed } \\
\text { stages) }\end{array}$ & $\begin{array}{l}\text { Lower is } \\
\text { better } \\
\text { Higher is } \\
\text { better }\end{array}$ \\
\hline $\begin{array}{l}\text { Verbal } \\
\text { learning \& } \\
\text { memory }\end{array}$ & $\begin{array}{l}\text { Verbal } \\
\text { Recognition } \\
\text { Memory } \\
\text { (VRM) }\end{array}$ & $\begin{array}{l}\text { Participants are } \\
\text { shown } 12 \text { words } \\
\text { and afterwards } \\
\text { had to reproduce } \\
\text { as many words as } \\
\text { possible as well as }\end{array}$ & $\begin{array}{l}\text { Free recall total words } \\
\text { correct } \\
\text { Immediate recognition } \\
\text { total correct }\end{array}$ & $\begin{array}{l}\text { Higher is } \\
\text { better } \\
\text { Higher is } \\
\text { better }\end{array}$ \\
\hline & & $\begin{array}{l}\text { to recognize the } \\
\text { words from a list } \\
\text { of } 24 \text { words. } \\
\text { Recognition phase } \\
\text { was repeated } \\
\text { after } 20 \text { minutes. }\end{array}$ & $\begin{array}{l}\text { Delayed recognition } \\
\text { total correct }\end{array}$ & $\begin{array}{l}\text { Higher is } \\
\text { better }\end{array}$ \\
\hline $\begin{array}{l}\text { Working } \\
\text { memory }\end{array}$ & $\begin{array}{l}\text { Spatial } \\
\text { Working } \\
\text { Memory } \\
\text { (SWM) }\end{array}$ & $\begin{array}{l}\text { A self-ordered } \\
\text { task which tests a } \\
\text { person's ability to } \\
\text { retain spatial } \\
\text { information and } \\
\text { to manipulate this } \\
\text { information. }\end{array}$ & $\begin{array}{l}\text { Total errors } \\
\text { Strategy }\end{array}$ & $\begin{array}{l}\text { Lower is } \\
\text { better } \\
\text { Lower is } \\
\text { better }\end{array}$ \\
\hline
\end{tabular}




\begin{tabular}{|c|c|c|c|c|}
\hline Domain & Task & Task description & Outcome measure & Direction \\
\hline \multirow[t]{2}{*}{$\begin{array}{l}\text { Attention \& } \\
\text { vigilance }\end{array}$} & $\begin{array}{l}\text { Rapid Visual } \\
\text { Processing } \\
\text { (RVP) }\end{array}$ & $\begin{array}{l}\text { Participants had } \\
\text { to detect target } \\
\text { sequences of } \\
\text { digits. }\end{array}$ & $\begin{array}{l}\text { A'prime (measure of } \\
\text { how good a subject } \\
\text { detects a target } \\
\text { sequences using total } \\
\text { hits and total false } \\
\text { alarms) }\end{array}$ & $\begin{array}{l}\text { Higher is } \\
\text { better }\end{array}$ \\
\hline & & & Mean latency & $\begin{array}{l}\text { Lower is } \\
\text { better }\end{array}$ \\
\hline \multirow[t]{2}{*}{$\begin{array}{l}\text { Processing } \\
\text { Speed }\end{array}$} & $\begin{array}{l}\text { Reaction Time } \\
\text { (RTI) }\end{array}$ & $\begin{array}{l}\text { Measures the } \\
\text { speed of response } \\
\text { to a visual target }\end{array}$ & $\begin{array}{l}\text { Simple reaction } \\
\text { (response to stimulus } \\
\text { in a single, } \\
\text { predictable location) }\end{array}$ & $\begin{array}{l}\text { Lower is } \\
\text { better }\end{array}$ \\
\hline & & & $\begin{array}{l}\text { 5-choice reaction } \\
\text { (response to a } \\
\text { stimulus in any of } 5 \\
\text { locations). }\end{array}$ & $\begin{array}{l}\text { Lower is } \\
\text { better }\end{array}$ \\
\hline $\begin{array}{l}\text { Reasoning } \\
\& \\
\text { problem } \\
\text { solving }\end{array}$ & $\begin{array}{l}\text { One Touch } \\
\text { Stockings of } \\
\text { Cambridge } \\
\text { (OTS) }\end{array}$ & $\begin{array}{l}\text { Spatial planning } \\
\text { task based on the } \\
\text { Tower of London } \\
\text { test. Participants } \\
\text { had to identify } \\
\text { how many moves } \\
\text { are required to } \\
\text { solve a problem }\end{array}$ & $\begin{array}{l}\text { Total number of } \\
\text { problems solved on } \\
\text { first choice }\end{array}$ & $\begin{array}{l}\text { Higher is } \\
\text { better }\end{array}$ \\
\hline $\begin{array}{l}\text { Social } \\
\text { cognition }\end{array}$ & $\begin{array}{l}\text { Emotion } \\
\text { Recognition } \\
\text { Test (ERT) }\end{array}$ & $\begin{array}{l}\text { Participants were } \\
\text { shown a series of } \\
\text { faces showing } \\
\text { specific primary } \\
\text { emotions and } \\
\text { choose the } \\
\text { emotion that } \\
\text { most closely } \\
\text { corresponded to } \\
\text { the emotion } \\
\text { shown in the face }\end{array}$ & $\begin{array}{l}\text { Total number of } \\
\text { correct identified } \\
\text { emotions }\end{array}$ & $\begin{array}{l}\text { Higher is } \\
\text { better }\end{array}$ \\
\hline
\end{tabular}




\section{Biperiden}

Biperiden (Akineton ${ }^{(}$, instant release, Knoll AG) belongs to the class of anticholinergic medication and is a muscarinic receptor antagonist. Clinically, biperiden is used for treatment of Parkinson's disease and extrapyramidal side effects induced by (first generation) antipsychotics. It is the most selective $M_{1}$ antagonist available for use in humans $(40,50)$ given its 10 -fold higher affinity for $M_{1}$ receptors compared to the $M_{2}-M_{5}$ receptors. The elimination constant of a single dose is initially steep and after 6 hours there is approximately $12 \%$ biperiden plasma concentration after which the elimination constant slowly levels off. Plasma levels are clear of biperiden 18 hours after administration, thereby restricting duration of potential side effects (49). Most commonly reported side effects (long term use) are drowsiness, headache, dizziness, blurred vision, dry mouth and obstipation (51). The dose of $4 \mathrm{mg}$ given in this study, lies within the interval of therapeutically recommended daily doses (1-4 $\mathrm{mg}$ ).

\section{Magnetic Resonance Spectroscopy}

${ }^{1} \mathrm{H}-\mathrm{MRS}$ data were acquired at the Department of Radiology (Academic Medical Centre Amsterdam, The Netherlands) using a 3 Tesla Ingenia MRI system (Philips, Best, The Netherlands), equipped with a 32 channel sense head coil. Metabolite concentrations were obtained for each subject from an $8 \mathrm{ml}(2 \times 2 \times 2)$ voxel of interest, manually positioned in the ACC and striatum (Figure 1). Iterative first order shimming was performed and spectra were acquired using a point-resolved spatially localized spectroscopy sequence (PRESS, TE=45 ms, TR=2000 ms, 96 averages). For anatomical localization transversal high-resolution structural T1weighted volumetric images, with full head coverage (180 slices; TR = $7.0 \mathrm{~ms}$; TE = $3.2 \mathrm{~ms}$; FOV = 256x240 mm; voxel size: $1.0 \times 1.0 \times 1.0 \mathrm{~mm}, 180$ slices) were acquired. ${ }^{1} \mathrm{H}-\mathrm{MRS}$ spectra were analyzed using the Linear Combination of Model spectra (LCModel) commercial spectral-fitting package (52). LCModel uses a library of reference spectra in a basis set recorded specifically for the scanner and calibrates using the tissue water signal as an internal standard. From the metabolites included in the LCModel basis set, we analyzed levels of the cho containing compounds glycerophosphocholine + phosphocholine (choline). MRS cho concentration was expressed as the ratio of cho by creatine (Cho/ $\mathrm{Cr}$ ), to reduce signal-to-noise ratio as creatine is considered a stable metabolite in the brain (Figure 2). Spectra with a Cramer-Rao Lower Bound (CRLB) higher than 20\% were considered poor quality and were excluded from further analyses (1 healthy control subject). The acquired T1-weighted image was segmented into percentage grey matter (GM), white matter (WM) and cerebrospinal fluid (CSF) using Statistical Parametric Mapping 12 
(SPM8, Wellcome Department of Imaging Neurosciences, University College London, UK). Subsequently the spectrocopic values were corrected for CSF fraction.

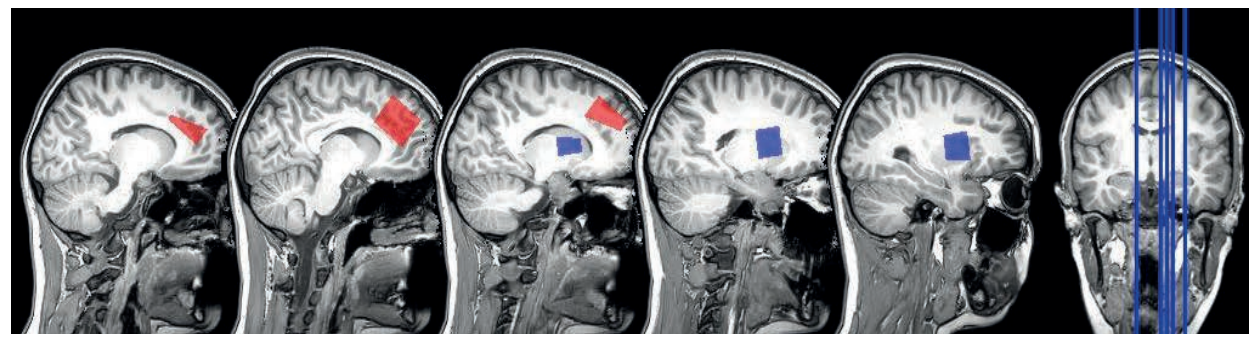

Figure 1. Voxel placement. The red box indicates the voxel placement in the anterior cingulate cortex. The blue box indicates the voxel placement in the striatum.

\section{Data-analyses}

All statistical analyses were performed with IBM SPSS Statistics, version 23. Differences in demographic variables (gender, age and IQ) and in PANSS scores and side-effects were analyzed by means of independent samples t-tests for continuous variables and chi-square tests for categorical variables. To measure a change in side effect, and whether this differed between both groups, a delta score was computed by subtracting the total score on the side-effects questionnaire after placebo from the total score after biperiden ( $\Delta$ side effects equals biperiden placebo). A univariate analysis of variance (ANOVA) was conducted to examine differences in ACC and striatal cho levels after placebo between subjects with a psychotic disorder and healthy controls. To examine the effects of biperiden on cho levels in both the ACC and striatum (main effect) as well as differential effects of biperiden on cho levels (medication $x$ group interaction) between subjects with a psychotic disorder and healthy controls, a repeated measures ANOVA was performed. Regarding cognitive analyses, first cognitive domain scores were computed by converting the raw scores into standardized Z-scores. Positive Zscores larger than 3 and negative scores larger than -3 were considered outliers and removed from further (cognitive) analyses. Then, the outcome measures where a lower score represents better performance were reversed so that a higher score represents better performance for all outcome measures. Subsequently, cognitive domain scores were computed by adding the standardized Z-scores of each domain (table 1). Finally, Pearson's correlation coefficient was computed to 
examine the relation between cho concentration in these regions and separate cognitive domains and psychotic symptom severity (PANSS scores).

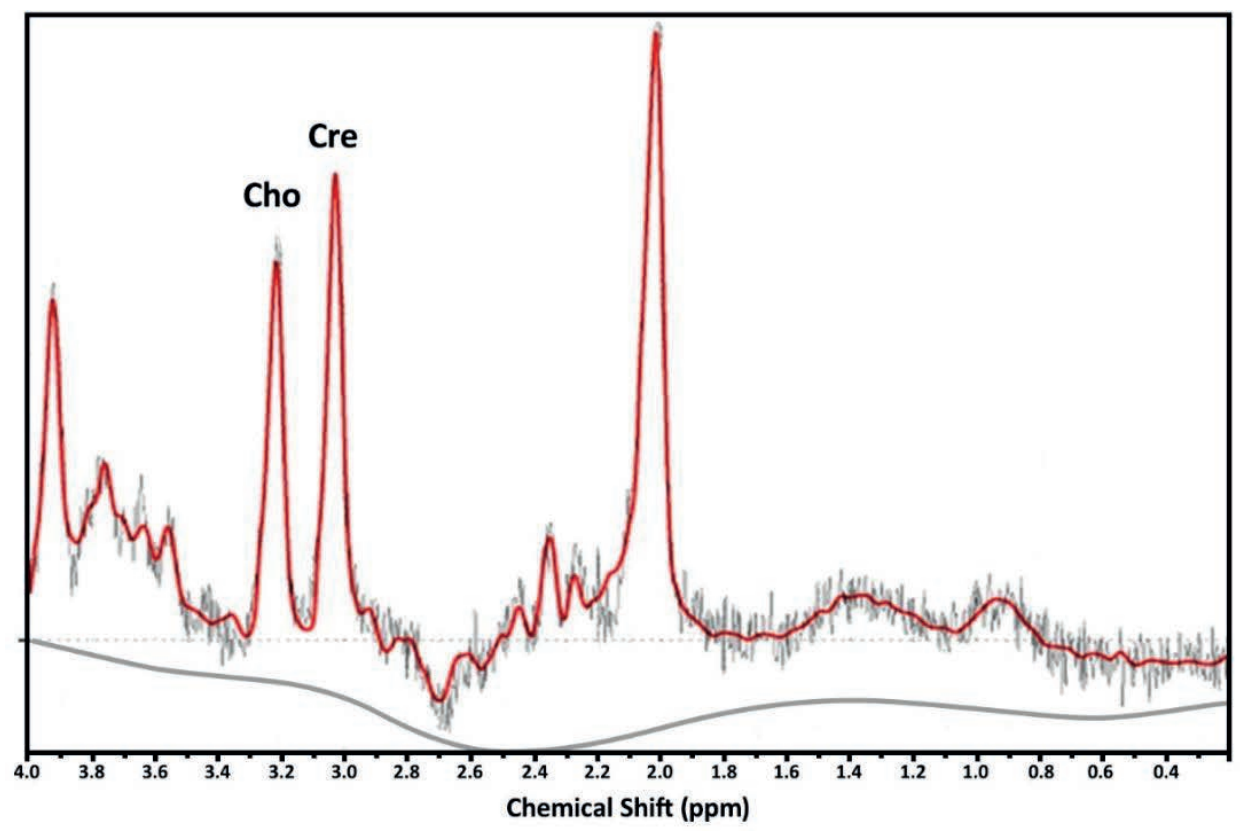

Figure 2. Example of a striatal spectrum derived from a healthy control subject. Choline resonates at 3.2 chemical shift. Creatine resonates at 3.0 chemical shift.

\section{Results}

The two groups did not significantly differ in terms of gender $\left(\chi^{2}(1)=0.13, p=\right.$ $0.793)$, age $(t(1,61)=-1.68, p=0.098)$ and IQ $(t(1,61)=1.72, p=0.090)$. As expected, subjects with a psychotic disorder scored higher on all subscales of the PANSS (positive symptoms $(t(1,61)=-6.05, p<0.001)$, negative symptoms $(t(1,61)$ $=-4.66, p<0.001)$, general psychopathology $(t(1,61)=-4.93, p<0.001)$ and total PANSS score $(t(1,61)=-6.07, p<0.001)$. Sample demographics are displayed in table 2. Subjects with a psychotic disorder reported significantly more unwanted effects in both the placebo $(t(1,61)=-3.29, p=0.002)$ and the biperiden condition $(t(1,55)=-2.08, p=0.042)$. However, delta scores for unwanted effects (total score biperiden - total score placebo) did not differ significantly between groups $(t(1,55)$ $=0.13, p=0.488$ ) indicating that biperiden did not cause significant unwanted effects in both groups. 
Table 2 Sample demographics.

\begin{tabular}{lcccc}
\hline & Psychosis & Healthy controls & & \\
\hline & Mean (SD) & Mean (SD) & Statistic & $\boldsymbol{P}$ \\
\hline Gender (male/female) & $22 / 10$ & $20 / 11$ & 0.13 & 0.793 \\
Age & $27.66(5.39)$ & $25.45(5.00)$ & -1.68 & 0.098 \\
IQ & $100.22(15.03)$ & $106.81(15.31)$ & 1.72 & 0.090 \\
Side effect severity placebo & $13.22(10.81)$ & $5.50(7.19)$ & -3.29 & $\mathbf{0 . 0 0 2}$ \\
Side effect severity biperiden & $13.55(12.14)$ & $7.86(8.07)$ & -2.08 & $\mathbf{0 . 0 4 2}$ \\
SSide effect severity (b-p) & $0.33(14.28)$ & $2.36(8.38)$ & 0.13 & 0.488 \\
PANSS & & & & \\
Positive symptoms & $11.56(4.17)$ & $7.10(0.30)$ & -6.05 & $<0.001$ \\
$\quad$ Negative symptoms & $11.81(5.16)$ & $7.42(1.34)$ & -4.66 & $<0.001$ \\
$\quad$ General psychiatry & $23.06(6.32)$ & $16.84(3.28)$ & -4.93 & $<0.001$ \\
$\quad$ Total score & $46.50(13.36)$ & $31.35(4.52)$ & -6.07 & $<\mathbf{0 . 0 0 1}$ \\
\hline
\end{tabular}

NB: IQ: Intelligence Quotient; $\Delta$ Side effect severity (b-p): total score on the side effects scale biperiden - total score on the side effects scale placebo; PANSS: Positive and Negative Syndrome Scale.

\section{Choline concentrations in the placebo condition}

No significant differences were found in both cho concentrations in both the ACC $(F(1,55)=1.288 ; p=0.261)$ and the striatum $(F(1,52)=0.677 ; p=0.415)$ between the two groups in the placebo condition (table 3 , Figure 3 ).

Table 3. Baseline choline concentrations.

\begin{tabular}{lccccccc}
\hline \multicolumn{7}{c}{ Psychosis } & \multicolumn{3}{c}{ Healthy controls } \\
\hline & $\mathbf{N}$ & Mean (SD) & $\mathbf{N}$ & Mean (SD) & F-Statistic & $\boldsymbol{P}$ & $\boldsymbol{\eta}^{2}$ \\
\hline ACC choline & 29 & $0.248(0.024)$ & 28 & $0.241(0.025)$ & 1.288 & 0.261 & 0.023 \\
Striatal choline & 29 & $0.238(0.023)$ & 25 & $0.234(0.025)$ & 0.677 & 0.415 & 0.013
\end{tabular}

NB: ACC: anterior cingulate cortex. Metabolite concentrations reported are the choline /creatine ratios. Analyses were repeated without the participants who tested positive on drug urine screening yielding comparable results. 

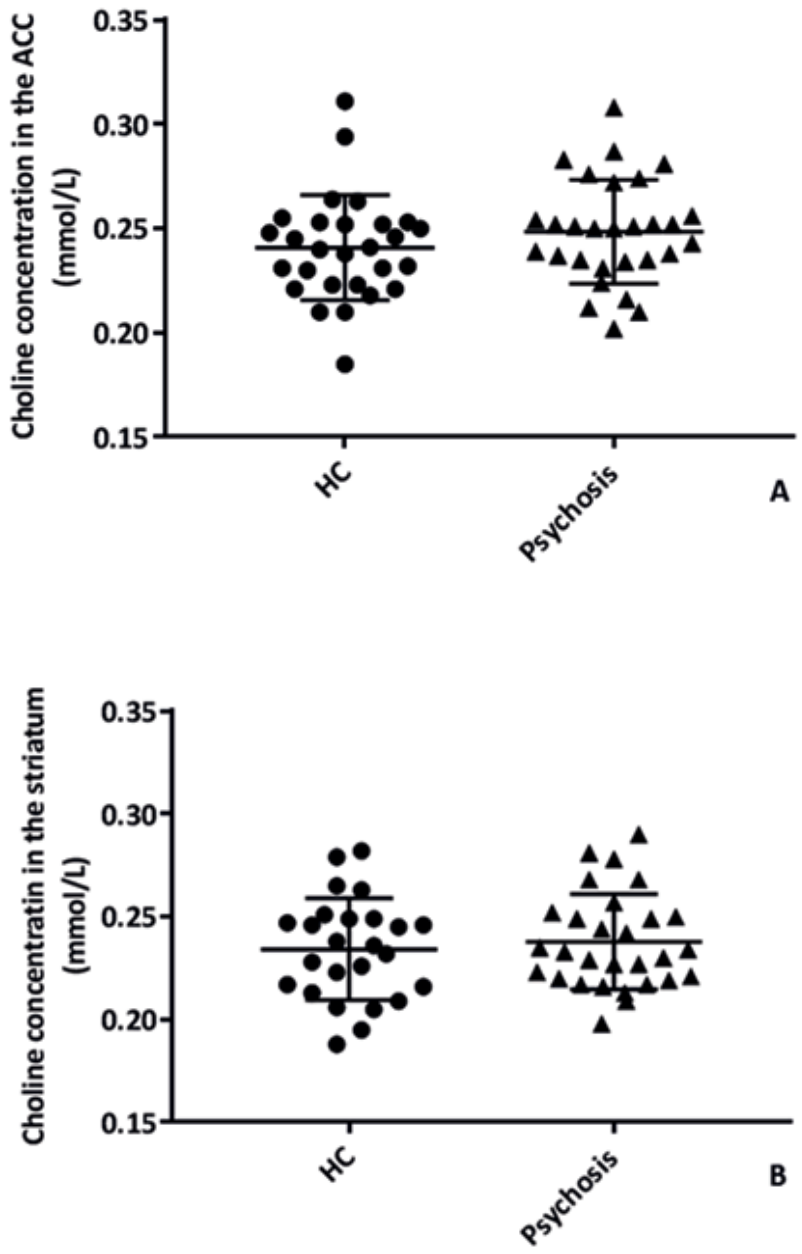

Figure 3. Figure A displays the distribution of choline concentrations (ratio choline / creatine) in the anterior cingulate cortex after placebo.

Figure $\mathrm{B}$ displays the distribution of choline concentrations (ratio choline / creatine) in the striatum after placebo. 


\section{Effect of biperiden on choline concentrations}

Biperiden did not have a significant main effect on cho concentrations in the ACC $(F(1,40)=0.256 ; p=0.615)$ and in the striatum $(F(1,41)=0.148 ; p=0.703)$. In addition, no significant group $x$ medication interaction effect was found in both the $\operatorname{ACC}(F(1,40)=2.893 ; p=0.097)$ and the striatum $(F(1,41)=0.003 ; p=0.957$, table 4, Figure $4 A)$.
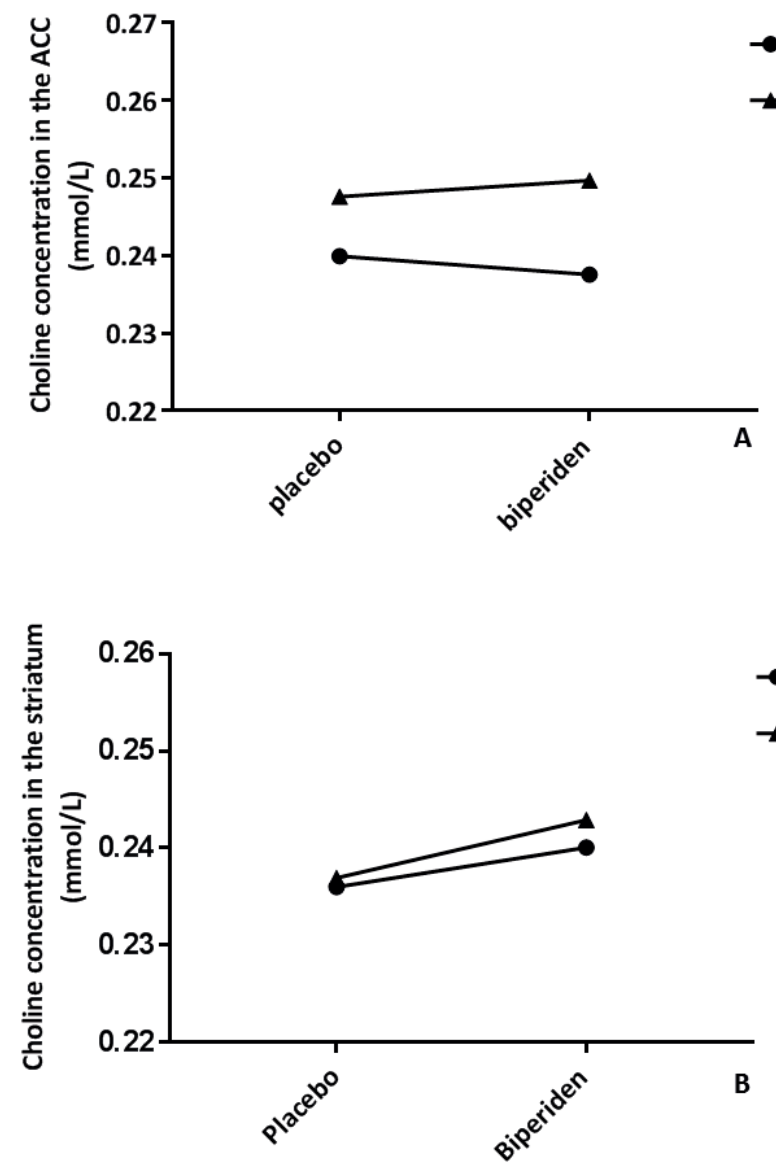

Figure 4. Figure $4 \mathrm{~A}$ displays the effects of biperiden on choline concentrations (ratio choline / creatine) in the ACC in both groups. Figure 4B displays the effect of biperiden on choline concentrations (ratio choline / creatine) in the striatum in both groups. 


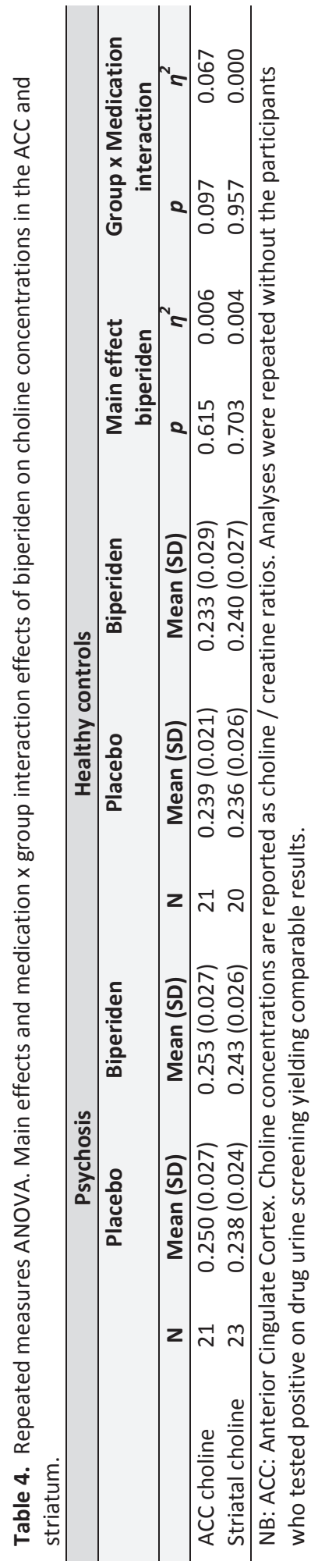


Relation between choline concentrations and cognition and psychotic symptoms

Striatal cho concentration was negatively associated with attention in the psychotic subjects ( $r=-0.422, n=28, p=0.025)$; higher cho concentrations were related to poorer attention (Figure 5). No such correlation was found in the healthy control group $(r=-0.074, n=23, p=0.731)$. Cho concentrations in the ACC were not significantly related to any of the cognitive domains. With regard to psychotic symptom severity, a trend level significant correlation was found between severity of negative symptoms and striatal cho concentrations $(r=0.355, n=29, p=0.059)$. None of the other PANSS subscales correlated significantly with striatal cho concentrations. Moreover, no significant correlation was found between cho concentrations in the ACC and the psychotic symptoms severity.

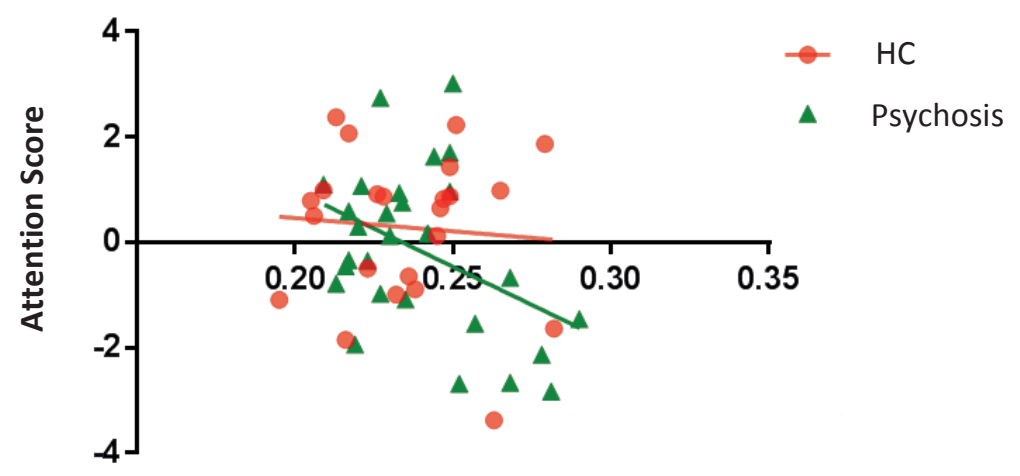

Striatal choline ( $\mathrm{mmol} / \mathrm{L})$

Figure 5. The relation between striatal choline concentrations and attention. 
Discussion

With this study we aimed to investigate whether there are differences in cho concentrations in the ACC and striatum between medication-free subjects with a psychotic disorder and healthy controls, and whether cho concentrations in these regions increase when blocking the muscarinic $M_{1}$ receptor. Contrary to our hypothesis, we did not find differences in striatal and ACC cho concentrations between subjects with a psychotic disorder and healthy controls. Based on findings of altered cholinergic neurotransmission in patients with schizophrenia (25-32), we expected that subjects with a psychotic disorder would have elevated cho levels in the ACC and striatum in comparison to healthy controls. Since findings in rodents showed increases in both free Ach and cho after blockade of the muscarinic receptors, this could implicate that there were no muscarinic abnormalities present in our psychosis sample. However, since biperiden is highly selective for $M_{1}$ receptors and has less affinity for other muscarinic subtypes, abnormalities in other muscarinic receptors or nicotinic receptors cannot be ruled out. Moreover, since we only measured cho in the ACC and striatum, we cannot rule out that there are differences in cho concentrations in other regions of the brain. Nevertheless, although results are inconsistent, previous MRS studies have demonstrated increased cho levels in first-episode and chronic schizophrenia in the DLPFC, caudate nucleus (part of the striatum) and the dorsal anterior cingulate (15-18). This discrepancy in findings could be related to methodological differences and sample characteristics. Two important differences between studies is the use of absolute concentrations versus creatine ratios and correction for CSF. The amount of CSF differs between subjects and disturbs the MRS signal. Therefore, results that are corrected for CSF are more reliable than uncorrected findings. The studies that did not find significant differences in cho levels between patients and controls (20-24) more often used smaller sample sizes and lower MRI field-strength (1.5 Tesla). This could indicate that differences in cho are subtle and therefore are only detected in larger samples or with a higher magnetic field strength (more reliable measurements can be obtained with higher field strength). Moreover, the lack of difference in cho concentrations between the two groups could be related to the sample characteristics of our psychosis group. We included a relatively small sample and the majority of the subjects with a psychotic disorder were not diagnosed with schizophrenia but with psychotic 
disorder not otherwise specified, schizoaffective or schizophreniform disorder, most often because their psychotic episode lasted shorter than 6 months. Possibly, our inclusion of medication-free patients may have led to inclusion of relatively stable patients with shorter duration and less severity of psychotic symptoms. Indeed, the studies describing increased cho concentrations more often included patients with (chronic) schizophrenia whereas studies with negative results tended to include first episode psychosis patient. This could indicate that altered cho concentrations are only present in chronic schizophrenia. Additionally, a positive correlation has been reported between duration of untreated psychosis and cho levels, indicating that cho concentrations may increase as the disease progresses. Moreover, we found a significant inverse correlation between attention as well as a trend level significant correlation with negative symptoms severity and striatal cho concentrations in subjects with a psychotic disorder whereas no such correlation was found in healthy controls. This could be indicative of altered cholinergic neurotransmission only in subjects with a psychotic disorder displaying more severe symptoms.

Contrary to our hypothesis, a single administration of the $M_{1}$ antagonist biperiden had no significant influence on cho concentrations in the ACC and striatum. We expected cho concentrations to increase after biperiden based on increased levels of both Ach and cho found in the striatum, frontal cortex and hippocampus of rodents after a single dose of scopolamine, which is a non-selective muscarinic antagonist (12-14). One possible explanation for the lack of a significant of biperiden on cho levels could be that a single dose of biperiden is not sufficient to detect subtle increases in cho concentrations in humans. Therefore, future studies investigating the role of cho and cholinergic neurotransmission in psychosis and comorbid cognitive symptoms should use long term treatment with biperiden. Also, the present findings could also indicate that instead of $M_{1}$ receptors, other muscarinic receptors such as the $M_{4}$ receptor subtype, which is also highly abundant in the striatum (53), play a more robust role in the altered cholinergic neurotransmission and associated cognitive impairment observed in patients with a psychotic disorder. Indeed, xanomeline which has been found to improve memory in patients with schizophrenia (35) as it has high affinity for both the $M_{1}$ and $M_{4}$ receptor. Another possibility that needs to be considered is that altered cho concentrations observed in schizophrenia are more strongly 
related with nicotinic receptor dysfunction since decreased nicotinic receptor expression has also been reported in several (post-mortem) studies (25-27). This hypothesis would be in line with the correlation we found between attention and striatal cho concentrations. Nicotinic receptor functioning has been repeatedly found to be associated with attention in both human and animal studies and although results are inclusive, nicotine and nicotinic agonist have been found to improve attention in schizophrenia (54). Unfortunately, studies that investigated cho concentrations in psychosis did not take cognitive measures into account. Therefore, the relationship between cho and attention should be examined further in future studies using pharmacological agents that selectively target the muscarinic $M_{4}$ receptor subtype or nicotinic receptors. Another possibility would be to use pharmacological agents that target Ach more directly such as acetylcholinesterase (enzyme that breaks down Ach thereby increasing choline) inhibitors, although there use may be limited by their side-effects .

Finally, the trend level significant positive association between striatal cho concentrations and negative symptom severity could implicate that the cholinergic system is involved in the negative symptoms of psychosis in addition to its role in cognitive function. Indeed, xanomeline, an $M_{1 / 4}$ receptor agonist was found to improve positive and negative symptoms in patients with schizophrenia, as well as memory (35). However, anticholinergics have been found to modestly improve negative symptoms in patients with schizophrenia (6). At present, not much is known about the relation between the cholinergic system and negative symptoms. Therefore, future studies should address this.

\section{Strengths and limitations}

An important strength of the present study is that unlike most other studies, the results are not confounded by present medication use since only medication-free subjects with a psychotic disorder were included. However, as outlined above, this also could have caused a selection bias of participants with less severe psychotic symptoms. In addition, by conducting an extensive cognitive test-battery, we were able to directly correlate functioning on separate cognitive domains to brain cho levels. However, when interpreting these findings some limitations have to be taken into account as well. First, the sample size was relatively small, resulting in limited power and an increase chance of a type II error. 
Second, we did not obtain blood samples from the participants to verify effects of biperiden in plasma, but the tablets were administered under supervision. Although subjects were scanned at the theoretical $\mathrm{T}_{\max }$ of biperiden, when the strongest effects of $M_{1}$ blockade on cho are expected to occur, we cannot rule out intersubject differences on the $T_{\max }$. Finally, we did not directly measure $M_{1}$ receptor availability and occupancy by biperiden. $M_{1}$ binding potential (a combined measure of receptor affinity and density), and occupancy by $M_{1}$ antagonist like biperiden, can be measured in-vivo using single photon emission computed tomography (SPECT) or photon emission tomography (PET) techniques and would have been a valuable additional measurement in this study (55). A combined measure of cho concentrations and $M_{1}$ receptors and its occupancy by biperiden as well as cognitive functioning in subjects with a psychotic disorder and healthy controls could provide important insight in this complex relation.

In conclusion, this study did not provide evidence for differences in striatal and ACC cho concentrations between subjects with a psychotic disorder and healthy controls nor an effect of $M_{1}$ receptor blockade with a single administration of biperiden on cho concentrations in both these regions. However, the inverse correlation between striatal cho levels and attention in the subjects whit a psychotic disorder implicates a role for cholinergic neurotransmission in this domain of cognition. 


\section{References}

1. Reichenberg A, Weiser M, Caspi A, Knobler HY, Lubin G, Harvey PD, et al. Premorbid intellectual functioning and risk of schizophrenia and spectrum disorders. J Clin Exp Neuropsychol. 2006;28(2):193-207.

2. Chen EYH, Hui CLM, Dunn ELW, Miao MYK, Yeung WS, Wong CK, et al. A prospective 3year longitudinal study of cognitive predictors of relapse in first-episode schizophrenic patients. Schizophr Res. 2005;77(1):99-104.

3. Vingerhoets WAM, Bloemen OJN, Bakker G, van Amelsvoort TAMJ. Pharmacological Interventions for the MATRICS Cognitive Domains in Schizophrenia: What's the Evidence? Front psychiatry. 2013;4:157.

4. Heinrichs RW. The primacy of cognition in schizophrenia. Am Psychol. 2005;60(3):22942.

5. Carruthers SP, Gurvich CT, Rossell SL. The muscarinic system, cognition and schizophrenia. Neurosci Biobehav Rev. 2015;55:393-402.

6. Raedler T, Bymaster F, Tandon R, Copolov D, Dean B. Towards a muscarinic hypothesis of schizophrenia. Mol Psychiatry. 2007;12:232-46.

7. Friedman J. Cholinergic targets for cognitive enhancement in schizophrenia: focus on cholinesterase inhibitors and muscarinic agonists. Psychopharmacology. 2004;174(1):45-53.

8. Klinkenberg I, Sambeth A, Blokland A. Acetylcholine and attention. Behav Brain Res. 2011;221(2):430-42.

9. Sarter M, Parikh V. Choline transporters, cholinergic transmission and cognition. Nat Rev Neurosci. 2005;6(1):48-56.

10. Artenie VG, Artenie GR, Ciobîcă A-S, Hriţcu L. CURRENT ASPECTS REGARDING THE ACETYLCHOLINE METABOLISM. Analele Ştiinţifice ale Univ „Alexandru Ioan CuzaAlexandru Ioan Cuza. 2010;11:1-10.

11. Parikh V, Pomerleau F, Huettl P, Gerhardt GA, Sarter M, Bruno JP. Rapid assessment of in vivo cholinergic transmission by amperometric detection of changes in extracellular choline levels. Eur J Neurosci. 2004;20(6):1545-54.

12. Watanabe H, Shimizu H. Effect of Anticholinergic Drugs on Striatal Acetylcholine Release and Motor Activity in Freely Moving Rats Studied by Brain Microdialysis. Jpn J Pharmacol. 1989;51:75-82.

13. Durkin TP, Messier C, de Boer P, Westerink BHC. Raised glucose levels enhance scopolamine-induced acetylcholine overflow from the hippocampus: an in vivo microdialysis study in the rat. Behav Brain Res. 1992;49(2):181-8.

14. Day J, Damsma G, Fibiger HC. Cholinergic activity in the rat hippocampus, cortex and striatum correlates with locomotor activity: An in vivo microdialysis study. Pharmacol Biochem Behav. 1991;38(4):723-9.

15. Kirtaş D, Karadağ RF, Balci Şengül MC, Kiroğlu Y. 1H-magnetic resonance spectroscopy in first episode and chronic schizophrenia patients. Turkish J Med Sci. 2016;46(3):86271.

16. Plitman E, de la Fuente-Sandoval C, Reyes-Madrigal F, Chavez S, Gómez-Cruz G, LeónOrtiz P, et al. Elevated Myo-Inositol, Choline, and Glutamate Levels in the Associative Striatum of Antipsychotic-Naive Patients With First-Episode Psychosis: A Proton Magnetic Resonance Spectroscopy Study With Implications for Glial Dysfunction. Schizophr Bull. 2016;42(2):415-24. 
17. Bustillo JR, Rowland LM, Lauriello J, Petropoulos H, Hammond R, Hart B, et al. High choline concentrations in the caudate nucleus in antipsychotic-naive patients with schizophrenia. Am J Psychiatry. 2002;159(1):130-3.

18. Bustillo JR, Chen H, Jones T, Lemke N, Abbott C, Qualls C, et al. Increased glutamine in patients undergoing long-term treatment for schizophrenia: a proton magnetic resonance spectroscopy study at 3 T. JAMA psychiatry. American Medical Association; 2014;71(3):265-72.

19. Théberge J, Al-Semaan Y, Drost DJ, Malla AK, Neufeld RW., Bartha R, et al. Duration of untreated psychosis vs. $\mathrm{N}$-acetylaspartate and choline in first episode schizophrenia: a $1 \mathrm{H}$ magnetic resonance spectroscopy study at 4.0 Tesla. Psychiatry Res Neuroimaging. 2004;131(2):107-14.

20. Block W, Bayer TA, Tepest R, Träber F, Rietschel M, Müller DJ, et al. Decreased frontal lobe ratio of $\mathrm{N}$-acetyl aspartate to choline in familial schizophrenia: a proton magnetic resonance spectroscopy study. Neuroscience Letters. 2000;289:147-151.

21. Kalaycı D, Özdel O, Sözeri-Varma G, Kıroğlu Y, Tümkaya S. A proton magnetic resonance spectroscopy study in schizoaffective disorder: Comparison of bipolar disorder and schziophrenia. Prog Neuro-Psychopharmacology Biol Psychiatry. 2012;37(1):176-81.

22. Uhl I, Mavrogiorgou P, Norra C, Forstreuter F, Scheel M, Witthaus $H$, et al. $1 \mathrm{H}-\mathrm{MR}$ spectroscopy in ultra-high risk and first episode stages of schizophrenia. J Psychiatr Res. 2011;45(9):1135-9.

23. Zabala A, Sánchez-González J, Parellada M, Moreno DM, Reig S, Burdalo MT, et al. Findings of proton magnetic resonance spectometry in the dorsolateral prefrontal cortex in adolescents with first episodes of psychosis. Psychiatry Res Neuroimaging. 2007; 156(1):33-42.

24. Galińska B, Szulc A, Tarasów E, Kubas B, Dzienis W, Czernikiewicz A, et al. Duration of untreated psychosis and proton magnetic resonance spectroscopy (1H-MRS) findings in first-episode schizophrenia. Med Sci Monit. 2009;15(2):CR82-88.

25. Freedman R, Hall M, Adler LE, Leonard S. Evidence in postmortem brain tissue for decreased numbers of hippocampal nicotinic receptors in schizophrenia. Biol Psychiatry. 1995;38(1):22-33.

26. Court J, Spurden D, Lloyd S, McKeith I, Ballard C, Cairns N, et al. Neuronal nicotinic receptors in dementia with lewy bodies and schizophrenia: $\alpha$-bungarotoxin and nicotine binding in the thalamus. J Neurochem. 1999;73(4):1590-7.

27. Marutle A, Zhang X, Court J, Piggott M, Johnson M, Perry R, et al. Laminar distribution of nicotinic receptor subtypes in cortical regions in schizophrenia. J Chem Neuroanat. 2001;22(1):115-26.

28. Crook JM, Ph D, Tomaskovic-crook E, Hons BS, Dean B. Low Muscarinic Receptor Binding in Prefrontal Cortex From Subjects With Schizophrenia: and the Effects of Neuroleptic Drug Treatment. Am J Psychiatry. 2001;158:918-25.

29. Dean B, Crook J, Opeskin K, Hill C, Keks N, Copolov D. The density of muscarinic M1 receptors is decreased in the caudate-putamen of subjects with schizophrenia. Mol Psychiatry. 1996;1:54-8.

30. Crook JM, Tomaskovic-Crook E, Copolov DL, Dean B. Decreased muscarinic receptor binding in subjects with schizophrenia: a study of the human hippocampal formation. Biol Psychiatry. 2000;48(5):381-8. 
31. Gibbons AS, Scarr E, Boer S, Money T, Jeon W-J, Felder C, et al. Widespread decreases in cortical muscarinic receptors in a subset of people with schizophrenia. Int J Neuropsychopharmacol. 2013;16(1):37-46.

32. Dean B, Mcleod M, Keriakous D, Mckenzie J, Scarr E. Decreased muscarinic 1 receptors in the dorsolateral prefrontal cortex of subjects with schizophrenia. Mol Psychiatry. 2002;7(10):1083-91.

33. Wallace TL, Porter RHP. Targeting the nicotinic alpha7 acetylcholine receptor to enhance cognition in disease. Biochem Pharmacol. 2011;82(8):891-903.

34. Beinat C, Banister SD, Herrera M, Law V, Kassiou M. The Therapeutic Potential of $\alpha 7$ Nicotinic Acetylcholine Receptor ( $\alpha 7 \mathrm{nAChR}$ ) Agonists for the Treatment of the Cognitive Deficits Associated with Schizophrenia. CNS Drugs. 2015;29(7):529-42.

35. Shekhar A, Potter WZ, Lightfoot J, Lienemann J, Dubé S, Mallinckrodt C, et al. Selective muscarinic receptor agonist xanomeline as a novel treatment approach for schizophrenia. Am J Psychiatry. 2008;165(8):1033-9.

36. Veselinović T, Vernaleken I, Janouschek H, Kellermann T, Paulzen M, Cumming P, et al. Effects of anticholinergic challenge on psychopathology and cognition in drug-free patients with schizophrenia and healthy volunteers. Psychopharmacology. 2015;232(9):1607-17.

37. Vingerhoets W, Bakker G, van Dijk J, Bloemen O, Booij J, van Amelsvoort T. The effect of the muscarinic M1 receptor antagonist biperiden on cognition in medication free subjects with psychosis. Submitted.

38. Levey Al. Immunological localization of $\mathrm{m} 1-\mathrm{m} 5$ muscarinic acetylcholine receptors in peripheral tissues and brain. Life Sci. Pergamon; 1993;52(5-6):441-8.

39. Levey Al, Kitt CA, Simonds WF, Price DL, Brann MR. Identification and localization of muscarinic acetylcholine receptor proteins in brain with subtype-specific antibodies. J Neurosci. 1991;11(10):3218-26.

40. Sambeth A, Riedel WJ, Klinkenberg I, Kähkönen S, Blokland A. Biperiden selectively induces memory impairment in healthy volunteers: no interaction with citalopram. Psychopharmacology. 2015;232(11):1887-97.

41. Bilder RM, Goldman RS, Volavka J, Czobor P, Hoptman M, Sheitman B, et al. Neurocognitive Effects of Clozapine, Olanzapine, Risperidone, and Haloperidol in Patients With Chronic Schizophrenia or Schizoaffective Disorder. Am J Psychiatry. 2002;159(6):1018-28.

42. Andreasen NC. The Comprehensive Assessment of Symptoms and History (CASH). Arch Gen Psychiatry. 1992;49(8):615.

43. Kay SR, Qpjer LA. The Positive and Negative Syndrome Scale (PANSS) for Schizophrenia. Schizophr Bull. 1987;13(2):261-76.

44. Klinkenberg I, Blokland A, Riedel W, Sambeth A. Human electrophysiological correlates of learned irrelevance: effects of the muscarinic M1 antagonist biperiden. Int J Neuropsychopharmacol. 2012;15(10):1375-85.

45. Velthorst E, Levine SZ, Henquet C, de Haan L, van Os J, Myin-Germeys I, et al. To cut a short test even shorter: reliability and validity of a brief assessment of intellectual ability in schizophrenia--a control-case family study. Cogn Neuropsychiatry. 2013;18(6):574-93.

46. Levaux M-N, Potvin S, Sepehry AA, Sablier J, Mendrek A, Stip E. Computerized assessment of cognition in schizophrenia: promises and pitfalls of CANTAB. Eur Psychiatry. 2007;22(2):104-15. 
47. Nuechterlein KH, Barch DM, Gold JM, Goldberg TE, Green MF, Heaton RK. Identification of separable cognitive factors in schizophrenia. Schizophr Res. 2004;72(1):29-39.

48. Barnett JH, Robbins TW, Leeson VC, Sahakian BJ, Joyce EM, Blackwell AD. Assessing cognitive function in clinical trials of schizophrenia. Neurosci Biobehav Rev. 2010;34(8):1161-77.

49. Hollmann M, Brode E, Greger G, Müller-Peltzer H, Wetzelsberger N. Biperiden effects and plasma levels in volunteers. Eur J Clin Pharmacol. 1984;27(5):619-21.

50. Bolden C, Cusack B, Richelson E. Antagonism by antimuscarinic and neuroleptic compounds at the five cloned human muscarinic cholinergic receptors expressed in Chinese hamster ovary cells. J Pharmacol Exp Ther. 1992;260(2):576-80.

51. Mintzer J, Burns A. Anticholinergic side-effects of drugs in elderly people. J R Soc Med. Royal Society of Medicine Press; 2000;93(9):457-62.

52. Provencher SW. Automatic quantitation of localized in vivo $1 \mathrm{H}$ spectra with LCModel. NMR Biomed. 2001;14(4):260-4.

53. Bymaster FP, McKinzie DL, Felder CC, Wess J. Use of M1-M5 Muscarinic Receptor Knockout Mice as Novel Tools to Delineate the Physiological Roles of the Muscarinic Cholinergic System. Neurochem Res. 2003;28:437-42.

54. Ripoll N, Bronnec M, Bourin M. Nicotinic receptors and schizophrenia. Curr Med Res Opin. 2004;20:1057-74.

55. Bakker G, Vingerhoets WA, van Wieringen J-P, de Bruin K, Eersels J, de Jong J, et al. 1231 -iododexetimide preferentially binds to the muscarinic receptor subtype M1 in vivo. J Nucl Med. 2015;56(2):317-22. 



\section{Part II}

Neurobiological mechanisms underlying substance use 


\section{Chapter | 5}

Relationship between working-memory network function and substance use: a 3-year longitudinal fMRI study in heavy cannabis users and controls

Janna Cousijn, Wilhelmina A.M. Vingerhoets, Laura Koenders, Lieuwe de Haan, Wim van den Brink, Reinout Wiers, Anna E. Goudriaan.

Addiction Biology, 2013, 19:282-293. 


\section{Abstract}

Deficient executive functions play an important role in the development of addiction. Working-memory may therefore be a powerful predictor of the course of drug use, but chronic substance use may also impair working-memory. The aim of this three-year longitudinal neuroimaging study was to investigate the relationship between substance use (e.g., alcohol, cannabis, nicotine, illegal psychotropic drugs) and workingmemory network function over time in heavy cannabis users and controls. Forty-nine participants performed an N-Back working-memory task at baseline and at three-year follow-up. At follow-up there were 22 current heavy cannabis users, 4 abstinent heavy cannabis users, and 23 noncannabis using controls. Tensor Independent Component Analysis (Tensor-ICA) was used to investigate individual differences in workingmemory network functionality over time. Within the group of cannabis users, cannabis related problems remained stable whereas alcohol related problems, nicotine dependence, and illegal psychotropic substance use increased over time. At both measurements, behavioral performance and network functionality during the N-Back task did not differ between heavy cannabis users and controls. Although N-back accuracy improved, working-memory network function remained stable over time. Within the group of cannabis users, working-memory network functionality was not associated with substance use. These results demonstrate that functionality of the network remains at normative levels over time, implying that sustained moderate to heavy levels of cannabis, nicotine, alcohol, and illegal psychotropic substance use do not impair working-memory network functionality. Moreover, baseline network-functionality did not predict cannabis use and related problems three years later, warranting longitudinal studies in more chronic or dependent cannabis users. 


\section{Introduction}

Approximately half of near-daily cannabis users meet DSM-IV criteria for cannabis dependence (1). Little is known, however, about the neurobiology underlying continued cannabis use and the potential progression towards dependence. Addiction models suggest that the imbalance between strong drug-oriented motivational processes (cuereactivity, craving) and compromised regulatory executive functions (disinhibition) plays an important role in trajectory from recreational use towards dependence (2-4).

Working-memory refers to the capacity to retain and manipulate online information and its integrity is required for many cognitive functions $(5,6)$. Working-memory capacity constrains attentional control and is especially important when behavior is triggered that conflicts with our pursued goals (6). This suggests that individuals with working-memory deficits may more easily give in to the urge to use. Indeed, working memory deficits appear common across different SUD populations including cannabis dependence (7). Also, associations between substance use and motivational processes like craving and cue-reactivity are stronger in individuals with relatively poor working-memory $(8,9)$. Moreover, working-memory deficits have been found to predict the development alcohol dependence (10) and relapse in smokers (11), whereas training of working-memory may be effective in SUD treatment $(12,13)$.

We previously showed that stronger connectivity within the workingmemory network during an N-Back working-memory task was related to an increase in cannabis use six months later (14). Behavioral performance and functionality (in terms of connectivity and activity) of the network did not differ between heavy cannabis users and control. This frontoparietal network consists of the dorsolateral prefrontal cortex (DLPFC), ventrolateral prefrontal cortex (VLPFC), premotor cortex, lateral/medial parietal cortex, paracingulate gyrus, and frontal pole $(15,16)$. Within the working-memory network, connectivity and activity generally increase with higher working-memory load levels (i.e., (14-16). Working-memory impairments have been linked to hyperactivity of the network $(15,16)$. Contrasting our earlier findings (14), chronic cannabis users generally show increased network activity during a working-memory task compared to non-using controls, despite similar task performance (17-21). Stronger connectivity and activity within the network have therefore been hypothesized to reflect increased effort to perform the task. 
Relatively poor working-memory and suboptimal functioning of the associated brain network may be a pre-existing risk factor for cannabis use disorders (14). The development of a SUD may also aversively influence functioning of prefrontal brain areas, resulting in impaired cognitive functioning (22). Moreover, drug specific neurotoxic effects may worsen cognitive functioning. $\Delta 9$-tetrahydrocannabinol (THC), the main psychoactive component of cannabis, binds predominately to the endogenous Cannabinoid Receptor-1 (CB1) (23). Animal studies have shown neurotoxic effects of chronic THC exposure resulting in structural and functional brain changes of brain areas with high CB1 levels like the prefrontal cortex (24). Human studies investigating the neurocognitive and potential neurotoxic effects of chronic cannabis exposure show contradicting findings. Both acute and chronic cannabis exposure have been associated with working-memory impairments, however, many studies investigating the association between cannabis exposure and working-memory impairments fail to find a dose-response relationship (i.e., $(14,19,25,26))$. Moreover, cannabis abstinence may restore workingmemory capacity $(21,27)$. Nevertheless, a recent 20 -year longitudinal study showed a decline in working-memory throughout adolescence in adolescent heavy cannabis users, suggesting neurotoxic effects of cannabis exposure during adolescent brain development (28). In sum, it appears that working-memory deficits and functional alterations of the underlying brain network are evident in cannabis dependent individuals and that age of onset plays an important role in the potential neurotoxic and neuroplastic consequences of chronic cannabis exposure $(7,28,29)$.

The primary goal of the present study was to elucidate the relationship between substance use and working-memory network functionality (connectivity and activity) in heavy cannabis users over time. At baseline and at three-year follow-up, heavy cannabis users and matched controls performed an N-Back working-memory task during which brain activity was recorded. Additionally, a detailed history of substance use and related problems was obtained at both measurements. Similarly to our previous study, Tensor Independent Component Analysis (Tensor-ICA, (30)) was used to identify and investigate functional characteristics of the working-memory network $(15,16)$. For the first time, it was investigated if exposure to cannabis, alcohol, nicotine, and illegal psychotropic substances (i.e., cocaine, heroine, amphetamine, XTC) was associated with deteriorating working-memory network functionality over this three- 
year period. We expected poor working-memory network functionality to be a pre-existing risk factor for SUDs rather than a (neurotoxic) consequence of prolonged cannabis use. We therefore did not expect working memory related network functionality to change over time in the heavy cannabis users or to correlate with quantitative measures of cannabis use.

In the present sample of heavy cannabis users we previously observed a predictive relationship between working-memory network functionality and cannabis use six months later (14). The secondary goal of this study therefore was to investigate if we could replicate our prior findings: Can working-memory network functionality as identified with ICA at baseline also predict cannabis use three years later?

\section{Materials and methods}

The present study was part of a 3-year longitudinal study investigating the effect of neurocognitive processes on the course of cannabis use in heavy cannabis users (14,31-33). In the current report only participants performing the $\mathrm{N}$-back at baseline and at 3-year follow-up are included in the analyses. The medical ethical committee of the Academic Medical Centre of the University of Amsterdam approved the study and all participants signed informed consent prior to participation. Participants were financially compensated for their participation.

\section{Participants}

A total of 49 participants performed the N-Back working-memory task at baseline and at 3-year follow-up. At baseline, 23 were treatment naïve heavy cannabis users and 26 were healthy matched non-cannabis using controls. At 3-year follow-up, 4 heavy cannabis users discontinued their cannabis use for at least 4 months (abstinence ranged between 120-640 days), whereas 3 controls became heavy cannabis users. For various reasons ${ }^{1}, 9$ out of 33 heavy cannabis users at baseline did not participate

1 The study was originally designed as a prospective neuroimaging study with a baseline neuroimaging test session and a 6-month follow-up telephone interview. Additional funding (from the Academic Medical Center) gave the opportunity to include a neuroimaging test-session after 3 years. At 3-year follow-up participants were contacted again using the phone number, email, and home address information they provided at 6-month follow-up. Contact was lost with 2 heavy cannabis users at 6-months follow-up and with 2 additional heavy cannabis users at 
at follow-up (attrition 27\%). Neuroimaging data at baseline was missing from one heavy cannabis user due to scanning issues. A Little's Missing Completely At Random (MCAR; (34)) test with all study variables indicated that these non-responders were missing at random $\left(\chi^{2}=80.93, d f=108\right.$, $p=0.98)$. At baseline, participants were aged $18-25$ and recruited through advertisements on the Internet and in cannabis outlets. Groups were matched for age, gender, education, premorbid intellectual functioning (35), and alcohol use (36). All heavy cannabis users used cannabis on more than 10 days per month for at least 1.5 years at baseline. At baseline, drug and alcohol use was controlled for by excluding participants with (1) an Alcohol Use Disorder Identification Test (AUDIT, (36)) score higher than 10, (2) smoking more than 20 cigarettes daily, (3) a positive urine screen for alcohol, amphetamines, benzodiazepines, opioids or cocaine, or (4) using non-cannabinoïd drugs on more than 100 occasions lifetime (5 participants $>10$ occasions, no participant >25 occasions). Other exclusion criteria were general MRI-contraindications and a lifetime prevalence of major physical or psychiatric disorders [assessed with the Mini-International Neuropsychiatric Interview, Dutch version 5.0 .0 (37)]. All participants were asked to refrain from alcohol and drugs 24-hours prior the test sessions. Although urine analysis of THC metabolites is insensitive to 24-hour abstinence, it increases accuracy of self-reported substance-use (38). Urine samples were therefore taken to control (36)for recent alcohol and illegal psychotropic substance use. Testing took place in the late afternoon.

\section{Questionnaires at baseline and follow-up}

Problem severity of cannabis use during the past six months was assessed with the Cannabis Use Disorder Identification Test (CUDIT, (39)). Problem severity of alcohol use during the past six months was assessed with the Alcohol Use Disorder Identification Test (AUDIT, (36)). Scores on the CUDIT and AUDIT can range between 0-40 with a cut-off score of 8 for at-

3-year follow-up. For various reasons, 3 heavy cannabis users did not want to participate at 3-year follow-up. A total of 2 heavy cannabis users wanted to participate but were not available at the time of the data collection. All 26 of the control participants had participated at baseline and 6-month follow-up and were invited (from a total control group pool of 43 individuals) to take, matching their age and gender to the heavy cannabis users group. 
risk cannabis or alcohol use. Severity of nicotine related problems during the last six months was measured with the Fagerström Test for Nicotine Dependence (FTND, (40)). In addition, a query on past and present cannabis and nicotine use was administered, including questions on daily use, lifetime use, and duration of use. Severity of depressive symptoms was assessed with the Beck Depression Inventory (BDI; (41)).

\section{N-back task}

Participants performed a letter N-back task during which fMRI-BOLD responses were recorded. The task consisted of alternating blocks with three load levels: 0-back, 1-back, and 2-back. During each block, participants viewed a stream of 15 letters with 5 targets. In 0-back blocks, participants were instructed to indicate when the target letter ' $X$ ' appeared on the screen. In 1-back blocks participants had to decide if the letter on the screen was identical to the previous one. In 2-back blocks, targets were those letters identical to the letter presented two trials back. Participants were instructed to press a right response box button for targets and a left button for non-targets. The 0-back blocks provide a letter recognition baseline, whereas the 1-back and 2-back blocks represent measures of working-memory at low and high load, respectively (42). Blocks lasted 30s (each stimulus lasted 2s) and interblock interval was $5 \mathrm{~s}$, during which the block instructions were repeated. Each load level was repeated four times resulting in a 7 minute task of 12 blocks (Figure 2C). Block order was the same for each participant. Letters were projected on a screen viewed through a mirror attached to the MRI head coil. Prior to scanning the participants briefly practiced each block of the task outside the scanner.

\section{Imaging parameters and preprocessing}

A 3T MRI scanner (Philips Intera, Best, The Netherlands) with a phased array SENSE RF eight-channel receiver head coil was used for image acquisition. At the start of each scan-session a T1 structural image was acquired (T1 turbo field echo, TR 9.6s, TE 4.6ms, 182 slices, slice thickness $1.2 \mathrm{~mm}$, FOV $256 \times 256 \mathrm{~mm}$, in-plane resolution $1 \times 1 \mathrm{~mm}$, flip angle $8^{\circ}$ ). During the N-back task, BOLD signal was measured with a $\mathrm{T} 2 *$ gradientecho EPI sequence (TR 2.29s, TE $30 \mathrm{~ms}, 38$ slices, slice thickness $3 \mathrm{~mm}$, interslice gap $0.3 \mathrm{~mm}$, FOV $220 \times 220 \mathrm{~mm}$, in-plane resolution $2.3 \times 2.3 \mathrm{~mm}$, 
flip angle $80^{\circ}$, sequential slice acquisition). Data pre-processing was conducted with FEAT (FMRI Expert Analysis Tool) version 6.0, part of FSL (FMRIB's Software Library, www.fmrib.ox.ac.uk/fsl). First, non-brain tissue and skull was removed with BET (Brain Extraction Tool). Images were then slice-time aligned, motion corrected, high-pass filtered in the temporal domain (sigma=50s), spatially smoothed with a $5 \mathrm{~mm}$ full-with-halfmaximum Gaussian kernel, and pre-whitened (43). Next, functional data were registered to the participants' structural image and transformed to MNI space (Montreal Neurological Institute) using FNIRT (FMRIB's Nonlinear Image Registration Tool). Inspection of the individual motion plots indicated that none of the participants showed excessive motion (>3mm).

\section{Statistical analysis}

Group analyses were focused on the comparison between current heavy cannabis users ( $n=22$, including three controls who became heavy cannabis users) and controls $(n=23)$ at 3-years follow-up. The four abstinent heavy cannabis users were left out of these analyses due to the small sample size. Scores on questionnaires and N-back behavioral performance were compared between groups over time with repeated measures analysis of variance (rANOVA) in SPSS for Windows (v.20). Nback behavioral performance was assessed in terms of median reaction time of correct responses and accuracy (proportion correct - error responses).

Tensor-ICA (30) was used to investigate working-memory network functionality within and between groups over time. Tensor-ICA (version 3.13, implemented in MELODIC part of FSL) allowed model-free fMRI analysis of all the N-Back data of both test sessions by means of a threeway data decomposition into independent components (ICS) representing signal or artifacts in the data in terms of temporal, spatial, and participant-dependent variations [see (30) for a detailed description of Tensor-ICA and a comparison with other methods]. The number of ICs was set to 20 and each IC was finally represented by a normalized timecourse and a spatial map of normalized Z-scores reflecting the degree to which each voxel time-course correlated with the overall IC time-course. Melodic also provides the relative effect-size per participant for a given component, thereby providing information regarding the strength of a component per participant at baseline and 3-year follow-up. 
Similar to our previous study only using the baseline N-Back data (14), the IC representing the working-memory network was identified by comparing the IC maps to a meta-analysis activation map of 24 normative $\mathrm{N}$-back fMRI studies (15). ICs with motion artifacts, a mean power above $0.1 \mathrm{~Hz}$, or driven by one participant were excluded from analysis. Overlap between the meta-analysis map and the IC maps (both thresholded at $Z>2.3$ ) was calculated in terms of percentage significant meta-analysis voxels falling within the thresholded IC map. Talairach Daemon database implemented in FSL and the LONI probability atlas (44) were used to verify significant cluster locations.

Within the GLM framework implemented in MELODIC, we assessed whether the network responded to task load. Changes in network function between heavy cannabis users and controls were investigated in multiple steps. First, to assess changes in network response strength between groups, individual network effect size (e.g., degree to which individual data contributed to the overall network) at baseline and followup were compared between groups with a rANOVA. Second, individual structural maps of the network were compared to assess voxel-wise spatial changes in connectivity between groups. These structural maps were reconstructed from the group network map with a dual regression approach (45), which uses the network time-course in a temporal regression against the individual $\mathrm{fMRI}$ data. The individual maps were compared using non-parametric permutation-testing with 10,000 permutations. The resulting contrast maps were thresholded with a TFCE (Threshold-Free Cluster Enhancement) approach (46), $p<.05$ corrected for multiple comparisons. Third, a standard Region of Interest (ROI) GLM analysis was performed to assess changes in activation amplitude of individual network areas between groups. Per participant, percent BOLD signal change was extracted from each area within the working-memory network for the 1-back>0-back and 2-back>0-back contrast at baseline and follow-up with Featquery (implemented in FSL). These were subsequently compared between groups with rANOVAs. Separate masks were made per area per hemisphere based on the working-memory network map thresholded at $Z>2.3$. Percent BOLD signal change was quantified with Featquery (implemented in FSL).

Within the group of individuals with a history of heavy cannabis use ( $\mathrm{n}=$ 26 , including the 4 abstainers) we investigated the relationship between network function and history of substance use. Separately for baseline 
and follow-up, Pearson correlations were calculated between individual network strength, network activation amplitude (1-back vs. 0-back and 2back vs. 1-back) and measures of cannabis, alcohol, nicotine, and other illegal psychotropic substance use exposure. Furthermore, the predictive power of baseline measures of substance use and working memory related network function for the prediction of 3-year changes in cannabis use and problem severity was investigated. Similarly, it was also investigated if baseline measures could predict changes in alcohol use and problems (AUDIT). Univariate associations were first assessed by calculating Pearson correlations with change in cannabis use (gram per week follow-up - gram per week baseline) and change in problem severity (CUDIT follow-up - CUDIT baseline) as the dependent variables. Second, potential significant predictors were entered in a regression model to assess the unique variance explained by each predictor. In the analyses we used a Bonferroni correction for multiple comparisons.

\section{Results $^{2}$}

\section{Sample characteristics over time}

Table 1 shows the changes in sample characteristics between groups over time. Verbal IQ did not significantly differ between groups and did not change over time. Analysis of symptoms of depression (BDI) indicated a main effect of group $\left(F_{1,43}=4.10, p=0.049, \eta^{2}=0.09\right)$ and an interaction effect between group and time $\left(F_{1,43}=4.62, p=0.037, \eta^{2}=0.10\right)$. Symptoms of depression were higher in the heavy cannabis users at baseline only $\left(p_{\text {corr }}=0.006\right)$ due to a reduction in symptoms in the heavy cannabis users group over time $\left(p_{\text {corr }}=0.016\right)$. Analysis of AUDIT scores indicated a main effect of time $\left(F_{1,43}=10.97, p=0.002, \eta^{2}=0.20\right)$. Alcohol use and problems did not significantly differ between groups at baseline but the group difference was marginally significant at follow-up $\left(p_{\text {corr }}=0.052\right)$ due to an increase in AUDIT scores in the heavy cannabis users $\left(p_{\text {corr }}=0.003\right.$ ). Analysis of illegal psychotropic substance use (lifetime episodes) indicated a main effect of time $\left(F_{1,43}=7.44, p=0.009, \eta^{2}=0.15\right)$, group $\left(F_{1,43}=11.42\right.$, $\left.p=0.002, \eta^{2}=0.21\right)$, and an interaction effects between time and group $\left(F_{1,43}=6.53, p=0.014, \eta^{2}=0.13\right)$. Illegal psychotropic substance use differed

\footnotetext{
${ }^{2}$ All group analyses were performed a second time comparing individuals with a history of heavy cannabis use (including four abstinent heavy cannabis users) to the control group. Results and interpretations were very similar.
} 
significantly between groups at baseline $\left(p_{\text {corr }}<0.001\right)$ and follow-up $\left(p_{\text {corr }}=0.005\right)$ and increased in the heavy cannabis users over time $\left(p_{\text {corr }}<0.001\right)$. Percentage of smokers did not change over time but there were more cigarette smokers among the heavy cannabis users at baseline $\left(x^{2}=8.32, p_{\text {uncorr }}=0.006\right)$ and follow-up $\left(x^{2}=11.03, p_{\text {uncorr }}<0.001\right)$. Given the low number of smokers in the control group, changes in smoking characteristics were only statistically investigated within the group of smoking heavy cannabis users; paired sample t-tests indicated an increase in FTND scores $\left(t_{11}=3.56, p_{\text {uncorr }}=0.005\right)$ and duration of smoking $\left(t_{11}=7.19\right.$, $\left.p_{\text {uncorr }}<0.001\right)$ whereas the average number of cigarettes per day did not change. Regarding cannabis use within the group of heavy cannabis users, average weekly cannabis use, cannabis related problems (CUDIT), and self-reported abstinence did not significantly change over time whereas duration of heavy cannabis use $\left(t_{22}=7.14, p_{\text {uncorr }}<0.001\right)$ and lifetime cannabis use $\left(t_{22}=2.44, p_{\text {uncorr }}=0.024\right)$ significantly increased. None of the heavy cannabis users sought treatment for their cannabis use during the follow-up period. 


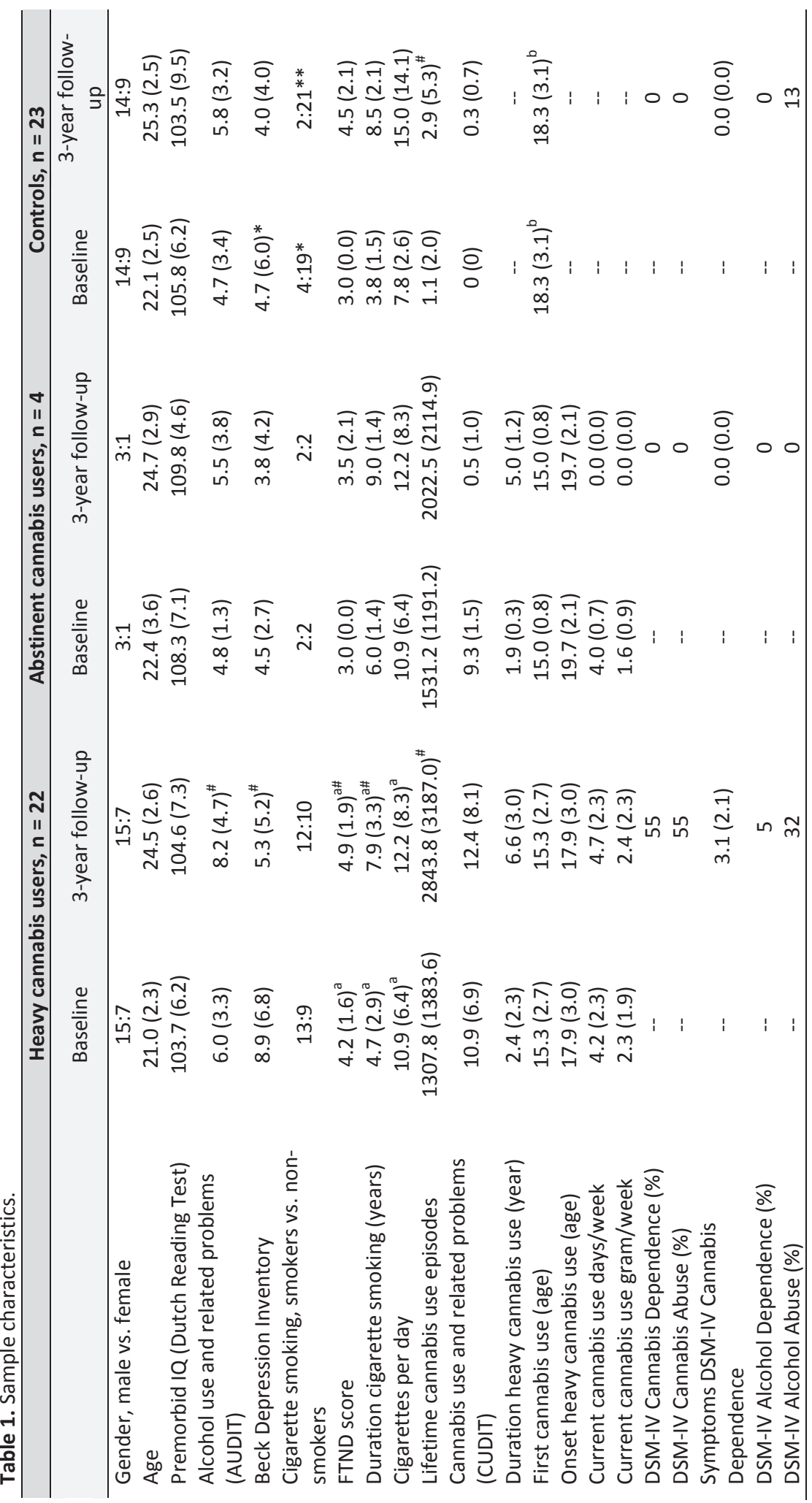




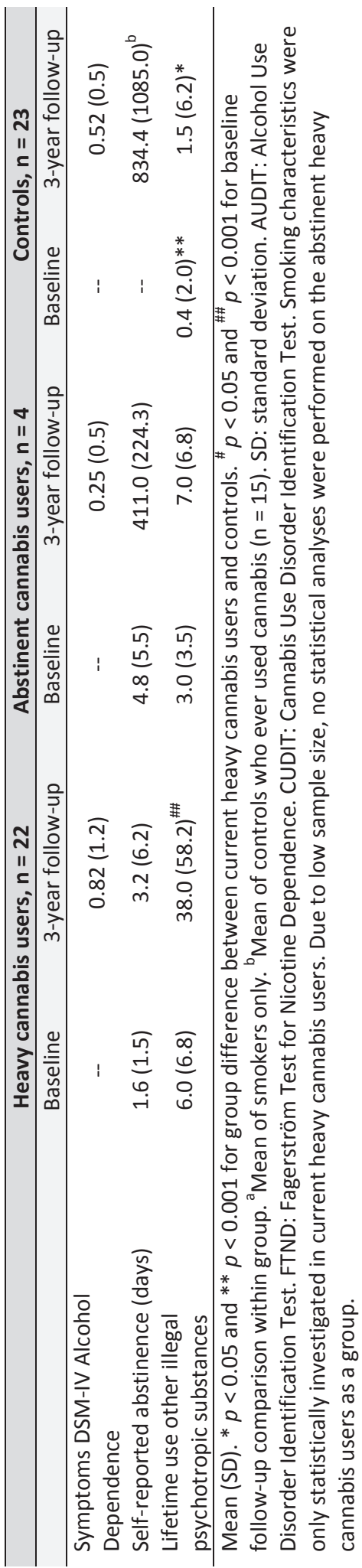




\section{$\mathrm{N}$-back behavioral performance over time}

Due to a technical error, behavioral N-Back data from two heavy cannabis users at follow-up was lost (remaining sample $n=20$ ). RTs and accuracy ( $A$ and $1 B$ ) were analyzed using rANOVAs with group as between-subject factor and memory-load (0-back, 1-back, and 2-back) and time (baseline, follow-up) as within subject factors. Analysis of RTs and accuracy indicated a main effect of memory-load (RTs: $F_{2,40}=72.29, p<0.001$, $\eta^{2}=0.78$; accuracy: $F_{2,40}=38.55, p<0.001, \eta^{2}=0.66$ ) that did not differ between groups (RTs: $F_{2,40}=2.00, p=0.25$; accuracy: $F_{2,40}=0.89, p=0.42$ ). Both at baseline and follow-up and consistent with normative $\mathrm{N}$-back performance (15), RTs increased and accuracy decreased with increasing memory load (1-back vs. 0-back and 2-back vs. 1-back: RTs $p_{\text {corr }}<0.001$, accuracy $\left.p_{\text {corr }}<0.006\right)$. Moreover, there was a main effect of time (RTs: $F_{1,41}=16.84, p<0.001, \eta^{2}=0.29$; accuracy: $F_{1,41}=12.88, p<0.001, \eta^{2}=0.24$ ) which did not differ between groups (RTs: $F_{1,41}=0.11, p=0.74$; accuracy: $F_{1,41}=0.16, p=0.69$ ) or memory load (RTs: $F_{2,40}=1.08, p=0.35$; accuracy: $\left.F_{2,40}=0.31, p=0.73\right)$. Although accuracy for each memory-load increased in both groups, RTs also increased over time (0-back: RTs $p_{\text {corr }}<0.001$, accuracy $p_{\text {corr }}=0.018$; 1 -back: RTs $p_{\text {corr }}<0.001$, accuracy $p_{\text {corr }}=0.018$; 2 -back: RTs $p_{\text {corr }}=0.01$, accuracy $p_{\text {corr }}=0.035$ ).

\section{Working-memory network selection}

The 20 ICs identified by Tensor-ICA explained $87 \%$ of the variance in the baseline and follow-up data. Of these components, 6 were excluded from analysis: 3 contained motion artifacts, and 3 were driven by a single participant. From the remaining 14 components, the working-memory network was identified. The best-matched component showed $86 \%$ overlap with the meta-analysis map provided by Owen and colleagues (15) [second-best component 51\%, 90\% overlap with working-memory network identified in baseline data (14)]. 
A)

口Heavy Cannabis Users aControls

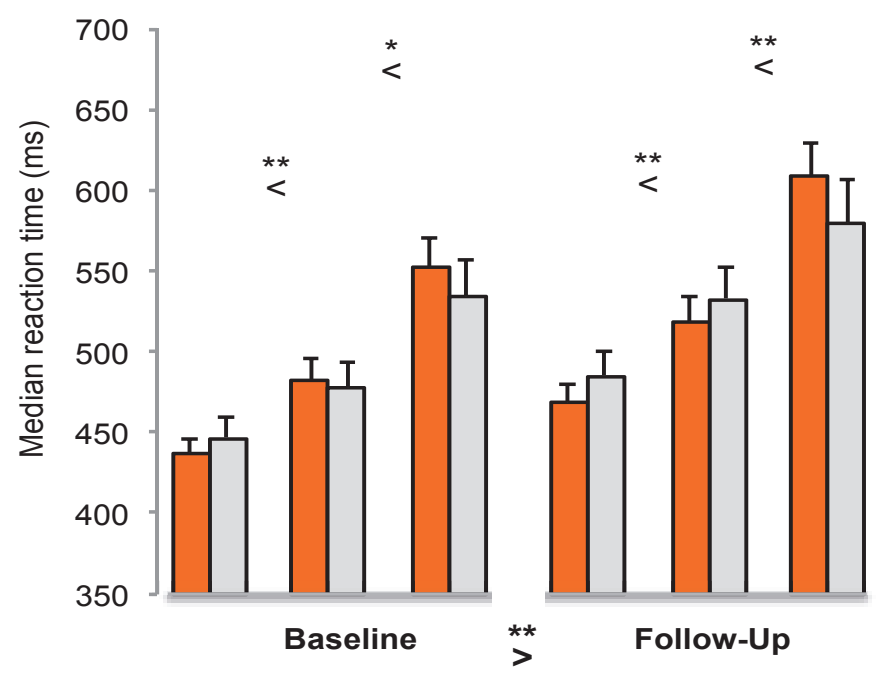

B)

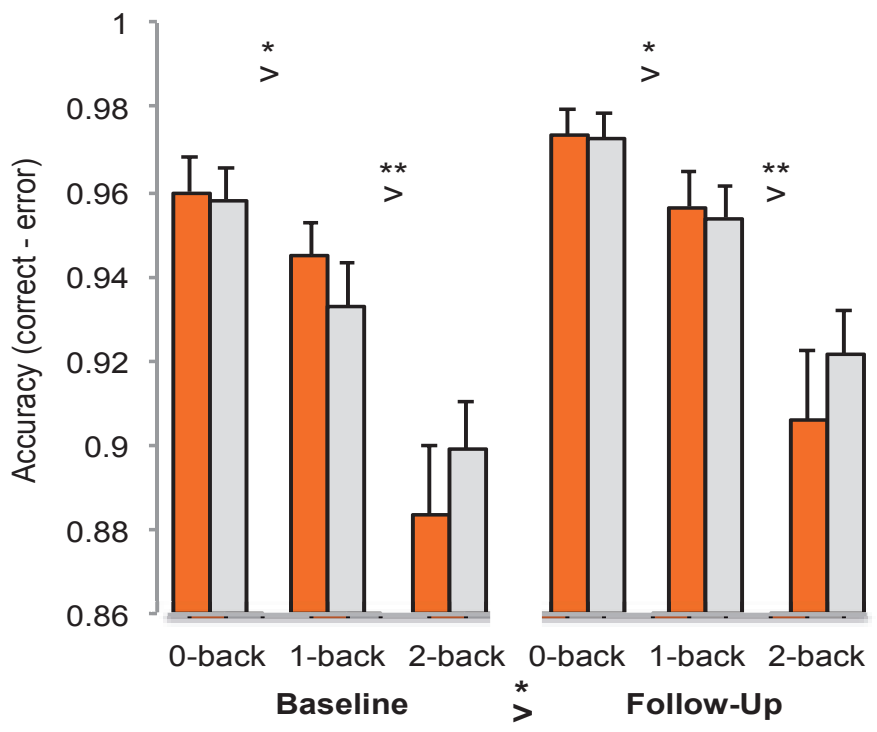

Figure $1 \mathrm{~N}$-back behavioral performance per memory load level over time in heavy cannabis users $(n=22)$ and controls $(n=23)$. (A) 0-back, 1-back, and 2-back median group RT of correct responses with standard error bars. (B) 0-back, 1back, and 2-back average group accuracy expressed as proportion correct responses minus errors with standard error bars. ${ }^{*} p<.05,{ }^{* *} p<.001$. 
Working-memory network functionality over time: group comparison $^{3}$

The working-memory network consisted of the bilateral frontal pole, VLPFC, DLPFC, premotor cortex, paracingulate cortex, and inferior parietal cortex (Figure 2A) and time-course of the network correlated strongly with the modeled $\mathrm{N}$-back time-course $(r=.96, p<.001$; Figure 2B). GLM analysis showed that network response strength significantly increased with task load (1-back>0-back, $Z=8.52, p<.001$; 2-back>1-back \& 0-back, $Z=15.48, p<.001)$. Network strength, however, was not associated with behavioral N-Back performance. Network strength did not significantly change over time $\left(F_{1,43}=0.26, p=0.62\right)$ or differ between groups $\left(F_{1,43}=0.09\right.$, $p=0.77$ ) and there was no significant interaction between time and group $\left(F_{1,43}=3.55, p=0.07\right)$. Further, dual-regression analysis indicated that there were no significant voxel-wise spatial differences between groups regarding the working-memory network at baseline, at follow-up, and over time. Also, ROI GLM analyses indicated that activity amplitude of areas within the network did not significantly change over time, did not differ between groups and showed no interaction between time and group (Table 2). There was a trend, however, towards an interaction between time and group driven by a baseline group difference in the right DLPFC, left premotor cortex, and the left/right paracingulate gyrus. A post-hoc analysis with the other 7 ICs that significantly reacted to task load also did not reveal significant group differences or changes over time.

3 A standard whole-brain higher-level GLM analysis with Feat yielded similar results. When looking an brain activations related to the 2 -back vs. 0 -back and 1-back vs. 0 back contrasts, there were no main effect of group and time and no interaction effect between group and time $(Z>2.3$, wholebrain cluster corrected at $p<0.05)$. 
A)
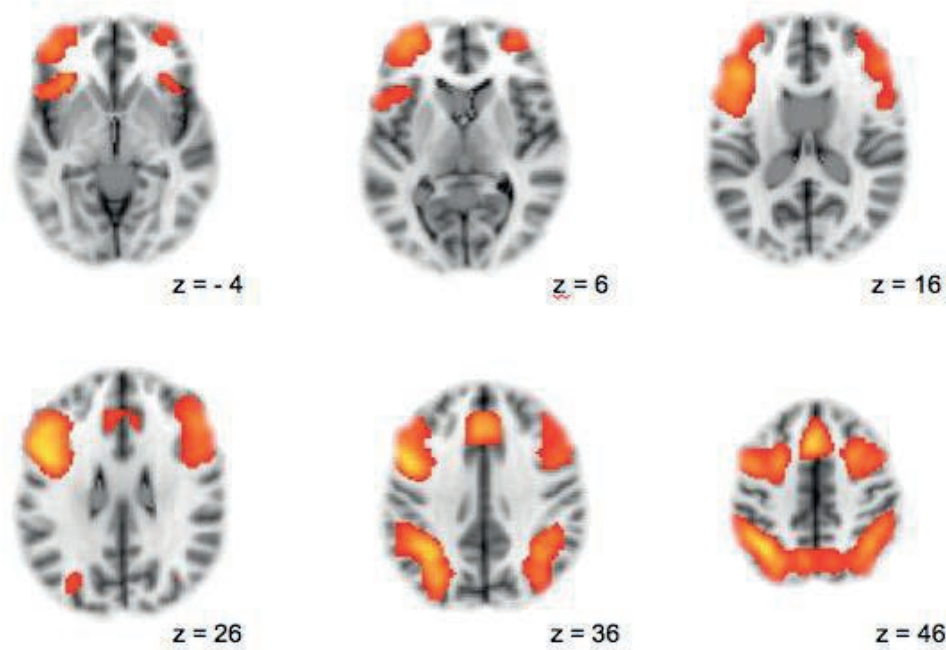

B)

Working-memory network

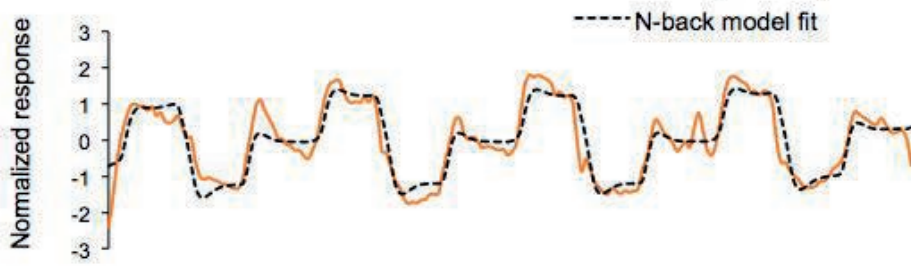

C)

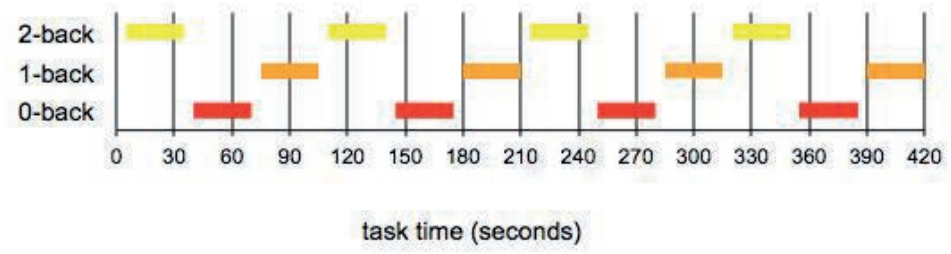

Figure 2 Spatial and temporal characteristics of the working-memory network extracted by tensor-ICA across groups. (A) Spatial characteristics. Significant clusters are overlaid on a standard MNI brain. Right side of the brain is depicted at right side. (B) Temporal characteristics. $Y$-axis: normalized response, $x$-axis: time (seconds), orange line: network time-course, black dotted line: task-model timecourse. (C) Task-model: order of 0-back, 1-back, and 2-back blocks during N-back task, $\mathrm{x}$-axis: time (seconds). 


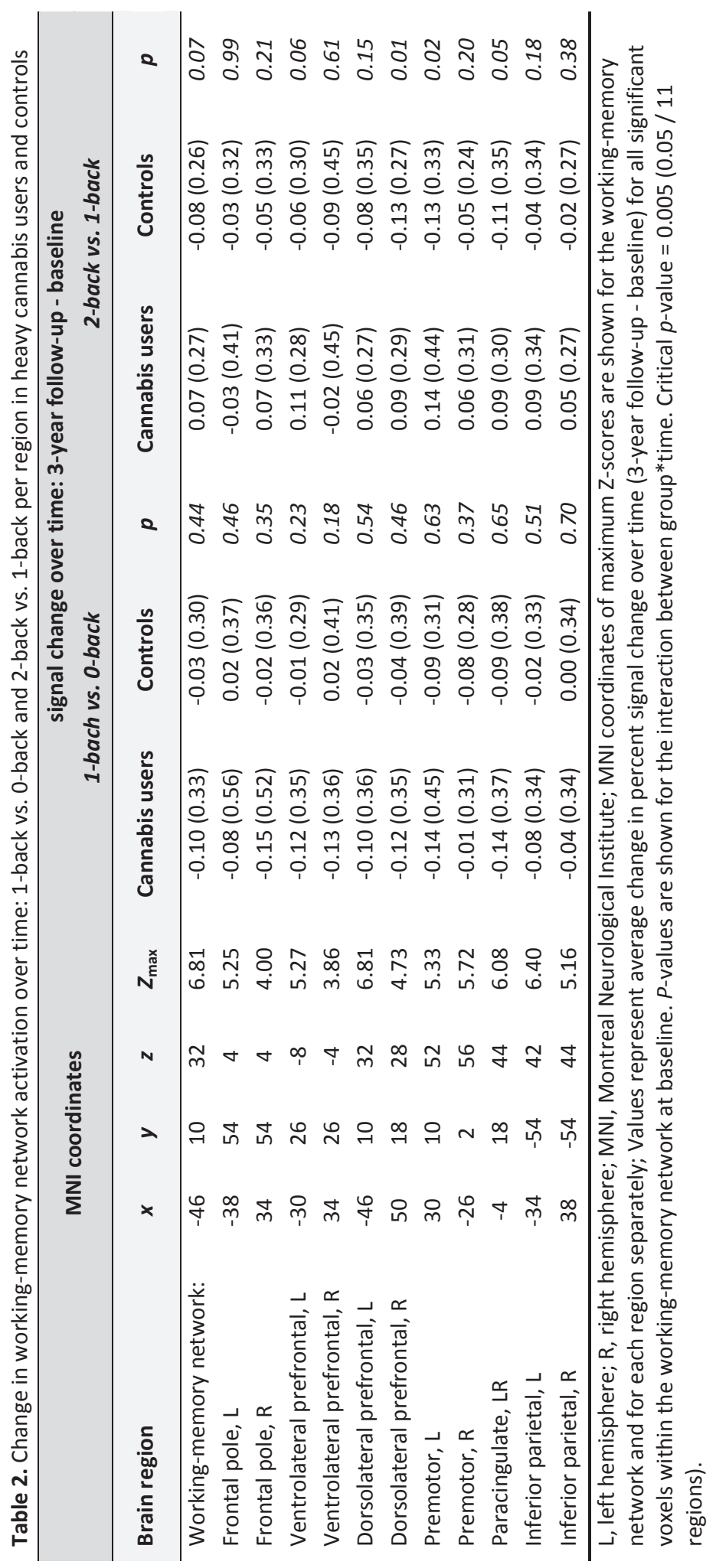


Working-memory network functionality: relationship with substance use Within the group of participants with a history of heavy cannabis use $(n=26)$, separate cross-sectional correlational analyses at baseline and follow-up indicated that network strength and activity amplitude were not significantly correlated with any measure of cannabis (including onset, duration, lifetime use, weekly use, and problems) alcohol, nicotine, or other illegal psychotropic substance use. Network strength and activity amplitude at follow-up did not differ between dependent $(n=13)$ and non-dependent $(n=13)$ cannabis users. Baseline network strength, activation amplitude, and measures of cannabis, alcohol, nicotine, or other illegal psychotropic substance use were not significantly associated with change in weekly cannabis use and problem severity over time. Similarly none of the baseline measures were significantly associated with changes in alcohol use and problems.

\section{Discussion}

The aim of this 3-year longitudinal fMRI study was to investigate the relationship between working-memory network functionality and substance use over time in heavy cannabis users and non-cannabis using controls. Accuracy during the $\mathrm{N}$-back task increased over time both in heavy cannabis users and controls, whereas working-memory network functionality did not differ or change between groups. Within the group of individuals with a history of heavy cannabis use, networkfunctionality showed no cross-sectional correlations with measures of substance use and problems (e.g., cannabis, alcohol, nicotine, illegal psychotropic substances) and did not differ between dependent and non-dependent heavy cannabis users. Moreover, individual differences in network response at baseline did not predict changes in weekly cannabis use, cannabis related problems, three years later, contrasting our previous findings in the same sample showing that workingmemory network functionality predicted changes in cannabis use six months later (14). Network functionality also did not predict changes in alcohol related problems. These findings indicate that working-memory network function in terms of connectivity, location, and activity remained stable over time in heavy cannabis users, despite increases in substance use including cannabis, nicotine, alcohol, and other illegal psychotropic substance use, and therefore these findings do not support the presence of neurotoxic or neuroplastic consequences of sustained frequent cannabis use. The present findings also do not support the hypothesis that working-memory network functionality predicts cannabis use and problems 
over a multiple year period (at least not in a relatively healthy and relatively stable heavy cannabis users).

Cannabis use disorders tend to increase during adolescence and then decrease again during the transition towards adulthood (47). However, average weekly cannabis use and cannabis related problems did not change over the course of three years in our heavy cannabis using group. Heavy cannabis users and controls were matched on IQ and since working memory is related to performance IQ (6), IQ matching may have resulted in a selection of heavy cannabis users with relative good working-memory. One could therefore question whether the current sample of heavy cannabis users is at high risk for developing a cannabis use disorder. Together, these factors may explain the lack of a 3-year longitudinal association between working-memory network functionality and cannabis use related problems. The decrease in depression symptoms in the heavy cannabis users further supports this explanation: internalizing disorders like depression and anxiety are strongly associated with cannabis dependence (1). Moreover, potential participants were excluded if they had any psychiatric disorder, which may have resulted in the selection of relatively healthy cannabis users. Nevertheless, more than half of the heavy cannabis users met DSM-IV criteria for cannabis dependence at follow-up and working-memory network functionality did not differ between these dependent $(n=13)$ and non-dependent $(n=13)$ cannabis users. To further elucidate the role of working-memory, more longitudinal research is needed including a large group of chronic or dependent cannabis users. It is thereby recommended to approach ecological validity by including participants with comorbid psychiatric problems.

Our current findings do not replicate our previous findings that baseline workingmemory network functionality predicted cannabis use six months later. A total of 7 heavy cannabis users dropped out between 6-month and 3-year follow-up (Footnote 1). Although the MCAR test (using the main study variables) indicated that these participants were missing at random, dropout could still be systematically driven by secondary factors not captured by the present design. Non-random dropout and the decrease in power potentially explain the discrepant findings. Indeed, a post hoc analysis excluding the individuals who dropped out showed that baseline network functionality no longer significantly predicted cannabis use at 6-month follow-up (beta=0.18, $p=0.21$ ). Alternatively, one could speculate that the predictors of more short-term cannabis use differ from predictors of long-term cannabis use. Nonetheless this is the first longitudinal neuroimaging study in heavy cannabis users, generating new insights and hypotheses to be tested in future studies. 
Mean alcohol use related problems did increase to at-risk levels after three years (mean AUDIT score>8, (36)). Similarly, nicotine use and dependence and illegal psychotropic substance use also increased. Heavy cannabis use often parallels heavy alcohol, nicotine, and illegal psychotropic substance use (48). Within the group with a history of heavy cannabis use, we therefore also investigated the relationship between working-memory network function and alcohol, nicotine, and illegal psychotropic substance use. We did not observe a relationship between working memory related network-functionality and any of the substance use measures. The current results therefore suggest that there is no dose-dependent relationship between working-memory network functionality and moderate to heavy levels of cannabis, nicotine, alcohol, and illegal psychotropic substance use in young adults.

Onset of heavy cannabis use during adolescence may be an important contributor to the potential neurotoxic and neuroplastic effects of chronic cannabis exposure (28). Maturation of the prefrontal cortex is thought to continue into adulthood (49). However, we did not observe a relationship between onset of heavy cannabis use and functionality of the working-memory network in the current sample of young adult users. Average age of onset of heavy cannabis use (mean $=17.9$ ) was relatively high, which is in line with the hypothesis that the aversive effects of cannabis exposure are prominent during early and mid-adolescence. Indeed, most studies that report hyperactivity of the working-memory network in heavy cannabis users were done in mid-adolescent populations $(17,18,20,21)$. Neurocognitive decline is most evident in cannabis users with a DSM-IV diagnosis of dependence with an onset before age 18 (28) and onset of heavy cannabis use before the age of 16 was found to be related to hyperactivity of the workingmemory network in adult cannabis users (25). The current findings argue against neurotoxic effects of chronic cannabis exposure during late adolescence and thereafter, however, more longitudinal studies are needed, preferably including a measurement before the onset of substance use.

Some potential limitations must be taken into account. Unfortunately, we did not measure cannabis dependence at baseline. We therefore could not investigate the relationship between working-memory network functionality and the transition towards dependence. Also, N-back performance was very high and ceiling effects ( $90 \%$ accuracy for the highest memory load) may have obscured cannabis induced working-memory deficits. We recommend including a 3-back level in future research. Moreover, the $\mathrm{N}$-Back task is a reliable task to investigate functionality of the working-memory network, but it has poor reliability as a behavioral measure of working memory (42). One should therefore also consider including a more 
reliable working-memory task outside the MRI-scanner. Furthermore, gender may moderate cannabis effects on brain function (50). In accordance with estimated gender ratios among cannabis dependent individuals, we included one-third female participants. Due to the limited number of female heavy cannabis users, we did not investigate gender effects. Finally, the results should be interpreted bearing in mind that all substance use measures were based on self-reports, which may have influenced the results.

In summary, the current 3-year longitudinal fMRI study is the first to demonstrate that functionality of the working-memory network in young adult heavy cannabis users remains at normative levels over time, despite prolonged and increasing substance use. These findings imply that moderate to heavy levels of cannabis, nicotine, alcohol, and illegal psychotropic substance use do not seem to impair working-memory network functionality and working memory performance in young adults. Moreover, baseline network-functionality did not predict cannabis use and related problems three years later, warranting longitudinal studies in more chronic or dependent cannabis users. 


\section{References}

1. van der Pol P, Liebregts N, de Graaf R, ten Have M, Korf DJ, van den Brink W, et al. Mental health differences between frequent cannabis users with and without dependence and the general population. Addiction. 2013;108(8):1459-69.

2. Goldstein RZ, Volkow ND. Drug Addiction and Its Underlying Neurobiological Basis: Neuroimaging Evidence for the Involvement of the Frontal Cortex. Am J Psychiatry. 2002;159(10):1642-52.

3. Verdejo-García A, Bechara A. A somatic marker theory of addiction. Neuropharmacology. 2009;56:48-62.

4. Wiers R, Bartholow B, van den Wildenberg E, Thush C, Engels R, Sher K, et al. Automatic and controlled processes and the development of addictive behaviors in adolescents: $A$ review and a model. Pharmacol Biochem Behav. 2007;86:263-83.

5. Baddeley A. Working memory. Curr Biol. 2010;20(4):R136-40.

6. Kane MJ, Engle RW. The role of prefrontal cortex in working-memory capacity, executive attention, and general fluid intelligence: an individual-differences perspective. Psychon Bull Rev. 2002;9(4):637-71.

7. Fernández-Serrano MJ, Pérez-García M, Verdejo-García A. What are the specific vs. generalized effects of drugs of abuse on neuropsychological performance? Neurosci Biobehav Rev. 2011;35(3):377-406.

8. Grenard JL, Ames SL, Wiers RW, Thush C, Sussman S, Stacy AW. Working memory capacity moderates the predictive effects of drug-related associations on substance use. Psychol Addict Behav. American Psychological Association; 2008;22(3):426-32.

9. Thush C, Wiers RW, Ames SL, Grenard JL, Sussman S, Stacy AW. Interactions between implicit and explicit cognition and working memory capacity in the prediction of alcohol use in at-risk adolescents. Drug Alcohol Depend. 2008;94(1-3):116-24.

10. Penick EC, Knop J, Nickel EJ, Jensen P, Manzardo AM, Lykke-Mortensen E, et al. Do Premorbid Predictors of Alcohol Dependence Also Predict the Failure to Recover From Alcoholism?*. J Stud Alcohol Drugs. 2010;71(5):685-94.

11. Patterson F, Jepson C, Loughead J, Perkins K, Strasser AA, Siegel S, et al. Working memory deficits predict short-term smoking resumption following brief abstinence. Drug Alcohol Depend. 2010;106(1):61-4.

12. Bickel WK, Yi R, Landes RD, Hill PF, Baxter C. Remember the Future: Working Memory Training Decreases Delay Discounting Among Stimulant Addicts. Biol Psychiatry. 2011;69(3):260-5.

13. Houben K, Wiers RW, Jansen A. Getting a Grip on Drinking Behavior: Training Working Memory to Reduce Alcohol Abuse. Psychol Sci. 2011;22(7):968-75.

14. Cousijn J, Wiers RW, Ridderinkhof KR, van den Brink W, Veltman DJ, Goudriaan AE. Effect of baseline cannabis use and working-memory network function on changes in cannabis use in heavy cannabis users: A prospective fMRI study. Hum Brain Mapp. 2014;35(5):2470-82.

15. Owen AM, McMillan KM, Laird AR, Bullmore E. N-back working memory paradigm: A metaanalysis of normative functional neuroimaging studies. Hum Brain Mapp. 2005;25(1):46-59.

16. Wager TD, Smith EE. Neuroimaging studies of working memory: Cogn Affect Behav Neurosci. 2003;3(4):255-74.

17. Jacobsen LK, Pugh KR, Constable RT, Westerveld M, Mencl WE. Functional Correlates of Verbal Memory Deficits Emerging During Nicotine Withdrawal in Abstinent Adolescent Cannabis Users. Biol Psychiatry. 2007;61(1):31-40. 
18. Jager G, Block RI, Luijten M, Ramsey NF. Cannabis Use and Memory Brain Function in Adolescent Boys: A Cross-Sectional Multicenter Functional Magnetic Resonance Imaging Study. J Am Acad Child Adolesc Psychiatry. 2010;49(6):561-572.e3.

19. Kanayama G, Rogowska J, Pope HG, Gruber SA, Yurgelun-Todd DA. Spatial working memory in heavy cannabis users: a functional magnetic resonance imaging study. Psychopharmacology. 2004;176(3-4):239-47.

20. Padula $C B$, Schweinsburg AD, Tapert SF. Spatial working memory performance and fMRI activation interaction in abstinent adolescent marijuana users. Psychol Addict Behav. 2007;21(4):478-87.

21. Schweinsburg AD, Schweinsburg BC, Medina KL, McQueeny T, Brown SA, Tapert SF. The Influence of Recency of Use on fMRI Response During Spatial Working Memory in Adolescent Marijuana Users. J Psychoactive Drugs. 2010;42(3):401-12.

22. Koob GF, Volkow ND. Neurocircuitry of addiction. Neuropsychopharmacology. 2010;35(1):217-38.

23. Burns HD, Van Laere K, Sanabria-Bohorquez S, Hamill TG, Bormans G, Eng W -s., et al. [18F]MK9470, a positron emission tomography (PET) tracer for in vivo human PET brain imaging of the cannabinoid-1 receptor. Proc Natl Acad Sci. 2007;104(23):9800-5.

24. Jager G, Ramsey NF. Long-term consequences of adolescent cannabis exposure on the development of cognition, brain structure and function: an overview of animal and human research. Curr Drug Abuse Rev. 2008;1(2):114-23.

25. Becker B, Wagner D, Gouzoulis-Mayfrank E, Spuentrup E, Daumann J. The impact of early-onset cannabis use on functional brain correlates of working memory. Prog Neuro-Psychopharmacology Biol Psychiatry. 2010;34(6):837-45.

26. Schweinsburg AD, Nagel BJ, Schweinsburg BC, Park A, Theilmann RJ, Tapert SF. Abstinent adolescent marijuana users show altered $\mathrm{fMRI}$ response during spatial working memory. Psychiatry Res Neuroimaging. 2008;163(1):40-51.

27. Hanson KL, Winward JL, Schweinsburg AD, Medina KL, Brown SA, Tapert SF. Longitudinal study of cognition among adolescent marijuana users over three weeks of abstinence. Addict Behav. 2010;35(11):970-6.

28. Meier MH, Caspi A, Ambler A, Harrington H, Houts R, Keefe RSE, et al. Persistent cannabis users show neuropsychological decline from childhood to midlife. Proc Natl Acad Sci. 2012;109(40):E2657-64.

29. Solowij N, Battisti R. The chronic effects of cannabis on memory in humans: a review. Curr Drug Abuse Rev. 2008;1(1):81-98.

30. Beckmann CF, Smith SM. Tensorial extensions of independent component analysis for multisubject FMRI analysis. Neuroimage. 2005;25(1):294-311.

31. Cousijn J, Goudriaan AE, Wiers RW. Reaching out towards cannabis: approach-bias in heavy cannabis users predicts changes in cannabis use. Addiction. 2011;106(9):1667-74.

32. Cousijn J, Goudriaan AE, Ridderinkhof KR, van den Brink W, Veltman DJ, Wiers RW. Neural responses associated with cue-reactivity in frequent cannabis users. Addict Biol. 2013;18(3):57080.

33. Cousijn J, Wiers RW, Ridderinkhof KR, van den Brink W, Veltman DJ, Porrino LJ, et al. Individual differences in decision making and reward processing predict changes in cannabis use: a prospective functional magnetic resonance imaging study. Addict Biol. 2013;18(6):1013-23.

34. Little RJA. A Test of Missing Completely at Random for Multivariate Data with Missing Values. J Am Stat Assoc. 1988;83(404):1198-202.

35. Schmand B, Bakker D, Saan R, Louman J. [The Dutch Reading Test for Adults: a measure of premorbid intelligence level]. Tijdschr Gerontol Geriatr. 1991;22(1):15-9. 
36. Saunders J, Aasland O, Babor T, de la Fuente J, Grant M. Development of the alcohol use disorders identification test (AUDIT): WHO collaborative project on early detection of persons with harmful alcohol consumption-II. Addiction. 1993;88:791-804.

37. Sheenan D, Lecrubier $Y$, Sheenan K, Amorim P, Janavs J, Weiler E. The MINI-International Neuropsychiatric Interview (M.I.N.I.): the development and validation of a structured diagnostic psychiatric interview for DSM-IV and ICD-10. J Clin Psychiatry. 1998;59:22-33.

38. Roese $\mathrm{N}$, Jamieson $\mathrm{D}$. Twenty years of bogus pipeline research: a critical review and meta-analysis. Psychol Bull. 1993;114:363-75.

39. Adamson SJ, Sellman JD. A prototype screening instrument for cannabis use disorder: the Cannabis Use Disorders Identification Test (CUDIT) in an alcohol-dependent clinical sample. Drug Alcohol Rev. 2003;22(3):309-15.

40. Heatherton TF, Kozlowski LT, Frecker RC, Fagerström KO. The Fagerström Test for Nicotine Dependence: a revision of the Fagerström Tolerance Questionnaire. Br J Addict. 1991;86(9):111927.

41. Beck A, Ward C, Mendelson M, Mock J, Erbaugh J. An inventory for measuring depression. Arch Gen Psychiatry. 1961;4:561-71.

42. Jaeggi SM, Buschkuehl M, Perrig WJ, Meier B. The concurrent validity of the $N$-back task as a working memory measure. Memory. 2010;18(4):394-412.

43. Woolrich MW, Ripley BD, Brady M, Smith SM. Temporal Autocorrelation in Univariate Linear Modeling of FMRI Data. Neuroimage. 2001;14(6):1370-86.

44. Shattuck DW, Mirza M, Adisetiyo V, Hojatkashani C, Salamon G, Narr KL, et al. Construction of a 3D probabilistic atlas of human cortical structures. Neuroimage. 2008;39(3):1064-80.

45. Filippini N, Maclntosh BJ, Hough MG, Goodwin GM, Frisoni GB, Smith SM, et al. Distinct patterns of brain activity in young carriers of the APOE- 4 allele. Proc Natl Acad Sci. 2009;106(17):7209-14.

46. Smith S, Nichols T. Threshold-free cluster enhancement: Addressing problems of smoothing, threshold dependence and localisation in cluster inference. Neuroimage. 2009;44(1):83-98.

47. Schulenberg JE, Merline AC, Johnston LD, O'Malley PM, Bachman JG, Laetz VB. Trajectories of Marijuana Use During the Transition to Adulthood: The Big Picture Based on National Panel Data. J Drug Issues. 2005;35(2):255-79.

48. Swift W, Coffey C, Degenhardt L, Carlin JB, Romaniuk H, Patton GC. Cannabis and progression to other substance use in young adults: findings from a 13-year prospective population-based study. J Epidemiol Community Health. 2012;66(7):e26-e26.

49. Casey BJ, Getz S, Galvan A. The adolescent brain. Dev Rev. 2008;28(1):62-77.

50. McQueeny T, Padula CB, Price J, Medina KL, Logan P, Tapert SF. Gender effects on amygdala morphometry in adolescent marijuana users. Behav Brain Res. 2011;224(1):128-34. 



\section{Chapter | 6}

Cue-induced striatal activity in frequent cannabis users independently predicts cannabis problem severity three years later

Wilhelmina A.M. Vingerhoets, Laura Koenders, Wim van den Brink, Reinout Wiers, Anna E. Goudriaan, Thérèse van Amelsvoort, Lieuwe de Haan, Janna Cousijn 


\begin{abstract}
Cannabis is the most frequently used illicit drug worldwide, but little is known about the mechanisms underlying continued cannabis use. Cue-reactivity (the physical, psychological, behavioural and neural reaction to substance related cues) might be related to continued cannabis use. In this three-year prospective neuroimaging study we investigated whether cannabis cue-induced brain activity predicted continued cannabis use and associated problem severity three years later. In addition, baseline brain activations were compared between dependent and non-dependent cannabis users at follow-up. Analyses were focussed on brain areas known to be important in cannabis cue-reactivity: anterior cingulate cortex, orbitofrontal cortex, ventral tegmental area, amygdala and striatum. At baseline, 31 treatment-naive frequent cannabis users performed a cue-reactivity fMRI task. Of these participants, 23 completed the 3-year follow-up. None of the cue-induced ROI activations predicted the amount of cannabis use at follow-up. However, cueinduced activation in the left striatum (putamen) significantly and independently predicted problem severity at follow-up $(p<.001)$ as assessed with the Cannabis use Disorder Identification Test. Also, clinically dependent cannabis users at follow-up showed higher baseline activation at trend level in the left striatum compared to non-dependent users. This indicates that neural cue-reactivity in the dorsal striatum is an independent predictor of cannabis use related problems. Given the relatively small sample size, these results are preliminary and should be replicated in larger samples of cannabis users.
\end{abstract}




\section{Introduction}

Cannabis is the most frequently used illicit drug (1), thereby leading to large numbers of individuals with cannabis dependence (2). With the exception of individual differences in genetic vulnerability (3), very little is known about why some people develop cannabis use related problems and cannabis dependence whereas others do not. More insight in the underlying neurobiological mechanisms of cannabis use related problems and cannabis dependence is important as it can contribute to development of new prevention and treatment strategies. Cuereactivity, defined as the physical, psychological, behavioural and neural reactions triggered by exposure to substance-related cues (4), reflects enhanced motivational processes towards substance use and has been associated with increased substance use (5). Furthermore, cue-reactivity has been found to predict treatment outcome and relapse in cigarette, alcohol and heroin addiction (6-9), suggesting that it may play a role in the continuation of drug use, including cannabis use and dependence. Much less is known about the role of cannabis cuereactivity in continued cannabis use and relapse. However, initial studies suggest that both brain and behavioural responses to cannabis cues may predict shortterm (i.e., over the course of six months or less) levels of cannabis use, associated psychiatric problems and treatment outcome (10-13). In this study we aimed to investigate if baseline cue-induced brain activity in brain regions associated with cue-reactivity, predicts the amount of cannabis use and associated problem severity in treatment-naive frequent cannabis users three years later.

In a previous report on the baseline findings of the present study, we found significant activation in the ventral tegmental area (VTA) when viewing cannabis versus neutral stimuli in frequent cannabis users compared to control subjects. These frequent cannabis users had used cannabis on average 5 days per week for a minimum of 2 years and did not have a treatment history. Moreover, these frequent cannabis users had varying levels of cannabis use related problems. Interestingly, activation in the orbitofrontal cortex (OFC), anterior cingulate cortex (ACC) and striatum was only found in those frequent users with high problem severity (14). These cross-sectional findings suggest that neural cue-reactivity may be an important predictor of cannabis problem severity. To test this hypothesis, we assessed levels of cannabis use and problem severity in the same sample of frequent cannabis users 3 years later. Using a similar approach as in the report on the baseline findings (14), regions of interest (ROIs) were the OFC, ACC, VTA, striatum and amygdala. All of these regions play a prominent role in substance use disorders and activity within these areas has been associated with cue-reactivity 
and reward evaluation in substance abusing populations $(14,15)$. To the best of our knowledge, this study is the first to investigate the causal role of neural cuereactivity in continued cannabis use and the development of cannabis dependence, using a 3-year follow-up design.

\section{Experimental Procedures}

This study was part of a 3-year follow-up study investigating several neurobiological and behavioural factors underlying continued cannabis use $(14,16)$, and was approved by the medical ethics committee of the Academic Medical Centre (AMC) of the University of Amsterdam. All participants signed informed consent prior to participation after the procedure had been fully explained.

\section{Participants}

Of the 31 treatment-naive frequent cannabis users recruited from the general Dutch population at baseline, 23 (16 male and 7 female) frequent cannabis users completed the 3 -year follow-up session. The remaining 8 subjects did not participate in the follow-up assessment for different reasons: contact lost $(n=3)$, refused $(n=3)$, not available $(n=2)$. At baseline, participants were recruited through advertisements and in cannabis outlets ("coffeeshops"). Participants were approached by email and telephone and invited for a follow-up test session at the Academic Medical Centre (AMC). Time interval between the two test sessions varied from 35 to 42 months (Mean $=39$ months, SD = 2.10). Mean age at followup was 24.14 years $(S D=2.44)$. Frequent cannabis use was defined at baseline as using cannabis on more than 10 days per month for at least two years. Baseline exclusion criteria were: a score higher than 10 on the Alcohol Use Disorder Identification Test (AUDIT;(17), smoking more than 20 cigarettes daily, a positive urine screen for alcohol, amphetamines, benzodiazepines, opioids or cocaine, or using non-cannabinoïd drugs on more than 100 occasions (18), major medical disorders or a history of axis I psychiatric disorders. Three of the frequent cannabis users at baseline had quit using cannabis completely for at least four months at follow-up. All participants were instructed to abstain from alcohol, cannabis and other drugs 24 hours prior to both the baseline assessment and the follow-up assessment. Urine samples were taken during the test session to control for recent illicit substance use. Although urine analysis of $\Delta 9$-tetrahydrocannabinol (THC) is not suitable for detection of 24-hour abstinence, it increases accuracy of selfreported substance use (19). At the start of both baseline and follow-up 
measurements, time of last cannabis use was recorded. The mean time of abstinence was 2.18 days $(S D=2.77)$ at baseline and 59 days at follow-up (SD= 171).

\section{Questionnaires}

At baseline and follow-up, demographic information was collected. In addition, a detailed history of cannabis use was taken (e.g. age of onset of regular use, amount of cannabis use in grams per day and number of joints per day). Cannabis related problem severity was measured using the Cannabis Use Disorder Identification Test (20). The CUDIT has good test-retest reliability $(r=0.85)$. The severity of nicotine dependence was assessed with The Fagerström Test for Nicotine Dependence (FTND; Heatherton et al. 1991). Craving was assessed before and after the baseline and follow-up test-session with the Marijuana Craving Questionnaire (MCQ; Heishman et al., 2009) from which session induced craving was computed. Alcohol use and problem severity was assessed with the Alcohol Use Disorder Identification Test (AUDIT; Saunders et al., 1993). All questionnaires had satisfactory or good test-retest reliability (23-25). At follow-up, the Mini International Neuropsychiatric Interview (MINI; Sheenan et al., 1998) was conducted by two experienced psychologists to screen for evidence of the presence of cannabis abuse and dependence and other mental disorders according to DSM-IV. All questionnaires and interviews were conducted at baseline and at follow-up.

\section{Neural cue-reactivity}

As described in detail in Cousijn et al (14), to measure cue-induced brain activity, an event-related fMRI-task was performed during which participants viewed fullcolour cannabis-related images $(N=30)$, control images $(N=30)$, and target images $(N=15)$. Cannabis images were photos of cannabis, individuals smoking cannabis, and objects for using cannabis. Control images were photos of individuals and objects visually matched to the cannabis images on colour and composition. Target images were photos of animals. Participants were instructed to pay close attention to the images and to press a key on a response box when they saw an animal to ensure maintained attention. Each image was presented $4 \mathrm{~s}$ preceded by a fixation-cross that lasted on average $4 \mathrm{~s}$, jittered between $2 \mathrm{~s}$ and 6 s. Total task time was 11 minutes. The stimuli were presented in the same semirandom order (max three images of the same category in a row) for each participant. The task was only conducted at baseline. 


\section{fMRI image parameters and data pre-processing}

For detailed information on image parameters and pre-processing the reader is referred to Cousijn et al. (14). Briefly, images were acquired with a 3T MRI scanner (Philips Intera, Best, The Netherlands) with a phased array SENSE RF eight-channel receiver head coil. BOLD signal during the cue-reactivity task was measured with a T2* gradient-echo EPI sequence (TR 2.29 s, TE 30ms, 38 slices, slice thickness $3 \mathrm{~mm}$, interslice gap $0.3 \mathrm{~mm}$, FOV 220x220mm, in-plane resolution 96x96, flip angle $80^{\circ}$ ). FEAT (FMRI Expert Analysis Tool) version 4.1, part of FSL (FMRIB's Software Library, www.fmrib.ox.ac.uk/fsl) was used for data pre-processing. Pre-processed functional data was registered to participants' structural image and transformed to MNI space (Montreal Neurological Institute) using FLIRT (FMRIB's Linear Image Registration Tool). At baseline, the Nielsen and Hansen's volume of interest database (Nielsen and Hansen, 2002) was used to obtain anatomical masks of the OFC, ACC, striatum, and amygdala. The VTA mask ( $x=-20$ to $20, y=-10$ to $24, z=-6$ to -22) was manually drawn on the standard MNI brain in FSL-view using the Talairach Daemon implemented in FSL and the LONI probability atlas (27) as described by Cousijn et al. (14). The mean percentage BOLD signal change for cannabis versus neutral stimuli was calculated in FSL 5.0.1 using the Featquery toolbox for all ROIs (ACC, OFC, VTA, striatum and amygdala).

\section{Data analyses}

\section{Demographic variables}

Analyses were conducted using the Statistical Package for the Social Science (IBM SPSS Statistics 20.0). Little's Missing Completely At Random (MCAR) test with all study variables was used to check if participants who did not complete the followup assessment were missing at random. Demographic data were analysed using paired sample t-tests to check for differences between baseline and follow-up.

\section{Predictors of weekly cannabis use and problem severity at 3-year follow-up}

First, pearsons $r$ was calculated to check which behavioural variables and ROI's (percentage signal change) correlated with weekly cannabis use (grams) and problem severity at follow-up. Then a hierarchal multiple regression analysis was carried out to determine whether cue-induced brain activation predicted weekly cannabis use and problem severity at 3-year follow-up. We entered the baseline percentage signal change of the ROIs in which activity correlated significantly with total CUDIT scores and weekly cannabis use (in grams) at follow-up in the model. 
Behavioural variables that correlated significantly with total CUDIT scores and weekly cannabis use were entered in the regression model as covariates, as were the behavioural variables that significantly changed during the 3-year follow up period.

\section{Exploratory Region of interest Analyses}

ROls (percentage signal change) that were found to significantly predict weekly cannabis use and/or problem severity, were separately and exploratively analysed to determine the exact location of the significant activation within that ROI. We used FLAME (FMRIBS's local analyses of mixed effects) stages 1 and 2 implicated in FSL. The contrast of interest was cannabis $>$ neutral.

\section{Activation patterns in dependent and non-dependent users}

Finally, to check for baseline differences in activation patterns between dependent and non-dependent users measured at follow-up, an independent samples t-test was performed between dependent and non-dependent cannabis users (determined by the MINI) with cue-induced brain activation at baseline as dependent variable. To adjust for multiple testing we applied a Bonferroni correction corrected for the number of ROIs and outcome variables with a critical p-value $\leq .005$.

\section{Results}

\section{Demographic variables}

Little's Missing Completely At Random (MCAR) showed that the frequent cannabis users that did not partake in the follow-up were missing at random $\left(\chi^{2}=80.93\right.$, d.f. $=108, p=.98$ ). A paired sample t-test showed that the mean severity of cannabis use related problems was stable over time, but that mean severity of tobacco dependence, mean alcohol use related problems and mean lifetime use of other psychotropic substances significantly increased during the 3 year follow-up period (Table 1$)^{1}$.

\footnotetext{
${ }^{11}$ An additional independent sample t-test using change scores was conducted with all variables listed in table 1 to check for differences in changes over time between dependent and non-dependent users at follow-up. Except for Lifetime cannabis use duration in years ( $p$ $=0.033$ ), no significant differences were found between the two groups.
} 
Table 1. Paired sample t-test with sample characteristics of frequent cannabis users $(\mathrm{N}=23)$ at baseline and follow-up.

\begin{tabular}{lll}
\hline & Baseline & Follow-up \\
\hline & Mean (SD) & Mean (SD) \\
\hline Age & $20.9(2.4)^{* * *}$ & $24.1(2.4)^{* * *}$ \\
Estimated verbal IQ (Dutch Reading Test) & $104.4(5.3)$ & $105.7(4.7)$ \\
Years of education & $13.8(2.2)^{* * *}$ & $16.7(3.2)^{* * *}$ \\
Current cannabis use days/week & $4.7(1.5)$ & $4.6(2.6)$ \\
Current cannabis use gram/week & $2.6(1.7)$ & $3.1(3.2)$ \\
Lifetime cannabis use duration (years) & $2.6(2.1)^{* * *}$ & $6.6(2.9)^{* * *}$ \\
Cannabis use and related problems & $12.7(6.4)$ & $12.1(8.6)$ \\
(CUDIT) & & \\
Lifetime use other psychotropic & $6.0(6.62)^{*}$ & $36.8(57.15)^{*}$ \\
substances & $2.5(2.4)^{* * *}$ & $4.9(1.8)^{* * *}$ \\
Severity of nicotine dependence (FTND) & $6.2(7.2)$ & $11.7(8.3)$ \\
Number of cigarettes per day & $3.1(3.5)^{* * *}$ & $7.7(3.2)^{* * *}$ \\
Duration cigarette smoking (years) & $3.7(11.5)$ & $3.7(7.5)$ \\
Session induced craving (MCQ) & $6.0(3.2)^{*}$ & $7.8(5.0)^{*}$ \\
Alcohol use and related problems (AUDIT) & & \\
\hline
\end{tabular}

${ }^{*} p \leq .05, * * p \leq .01, * * * p \leq .001$. CUDIT: Cannabis Use Disorder Identification Test, FTND:

Fagerström Test for Nicotine Dependence, MCQ: Marijuana Craving Questionnaire, AUDIT:

Alcohol Use Disorder Identification Test.

An additional independent sample t-test using change scores was conducted with all variables listed in table 1 to check for differences between dependent and non-dependent users at follow-up. Accept for Lifetime cannabis use duration in years $(p=0.033)$, no significant differences were found between the two groups.

\section{Predictors of weekly cannabis use at and problem severity at 3-year follow- up}

Linear correlational analyses showed that there were no significant associations between cannabis cue-induced brain activations at baseline in the ROls and the amount of cannabis that was used during follow-up. However, the total CUDIT score at follow-up was significantly associated with cue-induced left striatal ( $r$ $=.604, p=.002)$ and left VTA activity $(r=.462, p=.027)$ at baseline: higher activity during cannabis versus neutral images was related to more cannabis use related problems. Regarding behavioural variables, total CUDIT score at follow-up correlated significantly with baseline total CUDIT score $(r=.581, p=.004)$, baseline FTND score $(r=.528, p=.010)$, baseline number of cigarettes per day $(r=.466, p$ 
$=.025$ ) and baseline subjective craving (MCQ post-test - pre-test; $r=-.439, p$ $=.036)$.

Subsequently, the hierarchical multiple regression analysis was performed. Total CUDIT score at baseline was entered first. In the second step, the baseline variables that correlated significantly with the CUDIT score at follow-up (baseline FTND score, number of daily cigarettes, session induced craving) were entered in the regression model as covariates. In addition, baseline AUDIT scores and lifetime use of other psychotropic substances at baseline were entered as covariates, because these variables changed significantly over time. To investigate the unique variance in cannabis use and cannabis use related problems (CUDIT scores) at follow-up explained by neural cannabis cue-reactivity, left striatal and left VTA activations were entered in the third and final step. Preliminary analyses revealed one outlier with a total CUDIT score at follow-up of more than 3 standard deviations above the mean. This subject was excluded from further analyses. The assumptions of normality, linearity, multicollinearity and homoscedasticity were not violated (maximum standardized residual $=1.9$, maximum Cook's distance $=$ .280).

The hierarchical multiple regression analysis showed that activation in the left striatum significantly predicted problem severity $(p<.001)$, uniquely explaining $13 \%$ of the variance in follow-up CUDIT scores after correction for baseline CUDIT score, baseline AUDIT score, baseline FTND score, baseline number of cigarettes per day, baseline craving and baseline lifetime use of other psychotropic substances. VTA activation on the other hand did not. Besides striatal activity, total CUDIT score at baseline $(p<.001)$ was a significant predictor in the final model as were the number of daily cigarettes at baseline $(p=.014)$ and baseline AUDIT score $(p=.003)$. The final model (see Table 2$)$, consisting of left striatum activity at baseline, total baseline CUDIT score, total baseline AUDIT score and baseline number of daily cigarettes explained $87 \%$ of the variance in cannabis use related problem severity at follow-up, of which $73 \%$ was explained by the control variables and an additional $13 \%$ by cue induced left striatal activation at baseline. The additional ROI analysis showed one significant cluster in the left putamen (figure 1., $\mathrm{MNI}$ coordinates $\mathrm{x}=-24 ; \mathrm{y}=4 ; z=6)$. 
Table 2. Final hierarchical multiple regression analysis for variables associated with cannabis problem severity (CUDIT-scores) at 3 year follow up ( $N=22$ ).

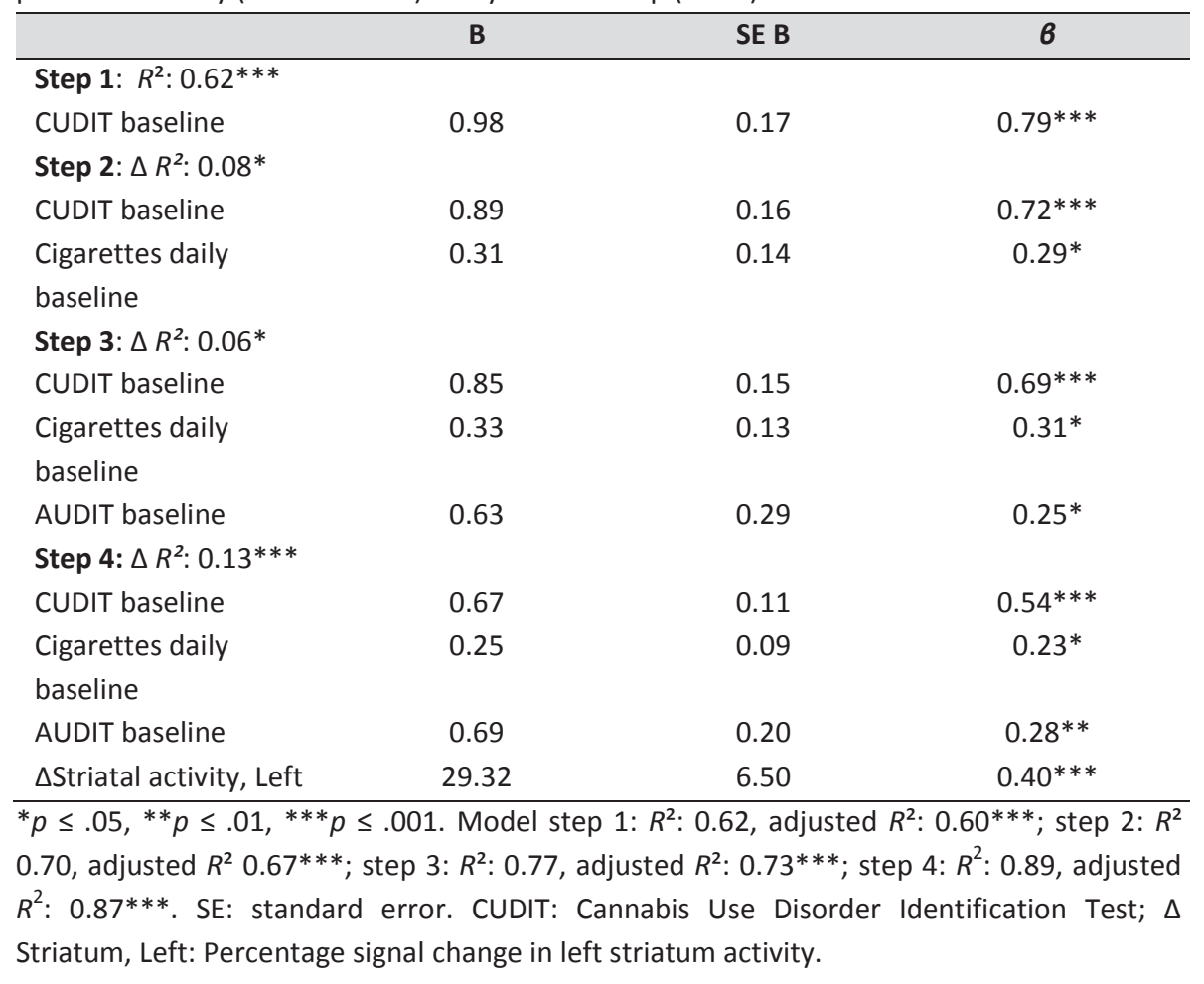

\section{Activation patterns in dependent and non-dependent users.}

Finally, an additional independent samples t-test showed a marginally significant difference $(p=.053)$ in cue-induced striatal activation at baseline between dependent $(\mathrm{N}=12)$ and non-dependent $(\mathrm{N}=11)$ cannabis users at follow-up (Table 3): dependent cannabis users at follow-up, showed higher activity for cannabis versus neutral stimuli at baseline, compared to non-dependent users. 
3.3
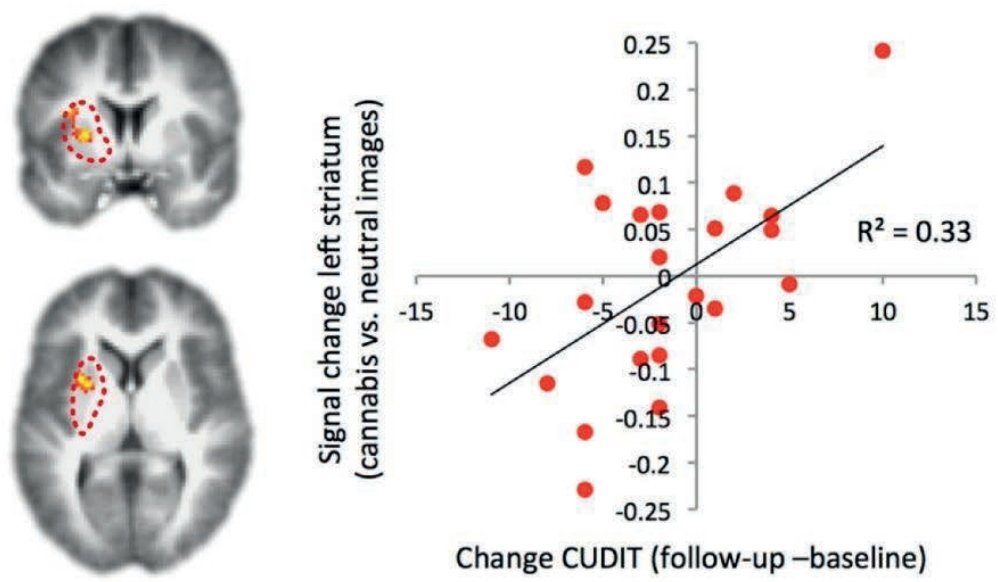

2.3

Change CUDIT (follow-up -baseline)

Figure 1. Relationship between changes in cannabis use-related problems over three years (CUDIT follow-up - CUDIT baseline) and striatal cannabis cue-reactivity at baseline (activity cannabis versus neutral images). The scatterplot displays this relation for activity extracted from the entire left striatum. The dotted line indicates the boundaries of the mask that was used. For descriptive purposes, the cluster of significant activation within the left striatum (putamen) is overlaid on a standard MNI brain at $\mathrm{y}=4 \mathrm{~mm}$ and $\mathrm{z}=6 \mathrm{~mm}$. Thresholded at $\mathrm{Z}>$ 2.3 , cluster-corrected at $p<0.05$ for the volume of the left striatum. Right side of the brain is depicted at the right side.

Table 3. Independent samples T-test of all ROIs.

\begin{tabular}{|c|c|c|c|c|c|c|}
\hline & \multicolumn{2}{|c|}{$\begin{array}{l}\text { Non-dependent at FU } \\
\qquad N=11\end{array}$} & \multicolumn{2}{|c|}{$\begin{array}{c}\text { Dependent at FU } \\
\mathrm{N}=12\end{array}$} & \multirow[b]{2}{*}{ t-value } & \multirow[b]{2}{*}{$p$} \\
\hline & Mean & SD & Mean & SD & & \\
\hline PSC ACC & -.04 & .12 & -.02 & .09 & -0.66 & .515 \\
\hline PSC OFC, R & -.09 & .18 & -.02 & .13 & -1.64 & .116 \\
\hline PSC OFC, L & -.08 & .18 & -.00 & .11 & -1.36 & .187 \\
\hline PSC VTA, R & -.01 & .17 & .09 & .10 & -1.66 & .112 \\
\hline PSC VTA, L & .05 & .30 & .14 & .22 & -0.76 & .459 \\
\hline PSC Striatum, R & -.04 & .07 & -.02 & .17 & -0.36 & .724 \\
\hline PSC Striatum, L & -.05 & .11 & .03 & .09 & -2.05 & .053 \\
\hline PSC Amygdala, R & -.05 & .13 & .03 & .19 & -1.07 & .297 \\
\hline PSC Amygdala, L & -.00 & .16 & .11 & .15 & -1.64 & .116 \\
\hline
\end{tabular}

Note: ${ }^{*} p \leq .05,{ }^{* *} p \leq .01,{ }^{* * *} p \leq .001$. PSC: percentage signal change. L: left hemisphere. R: right hemisphere. ACC: Anterior cingulate cortex; OFC: Orbital frontal cortex; VTA: Ventral Tegmental Area. 


\section{Discussion}

This study examined whether baseline cannabis cue-induced brain activity independently predicted the amount of cannabis use and problem severity in frequent cannabis users at 3-year follow-up. For the first time, we showed that neural cannabis cue-reactivity in the left striatum, specifically the putamen, is an independent predictor of cannabis use related problems 3 years later. However, analyses showed that cue-induced brain activity did not predict the amount of cannabis use at follow-up. Additionally, we found that dependent cannabis users at follow up showed higher left striatal activity at baseline compared to nondependent cannabis users at trend level.

Interestingly, the correlation between right striatal activity and problem severity did not reach significance. However, given the limited power of the study it is possible that a larger sample would reveal a bilateral relation between striatal activity and problem severity. Nevertheless, it is possible that involvement of the left putamen in cue-reactivity is stronger than involvement of the right putamen. A study by Wong et al. (28) has shown a significant correlation between cue-induced craving and change in dopamine receptor occupancy in the left putamen in frequent cocaine users which is presumably caused by an increased release of intra-synaptic dopamine.

These findings support an important role for the left putamen in the course of frequent cannabis use. As part of the dorsal striatum, the putamen is thought to play an important role in the progression from goal-directed to habitual substance use (29-31). This suggests that habit formation is an important factor in developing problematic cannabis use and dependence. Indeed, in our baseline comparison of cue-reactivity (14) we found higher striatal activation in frequent cannabis users with high versus low problem severity, whereas no differences in striatal activation were found between frequent cannabis users and controls, suggesting that habit formation is an important factor in problematic cannabis use but not in cannabis use per se. Current treatments of cannabis use disorders are mainly focused on motivational aspects and contingency management. A study by Feldstein Ewing et al. (10) indeed found a relation between striatal activity and treatment outcome using motivational interviewing techniques in a one month follow-up study in adolescents who had been using cannabis for at least 7 days in the month prior to scanning. However, our results suggest that habit formation/compulsive drug taking might be an additional target for treatment.

Our results are in line with findings concerning other substances of abuse. Several studies found higher cue-induced striatal activation in heavy alcohol users and that this activity was associated with severity and duration of dependence and amount 
of use in alcohol users (32-34). Moreover, higher activation in the dorsal striatum was associated with obsessive compulsive craving (34). In addition, Demos et al. (35) found that striatal activation in response to food images predicted weight gain in first-year college students. These results support the hypothesis generated by Everitt and Robbins (29) of a shift of learning processes from ventral to dorsal areas of the striatum when substance dependence progresses. Everitt and Robbins (29) stated that at the early stages of addiction a drug is voluntarily taken because of its rewarding effects but that this behaviour becomes habitual or compulsive due to loss of control over this behaviour. They hypothesized that this shift from voluntary to compulsive behaviour at the neural level reflects a transition from prefrontal cortical to striatal control and from ventral to dorsal areas of the striatum over drug taking behaviour. Our results provide preliminary evidence that this hypothesis also applies to cannabis, because cue-induced hyperactivity in the dorsal striatum predicted cannabis problem severity in frequent cannabis users who at time of scanning, were already using cannabis regularly for at least 2 years. Importantly, cue-induced activation in the other ROls at baseline did not predict cannabis problem severity at 3-year follow-up. Since the other ROIs are thought to be mainly involved in reward evaluation and motivational aspects of drug taking behavior, our results suggest that these processes may be involved in frequent and continued cannabis use, but are less important for the development of cannabis related problems and dependence.

Baseline alcohol related problem severity and the number of daily cigarettes also independently predicted cannabis use related problem severity at 3-year follow-up as well, suggesting that alcohol, tobacco and cannabis use related problems and dependence share a common risk factor represented by increased cue-induced activation of the dorsal striatum probably related to the - already mentioned - shift from goal directed learning to habit formation.

Interestingly, cannabis problem severity at follow-up correlated positively with VTA activation. However, VTA activation did not explain unique variance as it was no longer a significant predictor when entered in the regression model. Possibly, VTA activation did not differentiate enough between high and low problem severity users at baseline. The VTA projects dopamine into the striatum. Altered dopamine transmission has been reported in early stages of cannabis use disorders (36). This might explain why VTA activity correlated with, but did not uniquely predict cannabis problem severity. Indeed, we previously found higher cannabis cue-induced activation in the VTA in frequent cannabis users compared to controls, whereas VTA activation did not differ between cannabis users with highand low problem severity (14). 
When interpreting these findings some limitations have to be taken into account. First, our sample was relatively small, making it difficult to detect subtle effects. The limited sample size could also explain the lack of a bilateral effect as the relation between right striatal activity at baseline and problem severity at followup did nog reach significance. Second, since the MINI was used as a screening instrument at baseline and no full psychiatric interview, it could not be determined if cue-induced brain activity could predict transition to cannabis dependence. Third, although the participants refrained from cannabis 24 hours prior to scanning, sub-acute effects of cannabis use could have influenced the results as cannabis can be detected in urine for 24 days after using (37). Fourth, the testretest and validity of our cannabis history questionnaire was unknown. This could have influenced the results. Finally, not all participants recruited at baseline participated in the follow-up assessment. Although analyses indicated that nonresponders were missing at random, a selection bias in the present sample cannot be fully excluded.

In conclusion, cue-induced activation in the left striatum predicted cannabis use related problem severity in frequent cannabis users at 3-year follow-up, over and beyond behavioural predictors. These findings thereby support the important role of cannabis cue-reactivity in the dorsal striatum (putamen) in the course of cannabis use towards problematic cannabis use and possibly dependence. Since the dorsal striatum is strongly involved in habit formation and compulsive behaviour, treatment of cannabis use disorders should focus on this aspect of addiction. Given the relatively small sample size, these results are preliminary and should be replicated in larger samples of cannabis users. 


\section{References}

1. Degenhardt L, Hall W. Extent of illicit drug use and dependence, and their contribution to the global burden of disease. Lancet. 2012;379(9810):55-70.

2. Stinson FS, Ruan WJ, Pickering R, Grant B. Cannabis use disorders in the USA: prevalence, correlates and co-morbidity. Psychol Med. 2006;36:1447-1460.

3. Agrawal A, Lynskey MT. The genetic epidemiology of cannabis use, abuse and dependence. Addiction. 2006;101(6):801-12.

4. Chiamulera C. Cue reactivity in nicotine and tobacco dependence: a "multiple-action" model of nicotine as a primary reinforcement and as an enhancer of the effects of smoking-associated stimuli. Brain Res Brain Res Rev. 2005;48(1):74-97.

5. Henry EA, Kaye JT, Bryan AD, Hutchison KE, Ito TA. Cannabis cue reactivity and craving among never, infrequent and heavy cannabis users. Neuropsychopharmacology. 2014;39(5):1214-21.

6. Janes AC, Pizzagalli D a, Richardt S, deB Frederick B, Chuzi S, Pachas G, et al. Brain reactivity to smoking cues prior to smoking cessation predicts ability to maintain tobacco abstinence. Biol Psychiatry. 2010;67(8):722-9.

7. Payne TJ, Smith PO, Adams SG, Diefenbach L. Pretreatment cue reactivity predicts end-oftreatment smoking. Addict Behav. 2006;31(4):702-10.

8. Marissen M a E, Franken IH a, Waters AJ, Blanken P, van den Brink W, Hendriks VM. Attentional bias predicts heroin relapse following treatment. Addiction. 2006;101(9):1306-12.

9. Grüsser SM, Wrase J, Klein S, Hermann D, Smolka MN, Ruf M, et al. Cue-induced activation of the striatum and medial prefrontal cortex is associated with subsequent relapse in abstinent alcoholics. Psychopharmacology. 2004;175(3):296-302.

10. Feldstein Ewing SW, McEachern AD, Yezhuvath $U$, Bryan AD, Hutchison KE, Filbey FM. Integrating brain and behavior: Evaluating adolescents' response to a cannabis intervention. Psychol Addict Behav. 2013;27(2):510-25.

11. Cousijn J, Van Benthem P, Van der Schee E, Spijkerman R. Motivational and control mechanisms underlying adolescent cannabis use disorders: a prospective study. Dev Cogn Neurosci. 2015;

12. Cousijn J, Goudriaan AE, Ridderinkhof KR, van den Brink W, Veltman DJ, Wiers RW. Approach-bias predicts development of cannabis problem severity in heavy cannabis users: results from a prospective FMRI study. PLoS One. 2012;7(9):e42394.

13. Cousijn J, Goudriaan AE, Wiers RW. Reaching out towards cannabis: approach-bias in heavy cannabis users predicts changes in cannabis use. Addiction. 2011;106(9):1667-74.

14. Cousijn J, Goudriaan AE, Ridderinkhof KR, van den Brink W, Veltman DJ, Wiers RW. Neural responses associated with cue-reactivity in frequent cannabis users. Addict Biol. 2013;18(3):57080.

15. Filbey FM, Schacht JP, Myers US, Chavez RS, Hutchison KE. Marijuana craving in the brain. Proc Natl Acad Sci U S A. 2009;106(31):13016-21.

16. Cousijn J, Vingerhoets WAM, Koenders L, de Haan L, van den Brink W, Wiers RW, et al. Relationship between working-memory network function and substance use: a 3-year longitudinal fMRI study in heavy cannabis users and controls. Addict Biol. 2014;19(2):282-93.

17. Saunders J, Aasland O, Babor T, de la Fuente J, Grant M. Development of the alcohol use disorders identification test (AUDIT): WHO collaborative project on early detection of persons with harmful alcohol consumption-II. Addiction. 1993;88:791-804.

18. Pope HG, Gruber a J, Hudson JI, Huestis M a, Yurgelun-Todd D. Neuropsychological performance in long-term cannabis users. Arch Gen Psychiatry. 2001;58(10):909-15.

19. Roese $\mathrm{N}$, Jamieson $\mathrm{D}$. Twenty years of bogus pipeline research: a critical review and meta-analysis. 
Psychol Bull. 1993;114:363-75.

20. Adamson SJ, Sellman JD. A prototype screening instrument for cannabis use disorder: the Cannabis Use Disorders Identification Test (CUDIT) in an alcohol-dependent clinical sample. Drug Alcohol Rev. 2003;22(3):309-15.

21. Heatherton TF, Kozlowski LT, Frecker RC, Fagerström KO. The Fagerström Test for Nicotine Dependence: a revision of the Fagerström Tolerance Questionnaire. Br J Addict. 1991;86(9):1119-27.

22. Heishman SJ, Evans RJ, Singleton EG, Levin KH, Copersino ML, Gorelick D a. Reliability and validity of a short form of the Marijuana Craving Questionnaire. Drug Alcohol Depend. 2009;102(1-3):35-40.

23. Singleton EG, Trotman AJM, Zavahir M, Taylor RC, Heishman SJ. Determination of the reliability and validity of the Marijuana Craving Questionnaire using imagery scripts. Exp Clin Psychopharmacol. 2002;10(1):47-53.

24. Vink JM, Willemsen G, Beem AL, Boomsma DI. The Fagerström Test for Nicotine Dependence in a Dutch sample of daily smokers and ex-smokers. Addict Behav. 2005;30(3):575-9.

25. Selin $\mathrm{KH}$. Test-retest reliability of the alcohol use disorder identification test in a general population sample. Alcohol Clin Exp Res. 2003;27(9):1428-35.

26. Sheenan D, Lecrubier Y, Sheenan K, Amorim P, Janavs J, Weiler E. The MINI-International Neuropsychiatric Interview (M.I.N.I.): the development and validation of a structured diagnostic psychiatric interview for DSM-IV and ICD-10. J Clin Psychiatry. 1998;59:22-33.

27. Shattuck DW, Mirza M, Adisetiyo V, Hojatkashani C, Salamon G, Narr KL, et al. Construction of a 3D probabilistic atlas of human cortical structures. Neuroimage. 2008;39(3):1064-80.

28. Wong DF, Kuwabara H, Schretlen DJ, Bonson KR, Zhou Y, Nandi A, et al. Increased Occupancy of Dopamine Receptors in Human Striatum during Cue-Elicited Cocaine Craving. Neuropsychopharmacology. 2006;31(12):2716-27.

29. Everitt BJ, Robbins TW. Neural systems of reinforcement for drug addiction: from actions to habits to compulsion. Nat Neurosci. 2005;8(11):1481-9.

30. Sjoerds Z, de Witt S, van den Brink W, Robbins T, Beekman A, Penninx B, et al. Behavioral and neuroimaging evidence of overreliance on habit formation in alcohol dependent patientsle. Transl Psychiatry. 2013;3:e337.

31. Voon V, Derbyshire K, Rück C, Irvine MA, Worbe Y, Enander J, et al. Disorders of compulsivity: a common bias towards learning habits. Mol Psychiatry. 2015;20:347-352.

32. Schacht JP, Anton RF, Myrick H. Functional neuroimaging studies of alcohol cue reactivity: a quantitative meta-analysis and systematic review. Addict Biol. 2013;18(1):121-33.

33. Sjoerds Z, van den Brink W, Beekman ATF, Penninx BWJH, Veltman DJ. Cue reactivity is associated with duration and severity of alcohol dependence: an FMRI study. Fontenelle L, editor. PLoS One. 2014;9(1):e84560.

34. Vollstädt-Klein S, Wichert S, Rabinstein J, Bühler M, Klein O, Ende G, et al. Initial, habitual and compulsive alcohol use is characterized by a shift of cue processing from ventral to dorsal striatum. Addiction. 2010;105(10):1741-9.

35. Demos KE, Heatherton TF, Kelley WM. Individual differences in nucleus accumbens activity to food and sexual images predict weight gain and sexual behavior. J Neurosci. 2012;32(16):5549-52.

36. Koob GF, Volkow ND. Neurocircuitry of addiction. Neuropsychopharmacology. 2010;35(1):217-38.

37. Lowe RH, Abraham TT, Darwin WD, Herning R, Cadet JL, Huestis MA. Extended urinary $\Delta 9$ tetrahydrocannabinol excretion in chronic cannabis users precludes use as a biomarker of new drug exposure. Drug Alcohol Depend. 2009;105(1-2):24-32. 




\section{Chapter | 7}

Low Prevalence of substance use in people with 22q11.2 deletion syndrome

Claudia Vingerhoets, Mathilde van Oudenaren, Oswald Bloemen, Erik Boot, Esther van Duin, Laurens Evers, Ania Fiksinski, Elemi Breetvelt, Lisa Palmer, Elfi Vergaelen, Annick Vogels, Carin Meijer, Jan Booij, Genetic Risk and OUtcome of Psychosis (GROUP) investigators, Lieuwe de Haan, Ann Swillen, Jacob Vorstman, Anne Bassett, Thérèse van Amelsvoort 


\begin{abstract}
Introduction: 22q11.2 deletion syndrome (22q11DS), one of the most common recurrent copy number variant disorders, is associated with dopaminergic abnormalities and an increased risk for psychotic disorders. Given the elevated prevalence of substance use (SU) and dopaminergic abnormalities in non-deleted (ND) psychotic patients, we investigated the prevalence of SU in 22q11DS, compared with that in ND-psychotic and matched healthy control groups.
\end{abstract}

Methods: This cross-sectional study involved 422 22q11DS patients, 265 NDpsychotic patients and 114 healthy controls. Psychiatric diagnosis, FSIQ, and COMT Val ${ }^{158}$ Met genotype were determined in the 22q11DS patients. SU data were collected according to the Composite International Diagnostic Interview.

Results: The prevalence of total SU (37.5\%) and substance use disorders (SUD) (1.2\%), and weekly amounts of alcohol and nicotine use, in 22q11DS patients was significantly lower than in ND-psychotic patients or controls. Compared to controls, 22q11DS patients were 8.3 times less likely to use substances in general $(p<0.001)$; results were also significant for alcohol and nicotine use separately. There were no between-group differences in the prevalence of recreational drug use. Within the 22q11DS group, there was no relationship between the prevalence of SU and psychosis, COMT genotype or FSIQ. Male 22q11DS patients were more likely to use substances than female 22q11DS patients.

Conclusion: The results suggest that 22q11DS patients are at decreased risk for SU and SUD, despite the increased risk of psychotic disorders. Further research into both neurobiological and environmental factors involved in SU in 22q11DS is necessary to elucidate the mechanisms involved. 


\section{Introduction}

22q11.2 deletion syndrome (22q11DS) is one of the most common recurrent copy number variant disorders. It is caused by a microdeletion on the long arm of chromosome 22 and affects 1 in 2,000-4,000 live births (1). The phenotypic expression is highly variable and characteristics of the syndrome include heart malformations, palatal abnormalities, hypocalcaemia, intellectual disability and high rates of psychiatric illness (1).

One of the strongest associations with psychiatric illness in 22q11DS is that with psychotic disorders (2). Schneider et al. (1) reported a prevalence of schizophrenia spectrum disorders of about $20-25 \%$ in young adults (18-25 years) with 22q11DS and approximately $40 \%$ in patients over 25 years of age. The $22 q 11.2$ deletion is amongst the strongest genetic risk factors for the development of psychosis (3). The increased risk for developing psychotic disorders may be partially explained by altered dopamine transmission in these patients (4), posited to be related to reduced gene dosage, expression and/or enzyme activity, particularly in prefrontal areas, of catechol-O-methyltransferase (COMT), a gene in the 22q11.2 deletion region (5). Moreover, the COMT gene contains a common functional polymorphism, $\mathrm{Val}^{158} \mathrm{Met}$, of which the Met variant is associated with lower enzyme activity and subsequently less dopamine breakdown(5).

The majority of patients with idiopathic psychotic disorders use substances such as alcohol, nicotine and cannabis excessively: 95\% of patients with a psychotic disorder reported lifetime substance use (SU)(6), compared to $70 \%$ in the general population (7). Patients with schizophrenia are 4.6 times more likely to have a comorbid substance use disorder (SUD) relative to the general population (8). The underlying mechanisms of this high prevalence of SUD in schizophrenia are not well understood but are likely to be associated to the brain dopaminergic pathway (9). All substances of abuse directly or indirectly activate the mesolimbic dopamine pathway which is associated with the reward properties of drugs and the positive symptoms of schizophrenia (9).

Given the dopaminergic abnormalities in both psychosis and SUD and the high prevalence of psychotic disorders and dopamine abnormalities in 22q11DS, one might hypothesize that patients with 22q11DS are at an elevated risk for SU (disorders). We therefore investigated the prevalence of SU and SUD in patients with 22q11DS, in non-deleted (ND) psychotic patients and in healthy controls (HCs). We further explored the types and amounts of substances used. In addition, within the 22q11DS group we explored the relationship between SU and psychosis, COMT Val ${ }^{158}$ Met genotype, FSIQ and gender. 


\section{Methods}

\section{Participants}

In total, 801 participants were included in this study: 422 patients with 22q11DS (191 male, 231 female), 265 ND-psychosis patients (219 male, 46 female) and 114 HCs (72 male, 42 female). The mean age of the 22q11DS patients was 30.87 years $(S D=12.65)$, of the ND-psychotic patients 29.79 years $(S D=8.41)$ and of the HCS 29.78 years $(S D=10.42)$. All participants underwent comprehensive psychiatric assessment. 22q11DS diagnosis was established with multiplex ligation-dependent probe amplification analysis (MLPA), fluorescence in situ hybridization (FISH) using a standard 22q11.2 region probe, or other clinical lab method. 22q11DS participants were recruited through four sites: Department of Psychiatry of the Maastricht University Medical Centre ( $N=95$, Netherlands), the 22q11DS outpatient clinic of the Department of Psychiatry of the University Medical Center Utrecht ( $N=68$, Netherlands), the Center for Human Genetics of the University Hospital Gasthuisberg Leuven ( $N=50$, Belgium) and the Dalglish Family 22q Clinic for adults with 22q11.2 Deletion Syndrome and/or the Clinical Genetics Research Program at the Centre for Addiction and Mental Health ( $N=209$, Canada). Patients over 15 years of age with a confirmed diagnosis of 22q11DS were included. NDpsychotic patients and HCs were participants of the Genetic Risk and Outcome Psychosis (GROUP) study (Amsterdam site) (10). Inclusion criteria for the NDpsychosis patients were: age between 15 and 60 years, and a diagnosis of a nonaffective psychotic disorder (DSM-IV TR criteria). For the HCs inclusion criteria included age between 15 and 60 years, no lifetime diagnosis of a psychotic disorder and no first-degree relative with a lifetime psychotic disorder (10).

\section{Psychiatric Assessment}

For the 22q11DS patients, psychiatric diagnoses (DSM-IV-TR) were obtained by experienced clinicians using validated instruments (SCID: Structured Clinical Interview for DSM-IV Axis I Disorder; K-SADS: Schedule for Affective Disorders and Schizophrenia for School-age Children; MINI: Mini International Neuropsychiatric Interview; MINI PAS-ADD: Mini Psychiatric Assessment Schedules for Adults with Developmental Disabilities). For the ND-psychosis group, diagnosis was established by a trained research assistant, psychologist, psychiatrist, nurse or PhD student using the Comprehensive Assessment of Symptoms and History (CASH) (10).

\section{Substance use}

For the 22q11DS group, lifetime SU data were systematically gathered from the clinical files. SU in the ND-psychosis and HC group was assessed using sections B, J 
and $\mathrm{L}$ of The Composite International Diagnostic Interview (CIDI) (11). All groups were dichotomized into a substance using (SU+) and a non-substance using (SU-) group according to the CIDI guidelines. Participants who reported to have (lifetime) used substances for at least five times or more were assigned to the SU+ group whereas participants reporting less than five times of substance use were included in the SU-group. For all groups the mean amount of alcohol and nicotine use per week was also assessed. For illicit drug use only frequency (weekly, monthly or less) was known. To ensure that the same quantities were used for alcohol and nicotine use across sites, it was determined that one pouch of tobacco (shag) equals 40 cigarettes; CIDI alcohol equivalent guidelines (response card J1) were used to compute amount of glasses per week.

\section{Intelligence}

Full scale intelligent quotient (FSIQ) was available for a subgroup of 336 (79.6\%) 22q11DS patients. In the 22q11DS group, FSIQ was assessed using ageappropriate, standardized validated instruments, including the Wechsler Adult Intelligence Scale III (WAIS III), the Wechsler Intelligence Scale for Children III (WISC-III) and the abbreviated Scale of Intelligence (WASI). Instruments varied across sites. In the ND-psychosis and HC group, FSIQ was assessed using a shortened, validated version of the WAIS-III (10).

\section{COMT-genotype}

For a subgroup of 297 (70.1\%) 22q11DS patients, COMT-Val ${ }^{158}$ Met genotype was determined using previously described, validated, standardized methods $(4,12-$ 14).

\section{Data-analyses}

A one-way Analysis of Variance (ANOVA) and a chi-square test were used to analyze group differences in age, FSIQ and gender. Prevalence of total SU and alcohol, nicotine and illicit drug use separately was computed in percentage per group and compared between the three groups using chi-square tests. In addition, we computed the prevalence of use of multiple substances and SUD per group in percentages and compared these between groups using chi-square tests. The mean amount of alcohol and nicotine use per week was compared between the three groups using an ANOVA. Frequency of illicit drug use was compared between the three groups using chi-square analyses. Additionally, the prevalence of drug use was computed for separate classes of drugs (cannabis, cocaine, XTC/3,4methylenedioxymethamphetamine (MDMA), psychedelics, opiates, sedatives, 
stimulants and phencyclidine (PCP, Angel dust)). Prevalence of regular cannabis use (daily or weekly) was compared between the three groups using a chi-square test. This analysis was not conducted for other classes of drugs since the prevalence was very low in at least one of the groups.

Odds ratios were computed to examine the risk for total SU and alcohol, nicotine and illicit drug use separately for 22q11DS patients in comparison to HCs. Within the 22q11DS group the relationships between SU and psychotic disorders, gender, intellectual disability (ID, FSIQ <70) and COMT-genotype were examined by means of odds ratios. In addition, prevalence of SU was calculated for separate categories of ID and the relation between age and SU was computed. Statistical analyses were conducted with IBM SPSS Statistics, version 23 except for the odds ratios which were obtained using Medcalc online calculator (MedCalc Software, Ostend, Belgium; http://www.medcalc.org/).

\section{Results}

\section{Demographic variables}

The three groups significantly differed in gender distribution $\left(\chi^{2}(2)=95.41, p<.001\right)$ as well as in FSIQ $(F(2,696)=482.26 ; p<.001)$ (table 1). Of the 22q11DS patients, $\mathrm{n}=274(71.2 \%)$ were diagnosed with a psychiatric disorder, and of this group $n=165$ (39.1\%) had a psychotic disorder.

Table 1. Sample demographics.

\begin{tabular}{|c|c|c|c|c|c|c|c|}
\hline & \multicolumn{2}{|c|}{ 22q11DS } & \multicolumn{2}{|c|}{$\begin{array}{l}\text { ND-Psychotic } \\
\text { disorder }\end{array}$} & \multicolumn{2}{|c|}{ Healthy controls } & \multirow[b]{2}{*}{$P$} \\
\hline & $\mathbf{N}$ & Mean (SD) & $\mathbf{N}$ & Mean (SD) & $\mathbf{N}$ & Mean (SD) & \\
\hline Age & 422 & $30.87(12.6)$ & 265 & $29.79(8.4)$ & 114 & $29.78(10.4)$ & .387 \\
\hline \multirow[t]{3}{*}{$F S I Q^{a, b, c}$} & 336 & $66.69(14.4)$ & 254 & $97.73(16.2)$ & 109 & 111.17 & $<.001$ \\
\hline & & & & & & $(16.2)$ & \\
\hline & $\mathbf{N}$ & Distribution & $\mathbf{N}$ & Distribution & $\mathbf{N}$ & Distribution & $P$ \\
\hline $\begin{array}{l}\text { Gender } \\
\text { (male/female) }^{a, b, c}\end{array}$ & 422 & $191 / 231$ & 265 & $219 / 46$ & 114 & $72 / 42$ & $<.001$ \\
\hline Psychosis (y/n) & 421 & $165 / 256$ & 265 & $265 / 0$ & 114 & $0 / 0$ & \\
\hline
\end{tabular}

FSIQ: Full-Scale Intelligence Quotient. $\mathrm{a}=p<.05$ for 22q11DS vs. healthy controls $\mathrm{b}=p<.05$ for 22q11DS vs. ND (non-deleted)-psychotic disorder $\mathrm{c}=p<.05$ for ND-psychosis vs. healthy controls 


\section{Prevalence of substance use}

The prevalence of subjects with any SU was significantly lower $n=158$ (37.5\%) in the 22q11DS group than in the HC group ( $\left.n=94,82.5 \% ; \chi^{2}(d f=2) 18.99, p<.001\right)$ or in the ND-psychosis group ( $\left.n=233,87.9 \% ; \chi^{2}(d f=2) 112.40, p<.001\right)$ (Table 2). The prevalence of subjects who met DSM-IV-TR criteria for SUD (abuse or dependence) was also significantly less in the 22q11DS group compared to the HC and NDpsychosis groups, as were alcohol, nicotine and multiple drug use (Table 2). The prevalence of illicit drug use was significantly lower in the 22q11DS group than in the ND-psychosis group $\left(\chi^{2}(d f=2) 23.096, p<.001\right)$. No significant difference was found between 22q11DS and HCs $\left(\chi^{2}(d f=2) 1.918, p=0.17\right)$ or between HCs and ND-psychosis patients $\left(\chi^{2}(\mathrm{df}=2) 3.427, p=0.064\right)$.

Table 2. Prevalence of SU and SUD in 22q11DS, ND-psychosis and HCs.

\begin{tabular}{|c|c|c|c|c|c|c|c|c|}
\hline & \multicolumn{2}{|l|}{ 22q11DS } & \multicolumn{2}{|c|}{$\begin{array}{l}\text { ND-Psychotic } \\
\text { disorder }\end{array}$} & \multicolumn{2}{|l|}{$\begin{array}{l}\text { Healthy } \\
\text { controls }\end{array}$} & \multirow[b]{2}{*}{$x^{2}$} & \multirow[b]{2}{*}{$P$} \\
\hline & $\mathbf{N}$ & $\%$ & $\mathbf{N}$ & $\%$ & $\mathbf{N}$ & $\%$ & & \\
\hline Total SU & $160 / 422$ & 37.5 & $233 / 265$ & 87.9 & $94 / 114$ & 82.5 & 214.11 & $<.001$ \\
\hline$S U D^{a, b, c}$ & $5 / 422$ & 1.2 & $73 / 265$ & 27.5 & $10 / 114$ & 8.8 & 116.35 & $<.001$ \\
\hline Alcohol $^{a, b, c}$ & $128 / 414$ & 30.9 & $185 / 265$ & 69.8 & $86 / 94$ & 91.5 & 165.99 & $<.001$ \\
\hline Nicotine $e^{a, b, c}$ & $71 / 420$ & 16.9 & $166 / 264$ & 62.9 & $37 / 113$ & 32.7 & 152.03 & $<.001$ \\
\hline Illicit drugs ${ }^{b}$ & $28 / 412$ & 6.8 & $123 / 265$ & 46.5 & $12 / 102$ & 11.8 & 23.265 & $<.001$ \\
\hline $\begin{array}{l}\text { Multi drug } \\
\text { use }^{a, b, c}\end{array}$ & $6 / 412$ & 1.5 & $47 / 265$ & 17.7 & $9 / 102$ & 8.8 & 50.856 & $<.001$ \\
\hline
\end{tabular}

SU: substance use; SUD: substance use disorder; ND: non-deleted psychosis $a=p<.05$ for 22q11DS vs. healthy controls

$\mathrm{b}=p<.05$ for 22q11DS vs. ND-psychosis

$\mathrm{c}=p<.05$ for ND-psychosis vs. healthy controls

\section{Weekly substance use}

The mean weekly amount of alcohol (number of drinks) $(F(2,38)=17.00 ; p<.001)$ and nicotine (number of cigarettes) $(F(2,249)=29.36 ; p<.001)$ use differed significantly across all groups (Table 3 ). Post-hoc analyses showed that the weekly amount of alcohol use was significantly lower in the 22q11DS group compared to the ND-psychosis $(p<.001)$ and HC $(p<.001)$ groups. There was no significant difference in weekly alcohol use between the ND-psychosis and HC groups $(p=0.54)$. Nicotine use was significantly lower in the 22q11DS compared to the ND- 
psychosis group $(p<.001)$ but not compared to the HC group $(p=0.23)$. Nicotine use was significantly higher in the ND-psychosis group compared to the HC group $(p<.001)$.

Table 3. Mean amount of SU per week in 22q11DS, psychosis and healthy controls.

\begin{tabular}{|c|c|c|c|c|c|c|}
\hline & \multicolumn{2}{|c|}{ 22q11DS } & \multicolumn{2}{|c|}{ ND-Psychosis } & \multicolumn{2}{|c|}{ Healthy controls } \\
\hline & $\mathbf{N}$ & $\begin{array}{l}\text { Mean } \\
\text { (SD) }\end{array}$ & $\mathbf{N}$ & $\begin{array}{l}\text { Mean } \\
\text { (SD) }\end{array}$ & $\mathbf{N}$ & $\begin{array}{l}\text { Mean } \\
\text { (SD) }\end{array}$ \\
\hline $\begin{array}{l}\text { Alcohol } \\
\text { (number of drinks) }\end{array}$ & 117 & $2.6(4.2)$ & 185 & $10.6(15.0)$ & 86 & $8.9(10.3)$ \\
\hline $\begin{array}{l}\text { Nicotine } \\
\text { (number of cigarettes) }^{a, c}\end{array}$ & 50 & $49.1(56.3)$ & 166 & $121.7(65.7)$ & 36 & $71.9(61.7)$ \\
\hline \multicolumn{7}{|c|}{$a=p<.05$ for 22q11DS vs. ND (non-deleted)-psychosis. } \\
\hline \multicolumn{7}{|c|}{$b=p<.05$ for $22 q 11 D S$ vs. healthy controls } \\
\hline \multicolumn{7}{|c|}{$c=p<.05$ for psychosis vs. healthy controls } \\
\hline
\end{tabular}

\section{Frequency and characterization of illicit drug use}

Frequency of drug use (weekly, daily, or less) was low in the 22q11DS group; except for cannabis, all substances were used less than weekly. The number of patients using cannabis on a regular basis (daily or weekly) was significantly lower in the 22q11DS group compared to the ND-psychosis and HC group ( $\chi^{2}(d f=2)$ $48.215, p<.001)$. Table 4 displays an overview of frequency and classes of drugs used per group. The three groups differed significantly in multiple $S U\left(\chi^{2}(d f=2)\right.$ $60.67, p<.001$ ) (Figure 1). 
Table 4. Classes of illicit drugs and frequency of use in 22q11DS, non-deleted psychosis and healthy controls.

\begin{tabular}{|c|c|c|c|c|c|c|}
\hline & \multicolumn{2}{|c|}{ 22q11DS } & \multicolumn{2}{|c|}{ Psychosis } & \multicolumn{2}{|c|}{ Healthy controls } \\
\hline & $\mathbf{N}$ & $\%$ & $\mathbf{N}$ & $\%$ & $\mathbf{N}$ & $\%$ \\
\hline Cannabis & 28 & 8.5 & 122 & 37.7 & 25 & 24.5 \\
\hline Daily & 2 & 0.5 & 74 & 27.9 & 12 & 11.8 \\
\hline Weekly & 1 & 0.2 & 25 & 9.4 & 3 & 2.9 \\
\hline Less & 25 & 6.1 & 23 & 8.7 & 10 & 10.0 \\
\hline Cocaine & 2 & 0.5 & 34 & 12.8 & 4 & 3.9 \\
\hline Daily & 0 & 0.0 & 6 & 2.3 & 0 & 0.0 \\
\hline Weekly & 0 & 0.0 & 11 & 4.2 & 1 & 1.0 \\
\hline Less & 2 & 0.5 & 17 & 6.4 & 3 & 2.9 \\
\hline XTC / MDMA & 0 & 0.0 & 31 & 11.7 & 9 & 8.8 \\
\hline Daily & 0 & 0.0 & 1 & 0.4 & 0 & 0.0 \\
\hline Weekly & 0 & 0.0 & 5 & 1.9 & 1 & 1.0 \\
\hline Less & 0 & 0.0 & 25 & 9.4 & 8 & 7.8 \\
\hline Psychedelics & 3 & 0.7 & 22 & 8.3 & 4 & 3.9 \\
\hline Daily & 0 & 0.0 & 2 & 0.8 & 0 & 0.0 \\
\hline Weekly & 0 & 0.0 & 1 & 0.4 & 1 & 1.0 \\
\hline Less & 3 & 0.7 & 19 & 7.2 & 3 & 2.9 \\
\hline Opiates & 0 & 0.0 & 0 & 0.0 & 0 & 0.0 \\
\hline Daily & 0 & 0.0 & 0 & 0.0 & 0 & 0.0 \\
\hline Weekly & 0 & 0.0 & 0 & 0.0 & 0 & 0.0 \\
\hline Less & 0 & 0.0 & 0 & 0.0 & 0 & 0.0 \\
\hline Sedatives & 1 & 0.2 & 0 & 0.0 & 0 & 0.0 \\
\hline Daily & 0 & 0.0 & 0 & 0.0 & 0 & 0.0 \\
\hline Weekly & 0 & 0.0 & 0 & 0.0 & 0 & 0.0 \\
\hline Less & 1 & 0.2 & 0 & 0.0 & 0 & 0.0 \\
\hline Stimulants & 0 & 0.0 & 23 & 8.7 & 1 & 1.0 \\
\hline Daily & 0 & 0.0 & 6 & 2.3 & 0 & 0.0 \\
\hline Weekly & 0 & 0.0 & 2 & 0.8 & 1 & 1.0 \\
\hline Less & 0 & 0.0 & 15 & 5.7 & 0 & 0.0 \\
\hline РCP & 0 & 0.0 & 2 & 0.8 & 0 & 0.0 \\
\hline Daily & 0 & 0.0 & 0 & 0.0 & 0 & 0.0 \\
\hline Weekly & 0 & 0.0 & 0 & 0.0 & 0 & 0.0 \\
\hline Less & 0 & 0.0 & 2 & 0.8 & 0 & 0.0 \\
\hline
\end{tabular}

XTC: ecstasy; MDMA: 3,4-methylenedioxymethamphetamine; PCP: phencyclidine. 


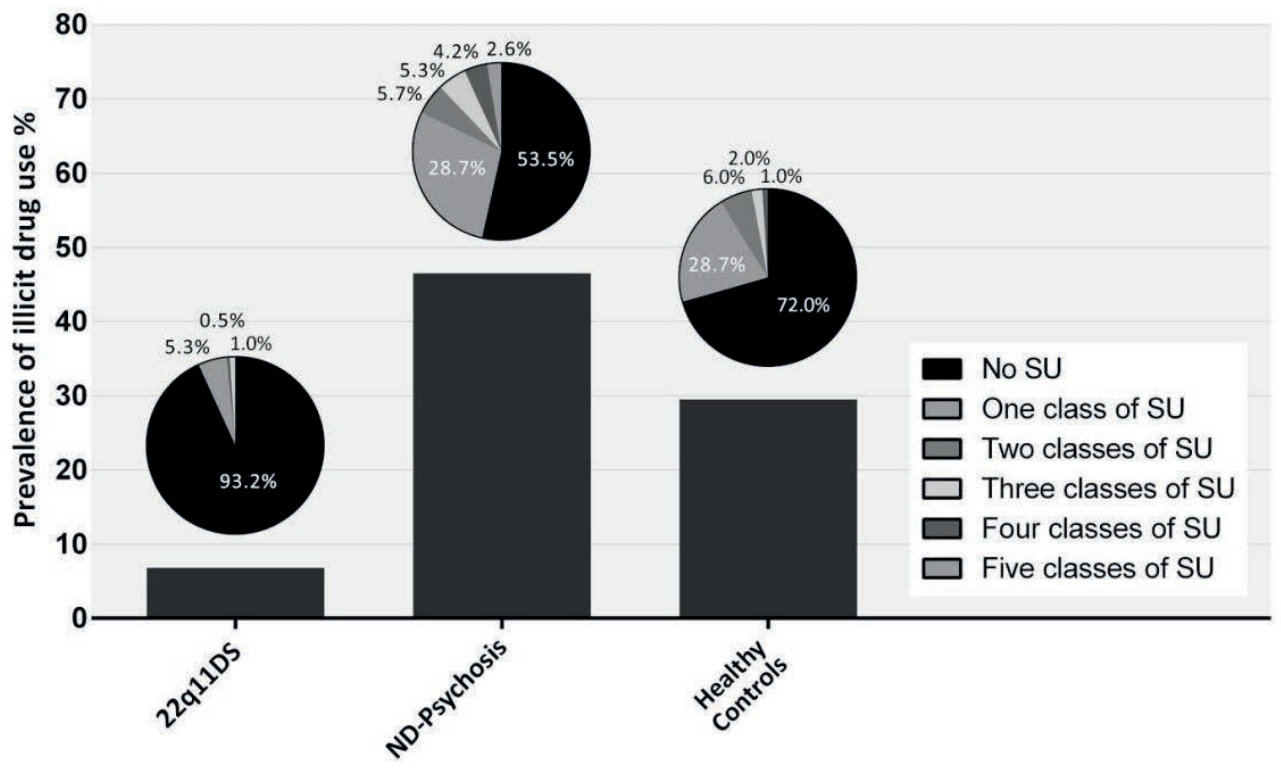

Figure 1. Prevalence of multi-substance use per group.

\section{Odds ratio}

Compared to HCs, 22q11DS patients were 8.3 times less likely to use substances in general $[\mathrm{OR}=0.12,95 \%$ confidence interval $(\mathrm{Cl}): 0.07-0.20 ; p<0.001]$. Specifically, patients with 22q11DS were 2.4 times less likely to use nicotine [OR=0.42 (95\% confidence interval $(\mathrm{Cl}): 0.26-0.67 ; p=0.003$ ] and 25 times less likely to use alcohol [OR=0.04 (95\% confidence interval $(\mathrm{Cl}): 0.02-0.09 ; p<.001]$. No significant difference was found for illicit drug use $[\mathrm{OR}=0.67$ (95\% confidence interval $(\mathrm{Cl})$ : $0.33-1.35 ; p=0.23]$.

Relationships between substance use and psychosis, COMT-genotype, gender and FSIQ

Within 22q11DS, the presence of a psychotic disorder [OR $=0.75,95 \%$ confidence interval $(\mathrm{Cl})$ : 0.50-1.12; $p=0.17$ ] or COMT Val ${ }^{158}$ Met-genotype [OR=0.75, 95\% (CI): $0.47-1.22 ; p=0.30$ ] did not significantly increase the likelihood of SU. Also, patients with ID were not at increased risk for SU [OR=0.80, 95\% (CI): 0.51-1.27; $p=0.35$ ]. Male patients with 22q11DS were 1.5 times more likely to use substances than female patients [OR=1.53, 95\% confidence interval $(\mathrm{Cl}): 1.02-2.27 ; p=0.038$ ]. 
Finally, a small but significant relation was found between age and SU $(r=0.156$, $\mathrm{N}=422, p=0.001$ ); prevalence of SU increased with age.

\section{Discussion}

This is the first study to investigate the prevalence of SU and SUD in a large sample of patients with 22q11DS compared to those in ND-psychosis patients and HCs. We report a significantly lower prevalence of overall SU and SUD in 22q11DS compared to HCs and ND-psychosis patients. 22q11DS patients were significantly less likely than HCs to use substances in general, alcohol and nicotine. Interestingly, patients with 22q11DS were not at decreased risk for illicit drug use. However, this could be due to the low prevalence number of subjects that reported illicit drug use. These results indicate that 22q11DS patients are at decreased risk for $\mathrm{SU}$, suggesting that the 22q11.2 deletion could be a protective factor for starting and/or continuing SU, despite the elevated risk of psychosis.

The underlying mechanisms of this reduced lifetime prevalence of SU in 22q11DS are currently unknown. Multiple factors are likely to be involved including environmental, personality, maturity and neurobiological factors. To gain more insight into these mechanisms, it is important to differentiate between initiating and continuing SU. In addition to a low prevalence of total SU, the mean amount of alcohol and nicotine used per week was also significantly lower in 22q11DS. This could suggest that different mechanisms underlie the initiation and continuation of SU in these patients. Decreased SU could be related to high levels of anxiety and anxiety disorders reported in 22q11DS $(1,15)$. High levels of anxiety are related to less of the sensation-seeking behavior (16) that is related to increased risk-taking behavior and illicit SU (16). Therefore, it could be hypothesized that patients with 22q11DS may be fearful to try new things, especially potential harmful things such as illicit drug use. This could also explain the low use of multiple substances in 22q11DS. Sensation-seeking is also related to antisocial and delinquent behavior (17). In typically developing subjects and subjects with mild or borderline ID without 22q11DS, SU and SUD are more prevalent in those with a forensic history or displaying antisocial behavior $(18,19)$. Although formal studies examining the prevalence of sensation-seeking or delinquency in 22q11DS are lacking, conduct disorder ( $C D$, often a harbinger of antisocial personality disorder) is rare in these patients (1). Therefore, it is likely that levels of sensation seeking and delinquent behavior are low in 22q11DS as well, which could also contribute to the decreased risk for SU in these patients.

Alternatively, lower risk of SU and SUD in 22q11DS may be related to aberrant reward processing. The reward processing system contains multiple components 
including reward anticipation (wanting, goal directed behavior), hedonic response (liking), and learning (20). This system is important in moderating human behavior, including feelings of pleasure. Reward processing is mainly modulated by dopamine arising from the ventral tegmental area (VTA) and projecting to nucleus accumbens (ventral striatum) and frontal cortex (9). Functional magnetic resonance imaging ( $\mathrm{FMRI}$ ) studies in SUD have shown a decreased blood-oxygenlevel dependent (BOLD) response in the striatum during non-drug related reward anticipation (21,22), but increased brain activation during drug related reward anticipation (related to drug-seeking behavior) (23). In schizophrenia, fMRI studies repeatedly showed altered reward processing, which, consistent with SUD, has been associated with decreased striatal activity during reward anticipation (24). However, the hedonic response remains intact (25), thereby potentially explaining SU continuation in ND-psychotic illness. The reward system in 22q11DS has been little studied. The one (fMRI) study investigating the neurobiological mechanisms of reward anticipation in 22q11DS reported, contrary to findings in SUD and schizophrenia, no differences in striatal activation between 22q11DS and HCs, suggesting different underlying mechanisms of reward processing in 22q11DS (14). However, 22q11DS patients had reduced activation in the medial frontal areas during monetary reward anticipation compared to HCs (14), which could indicate a decreased hedonic response during anticipation of possible reward. Indeed, deficits in anticipatory and consummatory pleasure in 22q11DS compared to HCs have recently been reported (26). These results suggest that 22q11DS patients may experience less pleasure when using substances which could help to explain low drug-seeking behavior in 22q11DS. These potential reduced reinforcing effects of substances of abuse in 22q11DS could be related to the dopaminergic abnormalities as a result of reduced COMT activity in these patients. All substances of abuse directly or indirectly activate the dopamine system (9) by generating a rapid increase (phasic dopamine response) in extracellular dopamine in the striatum which is associated with the reinforcing effects of drugs in both addicted and non-addicted subjects (9). Therefore, it could be hypothesized that, due to reduced COMT activity, 22q11DS is associated with higher tonic (background) dopamine, causing reduced reinforcing effects and subsequently, less SU (14). In contrast, compared to HCs, ND-psychotic patients have shown increased striatal dopamine synthesis in response to an acute amphetamine challenge (phasic dopamine signaling) (27), suggesting that ND-psychotic patients may be more sensitive to the rewarding effects of substances. This could help explain the high prevalence of SU in psychosis. However, all of these speculations require further investigation, including more studies focusing on the dopaminergic system. 
In ND-subjects with mild/borderline ID, increased risk of problematic SU and low prevalence of non-problematic SU have been reported (28). However, a recent study among subjects with mild / moderate ID in Belgium reported nonproblematic SU to be comparable to SU in the general population (29). In the current study, ID did not influence the risk for SU in 22q11DS. Previous studies have reported that SU is more likely in patients with ID and a psychotic disorder (19). However, in our 22q11DS sample we did not find a relation between psychotic disorders and SU. Similar to studies of general population samples and in ND-subjects with ID (30), we found that male patients with 22q11DS were more likely to use substances than female patients (30).

\section{Strengths and limitations}

An important strength of the current study is the large sample of adult 22q11DS patients. Since 22q11DS is a relatively rare and under-recognized disorder, most studies include small sample sizes, reducing statistical power. Another strength of this study is the inclusion of both a HC and a ND-psychosis group, enabling direct group comparisons.

When interpreting these findings, some limitations have to be taken into account. First, 22q11DS patients were recruited through outpatient clinics for 22q11DS and genetic departments and the psychotic patients and HCs were recruited for research purposes. Therefore, these samples are not true epidemiological samples and are likely to be biased to some extend by clinical ascertainment. Second, SU data of the 22q11DS patients was based on the clinical files and/or self-reports of the patients. Therefore, for the minority of the patients not all information was complete. Third, the current study had a cross-sectional design and the data were assessed across different sites by multiple researchers using different instruments. Although predetermined guidelines were used, inter-rater differences cannot be ruled out as cross-site inter-reliability analyses were not performed.

\section{Summary}

In conclusion, we found the prevalence of SU to be significantly lower in 22q11DS patients compared with both ND-psychotic patients and HCs. The results suggest that 22q11DS patients are at decreased risk for SU and SUD, despite their increased risk of psychosis. More research on both neurobiological mechanisms and environmental factors of SU in these patients is necessary in order to provide further insight into the mechanisms underlying psychosis and addiction. In addition, 22q11DS could be a valuable model to study genetic factors underlying SU and SUD in the general population. 


\section{References}

1. Schneider M, Debbané M, Bassett AS, Chow EWC, Fung WLA, van den Bree M, et al. Psychiatric disorders from childhood to adulthood in 22q11.2 deletion syndrome: results from the International Consortium on Brain and Behavior in 22q11.2 Deletion Syndrome. Amercian Journal of Psychiatry 2014; 171(6):627-39.

2. Bassett AS, Chow EWC, AbdelMalik P, Gheorghiu M, Husted J, Weksberg R. The schizophrenia phenotype in 22q11 deletion syndrome. American Journal of Psychiatry 2003; 160(9):1580-6.

3. Murphy KC, Jones LA, Owen MJ. High rates of schizophrenia in adults with velo-cardio-facial syndrome. Archives of General Psychiatry 1999; 56(10):940-5.

4. Boot E, Booij J, Zinkstok J, Abeling N, de Haan L, Baas F, et al. Disrupted dopaminergic neurotransmission in 22q11 deletion syndrome. Neuropsychopharmacology 2008; 33(6):1252-8.

5. Gothelf D, Law AJ, Frisch A, Chen J, Zarchi O, Michaelovsky E, et al. Biological effects of COMT haplotypes and psychosis risk in 22q11.2 deletion syndrome. Biological Psychiatry 2014; 75(5):406-13.

6. Barnes TRE, Mutsatsa SH, Hutton SB, Watt HC, Joyce EM. Comorbid substance use and age at onset of schizophrenia. Britisch Journal of Psychiatry 2006; 188(3):237-42.

7. Young SE, Corley RP, Stallings MC, Rhee SH, Crowley TJ, Hewitt JK. Substance use, abuse and dependence in adolescence: prevalence, symptom profiles and correlates. Drug \& Alcohol Dependence 2002; 68(3):309-22.

8. Chambers RA, Krystal JH, Self DW. A neurobiological basis for substance abuse comorbidity in schizophrenia. Biological Psychiatry $2001 ;$ 50(2):71-83.

9. Volkow ND. Substance use disorders in schizophrenia--clinical implications of comorbidity. Schizophrenia Bulletin 2009; 35(3):469-72.

10. Korver N, Quee PJ, Boos HBM, Simons CJP, de Haan L. Genetic Risk and Outcome of Psychosis (GROUP), a multi-site longitudinal cohort study focused on gene-environment interaction: objectives, sample characteristics, recruitment and assessment methods. International Journal of Methods in Psychiatry Research 2012; 21(3):205-21.

11. Robins LN. The Composite International Diagnostic Interview. Archives of General Psychiatry 1988; 45(12):1069.

12. Bassett AS, Caluseriu O, Weksberg R, Young DA, Chow EWC. Catechol-O-methyl transferase and expression of schizophrenia in 73 adults with 22q11 deletion syndrome. Biological Psychiatry 2007; 61(10):1135-40.

13. Vorstman JAS, Turetsky BI, Sijmens-Morcus MEJ, de Sain MG, Dorland B, Sprong M, et al. Proline affects brain function in 22q11DS children with the low activity COMT 158 allele. Neuropsychopharmacology 2009; 34(3):739-46.

14. van Duin EDA, Goossens L, Hernaus D, da Silva Alves F, Schmitz N, Schruers K, et al. Neural correlates of reward processing in adults with 22q11 deletion syndrome. Journal of Neurodevelopmental Disorders 2016; 8:25.

15. Angkustsiri K, Leckliter I, Tartaglia N, Beaton EA, Enriquez J, Simon TJ. An examination of the relationship of anxiety and intelligence to adaptive functioning in children with chromosome 22q11.2 deletion syndrome. Journal of Developmental Behavioral Pediatrics 2012; 33(9):713-20.

16. Roberti JW. A review of behavioral and biological correlates of sensation seeking. Journal of Research in Personality 2004; 38(3):256-79.

17. Harden KP, Quinn PD, Tucker-Drob EM. Genetically influenced change in sensation seeking drives the rise of delinquent behavior during adolescence. Developmental Science 2012; 15(1):150-63. 
18. Compton WM, Conway KP, Stinson FS, Colliver JD, Grant BF. Prevalence, Correlates, and Comorbidity of DSM-IV Antisocial Personality Syndromes and Alcohol and Specific Drug Use Disorders in the United States: Results From the National Epidemiologic Survey on Alcohol and Related Conditions. Journal of Clinical Psychiatry 2005; 66(6):677-85.

19. Raina P, Lunsky Y. A comparison study of adults with intellectual disability and psychiatric disorder with and without forensic involvement. Research in Developmental Disabilities. 2010; 31(1):21823.

20. Berridge KC, Robinson TE. Parsing reward. Trends in Neuroscience. 2003; 26(9):507-13.

21. van Hell H, Vink M, Ossewaarde L, Jager G, Kahn R, Ramsey N. Chronic effects of cannabis use on the human reward system: an fMRI study. European Neuropsychopharmacology 2010; 20(3):15363.

22. Martz ME, Trucco EM, Cope LM, Hardee JE, Jester JM, Zucker RA, et al. Association of Marijuana Use With Blunted Nucleus Accumbens Response to Reward Anticipation. JAMA Psychiatry 2016; 73(8):838

23. Wrase J, Schlagenhauf F, Kienast T, Wüstenberg T, Bermpohl F, Kahnt T, et al. Dysfunction of reward processing correlates with alcohol craving in detoxified alcoholics. Neuroimage 2007; 35(2):787-94.

24. Esslinger C, Englisch S, Inta D, Rausch F, Schirmbeck F, Mier D, et al. Ventral striatal activation during attribution of stimulus saliency and reward anticipation is correlated in unmedicated first episode schizophrenia patients. Schizophrenia Research 2012; 140(1):114-21.

25. Strauss GP, Waltz JA, Gold JM. A review of reward processing and motivational impairment in schizophrenia. Schizophrenia Bulletin 2014; 40 Suppl 2(Suppl 2):S107-16.

26. Dubourg L, Schneider M, Padula M, Eliez S. Reward processes, white matter pathways of the reward system and negative symptoms in 22q11DS. In: 3402. OHBM; 2016.

27. Laruelle M, Abi-Dargham A, van Dyck CH, Gil R, D'Souza CD, Erdos J, et al. Single photon emission computerized tomography imaging of amphetamine-induced dopamine release in drug-free schizophrenic subjects. Proceedings of the National Acadamy of Sciences of the United States of America 1996 ; 93(17):9235-40.

28. Carroll Chapman SL, Wu L-T. Substance abuse among individuals with intellectual disabilities. Research in Developmental Disabilities 2012; 33(4):1147-56.

29. Swerts C, Vandevelde S, VanDerNagel JEL, Vanderplasschen W, Claes C, De Maeyer J. Substance use among individuals with intellectual disabilities living independently in Flanders. Research in Developmental Disabilities 2016;

30. Chaplin E, Gilvarry C, Tsakanikos E. Recreational substance use patterns and co-morbid psychopathology in adults with intellectual disability. Research in Developmental Disabilities 2011; 32(6):2981-6. 



\section{Chapter | 8}

Summary and general discussion

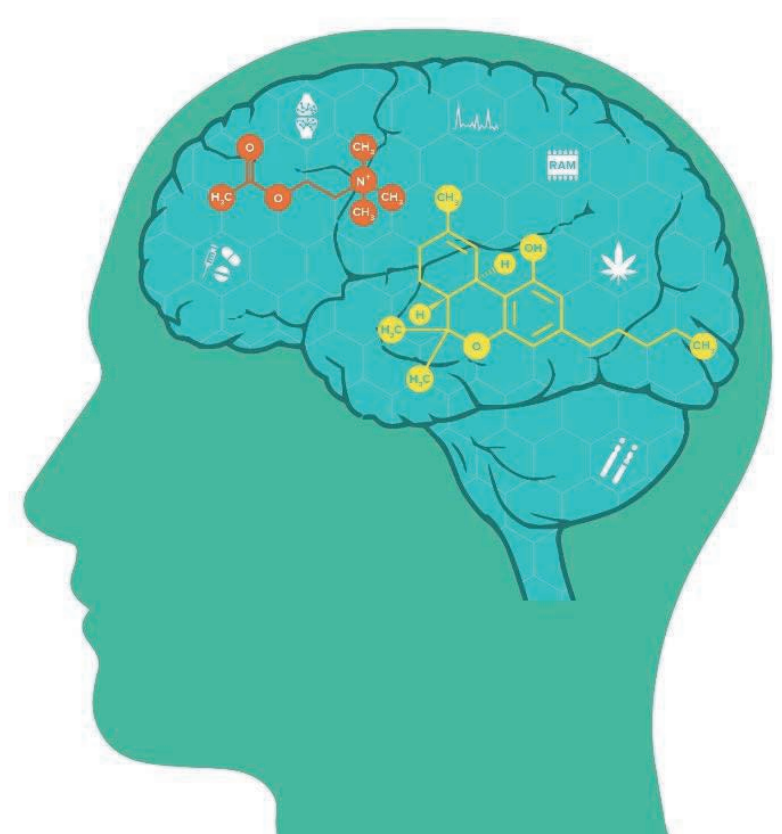




\section{Summary}

The overall aim of this thesis was to provide more insight into the neurobiological mechanisms underlying comorbid cognitive symptoms in psychosis and continued frequent substance use. In the first part of this thesis, neurobiological mechanisms of cognitive symptoms in subjects with a psychotic disorder were examined (chapter 2 - chapter 4), with a focus on the cholinergic system. In the second part of this thesis, underlying neurobiological mechanisms of substance use were examined, focusing on mechanisms underlying continued frequent cannabis use (chapter 5 - chapter 7). In this final chapter, the main findings of these studies are summarized and discussed as well as the clinical implications of these findings and future directions.

In chapter 2, the effectiveness of pharmacological interventions for separate cognitive domains critically impaired in schizophrenia patients, as established by the MATRICS initiative, were reviewed. The reviewed studies provided evidence for a role of the dopaminergic $D_{1}$ receptor subtype in processing speed and reasoning and problem solving. The serotonergic, GABA-ergic and glutamatergic system were found to be involved in different aspects of memory. The latter system was also found to be involved in reasoning and problem solving. Finally, nicotine acetylcholine receptors (nAChRs) have been found to modulate attention and vigilance. However, results from a limited number of studies suggested that memory functions may be enhanced with agents targeting the muscarinic system. Overall, these findings indicate that different mechanisms underlie separate aspects of cognition which suggest that patients with schizophrenia with different cognitive profiles may benefit from different intervention strategies.

In chapter 3 , the role of the muscarinic $M_{1}$ receptor in cognitive function in subjects with a psychotic disorder was examined by means of the $M_{1}$ antagonist biperiden as a pharmacological challenge. Blocking the $M_{1}$ receptor significantly impaired both visual and verbal learning and memory which is indicative of a role of this receptor in these cognitive domains. An interaction effect was found between medication and group on reasoning and problem solving; in the psychosis group this domain improved after biperiden administration, whereas performance on this domain in the healthy control group worsened after biperiden administration. This indicates that the effect of $M_{1}$ antagonism on this domain was different for both groups. The effects of biperiden on the other cognitive domains were comparable in the psychosis and the healthy control group. Although these 
results confirm a role of the $M_{1}$ receptor subtype in memory performance, the lack of a differential effect of $M_{1}$ blockade between the studied groups could indicate that $M_{1}$ receptor deficits were not present in our sample and are possibly only present in older, chronic schizophrenia patients.

Chapter 4 elucidates on the role of the cholinergic system in psychosis and associated cognitive impairments. We examined whether brain choline (cho) concentrations in the anterior cingulate cortex (ACC) and striatum differed between subjects with a psychotic disorder and controls and whether blockade of the $M_{1}$ receptor influenced cho concentrations in these regions. In addition, it was examined if cho concentrations were associated with separate domains of cognition. The significant inverse correlation between attention and striatal cho found in the psychotic subjects confirms previous findings of a role of the cholinergic system in cognitive symptoms of psychosis. Although we cannot rule out that there are cholinergic abnormalities present in chronic schizophrenia patients, the lack of a significant difference in cho concentrations between the groups, both after biperiden and placebo, in both brain regions could indicate that no severe cholinergic abnormalities were present in this sample of relative young and well-functioning psychotic subjects.

In chapter 5, the relationship between working memory network function and continued, frequent cannabis use was examined in a longitudinal 3-year follow-up functional MRI study. In the baseline study, it was found that despite comparable working memory network functioning and performance on a working-memory task (behavioral) in heavy cannabis users and healthy non-using control subjects, a stronger working memory network response was related to increased weekly cannabis use over a 6-month period. The follow-up results showed that despite improved performance on the working memory task in both groups, working memory network function did not change over the 3-year period. Contrary to previous findings, no association was found between baseline working memory network response and cannabis, nicotine, alcohol or other recreational drug use. These results suggest that continued cannabis use does not significantly influence working memory network functioning.

Elaborating on previously findings of increased activation in response to cannabis cues in heavy cannabis users compared to controls in the ventral tegmental area (VTA), as well as a higher activation in the ACC, orbitofrontal cortex (OFC) and striatum in more problematic cannabis users compared to less problematic 
cannabis users, chapter 6 describes the results of a follow-up study investigating the value of neural cue-reactivity in these brain regions in predicting changes in weekly cannabis use and related problem severity over a 3-year period. None of the regions identified in the baseline study were found to predict weekly cannabis use at 3-year follow-up. However, increased activation in the left (dorsal) striatum predicted cannabis related problem severity after 3 years which suggest cuereactivity might be a useful tool in predicting transition to problematic cannabis use and possibly cannabis dependence.

In chapter 7, the prevalence of substance use and substance use disorders in 22q11.2 deletion syndrome (22q11DS), a population at high risk for developing psychotic disorders, was determined. The deletion on chromosome 22q11.2 defining this group of patients includes genes which have been associated with both psychotic disorders and substance use disorders. Therefore, investigating patterns of substance use in these patients may provide valuable insight in the genetic aspects of both psychosis and substance use disorders. Compared to psychotic patients (88\%) and healthy controls subjects $(82 \%)$, the prevalence of overall substance use (37\%) and substance use disorders (1.2\%) was low in 22q11DS patients. Furthermore, we found that these patients were at decreased risk for overall substance use as well alcohol and nicotine use separately. Interestingly, prevalence of recreational drug use did not differ between the three groups. In addition, within the 22q11DS group no relationship was found between prevalence of substance disorders and psychosis, COMT-genotype and intelligence quotient (IQ). Comparable to findings in the general population, substance use was more common in male than in female 22q11DS patients. Further research into both neurobiological and environmental factors contributing to this decreased risk of substance use and substance use disorders in 22q11DS could provide new insights in the genetic aspects of substance use disorders in both psychotic patients as well as the general population. 


\section{General discussion}

The overall aim of this dissertation was to further examine neurobiological mechanisms underlying cognitive functioning in subjects with a psychotic disorder and substance use, heavy cannabis use in particular. In the first part of this dissertation, previous conducted studies investigating the effects of several pharmacological treatment strategies on cognitive symptoms in psychosis were reviewed. Furthermore, the role of the cholinergic system in these symptoms was examined. In the second part, possible neurobiological mechanisms of continued, frequent cannabis use were investigated using a longitudinal design. Moreover, prevalence and patterns of overall substance use and substance use disorders in 22q11.2 deletion syndrome (22q11DS) were examined in order to provide insight in genetic aspects contributing to substance use disorders.

\section{Neurobiological mechanisms underlying cognitive symptoms of psychosis}

Identifying potential targets for cognitive enhancement in schizophrenia: evidence from previous studies

The urgent need for effective treatment strategies for cognitive impairments reported by patients with a psychotic disorder has led to a tremendous increase of studies attempting to identify molecular targets which can enhance cognition in these patients. In chapter $\mathbf{2}$, several of these studies were reviewed. Both studies examining the effects of existing antipsychotics, which mainly target the dopaminergic $D_{2}$ and serotonin $2 A\left(5-H T_{2 A}\right)$ receptors, as well as studies examining pharmacological interventions targeting other systems were taken into account. An important observation is that the studies reviewed in this chapter do not provide evidence for positive effects of neither atypical and typical antipsychotics on cognitive impairments in schizophrenia, despite previous suggestions that atypical antipsychotics are superior to first-generation antipsychotics in treatment of cognitive symptoms (1). Although overall results have been unsatisfactory, some potential molecular targets have been identified over the years. Among the targets that hold promise for enhancement of cognitive function in psychosis are the dopamine $D_{1}$ receptors, serotonin $5-\mathrm{HT}_{1 \mathrm{~A}}$ and $5-\mathrm{HT}_{3 \mathrm{~A}}$ receptors, nicotinic $\alpha_{7}$ receptors, $\mathrm{GABA}_{\mathrm{A}}$ receptors and NMDA receptors. It appears that dysfunction in separate cognitive domains are related to different neurobiological processes which could partly explain unsatisfactory results as the majority of the studies combine separate cognitive domains in one overall cognitive composite score. 
Neurobiological mechanisms underlying cognitive impairment in psychosis: role of the cholinergic system

Although the cholinergic system has been repeatedly linked to a variety of cognitive domains (2), relatively little in-vivo research has been conducted on the role of cholinergic neurotransmission in psychotic disorders (3). Nonetheless, abnormalities in both nicotine acetylcholine receptors (nAChRs) and muscarinic acetylcholine receptors (mAChRs) have been described in post-mortem brains of patients with schizophrenia (4-10). However, due to the design of these postmortem studies, it is currently unknown how these cholinergic abnormalities relate to cognitive impairments in these patients. Therefore, the aim of chapters 3 and $\mathbf{4}$ was to provide more insight in this relationship in-vivo. We focused on the muscarinic $M_{1}$ receptor subtype because this subtype has been linked to both psychosis and cognition and because of all the mAChR subtypes, it has the highest expression rates in the central nervous system (CNS), particularly in brain regions instrumental for cognitive function including the striatum, frontal cortex and the hippocampus. We differentiated between 7 cognitive domains which have been found to be critically impaired in schizophrenia as established by the Measurement and Treatment to Improve Cognition in Schizophrenia (MATRICS) initiative since our findings in chapter $\mathbf{2}$ indicated that separate domains of cognition are associated with different neurobiological mechanisms. Cognitive functioning was measured with the Cambridge Neuropsychological Automated Test Battery (CANTAB) schizophrenia test battery which covers all the MATRICS domains and is considered to be the 'golden standard'. In line with previous studies in both animals and humans, the findings described in chapter $\mathbf{3}$ provide evidence for a role of the $M_{1}$ receptor in (verbal and visual) memory. Contrary to previous findings, acute $M_{1}$ receptor blockade did not affect working memory in both psychotic subjects and healthy controls, which could be related to characteristics of the task we used. Moreover, the lack of a differential effect between the two groups suggests that, contrary to post-mortem findings in schizophrenia $(6,7,11)$, $M_{1}$ deficits were not present in our sample. However, it must be noted that $M_{1}$ receptor density has been found to decrease with increasing age in healthy subjects (12) and that our participants were younger than the patients included in previous post-mortem studies. Nevertheless, these findings are in line with the lack of difference in choline concentrations in the ACC and striatum between medication-free subjects with a psychotic disorder and healthy controls (after placebo) described in chapter 4 . These latter findings are in contrast with previous studies reporting increased choline concentrations in both first-episode and chronic and medicated and un-medicated psychotic patients in different brain 
regions (13-15). Compared to these studies however, our sample was smaller and we included subjects with a diagnosis within the psychosis spectrum instead of limiting the inclusion criteria to schizophrenia. This, in addition to the positive relationship found between choline concentrations and duration of untreated psychosis (16), could suggest that cholinergic abnormalities are only present in older patients with (chronic) schizophrenia or in a subgroup of patients with severe cognitive impairments as proposed by Scarr and colleagues (11). The psychotic subjects we included displayed less severe cognitive impairments compared to schizophrenia patients generally included (17). Although this hypothesis has not been investigated, our finding of an inverse correlation between striatal choline levels and attention in psychotic subjects but not in controls (chapter 4), would be in line with this hypothesis since attention was one of the few cognitive domains on which subjects with a psychotic disorder performed significantly worse than healthy controls. The lack of effect of $M_{1}$ blockade on attention and vigilance in chapter 3 suggests that this cognitive domain may be primarily modulated by the nAChRs or other mAChR subtypes. This would be in line with previous studies (chapter 2) describing a positive effect of nicotine in healthy smoking and nonsmoking individuals (18) and nicotine and nicotinic $\alpha_{7}$ receptor agonists on attention in schizophrenia $(19,20)$. Moreover, non-selective mAChR antagonists such as scopolamine have been found to impair attention, besides memory (21). To summarize, these findings confirm a role for the muscarinic cholinergic, and possibly nicotinergic system in cognitive functioning in subjects with a psychotic disorder, warranting further research. To investigate our hypothesis of more prominent cholinergic abnormalities in chronic patients, future studies should include both psychosis patients in the early phase and in a later stage of the disease. Alternatively, a longitudinal design could be used to examine progressive cholinergic abnormalities in psychosis. Moreover, future studies using a similar paradigm should use multiple day treatment with biperiden to examine delayed effects on cognition. Preferably, future research includes a direct in-vivo measurement of $\mathrm{M}_{1}$ receptor expression using for example ${ }^{123}$ I-IDEX single photon emission computed tomography (SPECT) imaging in both patients and healthy controls (22).

Neurobiological mechanisms underlying substance use disorders and continued, frequent cannabis use

The second part of this dissertation was aimed at identifying neurobiological processes involved in substance use and substance use disorders, focusing on mechanisms cannabis use. In chapters 5 and $\mathbf{6}$ we tested the (predictive) relation 
between working memory network function (as a part of regulatory executive functions and cognitive control) and cue-reactivity (as a part of motivational processes) and continued, frequent cannabis use over a 3-year period. Both processes could provide new insights in the development of substance use disorders since they are considered features of two core aspects underlying addiction: imbalanced regulatory functions and motivational processes (23-26). In chapter 5, we found that working memory task performance was comparable between heavy cannabis users and healthy controls and increased in both groups after 3 years. However, working memory network function did not differ between the two studied groups and did not change over the 3-year period, implying that cannabis does not have negative effects on working memory network function. This would in turn suggest that the effects on working memory performance and function may be substance specific since impaired working memory has been found in heroin and cocaine users (27-29). Furthermore, the lack of impaired working memory in gambling addicts (27) could indicate that impaired working memory is the result of the use of specific substances of abuse instead of it playing a causal role in the overall development of substance use disorders. These hypotheses could be investigated in future longitudinal studies. By means of regular monitoring of working memory network function in a large cohort of nonusing, recreational using and heavy substance using adolescents, more insight can be provided in the causal role of working memory network functioning in development of substance use disorders. By comparing groups of different substance users, substance specific negative effects on working memory can be examined.

Interestingly, although in the baseline study working memory network functioning was found to predict cannabis use after 6 months, such a predictive relation was not found after 3 years. These contradictory findings could be due to loss of power since 7 heavy cannabis users dropped out at follow-up. Therefore, replication in a bigger sample is warranted. However, these findings could also indicate that predictors of short-term cannabis use differ from those predicting long-term use. Alternatively, given the predictive relation between cannabis cue-induced activity in the dorsal striatum and problem severity we found in chapter 6, this could indicate that regulatory executive control processes and motivational processes have differential roles in recreational cannabis use and problematic use, since motivational processes are considered to be expressions of sensitized and conditioned responses towards substance related cues (26). Since neural cuereactivity did not predict the amount of cannabis use at follow-up, this suggests that cannabis-induced activity in the dorsal striatum could be a predictor of 
cannabis addiction. Unfortunately, cannabis dependence was not assessed at baseline, causing this hypothesis to remain speculative. Contrary to the differential effects of different substances on working memory, striatal cue-reactivity is less likely to be substance specific since comparable results have been found in heavy alcohol users and addiction (30-32). Motivational processes are mediated by the reinforcing properties of substances because of the ability to strengthen the conditioned response (33). During transition from recreational (reward driven drug use) to addiction, a shift occurs from positive reinforcing effects of substances and impulsive behavior, mediated by the ventral striatum and the medial prefrontal cortex, to automatic, compulsive drug use and negative reinforcement (withdrawal) which has been linked to the dorsal striatum and lateral prefrontal cortex $(25,34)$.

The results described in chapter 7 suggest that genetic factors may contribute to the rewarding properties of substance of abuse and thus mediate motivational processes including cue-reactivity. In this chapter we found a low prevalence and decreased risk of substance use and substance use disorders in patients with 22q11.2 deletion syndrome (22q11DS), a genetic disorder characterized by a deletion on chromosome 22 . We hypothesized that this lower risk of substance use and substance use disorders may be related to different reward processing in these patients. FMRI studies have found a decreased striatal BOLD response in subjects with substance use disorders during non-drug related reward anticipation $(35,36)$ and increased brain activation during drug reward anticipation (37). Although little research has been conducted on reward processing in 22q11DS, one study reports no difference in striatal activity during monetary reward anticipation and decreased activation in medial frontal areas in these patients (38), which could indicate a decreased hedonic response. A decreased hedonic response could in turn be related to the decreased risk of substance use in these patients. These potential reduced rewarding effects of substances in 22q11DS could be related to dopaminergic abnormalities as a result of reduced COMT activity in these patients (39). Processing of reward is primarily modulated by dopaminergic neurons projecting from the ventral tegmental area (VTA) to the nucleus accumbens, which is part of the ventral striatum, and frontal cortex (40). The dopaminergic system as well as the striatum and frontal cortex are strongly involved in both psychotic and substance use disorders. Interestingly, despite the high risk of developing a psychotic disorder in 22q11DS, we did not find a relation between psychosis and substance use in these patients despite increased substance use and substance use disorders in schizophrenia. Studying the relation between altered neurobiological mechanisms due to 22q11DS and patterns of 
substance use could provide more insight in the role of specific genes in the development of substance use disorders in both psychotic and healthy populations. Future genetic studies should therefore focus on genes lying within the deleted region of 22q11DS. Furthermore, studying the role of dopaminergic abnormalities (related to genetic variation) in reward processing in 22q11DS, psychosis and substance use disorders using a similar paradigm could provide further insight in the role of motivational processes underlying substance use disorders.

To summarize, regulatory executive functions and motivational processes may have differential roles in the transition from recreational substance use to substance use disorders.

\section{Methodological considerations}

The results described and discussed in this dissertation should be considered in the context of several methodological strengths, limitations and differences between studies. Although strengths and limitations are described in the separate chapters, a few overall strengths and limitations as well as differences in methods are mentioned here because they are important for the entire research field.

Contrary to the majority of previous conducted studies, an important strength of the studies described in chapters $\mathbf{3}$ and $\mathbf{4}$ are the inclusion of medication-free subjects with a psychotic disorder as this eliminates acute confounding effects of antipsychotics. Furthermore, we conducted an extensive and well validated cognitive test battery (CANTAB) which is considered to be the 'gold standard' in psychosis research, enabling us to differentiate between the separate cognitive domains critically impaired in schizophrenia as established by the MATRICS. An important strength of the studies described in chapters $\mathbf{5}$ and $\mathbf{6}$ is the use of a longitudinal design. These studies are the first studies that used a 3-year follow-up measurement enabling examining consequences of long-term use cannabis.

The unsatisfactory results of the studies that were reviewed in chapter $\mathbf{2}$ could be at least partly related to methodological shortcomings of several of the reviewed studies. For example, in pharmacological intervention studies, the agent of interest is often prescribed as add-on therapy besides antipsychotic medication which may interact with the added agent since the exact mechanism of actions of antipsychotics are often not known (41). Moreover, these mechanisms of action differ across the different types of antipsychotic drugs, which is often not controlled for. An additional problem when studying neurobiological mechanisms in psychosis is excessive substance use in a substantial number of patients since substances of abuse, including alcohol, nicotine and cannabis influence the results. 
Moreover, methodological differences between studies make it difficult to compare results of these studies. For example, use of different cognitive tests and different doses of medication could contribute to the inconsistent findings across studies. To minimize these methodological differences, the MATRICS initiative has been established, and since then a shift to standardized test batteries is observable.

When comparing our findings described in chapter 4 to other studies, it is noticeable that the results vary greatly between studies. These inconsistent findings are probably related to differences in data acquisition and analyzing methods. Perhaps the most important difference between studies is the strength of the magnetic field (expressed in Tesla) used. Since the different resonance signals are determined by the strength of the external magnetic field (42), higher field strength leads to more specific, reliable results. Higher field strength increases the signal to noise ratio (SNR) and narrows the width of the peak resulting in better spectral resolution and sensitivity (42). Other important factors contributing to the reliability of MRS data are the size and location of the brain region measured (42). Because of differences in magnetic susceptibility between tissue types, it is difficult to acquire spectra of good quality in brain regions adjacent to other types of tissue such as bone, fat and water (43). This also emphasizes the importance of correcting for the amount of cerebrospinal fluid (CSF) within the voxel of interest which is not always done. Furthermore, discrepancies in findings between studies could be related to the methods used for analyzing the data. Some studies reported absolute metabolite concentrations whereas others reported ratios with creatine. Although creatine is a relative stable metabolite and these ratios are considered to have good intra-subject validity, between subjects validity of creatine ratios have been questioned because a decrease in creatine with increasing age has been reported in patients with schizophrenia $(44)$ but not in controls $(44,45)$.

When interpreting the findings described in the separate chapters, some limitations have to be taken in to account. First, with the exception of chapter $\mathbf{7}$, the sample sizes of the conducted studies were modest, which could have led to insufficient power and subsequently type II errors. Furthermore, the heavy cannabis users (chapters 5 and 6) used other substances (alcohol, nicotine and recreational drugs) in addition to cannabis thereby confounding the effects of cannabis use. Moreover, despite instructions to refrain from substance use 24 hours prior to participation, a few subjects with a psychotic disorder (chapters 3 and 4) tested positive on a urine drug screening. Although analyses were repeated without these particular subjects and yielded comparable results, possible 
confounding effects of substance use cannot be ruled out. Finally, the inclusion criteria may have caused a selection bias. In chapters 3 and $\mathbf{4}$, we included medication-free psychotic subjects. Although this has the important benefit of eliminating acute confounding effects of antipsychotic drug use, this may have led to a selection bias of relatively well functioning psychotic subjects thereby limiting generalizability of our findings. In chapters $\mathbf{5}$ and $\mathbf{6}$, at baseline heavy cannabis users without a history or present diagnosis of substance use disorders were included. Since heavy cannabis use was defined at baseline as using cannabis at least 10 days per month for at least two years, we may have selected a group of well-functioning cannabis users which could partially explain the negative findings in chapter 5 .

\section{Clinical implications and future directions}

All studies described in this dissertation have been carried out with the aim of increasing knowledge about neurobiological mechanisms underlying cognitive symptoms of psychotic disorders and substance use disorders in order to contribute to the development of new, effective treatment and prevention strategies. Although there is still much unknown and we have a long way to go before we have unraveled these complex mechanisms, the studies described in this dissertation have provided new insights which could benefit clinical practice and give rise to further research.

First, the studies reviewed in chapter $\mathbf{2}$ outline that distinct domains of cognition are modulated via different neurobiological mechanisms. Therefore, future studies investigating neurobiological mechanisms of cognitive impairment in psychosis should differentiate between separate cognitive domains. Regarding clinical practice, these findings plead for a more individually oriented treatment approach given the highly heterogeneous (cognitive) profile of psychotic disorders instead of a protocol based approach. Although protocols and treatment guidelines are useful, these findings highlight the need for extensive mapping of the individual profile and to accordingly adjust the treatment approach. However, development of pharmacological agents with a selective mechanism of action has been proven difficult given the interaction between different neurobiological systems. Nevertheless, several add-on pharmacological agents were found to effectively enhance different cognitive domains and their use in clinical treatment warrant further investigation. The Research Domain Criteria (RDoC) approach could be suitable for this purpose. RDoC refers to a framework for new ways of studying mental disorders, including psychosis, which integrates multiple levels of information ranging from self-report to genetic and biological markers in order to 
better understand basic dimensions of functioning underlying both normal and abnormal behavior. The studies described in chapters 3 and 4 provide further evidence of a role for the cholinergic system in attention, reasoning and problem solving and memory, implying that pharmacological interventions targeting this system can improve these cognitive domains in psychosis. Future studies should further investigate this in a sample of more severely cognitive impaired patients diagnosed with schizophrenia to further investigate altered cholinergic markers in psychosis. Nevertheless, psychotic patients may benefit from interventions targeting the mAChRs and nAChRs. Indeed, previous studies using $\mathrm{M}_{1 / 4}$ receptor agonist xanomeline already showed improvement in memory as well as psychotic symptoms in schizophrenia patients (46). However, xanomeline also produced several side effects. Contrary, studies using acetylcholinesterase inhibitors, which are mainly prescribed for treatment of Alzheimer's disease, did not yield positive results in schizophrenia (47-49). Therefore, the $M_{1}$ receptor subtype in particular could be value target for memory enhancement as is it may produce less side effects due to its relative low expression in the peripheral nerve system.

With regard to substance use disorders, the predictive relation between putamen activity and cannabis use related problem severity described in chapter 6 suggest that habit formation should be a focus point in the treatment of cannabis use disorders. Increased putamen activity in response to cannabis cues seems already to be present in early stages of cannabis use and could therefore be of use in preventing a transition from recreational use to dependence. However, despite the fact that $\mathrm{fMRI}$ is a reliable technique to measure group differences, it is not suitable for detecting aberrant activation patterns at the individual level. Yet, advances in new, quickly developing techniques such as machine learning may be able to change this in the future (50). Nevertheless, given the relative small sample we used our findings should be replicated in a bigger sample. Moreover, future studies should also investigate whether cue-reactivity also predicts a transition to cannabis addiction.

In addition to identifying risk-factors, identification of protective factors could also make a valuable contribution to the development of effective treatment and prevention strategies for substance use disorders. The observation of a decreased risk for substance use and substance use disorders in patients with 22q11DS (chapter 7) indicates that 22q11DS may be a valuable model to study both genetic factors underlying substance use disorders as well potential protective environmental factors. Moreover, because of the increased risk for psychotic disorders in this population, studying patterns of substance use and related 
disorders could also provide insight in the genetic aspect of substance use schizophrenia.

To conclude, the studies described in this dissertation have provided new insights in the neurobiological mechanism underlying cognitive functioning in psychotic subjects and substance use disorders. Although these findings are just small pieces of a large and highly complex puzzle, these pieces are important for completing this puzzle in the future. 


\section{References}

1. Kapur S, Remington G. Atypical Antipsychotics: New Directions and New Challenges in the Treatment of Schizophrenia. Annu Rev Med. 2001;52(1):503-17.

2. Jones CK, Byun N, Bubser M. Muscarinic and Nicotinic Acetylcholine Receptor Agonists and Allosteric Modulators for the Treatment of Schizophrenia. Neuropsychopharmacology. 2012;37(1):16-42.

3. Booij J, van Amelsvoort T. Imaging as Tool to Investigate Psychoses and Antipsychotics. Gross G, Geyer MA, editors. Berlin, Heidelberg: Springer Berlin Heidelberg; 2012. (Handbook of Experimental Pharmacology; vol. 212).

4. Dean B, Crook JM, Opeskin K, Hill C, Keks N, Copolov DL. The density of muscarinic M1 receptors is decreased in the caudate-putamen of subjects with schizophrenia. Mol Psychiatry. 1996;1(1):548.

5. Crook JM, Tomaskovic-Crook E, Copolov DL, Dean B. Decreased muscarinic receptor binding in subjects with schizophrenia: a study of the human hippocampal formation. Biol Psychiatry. 2000;48(5):381-8.

6. Crook JM, Ph D, Tomaskovic-crook E, Hons BS, Dean B. Low Muscarinic Receptor Binding in Prefrontal Cortex From Subjects With Schizophrenia: and the Effects of Neuroleptic Drug Treatment. 2001;158:918-25.

7. Dean B, Mcleod M, Keriakous D, Mckenzie J, Scarr E. Decreased muscarinic 1 receptors in the dorsolateral prefrontal cortex of subjects with schizophrenia. Mol Psychiatry. 2002;7(10):1083-91.

8. Freedman R, Hall M, Adler LE, Leonard S. Evidence in postmortem brain tissue for decreased numbers of hippocampal nicotinic receptors in schizophrenia. Biol Psychiatry. 1995;38(1):22-33.

9. Marutle A, Zhang X, Court J, Piggott $M$, Johnson M, Perry R, et al. Laminar distribution of nicotinic receptor subtypes in cortical regions in schizophrenia. J Chem Neuroanat. 2001;22(1):115-26.

10. Court J, Spurden D, Lloyd S, McKeith I, Ballard C, Cairns N, et al. Neuronal nicotinic receptors in dementia with lewy bodies and schizophrenia: $\alpha$-bungarotoxin and nicotine binding in the thalamus. 1999;73(4):1590-7.

11. Scarr E, Cowie TF, Kanellakis S, Sundram S, Pantelis C, Dean B. Decreased cortical muscarinic receptors define a subgroup of subjects with schizophrenia. Mol Psychiatry. Nature Publishing Group; 2009;14(11):1017-23.

12. Dewey SL, Volkow ND, Logan J, MacGregor RR, Fowler JS, Schlyer DJ, et al. Age-related decreases in muscarinic cholinergic receptor binding in the human brain measured with positron emission tomography (PET). J Neurosci Res. 1990;27(4):569-75.

13. Plitman E, de la Fuente-Sandoval C, Reyes-Madrigal F, Chavez S, Gómez-Cruz G, León-Ortiz P, et al. Elevated Myo-Inositol, Choline, and Glutamate Levels in the Associative Striatum of AntipsychoticNaive Patients With First-Episode Psychosis: A Proton Magnetic Resonance Spectroscopy Study With Implications for Glial Dysfunction. Schizophr Bull. 2016;42(2):415-24.

14. Bustillo JR, Rowland LM, Lauriello J, Petropoulos H, Hammond R, Hart B, et al. High Choline Concentrations in the Caudate Nucleus in Antipsychotic-Naive Patients With Schizophrenia. Am J Psychiatry. 2002;159(1):130-3.

15. Bustillo JR, Chen H, Jones T, Lemke N, Abbott C, Qualls C, et al. Increased glutamine in patients undergoing long-term treatment for schizophrenia: a proton magnetic resonance spectroscopy study at 3 T. JAMA psychiatry. 2014;71(3):265-72.

16. Théberge J, Al-Semaan Y, Drost DJ, Malla AK, Neufeld RW., Bartha R, et al. Duration of untreated psychosis vs. $\mathrm{N}$-acetylaspartate and choline in first episode schizophrenia: a $1 \mathrm{H}$ magnetic resonance spectroscopy study at 4.0 Tesla. Psychiatry Res Neuroimaging. 2004;131(2):107-14. 
17. Keefe RS., Goldberg TE, Harvey PD, Gold JM, Poe MP, Coughenour L. The Brief Assessment of Cognition in Schizophrenia: reliability, sensitivity, and comparison with a standard neurocognitive battery. Schizophr Res. 2004;68(2):283-97.

18. Ripoll N, Bronnec M, Bourin M. Nicotinic receptors and schizophrenia. Curr Med Res Opin. 2004;20:1057-74.

19. Dépatie L, O’Driscoll G a, Holahan A-L V, Atkinson V, Thavundayil JX, Kin NNY, et al. Nicotine and behavioral markers of risk for schizophrenia: a double-blind, placebo-controlled, cross-over study. Neuropsychopharmacology. 2002;27(6):1056-70.

20. Freedman R, Olincy A, Buchanan RW, Harris JG, Gold JM, Johnson L, et al. Initial phase 2 trial of a nicotinic agonist in schizophrenia. Am J Psychiatry. 2008;165(8):1040-7.

21. Klinkenberg I, Blokland A. The validity of scopolamine as a pharmacological model for cognitive impairment: a review of animal behavioral studies. Neurosci Biobehav Rev. 2010;34(8):1307-50.

22. Bakker G, Vingerhoets WA, van Wieringen J-P, de Bruin K, Eersels J, de Jong J, et al. 123Iiododexetimide preferentially binds to the muscarinic receptor subtype M1 in vivo. J Nucl Med. 2015;56(2):317-22.

23. Koob GF, Volkow ND. Neurocircuitry of addiction. Neuropsychopharmacology. 2010;35(1):217-38.

24. Cousijn J, Van Benthem P, Van der Schee E, Spijkerman R. Motivational and control mechanisms underlying adolescent cannabis use disorders: a prospective study. Dev Cogn Neurosci. 2015;16:36-45.

25. Everitt BJ, Robbins TW. Neural systems of reinforcement for drug addiction: from actions to habits to compulsion. Nat Neurosci. 2005;8(11):1481-9.

26. Wiers R, Bartholow B, van den Wildenberg E, Thush C, Engels R, Sher K, et al. Automatic and controlled processes and the development of addictive behaviors in adolescents: $A$ review and a model. Pharmacol Biochem Behav. 2007;86:263-83.

27. Yan W-S, Li Y-H, Xiao L, Bechara A, Sui N. Working Memory and affective decision-making in addiction: A neurocognitive comparison between heroin addicts, pathological gamblers and healthy controls. Drug Alcohol Depend. 2014;134:194-200.

28. Goldstein R, Leskovjan A, Hoff A, Hitzemann R, Bashan F, Khalsa S, et al. Severity of neuropsychological impairment in cocaine and alcohol addiction: association with metabolism in the prefrontal cortex. Neuropsychologia. 2004;42:1447-58.

29. Sullivan E, Rosenbloom M, Pfefferbaum A. Pattern of motor and cognitive performance in detoxified alcoholic men. Alcohol Clin Exp Res. 2000;24:611-21.

30. Vollstädt-Klein S, Wichert S, Rabinstein J, Bühler M, Klein O, Ende G, et al. Initial, habitual and compulsive alcohol use is characterized by a shift of cue processing from ventral to dorsal striatum. Addiction. 2010;105(10):1741-9.

31. Sjoerds Z, van den Brink W, Beekman ATF, Penninx BWJH, Veltman DJ. Cue reactivity is associated with duration and severity of alcohol dependence: an FMRI study. PLoS One. 2014;9(1):e84560.

32. Schacht JP, Anton RF, Myrick H. Functional neuroimaging studies of alcohol cue reactivity: a quantitative meta-analysis and systematic review. Addict Biol. 2013;18(1):121-33.

33. Kelley A, Berridge K. The Neuroscience of Natural Rewards: Relevance to Addictive Drugs. J Neurosci. 2002;22:3306-11.

34. Lorenzetti V, Cousijn J, Solowij N, Garavan H, Suo C, Yücel M, et al. The Neurobiology of Cannabis Use Disorders: A Call for Evidence. Front Behav Neurosci. 2016;10:86.

35. van Hell H, Vink M, Ossewaarde L, Jager G, Kahn R, Ramsey N. Chronic effects of cannabis use on the human reward system: an fMRI study. Eur Neuropsychopharmacol. 2010;20(3):153-63. 
36. Martz ME, Trucco EM, Cope LM, Hardee JE, Jester JM, Zucker RA, et al. Association of Marijuana Use With Blunted Nucleus Accumbens Response to Reward Anticipation. JAMA Psychiatry. 2016;73(8):838.

37. Wrase J, Schlagenhauf F, Kienast $T$, Wüstenberg $T$, Bermpohl F, Kahnt $T$, et al. Dysfunction of reward processing correlates with alcohol craving in detoxified alcoholics. Neuroimage. 2007;35(2):787-94.

38. van Duin EDA, Goossens L, Hernaus D, da Silva Alves F, Schmitz N, Schruers K, et al. Neural correlates of reward processing in adults with $22 q 11$ deletion syndrome. J Neurodev Disord. 2016;8:25.

39. Gothelf D, Law AJ, Frisch A, Chen J, Zarchi O, Michaelovsky E, et al. Biological effects of COMT haplotypes and psychosis risk in 22q11.2 deletion syndrome. Biol Psychiatry. 2014;75(5):406-13.

40. Volkow ND. Substance use disorders in schizophrenia--clinical implications of comorbidity. Schizophr Bull. 2009;35(3):469-72.

41. Harvey PD. Pharmacological cognitive enhancement in schizophrenia. Neuropsychol Rev. 2009;19(3):324-35.

42. Schwerk A, Alves FDS, Pouwels PJW, van Amelsvoort T. Metabolic alterations associated with schizophrenia: a critical evaluation of proton magnetic resonance spectroscopy studies. J Neurochem. 2014;128(1):1-87.

43. Gujar SK, Maheshwari S, Björkman-Burtscher I, Sundgren PC. Magnetic resonance spectroscopy. J Neuroophthalmol. 2005;25(3):217-26.

44. Chang L, Friedman J, Ernst T, Zhong K, Tsopelas ND, Davis K. Brain Metabolite Abnormalities in the White Matter of Elderly Schizophrenic Subjects: Implication for Glial Dysfunction. Biol Psychiatry. 2007;62(12):1396-404.

45. Maudsley AA, Domenig C, Govind V, Darkazanli A, Studholme C, Arheart K, et al. Mapping of brain metabolite distributions by volumetric proton MR spectroscopic imaging (MRSI). Magn Reson Med. 2009;61(3):548-59.

46. Shekhar A, Potter WZ, Lightfoot J, Lienemann J, Dubé S, Mallinckrodt C, et al. Selective muscarinic receptor agonist xanomeline as a novel treatment approach for schizophrenia. Am J Psychiatry. 2008;165(8):1033-9.

47. Birks J. Cholinesterase inhibitors for Alzheimer's disease. Cochrane database Syst Rev. 2006 (1):CD005593.

48. Lenzi A, Maltinti E, Poggi E, Fabrizio L, Coli E. Effects of rivastigmine on cognitive function and quality of life in patients with schizophrenia. Clin Neuropharmacol. 2003;26(6):317-21.

49. Friedman JI, Adler DN, Howanitz E, Harvey PD, Brenner G, Temporini H, et al. A double blind placebo controlled trial of donepezil adjunctive treatment to risperidone for the cognitive impairment of schizophrenia. Biol Psychiatry. 2002;51(5):349-57.

50. Dosenbach NUF, Nardos B, Cohen AL, Fair DA, Power JD, Church JA, et al. Prediction of Individual Brain Maturity Using fMRI. Science. 2010;329(5997). 



\section{Chapter | 9}

Summary in Dutch | Nederlandse samenvatting 


\section{Nederlandse Samenvatting}

Het overkoepelende doel van dit proefschrift was om meer inzicht te verkrijgen in de onderliggende neurobiologische mechanismen van co-morbide cognitieve symptomen bij psychose en aanhoudend, frequent middelengebruik. In het eerste deel van dit proefschrift werden neurobiologische mechanismen die ten grondslag liggen aan cognitieve symptomen bij personen met een psychotische stoornis onderzocht (hoofdstuk 2 - hoofdstuk 4), met een focus op de rol van het cholinerge systeem. In het tweede deel van dit proefschrift werden onderliggende neurobiologische mechanismen van middelengebruik onderzocht met een focus op onderliggende mechanismen van frequent cannabisgebruik (hoofdstuk 5 hoofdstuk 7).

In hoofdstuk 2 werd de effectiviteit van farmacologische interventies onderzocht voor afzonderlijke cognitieve domeinen, die over het algemeen aangedaan zijn in patiënten met schizofrenie, zoals bepaald door het MATRICS-initiatief. De bestudeerde studies vonden bewijs voor een rol van de dopaminerge $D_{1}$ receptor bij de informatieverwerkingssnelheid en het logisch redeneren alsook het probleemoplossend vermogen. Het serotonerge, GABA-erge en glutamaat systeem lijken betrokken te zijn bij verschillende aspecten van geheugen. Dit laatste systeem lijkt ook betrokken te zijn bij logisch redeneren en probleemoplossend vermogen. Ten slotte werd aannemelijk gemaakt dat aandacht en alertheid gemoduleerd wordt door nicotinerge-acetylcholine receptoren. Echter resultaten van een beperkt aantal studies gaven aan dat geheugenfuncties mogelijk verbeterd kunnen worden door middelen die het muscarine systeem beïnvloeden. Over het algemeen toonden deze bevindingen aan dat er verschillende mechanismen ten grondslag liggen aan afzonderlijke aspecten van cognitie. Als dit inderdaad het geval is, impliceert dit dat patiënten met schizofrenie met verschillende cognitieve profielen baat zouden kunnen hebben van verschillende interventiestrategieën.

In hoofdstuk 3 werd de rol van de muscarine $\mathrm{M}_{1}$-receptor in cognitieve functies bij personen met een psychotische stoornis onderzocht met behulp van de $\mathrm{M}_{1}$ antagonist biperideen als een farmacologische challenge. Het blokkeren van de $M_{1}$ -receptor verminderde significant zowel het visueel als verbaal leren en geheugen, hetgeen aangeeft dat deze receptor een rol speelt in deze cognitieve (dys)functies. Verder werd een interactie-effect gevonden tussen medicatie en groep voor logisch redeneren en probleemoplossend vermogen; in de psychosegroep 
verbeterde dit domein na toediening van biperideen, terwijl prestatie op dit domein in de gezonde controle groep juist verslechterde na biperideen toediening. Het effect van $M_{1}$-antagonisme op dit domein was dus verschillend voor beide groepen. Het effect van biperideen op de andere cognitieve domeinen was echter vergelijkbaar in de psychose- en de gezonde controlegroep. Hoewel deze resultaten de rol van de $\mathrm{M}_{1}$-receptor in geheugen bevestigt, geeft het gebrek aan een verschillend effect van $\mathrm{M}_{1}$-blokkade tussen de groepen mogelijk aan dat het disfunctioneren van de $\mathrm{M}_{1}$-receptor niet aanwezig was in onze steekproef. Het sluit echter niet uit dat dit wel aanwezig is in oudere, chronische patiënten met schizofrenie.

Hoofdstuk 4 geeft een toelichting op de rol van het cholinerge systeem in psychose en geassocieerde cognitieve stoornissen. We onderzochten of choline concentraties in de anterior cingulate cortex (ACC) en het striatum verschilde tussen personen met een psychotische stoornis en controles, en of blokkade van de $\mathrm{M}_{1}$-receptor de choline concentraties in deze gebieden beïnvloedde. Daarnaast werd onderzocht of choline concentraties geassocieerd waren met afzonderlijke domeinen van cognitie. Aangetoond werd een significante negatieve correlatie tussen aandacht en choline in het striatum bij psychotische personen die afwezig was bij controles, hetgeen eerdere bevindingen van de rol van het cholinerge systeem in cognitieve symptomen van psychose bevestigt. Het ontbreken van een significant verschil in choline concentraties tussen beide onderzochte groepen, zowel na biperideen als placebo, en in beide hersengebieden, geeft mogelijk aan dat er geen ernstige cholinerge afwijkingen aanwezig waren in deze steekproef van psychotische personen, hoewel we niet kunnen uitsluiten dat er cholinerge afwijkingen aanwezig zijn bij chronische schizofreniepatiënten.

In hoofdstuk 5 werd de relatie tussen het functioneren van het werkgeheugennetwerk en aanhoudend, frequent cannabisgebruik onderzocht in een longitudinale drie jaar durende functionele MRI-studie. Bij de aanvangsmeting werd bevonden dat, ondanks een vergelijkbaar werkgeheugennetwerkfunctie en prestatie op een werkgeheugentaak (gedragsmatig) in zware cannabisgebruikers en gezonde niet-gebruikende controles, een sterker werkgeheugen netwerkreactie geassocieerd was met verhoogd wekelijks cannabisgebruik over een periode van zes maanden. De follow-up resultaten lieten zien dat, ondanks verbeterde prestatie op de werkgeheugentaak in beide groepen, werkgeheugennetwerkfunctie niet veranderde over de periode van drie jaar. In tegenstelling tot eerdere bevindingen werd er geen significante associatie 
gevonden tussen het functioneren van het werkgeheugennetwerk tijdens de aanvangsmeting en cannabis-, nicotine-, alcohol- of ander recreationeel drugsgebruik. Deze resultaten geven aan dat aanhoudend cannabisgebruik het functioneren van het werkgeheugennetwerk niet significant beïnvloedt.

Voortbordurend op eerdere bevindingen van verhoogde activatie in reactie op cannabisstimuli in het ventrale tegmentumgebied (VTA) in zware cannabisgebruikers in vergelijking met controles, alsmede een hogere activatie in de ACC, orbitofrontale cortex (OFC) en striatum in meer problematische cannabisgebruikers, werden in hoofdstuk 6 de resultaten van een follow-up studie beschreven waarin werd onderzocht of hersenactiviteit in reactie op cannabis gerelateerde stimuli in deze hersengebieden voorspellend was voor veranderingen in wekelijks cannabisgebruik en de ernst van aan cannabis gerelateerde problemen. Geen van de onderzochte gebieden voorspelde wekelijks cannabisgebruik na drie jaar. Echter, verhoogde activatie in het linker (dorsale) striatum voorspelde de ernst van aan cannabis gerelateerde problemen na drie jaar, wat aangeeft dat cue-reactiviteit mogelijk een bruikbaar hulpmiddel is in het voorspellen van de transitie naar problematisch cannabisgebruik en mogelijk ook cannabisafhankelijkheid.

In hoofdstuk 7 werd de prevalentie van middelengebruik en middelen gebonden stoornissen in 22q11.2 (22q11DS) deletie syndroom, een populatie met een hoog risico op het ontwikkelen van psychotische stoornissen, bepaald. De deletie op chromosoom 22q11.2 die deze groep patiënten definieert, bevat genen die zijn geassocieerd met zowel psychotische stoornissen als middelen gebonden stoornissen. Derhalve kan het onderzoeken van patronen van middelengebruik bij deze patiënten mogelijk waardevolle inzichten geven in de genetische aspecten van zowel psychose als middelen gebonden stoornissen. Vergeleken met psychotische patiënten (88\%) en gezonde controles (82\%), was de prevalentie van algemeen middelengebruik (37\%) en middelen gebonden stoornissen (1.2\%) laag in 22q11DS-patiënten. Bovendien vonden we dat deze patiënten een verlaagd risico hebben op zowel algemeen middelengebruik als alcohol- en nicotinegebruik afzonderlijk. Interessant is dat recreationeel drugsgebruik niet verschilde tussen de drie groepen. Daarnaast werd binnen de groep 22q11DS-patiënten geen relatie gevonden tussen de prevalentie van middelengebruik en psychose, COMTgenotype en intelligentie quotiënt (IQ). Vergelijkbaar met bevindingen in de algemene populatie was middelengebruik gebruikelijker bij mannelijke dan vrouwelijke 22q11DS-patiënten. Vervolgonderzoek naar zowel neurobiologische 
als omgevingsfactoren die bijdragen aan dit verlaagde risico op middelengebruik en aan middelen gebonden stoornissen in 22q11DS is nodig, aangezien dit nieuwe inzichten kan geven in de genetische aspecten van aan middelen gebonden stoornissen bij zowel psychotische patiënten als de algemene populatie.

Concluderend hebben de studies van dit proefschrift nieuwe inzichten gegenereerd in de neurobiologische mechanismen die ten grondslag liggen aan comorbide cognitieve symptomen in psychose en aan middelen gebonden stoornissen. Echter, deze studies hebben ook nieuwe vragen opgeroepen en vervolgonderzoek is nodig om deze vragen te beantwoorden en de verkregen inzichten te vertalen naar de klinische praktijk. 



\section{Appendices | \&}

Valorisation

List of publications

Acknowledgements | Dankwoord

Curriculum Vitae 



\section{Valorisation}

The primary goal of scientific research in medicine is to I) increase knowledge II) to diminish illness and suffering thereby improving quality of life and III) in the future, prevention illness. To accomplish this goal, we need to develop new treatment strategies. The work described in this thesis was aimed at identifying possible molecular targets for development of new treatment strategies for cognitive symptoms of psychotic disorders and substance use disorders.

The first part of this dissertation was aimed at providing more insight into neurobiological mechanisms underlying the comorbid cognitive symptoms of psychosis. Psychotic disorders can be very disabling and may have a major negative influence on quality of life. The disorder is associated with a significant and long-lasting health, social, and financial burden, not only for patients but also for families, other caregivers, and the wider society. The costs of mental health care for psychotic patients worldwide are high. In The Netherlands the mental health costs for schizophrenia alone, the most severe form of psychotic disorders, are estimated at 517 million euros per year. Cognitive symptoms of psychosis are found to be predictive of functional outcome, relapse and medication compliance. Moreover, cognitive decline in adolescents with a psychotic disorder increases drop-out of school and is one of the main reasons why patients with psychosis struggle to find or keep jobs. Therefore, better treatment is urgently needed and being able to treat these symptoms could not only drastically improve quality of life of patients. It could also significantly reduce mental health costs as it leads to shorter admissions, more participation in society and less need for social support. The work presented in this dissertation was aimed at providing more insight into the neurobiological mechanisms underlying these symptoms and at identifying possible new molecular targets for development of cognitive enhancing pharmacological agents, since currently available antipsychotic medication mainly targets dopaminergic neurotransmission and have no or little beneficial effects on cognition. Therefore, it is highly important that the role of other neurotransmitter systems in the development of cognitive impairment are explored. We showed that the cholinergic system holds promise as a potential target for cognitive enhancement in psychosis which lays the groundwork for future studies. Our results also highlight the need for more personalized treatment rather than a protocol based approach given the highly heterogeneous (cognitive) profile observed in patients with a psychotic disorder. Although protocols and treatment guidelines are useful, the work described in this dissertation highlights the need 
for extensive mapping of the individual profile and to accordingly adjust the treatment approach.

In the second part of this dissertation we tried to gain more insight into mechanisms underlying substance use disorders, thereby focusing on cannabis use. Cannabis is the most frequently recreational drug used worldwide. The lifetime prevalence of cannabis use among adolescents in the Netherlands is estimated at $23 \%$. Approximately one out of 10 weekly cannabis users transitions to cannabis dependence. To date, the key question, why some people transit to cannabis dependence whereas others do not, remains unanswered. Another unanswered question is why people with psychotic disorders are more likely to use cannabis and to develop cannabis related disorders. The work included in this dissertation provides some insight into the mechanisms involved in continued, frequent cannabis use. We showed that cue-induced reactivity in the putamen, a brain region strongly involved in the formation of habits, predicted cannabis use related problems after a 3-year period. This suggest that habit formation is an important focus point for treatment of cannabis use disorders. Moreover, since this sensitized reaction to cannabis cues seems already present in early stages of cannabis use, this may be a valuable target in the prevention of cannabis use. Development of programs aimed at prevention of cannabis use disorders could also benefit from more insight in protective factors. The work included in this dissertation showed that studying patterns of substance use in patients with 22q11.2 deletion syndrome has the potential to provide insight in both genetic factors and protective environmental factors of substance use disorders given that these patients seem to have a decreased risk for developing substance use and substance use disorders. Additionally, because of the increased risk for psychotic disorders in this population, studying patterns of substance use and related disorders could also provide insight in the genetic aspect of substance use in schizophrenia.

Overall, the work reported in this dissertation is a small step towards a better understanding of the neurobiological mechanisms underlying comorbid cognitive symptoms in psychosis and substance use disorders in order to develop new and effective treatment and in the future, possibly preventive strategies of these disorders. 




\section{List of Publications}

Vingerhoets WAM, Bloemen OJ, Bakker G \& Van Amelsvoort TA (2013) Pharmacological interventions for the MATRICS cognitive domains in schizophrenia: what's the evidence? Front. Psychiatry 4:157.

Vingerhoets WAM, Koenders L van den Brink W, Wiers RW, Goudriaan AE, van Amelsvoort TAMJ, de Haan L \& Cousijn J. Cue-induced striatal activity in frequent cannabis users is a strong independent predictor of cannabis problem severity three years later. Journal of Psychopharmacology, 30:152-158.

Bakker G/ Vingerhoets WAM*, van Wieringen JP, de Bruin K, Eersels J, de Jong J, Chahid $Y$ et al.(2015) ${ }^{123}$ I-iodo-dexetimide preferentially binds to the muscarinic receptor subtype $\mathrm{M}_{1}$-receptor in-vivo. Journal of Nuclear Medicine, 56:317-322.

Cousijn J, Vingerhoets WAM, Koenders L, de Haan L, van den Brink W, Wiers RW and Goudriaan AE (2013). Relationship between working-memory network function and substance use: a three-year longitudinal fMRI study in heavy cannabis users and controls. Addiction biology, doi:10.1111/adb.12111

Cousijn J, Watson P, Koenders L, Vingerhoets WAM, Goudriaan AE \& Wiers RW (2013). Cannabis dependence, cognitive control and attentional bias for cannabis words. Addictive Behaviors 38, 2825-32.

Koenders L, Cousijn J, Vingerhoets WAM, van den Brink W, Wiers RW, Meijer CJ, Machielsen MWJ, Veltman D, Goudriaan AE \& de Haan L. (2016). Grey matter changes associated with heavy cannabis use: A longitudinal SMRI study. PLOS ONE, doi.org/10.1371/journal.pone.0152482.

Bakker G, Chekrouni N, Vingerhoets WAM, van Wieringen JP, de Bruin K, Eersels J, de Jong J, Bloemen O, van Amelsvoort T \& Booij J. (2016). The antagonist SPECT tracer $123 \mathrm{I}$-iodexetimide binds preferentially to the muscarinic $\mathrm{M} 1$ receptor in-vivo but is also a potential to assess the occupancy of muscarinic M1 agonists? Receptors \& Clinical Investigation, 3: e1163. doi: 10.14800/rci.1163.

Bakker G, Caan MWA, Schluter R, Bloemen OJN, Vingerhoets WAM, da Silva-Alves F, de Koning M, Boot E, Nieman DH, de Haan L, Booij J \& van Amelsvoort TAMJ. (2016). Distinct white matter aberrations in 22q11 deletion syndrome and patients at ultra-high risk for psychosis. Psychological Medicine, 46, 2299-2311. 
Bakker G, Caan MWA, Vingerhoets WAM, da Silva-Alves F, de Koning M, Boot E, Nieman DH, de Haan L, Bloemen OJN, Booij J \& van Amelsvoort TAMJ. Cortical morphology differences in subjects at increased vulnerability for developing a psychotic disorder: a comparison between subjects with ultra-high risk and 22q11.2 deletion syndrome. (2016). Plos One, 11, e0159928.

*Joint first author

Book chapters:

Claudia (WAM) Vingerhoets, Maarten Bak \& Therese van Amelsvoort. Psychotic disorders and intellectual disability. Guidebook Intellectual disability and psychiatric disorders. In Didden,R., Groen, W., Moonen, X. Troost, P. Wouter Groen, Xavier Moonen en Pieter Troost (red) Guidebook Intellectual disability and psychiatric disorders. Scheduled to appear December 15, 2016. Utrecht: De Tijdstroom.

\section{Submitted work}

Vingerhoets C, Bloemen OJN, Boot E, Bakker G, de Koning MB, da Silva-Alves F, Abeling N, Booij J \& van Amelsvoort TAMJ. Dopamine in high-risk populations: a comparison of subjects with 22q11.2 deletion syndrome and subjects at ultra-highrisk for psychosis.

Vingerhoets $C$, van Oudenaren MJF, Bloemen OJN, Boot E, van Duin EDA, Evers LJM, Fiskinski A, Breetvelt E, Palmer L, Vergaelen E, Vogels, Meijer C, Booij J, Genetic Risk and Outcome of Psychosis (GROUP) investigators, de Haan L, Swillen A, Vorstman JAS, Bassett A \& van Amelsvoort TAMJ. Low prevalence of substance use in people with 22q11.2 Deletion Syndrome.

Vingerhoets C, Bakker G, van dijk J, Chan, RCK, Bloemen OJN, Wang Y, Booij J, van Amelsvoort TAMJ. The effect of the muscarinic $M_{1}$ receptor antagonist biperiden of cognition in medication-free subjects with a psychotic disorder.

Vingerhoets C, Bakker G, van der Pluijm M, Bloemen OJN, Caan M, Booij J, van Amelsvoort TAMJ. Cholinergic neurotransmission and cognition in psychosis: a placebo-controlled, cross-over MRS study. 
Bakker G, Vingerhoets C, Caan M, Bloemen OJN, Eersels J, Booij J \& van Amelsvoort TAMJ. Muscarinic $M_{1}$ receptor binding and cognition in medicationfree subjects with psychosis.

Koenders L/Machielsen MJ, Vingerhoets WAM, [..] de Haan L. Brain volume, Cortical Thickness and Cortical Surface Area in recent onset Schizophrenia.

Koenders L, Lorenzetti V/Cousijn J, Suo C, Vingerhoets WAM, Van den Brink W, Wiers RW, Meijer CJ, Goudriaan AE, Yucel M, Veltman DJ, De Haan L. Hippocampal alterations associated with cannabis use: a longitudinal sMRI study in heavy cannabis users and healthy control.

Van Dam DS, Koenders L, Vingerhoets WAM, Machielsen MWJ, Velthorst E, Meijer CJ, De Haan L. A history of childhood trauma in patients with psychotic disorders is associated with brain morphology. 



\section{Dankwoord}

En toen was daar eindelijk een proefschrift. De afgelopen jaren zijn in sneltreinvaart voorbijgegaan. Graag wil ik iedereen bedanken die me, direct of indirect, geholpen heeft bij het tot stand komen van dit proefschrift.

Als eerst wil ik graag alle deelnemers bedanken die mee hebben gedaan aan de verschillende studies die ik de afgelopen jaren uit heb mogen voeren. Tientallen vragen hebben jullie ingevuld en eindeloos veel taakjes uitgevoerd zowel in als buiten de scanner. Bedankt dat ik een kijkje in jullie hersenen mocht nemen.

Dan mijn promotieteam, Thérèse, Jan en Oswald, een echt dreamteam wat mij betreft. Thérèse, ik kan me voorstellen dat ik zonder neuro- of medische achtergrond misschien niet de meest voor de hand liggende keus was voor dit project. Bedankt dat je me deze kans hebt gegeven en voor het vertrouwen dat je in mij (en Geor natuurlijk ook) hebt gehad om dit aanvankelijk toch redelijk problematische project, tot een goed einde te brengen. Daarnaast heb je me de ruimte gegeven om mezelf verder te ontwikkelen. Je deur stond altijd open en je goede adviezen vormen de basis voor een (hopelijk) mooie onderzoekscarrière. Jan, jouw onvoorwaardelijke optimisme en positieve instelling hebben ervoor gezorgd dat ik tijdens de lange periode van wachten op METC-goedkeuring nooit het vertrouwen ben verloren in een goede afloop en altijd met plezier naar het $A M C$ ging. Daarnaast heb je me met je oneindige kennis en geduldige uitleg wegwijs gemaakt in de wereld van SPECT- en PET-onderzoek, iets waar ik me graag nog verder in wil verdiepen in de toekomst. Hoewel ik blij was toen het project dan eindelijk was goedgekeurd, miste ik stiekem onze altijd gezellige 'METC-tactiek besprekingen' wel. Oswald, twee ongestructureerde en ongeorganiseerde typetjes bij elkaar waren we. Toch verliep onze samenwerking ontzettend goed. Je hebt me de afgelopen jaren met veel geduld maar vooral ook veel humor begeleid. Je kon overal de grap van inzien, zelfs van deprimerende MRS-poweranalyses en hersenactiviteit bij een dode zalm. Bedankt daarvoor!

Matthan, ondanks dat je officieel alleen copromotor van Geor was, stond je ook altijd voor mij klaar, niet alleen als de MRI scanner het niet deed maar ook als bodyguard wanneer er een deelnemer met enkelband gescand moest worden. Je enorme MRI kennis en kritische blik zijn echt een toegevoegde waarde voor het hele team geweest. Kom je na de verdediging een toetje mee eten?

Leden van de leescommissie, Professor Ramaekers, Professor Schruers, Professor Riedel, Professor Meeter en dr. Bruggeman, bedankt voor jullie deskundige 
oordeel en aanwezigheid bij de promotie. Ik zie uit naar de geregelde gedachtenwisseling.

Uiteraard wil ik ook alle collega's van het AMC bedanken. Ik begon op 21 jarige leeftijd en ben sindsdien niet meer weggegaan. Eerst bij vroege psychose, later de AIAR en uiteindelijk ben ik op Z-O beland. Om maar bij het begin te beginnen. Jet en Marise, bij jullie begon mijn AMC avontuur in 2010. Bedankt voor jullie begeleiding en enthousiasme. Dit heeft me uiteindelijk over de streep getrokken om toch het onderzoek in te gaan. Marise, jij kwam uit het niets met de mededeling dat je een PhD plek voor me had gevonden. En je had gelijk. Daar kan ik je niet genoeg voor bedanken. Daniëlla, jij hebt de begeleiding van mijn tweede scriptie op je genomen. Wat was het fijn om met je te werken en wat is je proefschrift mooi geworden. Ik ben blij dat we nog steeds af en toe een inspirerende koffiedate hebben. Dus ja, wat mij betreft blijven we dat doen. Nathalie, bedankt voor je hulp bij de werving van deelnemers voor de SMURF studie. Op het punt dat ik begon te denken dat we echt niet genoeg mensen zouden gaan vinden was jij daar als reddende engel met een database vol geschikte deelnemers, waarvan een aantal ook nog eens daadwerkelijk mee heeft gedaan. Lieve Tamar, Frederike, Dorien, Soleil, Carin, Karin, Floor, Lindy en Eva, bedankt voor alle betrokkenheid, gezelligheid en mental support de afgelopen jaren. Eva, wat leuk om je in New York weer tegen te komen.

$\mathrm{Na}$ vroege psychose heb ik een uitstapje naar verslavingsgang gemaakt. Dit uitstapje bleek achteraf het tweede deel van mijn proefschrift te gaan vormen. Janna, Wim, Reinout, Anneke en Lieuwe bedankt dat jullie mij de mogelijkheid hebben gegeven om een paper te schrijven over de data en voor jullie kritische blik en brainstormsessies gedurende het proces. Lieuwe, bedankt voor de gastvrijheid de afgelopen jaren, ook toen ik eigenlijk niet meer op jouw afdeling werkte. Daarnaast wil ik je bedanken voor je hulp bij de werving van deelnemers voor SMURF. Laura, wat een geluk dat ik met jouw mocht samenwerken op het cannabisproject. Avonden en weekenden scannen was op deze manier toch echt een stuk leuker. Wat waren we een goed team! De vele borrels en feestje zijn natuurlijk onvergetelijk maar het absolute hoogtepunt was toch wel het congres in New York. Hopelijk blijven we af en toe nog een wijntje drinken.

Na psychiatrie was het tijd om over te stappen naar Z-0 en nucleaire geneeskunde. Lieve collega's van Z-0, Bram, Lena, Jithsa, Anne-Marije, Wouter, Oliver, Jos, Pim, Ot, Kevin, Valentina, Tanja, Cheima, Esther, Hyke, Henk-Jan, Sofieke, Eva, Jordi, Luuk, Lucas, Kerry, Ot, André, Kevin, Jules en Raschel, bedankt voor alle 
fantastische vrijdagmiddagborrels (of bij mooi weer iedere andere middag) en geweldige lunches. Vooral de uitgebreide analyse van March of the penguins is me bij gebleven. Gelukkig kon ik de vaak technische onderwerpen door de jaren heen steeds beter volgen. Schlutie, wat jammer dat je naar psychiatrie bent verhuisd. Anouk, Eline, Geor, Martin, JP, Michelle, Dorien, Josien en Chiel: jullie zijn allemaal geweldige kamergenoten geweest (sommige zijn dat nog steeds) en hebben voor de nodige gezelligheid gezorgd.Specielle, bedankt voor het invoeren van Disney donderdag. Paul, bedankt dat je zo'n goede surrogaat-Clau bent geweest tijdens mijn afwezigheid. Een paar mensen krijgen een speciale plek in dit dankwoord. Aart, bedankt voor de gastvrijheid de afgelopen jaren. Gustav, bedankt dat je ons uit de brand hielp in moeilijke tijden. Het heeft je een mooie mok opgeleverd. Zuster Sandra, bedankt voor de praatjes tijdens het scannen en dat je altijd klaar stond om te helpen, ook wanneer er in de avonduurtjes met spoed x-orbita's geregeld moesten worden. Paul (de Groot), om te beginnen sorry dat we je regelmatig in het weekend lastig vielen omdat de scanner het weer eens niet deed. Daarnaast wil ik je ook bedanken voor alle hulp bij het maken van de fMRI taken, je eindeloze geduld als ik telefonisch op zoek moest naar de juiste scannerkabel om te controleren en talloze andere technische zaken waarbij je ons geholpen hebt de afgelopen jaren. Dennis, naast collega stond jij ook als verhuizer en muizenvanger klaar in tijden van nood. Ik vind het gezellig dat je nog steeds af en toe mee gaat quizzen en ik verheug me op de bruiloft van jou en Tanja in Curaçao! $J P$, bedankt voor al je geduldige uitleg over farmacologische principes en medicatie en voor het kritisch beoordelen van de cover van dit boekje. Je was een geweldige buurman. Maar bovenal bedankt voor alle gezelligheid de afgelopen jaren. Je was altijd in voor een biertje, een kindersurprise-ei of een spelletje uil-honkbal. Het was een eer om jouw paranimf te zijn en naast je te mogen staan op jouw grote dag. Joena, jij bent echt van alle markten thuis! Ik heb de laatste jaren gebruik mogen maken van je skills als secretaresse, kattenoppas, partyplanner en vriendin. Je bent echt de baas van Z-0. Dat er in de toekomst maar veel biertjes en koffiedates mogen volgen.

Alle collega's van nucleaire geneeskunde, zonder jullie was de SPECT studie echt een ramp geworden. Jos, bedankt het produceren van de ${ }^{123}$ I-IDEX in de vroege uurtjes. Jan (de Jong), Youssef en Chyntia, bedankt voor het regelen van alle ${ }^{123}$ IIDEX en biperideen bestellingen. Het was altijd weer een opluchting om jullie in dat witte pak achter het raampje in de weer te zien. Mette en Sophie, bedankt voor de ondersteuning bij de Inspira. Bastiaan, bedankt voor het leren scannen en de technische ondersteuning. Soer, Rianne en Kelly, bedankt voor de hulp bij de planningen in EPIC en vooral voor jullie eindeloze flexibiliteit in het verzetten van 
afspraken. Kora, bedankt voor het 'lenen' van alle benodigdheden voor de pbmc's en het lenen van je attributen voor promotiefilmpjes. Dankzij jou ben ik een stuk beter op de hoogte van de anatomie van de rat. Niet stiekem die verdamper mee naar huis nemen hoor. En uiteraard ook veel dank voor alle artsen en laboranten die iedere week weer bereid waren om eindeloos veel buisjes bloed af te nemen en ${ }^{123}$ I-IDEX toe te dienen.

Ook niet te vergeten alle studenten die geholpen bij de dataverzameling en analyses voor dit proefschrift. Mattie, als mijn eerste student heb je de lat hoog gelegd. Je vond onderzoek zo leuk dat je na je stage zelfs nog een half jaar bent gebleven om te helpen bij het 22q11 project in Maastricht. Dan zorgde je altijd voor koffie, taart en bananenbrood, zelfs nadat ik je al een cijfer had gegeven. Jelske, Daphne, Iris, Marieke, Ruben bedankt voor jullie inzit voor SMURF. Jelske, bedankt voor alle konijnentips. Brillie, bedankt voor je hulp bij de MRS analyses toen ik in het buitenland was. Ik heb ontzettend hard gelachen om je droge grapjes. Ruben, geen zorgen, er gaat een eind komen aan die scriptie. Jytte, India, Merel en Michelle, bedankt voor jullie hulp bij de 22q11-studie. Marta, although we just met, I am already grateful for all your help with my new project.

Mijn collega's in Maastricht wil ik ook graag bedanken voor hun bijdrage aan dit proefschrift. Allereerst de datamanagers Wendy, Debora en Truda. Wendy, wat een super datamanager was je! Ik hoefde maar een kick te geven en je regelde alles. Ik vond het supergezellig om bij je te logeren toen ik vroeg in Maastricht moest zijn om te scannen (alles voor de proefpersonen). Ontzettend jammer dat je gestopt bent maar hopelijk blijven we elkaar nog regelmatig zien op de UM. Debora, hetzelfde geldt voor jou. Je was (en bent nog steeds) een enorme hulp geweest met je 'creatieve' datamanagement, maar vooral ook je gezelligheid. Gelukkig blijven we ook nu nog samenwerken. En dat speciale cadeau voor Wendy moeten we toch echt een keer gaan regelen. Truda, ondanks dat we officieel niet zoveel met je te maken hadden, heb je op de achtergrond toch een behoorlijke bijdrage geleverd met de data-invoer. Daarnaast was het altijd gezellig om even een praatje met je te maken en stond je altijd voor ons klaar met advies. Floore, leuk om je via het onderzoek wat beter te leren kennen. Ron, bedankt voor alle technische ondersteuning en het steeds maar weer oplappen van mijn bejaarde laptop. Je bent vast blij dat ik in mijn laatste jaar toch maar een nieuwe heb aangeschaft. De dames van het secretariaat, Trees, Ine en Jolanda, bedankt voor jullie hulp bij alle declaraties, het inplannen van afspraken en andere administratieve rompslomp. Koen, wat gezellig dat je altijd even een praatje kwam 
maken als ik naar het verre Maastricht was afgereisd. Ik vind het een eer dat je als kersverse hoogleraar in mijn commissie zit. Ook mijn mede-PhD'-ers en postdocs van de afdeling wil ik graag bedanken. In het bijzonder Yori, Catherine en Anne, bedankt voor jullie hulp bij wat een onmogelijke opgave leek: het vinden van 30 medicatievrije psychosepatiënten. Jindra en Stijn: superfijn dat jullie altijd bereid waren onderwijs over te nemen wanneer er weer eens geen treinen reden of als ik al een vakantie op de planning had staan. Zuzana, Stijn and Iris, thanks for making SOBP 2015 more fun. Elsje en Jonas, zonder jullie zou research retreat niet hetzelfde zijn. Dennis, bedankt voor de prettige samenwerking en je goede raad. Het was altijd fijn om even met je te kunnen sparren. Hopelijk pakken we dit weer op als je terugkomt uit the States. Ehsan, old friend, thanks for all the good talks and showing me and Geor the real Maastricht. The night at the Alla was one to remember.

Dear Des, thanks for all your help with the 22q11 MRS-project. You made scanning so much more fun for me. Although I will miss working with you, I wish you all the best at your new job in Australia and I hope our paths will cross again.

I would also like to thank my colleagues at the Icahn School of Medicine at Mount Sinai Hospital where I spend the last months completing my dissertation. Dear Sophia, thanks for giving me the opportunity to work in your lab for a couple of months. I learned a lot and had a great time. Thanks for having me! My colleagues Dominic, Gaelle and Won, thanks for the warm welcome and good company. Fridyay drinks were always a nice distraction. Sean, it was great having you as a neighbour. You were a brilliant secretary. Emma, bedankt voor de goede begeleiding gedurende mijn tijd op Mount Sinai. Daarnaast wil ik je bedanken voor de gezelligheid (stiekem was het best fijn om niet de enige Nederlander te zijn) en je goede adviezen. Hopelijk zie ik je bij de verdediging en gaan we elkaar nog veel tegenkomen wanneer je aan je dik verdiende assistant-professorschap gaat beginnen in Nijmegen.

Naast mijn collega's wil ik ook mijn lieve vrienden en vriendinnetjes bedanken. Lou en Maart, bedankt voor het aanleveren van gezonde controles en natuurlijk voor alle gezellige koffietjes, biertjes, etentjes en zoveel meer. Best friends forever!! Mijn andere lieve CWD-vriendinnetjes, wat heb ik toch maar geluk met jullie. Bedankt voor alle grappige en leuke momenten de afgelopen jaren. Kneetje bedankt voor al je saaie grapjes door de jaren heen, alle uren samen Friends en andere series kijken. Laura, la reina, wat een fijne huisgenoot was je de eerste jaren van mijn PhD. Rach, bedankt voor je hulp bij de Nederlandse samenvatting. 
Je hebt die kaasmesjes dubbel en dwars verdiend. Gabbie, ondanks dat het geen bruiloft is hoop ik dat je in lila komt. Likey, altijd in voor een feestje of een borrel. Bedankt voor de nodige afleiding. Flootje, bedankt voor de vreselijke verzameling 'I love... spullen die je voor me verzameld hebt. Waag het niet om op reis te zijn tijdens mijn promotiefeest! Pleuntje, nu dit boekje af is kom ik nog vaker bij je in de tuin chillen. Smellie, binnenkort proosten we ook op jouw promotie! Nikos, ik ben blij dat je helemaal uit Groningen komt om bij het feest te zijn. Eef en Tess, ik ben blij dat Lau jullie stiekem de groep binnen heeft geloodst. Soof, jammer dat je er als mede amc-er niet bij kan zijn omdat je aan het shinen bent in New York. Juul en Chan, hopelijk gaan we elkaar weer wat vaker zien vanaf nu. Anke, super leuk dat je altijd zoveel interesse hebt gehad in mijn onderzoek en natuurlijk dat je twee keer naar Maastricht wilde afreizen! Caro en Jits, a.k.a. de Bredaase Renée en Clau van psychologie, wat ben ik blij dat ik jullie heb leren kennen. Laten we onze ‘ tasted the pudding' app nooit weghalen. Yrza, onze vakantie in Cambodja was hilarisch en een zeer welkome afleiding tijdens het lange wachten op METCgoedkeuring. Aranka, jouw geniale ondoordachte opmerkingen vrolijken me altijd op. Joyce, via Robje leerde ik jou kennen. Wat een gezelligheid om samen cakejes te versieren en poncho's te pimpen. Angelique, eigenlijk sta jij aan de basis van mijn hele promotietraject toen je me vroeg om jouw medestagiaire te worden op het $A M C$ toen ik je nog maar net kende. Ik ben blij dat we nu, inmiddels bijna zeven jaar later nog steeds vriendinnen zijn. Martin, oftewel Jesus, ik had je op zo'n beetje iedere plek in dit dankwoord kunnen noemen. Wat gezellig was het dat ik naast je kwam te zitten op Z-0. Sinds je vertrek naar New York heb ik onze koffiedates, foutmijn-uurtjes, pubquiz-avonden en andere gekke rituelen gemist (hoewel ik nu wel een stuk productiever ben). Ik ben dan ook blij dat je binnenkort weer terug naar NL komt. Maar Mart, bovenal bedankt dat je me hebt voorgesteld aan Geoffel. Je bent bij dezen niet meer verplicht om te komen helpen bij toekomstige verhuizingen.

Dan mijn paranimfen. Robje, mijn kleine broertje die al lang zo klein niet meer is. Ook jij hebt me de afgelopen jaren regelmatig uit de brand geholpen. Je was altijd bereid om naar mijn (soms onbegrijpelijke) verhalen te luisteren en gelukkig niet te beroerd om me op te zoeken in New York samen met Joyce. Ik kijk uit naar de dag dat je eindelijk naar Amsterdam verhuist zodat we elkaar wat vaker zien. Maar voor nu ben ik blij dat je aan mijn kant staat vandaag!

Geor (a.k.a. Geordel, Geordie-shore, Igor, mr. Bakker), ondanks dat je niet de grote Oostblok man bleek te zijn die ik had verwacht, je altijd al mijn eten opat, je niet kan fietsen met iemand achterop, je gebrek aan topografische kennis van 
Nederland ("is Den Bosch hetzelfde als 's-Hertogenbosch?") en je slechte muzieksmaak (Akon en Waksu bumper) ben ik blij dat jij de afgelopen jaren mijn partner in crime en mede-SMURF bent geweest. Ik ben ontzettend blij dat je naast me staat tijdens de verdediging. Hopelijk gaat ons eigen lab er in de toekomst ook echt komen. Never change a winning team!

Olaf, bedankt voor alle overheerlijke slowcookermaaltijden op vrijdagavond en voor het overhalen van Geof om er ook een aan te schaffen. Sorry dat ik Geor Brabants heb geleerd.

Pap, bedankt dat je me altijd alle vrijheid hebt gegeven om te doen wat ik wilde en dat je altijd voor ons klaarstaat. Ondanks je pogingen om het te begrijpen heb je volgens mij nog steeds geen idee wat ik eigenlijk de hele dag uitvoer. Als je dit boekje leest kom je er eindelijk achter. Jacqueline, bedankt dat je altijd met zoveel interesse naar mijn onderzoeksverhalen hebt geluisterd en voor je goede adviezen, zowel op persoonlijk als farmacologisch gebied. Sandra, bedankt voor je luisterend oor en uiteraard voor de hoognodige spellingscontrole. Lieve mama, jij hebt mij geleerd wat doorzetten is en bent na al die jaren nog steeds een voorbeeld voor me.

Ank en Henk, jullie kunnen natuurlijk niet ontbreken hier. Bedankt dat jullie al vele jaren zulke goede surrogaat ouders zijn.

Lieve Geoff, wat ben ik blij dat Martin ons aan elkaar heeft gekoppeld. Gelukkig hebben we 'tandenborstelgate' overleefd want wat ben je belangrijk voor me geweest de afgelopen jaren (en nee, niet alleen bij het maken van plaatjes). Bedankt dat je zo geduldig naar me hebt geluisterd (of in ieder geval deed alsof) terwijl ik hardop aan het nadenken was over ingewikkelde analyses of onderzoeksresultaten. Maar vooral bedankt voor je saaie grapjes waarmee je me altijd aan het lachen maakt na lange en vermoeiende scandagen. Je bent grappig. Nu kunnen we dan eindelijk een feestje vieren samen met onze twee kleine baby's Tony Ravioli en Fritz Eugène Limoncello. 



\section{Curriculum Vitae}

Claudia (W.A.M.) Vingerhoets was born on May 6, 1988 in Oirschot (Noord-Brabant), The Netherlands. She obtained her high-school degree in 2006 from the Jacob Roeland Lyceum in Boxtel and afterwards moved to Utrecht to study Clinical and Health Psychology at the University of Utrecht. She obtained her bachelor degree in 2010, and went on to simultaneously do a Master Degree in Clinical Forensic Psychology at the University of Amsterdam and a Master Degree in Clinical and Healthy psychology from which she both graduated in 2012 (Master in Clinical and Healthy Psychology cum laude). During this period she completed both a clinical and a research internship. After obtaining both her Master Degrees she worked as research assistant at the Institute of Addiction Research (AIAR, Amsterdam), in collaboration with Janna Cousijn, Wim van den Brink, Reinout Wiers, Lieuwe de Haan, Anneke Goudriaan and Laura Koenders. From 2013 to 2017 she carried out her PhD research together with Geor Bakker, under supervision of Therese van Amelsvoort, Jan Booij and Oswald Bloemen at the department of Psychiatry \& Psychology of Maastricht University, in collaboration with the department of Nuclear Medicine of the Academic Medical Center (AMC, University of Amsterdam. In 2016 she spend 3 months at the Icahn School of Medicine at Mount Sinai Hospital in New York to work on high-field neuroimaging data at the lab of Prof. Sophia Frangou. Claudia is currently employed as a post-doctoral researcher at the Department of Psychiatry and Psychology at Maastricht University, where she continues to investigate neurobiological mechanisms underlying cognition. In 2016, she obtained a grant (Cambridge Cognition and Brains Unlimited Pioneer Fund) to conduct a pilot study investigating the role of neuroinflammation in cognition. 
